\title{
In Situ Vitrification of Transuranic Wastes: Systems Evaluation and Applications Assessment
}
K. H. Oma
G. B. Mellinger
D. R. Brown
B. A. Napier
J. L. Buelt
D. J. Silviera
V. F. FitzPatrick
S. L. Stein
K. A. Hawley
C. L. Timmerman

September 1983

Prepared for the U.S. Department of Energy under Contract DE-AC06-76RLO 1830

Pacific Northwest Laboratory Operated for the U.S. Department of Energy by Battelle Memorial Institute 


\title{
DISCLAIMER
}

This report was prepared as an account of work sponsored by an agency of the United States Government. Neither the United States Government nor any agency thereof, nor any of their employees, makes any warranty, express or implied, or assumes any legal liability or responsibility for the accuracy, completeness, or usefulness of any information, apparatus, product, or process disclosed, or represents that its use would not infringe privately owned rights. Reference herein to any specific commercial product, process, or service by trade name, trademark, manufacturer, or otherwise, does not necessarily constitute or imply its endorsement, recommendation, or favoring by the United States Government or any agency thereof. The views and opinions of authors expressed herein do not necessarily state or reflect those of the United States Government or any agency thereof.

\author{
PACIFIC NORTHWEST LABORATORY \\ operated by \\ BATTELLE \\ for the \\ UNITED STATES DEPARTMENT OF ENERGY \\ under Contract DE-AC06-76RLO 1830
}

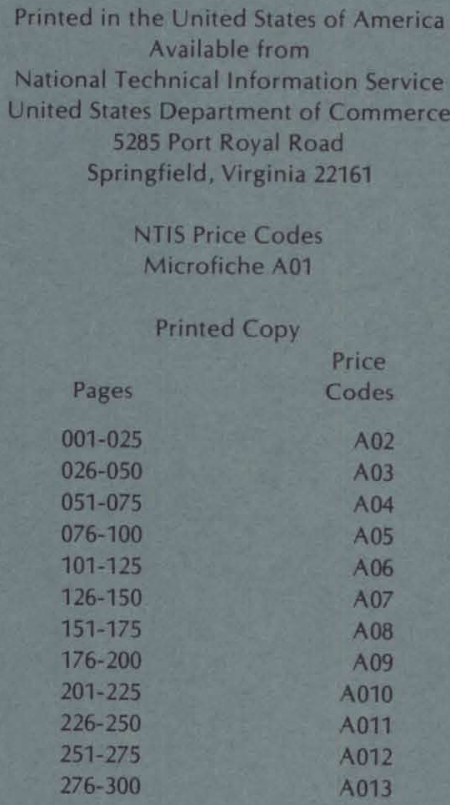


IN SITU VITRIFICATION OF TRANSURANIC WASTES: SYSTEMS EVALUATION AND APPLICATIONS ASSESSMENT

K. H. Oma

D. R. Brown

J. L. Buelt

V. F. FitzPatrick

K. A. Hawley

G. B. Mellinger

B. A. Napier

D. J. Silviera

S. L. Stein

C. L. Timmerman

September 1983

Prepared for

the U.S. Department of Energy

under Contract DE-AC06-76RLO 1830

Pacific Northwest Laboratory

Richland, Washington 99352 


\section{ACKNOWLEDGMENTS}

The authors wish to thank W. F. Bonner and J. M. Latkovich for their technical and programmatic guidance during the course of this research. Many fellow scientists and technicians contributed to the research effort. The list below includes individual contributors and their areas of expertise:

$$
\begin{aligned}
& \text { R. A. Brouns - ISV Tests } \\
& \text { J. G. Carter - ISV Tests } \\
& \text { R. K. Farnsworth - ISV Tests } \\
& \text { C. R. Hymas - ISV Tests } \\
& \text { Y. B. Katayama - Product Durability } \\
& \text { R. A. Libby - Criticality Analysis } \\
& \text { M. L. Longaker - ISV Tests } \\
& \text { P. J. Mellinger - Economic and Safety Analysis } \\
& \text { R. N. Rogers (a) - Explosive Inclusion Analysis } \\
& \text { J. L. Ryan - Chemistry of Plutonium in Glass } \\
& \text { J. K. Soldat - Safety Analysis } \\
& \text { L. A. Stout - Safety Analysis } \\
& \text { E. C. Watson - Safety Analysis }
\end{aligned}
$$

Substantial effort has been expended in coordinating, typing, and producing this report. We appreciate the contributions of the following people:
S. E. King, Editor
V. M. Groves, Word Processor
C. M. Gilbert, Word Processor.

(a) From Los Alamos National Laboratory. 


\section{CONTENTS}

ACKNOWLEDGMENTS

i i i

EXECUTIVE SUMMARY $\ldots \ldots \ldots \ldots \ldots \ldots \ldots \ldots \ldots \ldots \ldots \ldots \ldots \ldots \ldots \ldots \ldots \ldots \ldots \ldots \ldots$

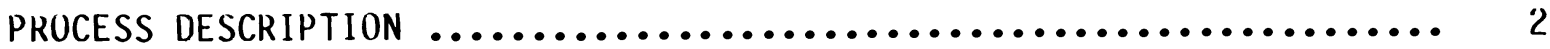

Power System Design ................................ 4

Off-Gas Treatment System $\ldots \ldots \ldots \ldots \ldots \ldots \ldots \ldots \ldots \ldots \ldots \ldots \ldots \ldots . \ldots \ldots$

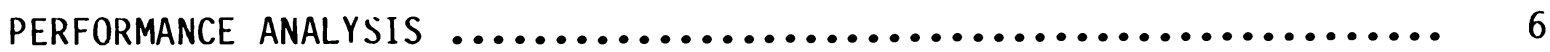

PROCESS PARAMETERS $\ldots \ldots \ldots \ldots \ldots \ldots \ldots \ldots \ldots \ldots \ldots \ldots \ldots \ldots \ldots \ldots \ldots \ldots$

ECONOMIC ANALYSIS $\ldots \ldots \ldots \ldots \ldots \ldots \ldots \ldots \ldots \ldots \ldots \ldots \ldots \ldots \ldots \ldots \ldots \ldots \ldots$

ANALYSIS OF OCCUPATIONAL AND PUBLIC SAFETY ................. 11

ASSESSMENT OF WASTE SITE APPLICATIONS $\ldots \ldots \ldots \ldots \ldots \ldots \ldots \ldots \ldots \ldots \ldots$

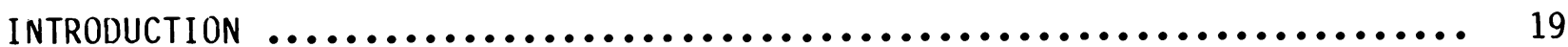

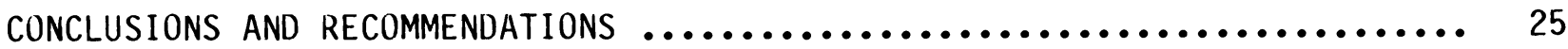

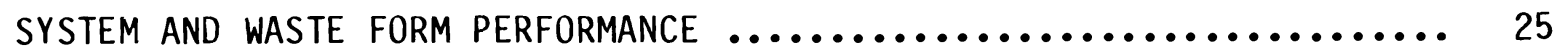

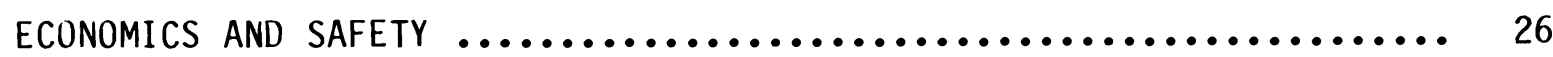

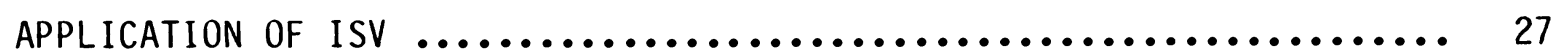

RECOMMENDATIONS.................................... 28

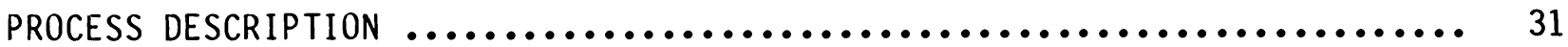

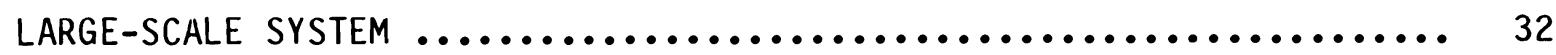

Power System Design $\ldots \ldots \ldots \ldots \ldots \ldots \ldots \ldots \ldots \ldots \ldots \ldots \ldots \ldots \ldots . \ldots \ldots$

Off-Gas Containment and Electrode Support Hood ............ 37

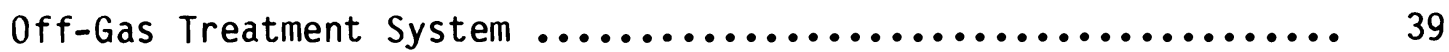

PILOT-SCALE RADIOACTIVE TEST SYSTEM $\ldots \ldots \ldots \ldots \ldots \ldots \ldots \ldots \ldots \ldots \ldots \ldots \ldots$

Power System Design ................................ 42

Off-Gas Containment and Electrode Support Hood ............. 43

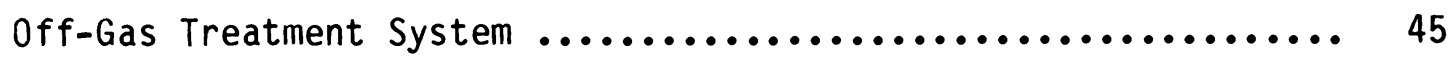


PILOT-SCALE FIELD TEST SYSTEM $\ldots \ldots \ldots \ldots \ldots \ldots \ldots \ldots \ldots \ldots \ldots \ldots \ldots, 50$

Power System Design $\ldots \ldots \ldots \ldots \ldots \ldots \ldots \ldots \ldots \ldots \ldots \ldots \ldots \ldots . . \ldots \ldots$

Off-Gas Containment and Electrode Support Hood ............. 52

Off-Gas Treatment System $\ldots \ldots \ldots \ldots \ldots \ldots \ldots \ldots \ldots \ldots \ldots \ldots \ldots, 52$

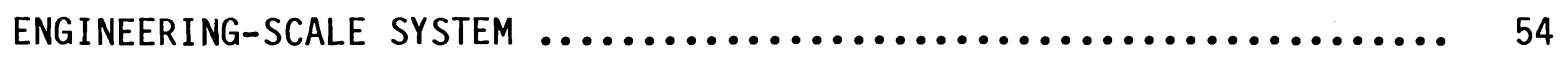

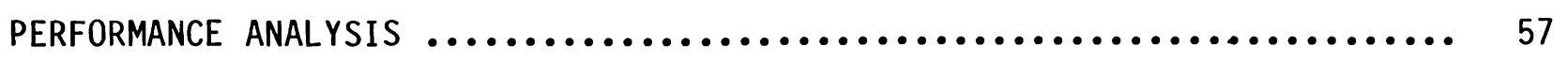

EqUIPMENT PERFORMANCE $\ldots \ldots \ldots \ldots \ldots \ldots \ldots \ldots \ldots \ldots \ldots \ldots \ldots \ldots \ldots \ldots \ldots \ldots \ldots \ldots \ldots \ldots$

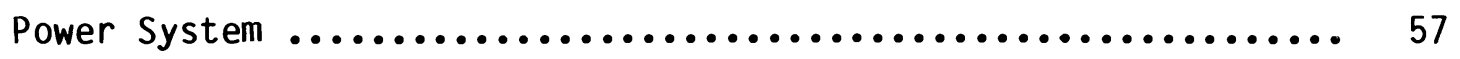

Off-Gas Containment Hood $\ldots . \ldots \ldots \ldots \ldots \ldots \ldots \ldots \ldots \ldots \ldots \ldots . . ., 58$

Off-Gas Treatment System $\ldots \ldots \ldots \ldots \ldots \ldots \ldots \ldots \ldots \ldots \ldots \ldots \ldots . \ldots \ldots$

PROCESSING PERFORMANCE $\ldots \ldots \ldots \ldots \ldots \ldots \ldots \ldots \ldots \ldots \ldots \ldots \ldots \ldots \ldots \ldots, 62$

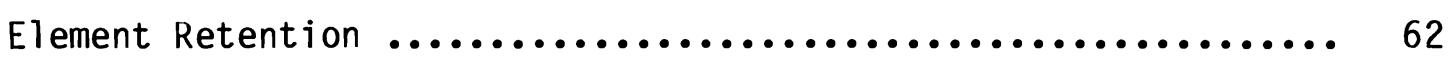

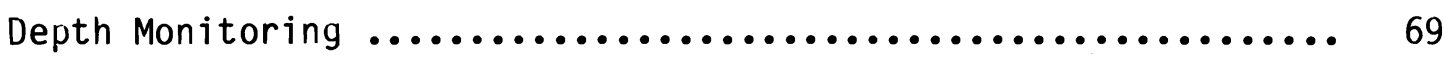

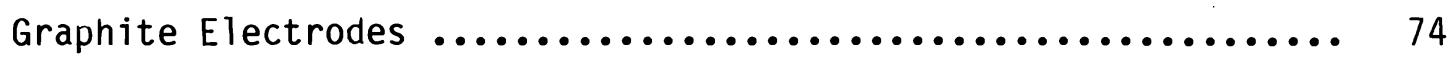

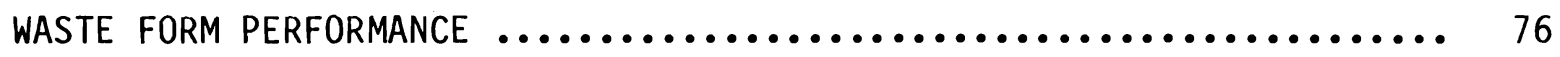

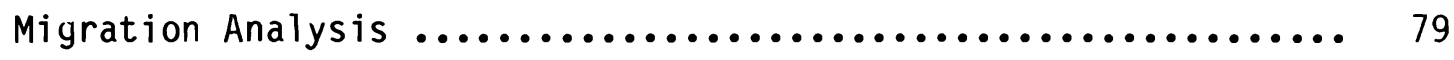

Product Durability $\ldots \ldots \ldots \ldots \ldots \ldots \ldots \ldots \ldots \ldots \ldots \ldots \ldots \ldots . . . \ldots 1$

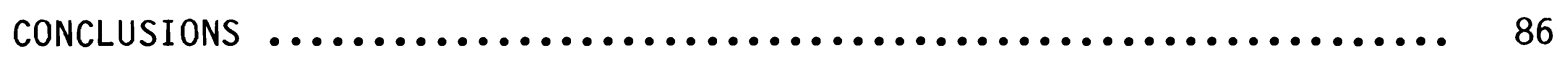

PROCESS PARAMETERS $\ldots \ldots \ldots \ldots \ldots \ldots \ldots \ldots \ldots \ldots \ldots \ldots \ldots \ldots \ldots \ldots \ldots \ldots \ldots . \ldots \ldots$

INFLUENCE OF SOIL PROPERTIES $\ldots \ldots \ldots \ldots \ldots \ldots \ldots \ldots \ldots \ldots \ldots \ldots \ldots, 89$

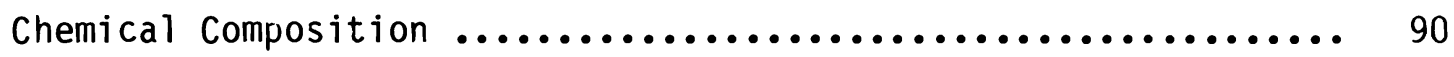

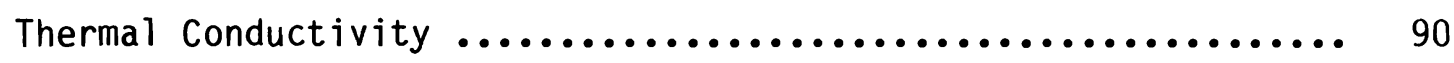

Fusion Temperature $\ldots \ldots \ldots \ldots \ldots \ldots \ldots \ldots \ldots \ldots \ldots \ldots \ldots \ldots . .9 . \ldots$

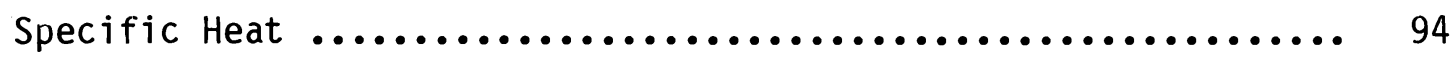

Electrical Conductivity $\ldots \ldots \ldots \ldots \ldots \ldots \ldots \ldots \ldots \ldots \ldots \ldots . . . \ldots 6$

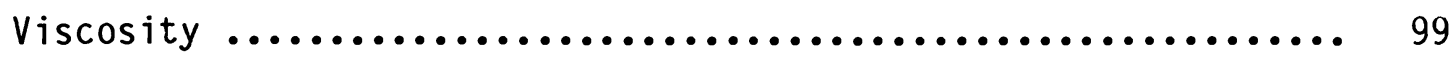


Density

100

PERFORMANCE PREDICTIONS FOR DIFFERENT SITE GEOMETRIES ........... 103

Mathematical Model ................................... 104

Large-Scale Mathematical Predictions ..................... 108

Hanford Predictions ................................. 108

Eastern Site Predictions .............................. 109

ANALYSIS OF WASTE INCLUSION LIMITS $\ldots \ldots \ldots \ldots \ldots \ldots \ldots \ldots \ldots \ldots \ldots \ldots \ldots$

Metals $\ldots \ldots \ldots \ldots \ldots \ldots \ldots \ldots \ldots \ldots \ldots \ldots \ldots \ldots \ldots \ldots \ldots \ldots \ldots \ldots \ldots \ldots$

Cements and Ceramics $. \ldots \ldots \ldots \ldots \ldots \ldots \ldots \ldots \ldots \ldots \ldots \ldots \ldots \ldots \ldots \ldots . \ldots \ldots$

Combustibles.$\ldots \ldots \ldots \ldots \ldots \ldots \ldots \ldots \ldots \ldots \ldots \ldots \ldots \ldots \ldots \ldots \ldots \ldots \ldots$

Sealed Containers $\ldots \ldots \ldots \ldots \ldots \ldots \ldots \ldots \ldots \ldots \ldots \ldots \ldots \ldots \ldots \ldots \ldots \ldots$

Explosives....................................... 130

Criticality $\ldots \ldots \ldots \ldots \ldots \ldots \ldots \ldots \ldots \ldots \ldots \ldots \ldots \ldots \ldots \ldots \ldots \ldots \ldots$

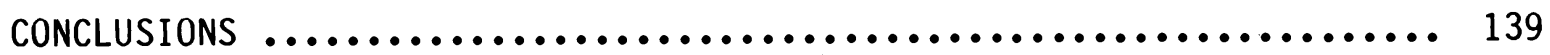

ECONOMIC ANALYSIS $\ldots \ldots \ldots \ldots \ldots \ldots \ldots \ldots \ldots \ldots \ldots \ldots \ldots \ldots \ldots \ldots \ldots \ldots \ldots \ldots$

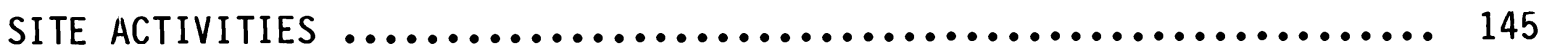

EQUIPMENT REQUIREMENTS $\ldots \ldots \ldots \ldots \ldots \ldots \ldots \ldots \ldots \ldots \ldots \ldots \ldots \ldots \ldots \ldots \ldots$

OPERATIONS $\ldots \ldots \ldots \ldots \ldots \ldots \ldots \ldots \ldots \ldots \ldots \ldots \ldots \ldots \ldots \ldots \ldots \ldots \ldots \ldots \ldots \ldots$

Process Preparation $. \ldots \ldots \ldots \ldots \ldots \ldots \ldots \ldots \ldots \ldots \ldots \ldots \ldots \ldots \ldots . \ldots . \ldots . \ldots$

Processing.$\ldots \ldots \ldots \ldots \ldots \ldots \ldots \ldots \ldots \ldots \ldots \ldots \ldots \ldots \ldots \ldots \ldots \ldots \ldots$

Consumable Supplies ................................. 152

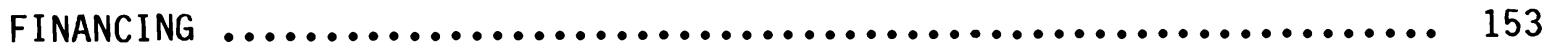

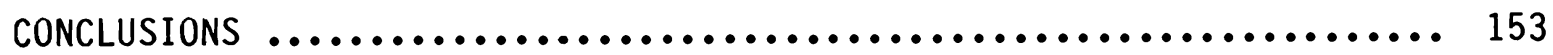

ANALYSIS OF OCCUPATIONAL AND PUBLIC SAFETY $\ldots \ldots \ldots \ldots \ldots \ldots \ldots \ldots \ldots \ldots \ldots \ldots$

SELECTION AND DESCRIPTION OF THE 216-Z-1A TILE FIELD ............ 159

Radionuclide Waste Form and Inventory $\ldots \ldots \ldots \ldots \ldots \ldots \ldots \ldots \ldots$ 
Chemical Waste Form $\ldots \ldots \ldots \ldots \ldots \ldots \ldots \ldots \ldots \ldots \ldots \ldots \ldots \ldots \ldots, 163$

POTENTIAL NEAR-TERM RADIATION EXPOSURES $\ldots \ldots \ldots \ldots \ldots \ldots \ldots \ldots \ldots \ldots . \ldots \ldots$

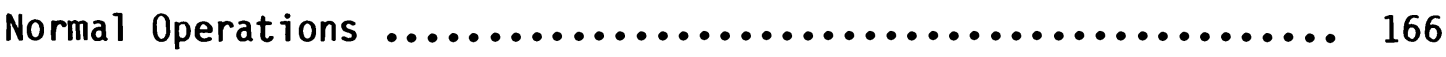

Postulated Abnormal Operations ........................ 173

POTENTIAL FAR-TERM RADIATION EXPOSURES $\ldots \ldots \ldots \ldots \ldots \ldots \ldots \ldots \ldots \ldots \ldots, 180$

POTENTIAL CHEMICAL HAZARDS $\ldots \ldots \ldots \ldots \ldots \ldots \ldots \ldots \ldots \ldots \ldots \ldots \ldots \ldots, 186$

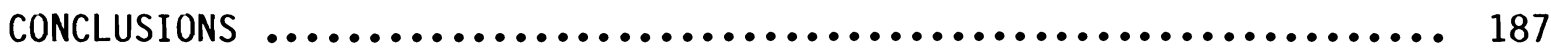

WASTE SITE APPLICATIONS ASSESSMENT $\ldots \ldots \ldots \ldots \ldots \ldots \ldots \ldots \ldots \ldots \ldots \ldots \ldots \ldots . . \ldots 1$

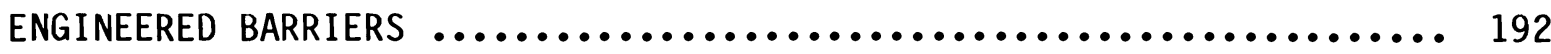

EXHUMATION AND REPOSITORY DISPOSAL $\ldots \ldots \ldots \ldots \ldots \ldots \ldots \ldots \ldots \ldots \ldots \ldots, 193$

SELECTIVE ISV AT HANFORD $\ldots \ldots \ldots \ldots \ldots \ldots \ldots \ldots \ldots \ldots \ldots \ldots \ldots \ldots \ldots, 195$

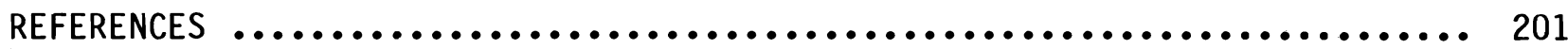




\section{FIGURES}

1. In Situ Vitrification Process Sequence ....................... 3

2. Schematic for the Large-Scale Off-Gas System .................. 5

3. Leach Resistances of Selected Materials ...................... 6

4. Waste Distribution in a $90 \times 4 \times 4$ m Site ..................... 10

5. Characteristics of a Generic Waste Trench ..................... 12

6. In Situ Vitrification Process Sequence ...................... 31

7. Three Portable Semi-Trailers for the Large-Scale System .......... 33

8. Scott-Tee Transformer Design for the Large-Scale System .......... 34

9. Effect of Increased Number of Voltage Taps on Average
Power Output $\ldots \ldots \ldots \ldots \ldots \ldots \ldots \ldots \ldots \ldots \ldots \ldots \ldots \ldots \ldots \ldots \ldots \ldots \ldots \ldots \ldots \ldots \ldots \ldots$

10. Off-Gas Containment Hood for the Large-Scale System ............. 38

11. Design of Hood Feed-Through for Electrode Buss Bar .............. 39

12. Schematic for the Large-Scale Off-Gas System .................. 40

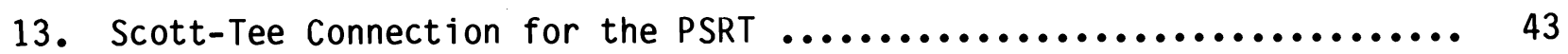

14. Off-Gas Containment and Electrode Support Hood for the PSRT ....... 44

15. Off-Gas System Schenlatic for the PSRT ...................... 46

16. Plan View of Off-Gas System in Semi-Trailer for the PSRT.......... 47

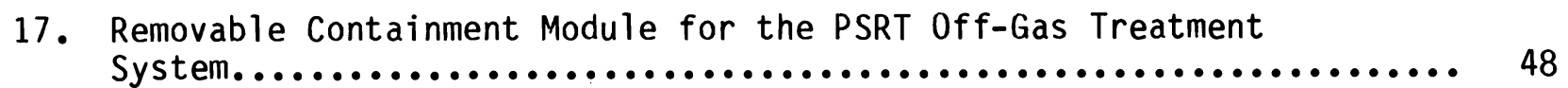

18. Tandem Nozzle Hydro-Sonic Scrubber ......................... 50

19. Open-Delta Connection for the PSFT Power System ............... 51

20. Off-Gas System Schematic for the PSFTs ...................... 53

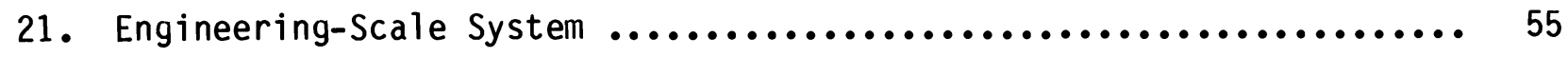

22. Effect of Burial Depth on the Retention of Selected Species Within the Vitrification Zone ............................. 65

23. Effect of Cold Cap on the Release of $\mathrm{Cs}$ and $\mathrm{Sr}$ to the $0 \mathrm{ff}$ Gas During PSFT 2 
24. Effect of Gas Generation on the Release of CS, Sr, and Lanthanides

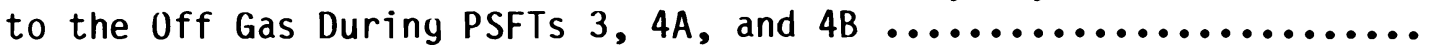

25. Effect of Gas Generation on the Release of Heavy Metals to the Off Gas During PSFTs $3,4 A$, and $4 B \ldots \ldots \ldots \ldots \ldots \ldots \ldots \ldots \ldots \ldots \ldots . \ldots . \ldots . \ldots . \ldots$

26. Effect of Chemical Form on the Release of Simulated Fission Products to the $0 \mathrm{ff}$ Gas in PSCT 1 .......................... 69

27. Depth Transmitter System Configuration for Monitoring Melt Depth .... 70

28. Design of Thermal Switch Depth Sensor $\ldots \ldots \ldots \ldots \ldots \ldots \ldots \ldots \ldots \ldots \ldots \ldots \ldots$

29. Design of 0ptical Fiber Depth Sensor ........................ 72

30. Effect of Silica Fiber End Temperature on Phototransistor Output .... 73

31. Calculated Thermal Profile of Vertical Rods $15 \mathrm{~cm}$ dia by $1.2 \mathrm{~m}$ Long with a Bottom End Temperature of $1200^{\circ} \mathrm{C} \ldots \ldots \ldots \ldots \ldots \ldots \ldots \ldots$

32. Typical Configuration for a Graphite Electrode $\ldots \ldots \ldots \ldots \ldots \ldots \ldots \ldots$

33. Interior of a Vitrified Soil Block from a Pilot-Scale Test ......... 78

34. Cerium Concentration Profile Before and After Vitrification,

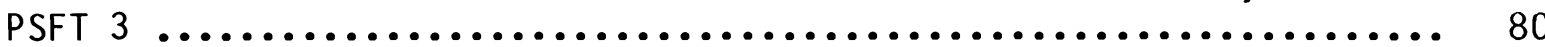

35. Leach Resistances of Selected Materials ..................... 81

36. Thermal Conductivities of Hanford Soil $\ldots \ldots \ldots \ldots \ldots \ldots \ldots \ldots \ldots \ldots \ldots$

37. Specific Heat of Hanford Soil 28-2 at Various Temperatures ........ 97

38. Electrical Conductivities of Molten Soils ..................... 98

39. Electrical Conductivities at $40 \mathrm{~Hz}$ of Vitrified Hanford Soil from PSFT 4 ..................................... 100

40. Viscosities of Molten Soils $\ldots \ldots \ldots \ldots \ldots \ldots \ldots \ldots \ldots \ldots \ldots \ldots \ldots \ldots \ldots \ldots$

41. Change in Hanford Soil Density During Processing ................ 103

42. Predicted and Measured Operating Parameters for PSFT $1 \ldots \ldots \ldots \ldots$...... 107

43. Predicted and Measured Operating Parameters for the PSRT ......... 107

44. Scale-Up Correlations for Startup ......................... 109

45. Effect of Electrode Separation on Melt Depth and Run Time for Hanford Soil with Nominal Heat Losses and 5\% Moisture 
46. Effect of Electrode Separation on Melt Depth and Run Time for Hanford Soil with High Heat Losses and 5\% Moisture ............... 111

47. Effect of Electrode Separation on Melt Depth and Run Time for Hanford Soil with High Heat Losses and 25\% Moisture .............. 112

48. Burial-Ground Scenario for Moisture Limitations Analysis ......... 113

49. Effect of Sandy Aquifer on Melt Depth for Saturated ORNL Soil with High Heat Losses ......................................... 114

50. Metal Inclusion Model .................................. 115

51. Effect of Metal Width on Power and Electrode Potential ........... 116

52. Effect of Metal Width on Power Distribution ................... 117

53. Measured and Predicted Voltage Drop Due to a Metallic Inclusion ..... 118

54. Effect of Concrete Inclusions on Melt Zone Resistance ........... 122

55. Off-Gas Capacities Required for Various Cement and Concrete Loadings ........................................... 123

56. Simulated Waste Configuration for PSFT $3 \ldots \ldots \ldots \ldots \ldots \ldots \ldots \ldots$

57. Gas Release from a Combustible Volume ......................... 127

58. Gas Release from a Void Volume $\ldots \ldots \ldots \ldots \ldots \ldots \ldots \ldots \ldots \ldots \ldots \ldots \ldots \ldots \ldots \ldots$

59. Gas Release from a Sealed Metal Container ....................... 129

60. The Effect of Charge Diameters on Critical Temperatures

for Some Pure Explosives ................................. 132

61. Standard Free Energy of Formation for Various Metal 0xides ........ 138

62. Characteristics of a Generic Waste Trench .................... 155

63. Construction of the $216-Z-1$ A Tile Field .................... 160

64. Plot Plan for 216-Z-1A, 216-Z-1, 216-Z-2, and 216-Z-3 .......... 162

65. Distribution of Total Transuranic Activity, North-South Cross

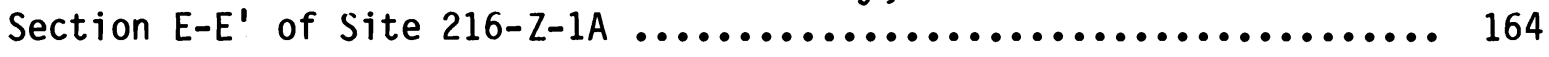

66. Distribution of Total Transuranic Activity, East-West Cross

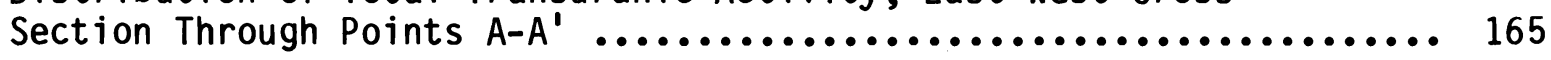

67. Distribution of Total Transuranic Activity, East-West Cross

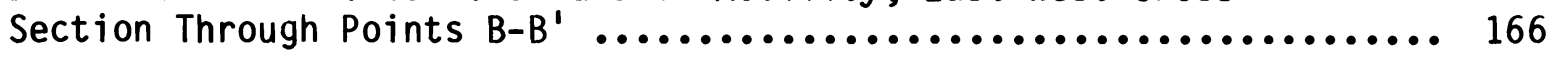


68. Distribution of Total Transuranic Activity, East-West Cross Section Through Points C-C'

69. Waste Distribution in $90 \times 4 \times 4 \mathrm{~m}$ Site $\ldots \ldots \ldots \ldots \ldots \ldots \ldots \ldots \ldots \ldots$

70. Important Exposure Pathways at Hanford ...................... 184

71. Cross-Section View of Trench Incorporating Greater Confinement

Stabilization Technique .................................. 197

72. Large-Scale ISV System Capabilities .......................... 199

73. Vitrification of a Typical Hanford Caisson ................... 200

\section{TABLES}

1. Cost Estimates of Five ISV Large-Scale Configurations ............ 10

2. Cost Estimates for Vitrifying a Waste Trench ................. 12

3. Whole Body Radiation Doses from Routine Operations .............. 12

4. Public Dose Commitments from Routine Operations ............... 13

5. Occupational Doses from Accidental Releases.................... 14

6. Public Dose Commitments from Postulated Abnormal 0ccurrences ....... 14

7. Public Dose Estimates for Far-Term Routine Scenarios ............. 15

8. Public Dose Commitments for Far-Term Intrusion ................ 16

9. Summary of Results of Engineering-Scale Laboratory Tests ......... 20

10. Summary of Results of Pilot-Scale Field Tests ................. 21

11. Summary of Results of Pilot-Scale Cold and Radioactive Tests ....... 22

12. Comparison of Power System Performance of Three Pilot-Scale

Field Tests ............................................

13. Comparison of Power System Performance for the Pilot-Scale Field Tests ......................................... 60

14. Operating Parameters for the Pilot-Scale Off-Gas System .......... 61

15. Element Removal by Off-Gas System During PSCT $1 \ldots \ldots \ldots \ldots \ldots \ldots$ 
16. Predicted Soil-to-0ff-Gas Decontamination Factors for the

Large-Scale System

17. Soil-to-0ff-Gas Decontamination Factors for Nonradioactive

Pilot-Scale Tests

18. Soxhlet Leach Test Results for PSFTs 1 and 2

19. Comparison of ISV Glass/Crystalline Leach Resistances with

Commercial Waste Glass PNL 76-68

20. MCC-1 Leach Test Results for TRU Waste Forms

21. Oxide Composition of Soils

22. Thermal Conductivities of Soils at Ambient Temperature

23. Fusion Temperatures of Soils

24. Specific Heats of Various Soil Types

25. Bulk Density of Unmelted Soil and Density of Vitrified Soil 102

26. Model Parameters Used for PSFT 1 and the PSRT ... 106

27. Actual and Predicted Test Data for PSFT 1 and the PSRT 106

28. Summary of Results from Engineering-Scale Laboratory Tests Containing Metal Inclusions

29. Composition of Various Cements 120

30. Summary of Results from Engineering-Scale Laboratory Tests Containing Concrete Inclusions

31. Waste Drum Combustibles Content During PSFT 3 127

32. Gas Release Rates from a Sealed Metal Container 129

33. Estimated Sub-Critical Mass Limits for Various Transuranic Nuclides

34. Radionuclide Content of Buried and Retrievable TRU Waste at INEL .... 134

35. Minimum Critical Mass of Plutonium in Water-Saturated Soil ........ 136

36. Descriptions of Six Configurations for ISV of TRU Contaminated Soil. 
38. Power Equipment and Heavy Equipment Costs for the Pilot- and Large-Scale Systems

39. Off-Gas System and Electrode Frame and Hood Costs for the Pilotand Large-Scale Systems

40. Time Requirements for Each Setting

41. Electrode Spacing and Vitrification Settings

42. Manpower Requirements for Process Preparation

43. Manpower Rates for In Situ Vitrification

44. Labor Estimate for Processing Operations at a Radioactive Site

45. Power Requirements for ISV Configurations 1 Through 6

46. Federal Financing Assumptions

47. Cost Summary for ISV Configurations 1 Through 6 .

48. Operating Parameters for a Large-Scale ISV Process .............. 156

49. Cost Summary for ISV Trench Configurations 7 Through $12 \ldots \ldots \ldots \ldots . . . .157$

50. Estimate of Waste Volume, Plutonium and Americium Discharged

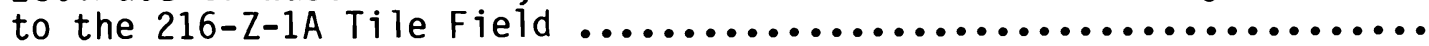

51. Elemental Fractions Released During Vitrification of the 216-Z-1A Site

52. Decontamination Factors for the Off-Gas Treatment System

53. Inventories and Released Fractions for $120 \mathrm{~h}$ Runs at the 216-Z-1A Site

54. Occupational Doses for 216-Z-1A Vitrification, 120 Hour Run,

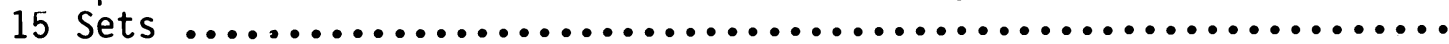

55. Critical Organ Dose Commitments to the Public from Routine ISV Operations

56. Radionuclides Released from Postulated Accidents ............... 176

57. Occupational Doses from Postulated Accidental Releases............ 179

58. Public Dose Commitments from Postulated Accidental Releases ........ 179

59. Public Dose Estimates for Far-Term Routine Scenarios ............. 184

60. Public Dose Commitments for Far-Term Intrusion................. 186 
61. Cost Considerations Associated with Exhumation of TRU and Its Disposal in a Geological Repository .......................... 194

62. Candidate Liquid Waste Sites for Selective Vitrification and Engineered Barriers as a Disposal Technique ................... 196

63. Candidate Solid Waste Sites for Selective Vitrification and Engineered Barriers as a Disposal Technique 


\section{EXECUTIVE SUMMARY}




\section{EXECUTIVE SUMMARY}

In situ vitrification (ISV) is the conversion of buried wastes and contaminated soil into a durable ylass and crystalline waste form through melting by joule heating. The technology for in situ vitrification of buried waste is based upon electric melter technology developed at the Pacific Northwest Laboratory (PNL) for the immobilization of high-level nuclear waste. In situ vitrification was initially tested by researchers at PNL in August 1980 (U.S. Patent 4,376,598--Brouns, Buelt, and Bonner 1983). Since then ISV has grown from a concept to an energing technology through a series of 18 engineeringscale (laboratory) tests and 7 pilot-scale (field) tests. The program has been sponsored by the U.S. Department of Energy's (DOE's) Richland Operations Office for application to Hanford sites. Additional support has been provided by the National Transuranic Waste Management Program since FY 1982.

The ISV development program is utilizing three sizes of vitrification systems. The distinguishing characteristics of each system are power level, electrode spacing, and mass of block produced, as shown below:

\begin{tabular}{|c|c|c|c|}
\hline System & Power & Electrode Spacing & Block Mass \\
\hline Enyineering & $30 \mathrm{~kW}$ & $30 \mathrm{~cm}$ & $50 \mathrm{~kg}$ \\
\hline Pilot & $500 \mathrm{~kW}$ & $1.2 \mathrm{~m}$ & $10 \mathrm{t}$ \\
\hline Large & $3750 \mathrm{~kW}$ & $5 \mathrm{~m}$ & $175 t$ \\
\hline
\end{tabular}

The most recent pilot-scale test, completed in June 1983, vitrified a makeup site in which $25 \mathrm{~kg}$ of soil containing $600 \mathrm{nCi} / \mathrm{g}$ transuranic (TRU) waste simulated a highly radioactive area (or "hot spot"). The made-up source also contained mixed fission products with a total activity of $30,000 \mathrm{nci} / \mathrm{g}$, which exhibited a surface exposure rate of $100 \mathrm{R} / \mathrm{h}$ before it was emplaced in the test site. Assuming that during the vitrification the material was distributed uniformly within an $8 \mathrm{t}$ block, the resulting concentration is $<5 \mathrm{nci} / \mathrm{g}$ TRU. No radionuclides were released to the environment during the vitrification process. 
With the successful completion of the radioactive test, the focus of the program has turned to the conceptual design of a large-scale system to be capable of vitrifying an actual waste site. This system is expected to be fabricated and acceptance testing completed early in FY 1985, with vitrification of actual sites planned in later fiscal years.

Major advantages of in situ vitrification as a means of stabilizing radioactive waste are:

- long term durability of the waste form

- cost effectiveness

- safety in terms of minimizing worker and public exposure

- applicability to different kinds of soils and buried wastes.

This document describes ISV technology that is available as another viable tool for in place stabilization of waste sites.

The following sections correspond to the chapters in the body of this document:

- description of the ISV process

- analysis of the performance of the ISV tests conducted thus far

- parameters of the ISV process

- cost analysis for the ISV process

- analysis of occupational and public exposure

- assessment of waste site applications.

\section{PROCESS DESCRIPTION}

In situ vitrification is a process for stabilizing and immobilizing buried waste by vitrifying the waste and/or contaminated soil. To begin the process, which is shown in Figure 1 , graphite electrodes are inserted vertically in the ground in a square array. Graphite is placed on the surface of the soil between the electrodes to form a conductive path, and an electrical current is passed between the electrodes, creating temperatures high enough to melt the soil. The molten zone grows downward, encompassing the buried wastes and soil and producing a vitreous mass. Convective currents within the melt distribute the wastes evenly. During the process, off gas emitted from the molten mass is collected by a hood over the area and routed through a line to a treatment 


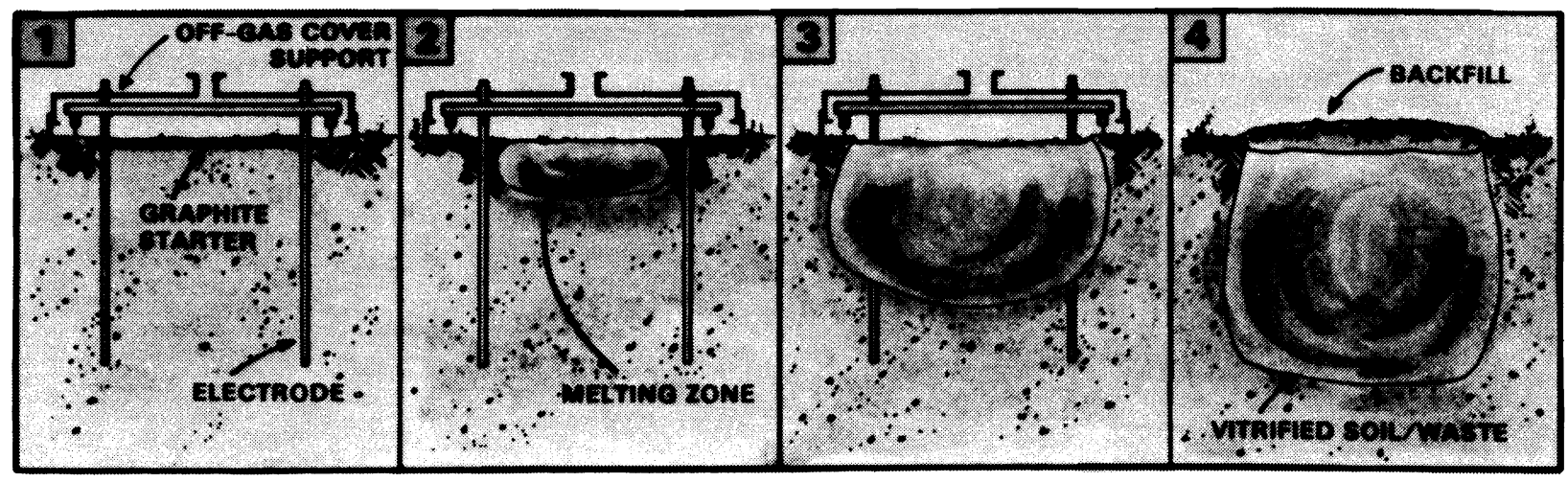

FIGURE 1. In Situ Vitrification Process Sequence

system. When power to the system is turned off, the molten volume begins to cool. The product is a block of glasslike material resembling natural obsidian. Any subsidence can be covered with uncontaminated backfill to the original grade level.

The principle of operation is joule heating, which occurs when an electrical current passes through the molten media. As this molten mass grows, resistance decreases, so to maintain the power level high enough to continue melting the soil, the current must be increased. This is accomplished by a transformer equipped with multiple voltaye taps. The multiple taps allow more efficient use of the power system by maintaining the power factor (the relationship between current and voltage) near maximum. The process continues until the appropriate depth is reached. Melt depth is limited as the heat losses from the melt approach the energy deliverable to the molten soil by the electrodes.

To contain off gases that are released from the melting process, an offgas hood that is operated under a slight vacuum covers the vitrification zone. The hood also provides support for the electrodes. The off gases are routed to a treatment system, which scrubs and filters hazardous components.

A more detailed system description outlining the power system design and the off-gas treatment system for the large-scale system, the pilot-scale radioactive test system, and the engineering-scale system follows. 
Power System Design

The power system design is similar for all three scales of the ISV program. A transformer connection converts three-phase alternating current electrical power to two single-phase loads. The single-phase loads are connected to two of the electrodes, which are arranged in a square pattern, creating a balanced electrical load on the secondary. The even distribution of current within the molten soil produces a vitrified product almost square in shape to minimize overlap among adjacent settings. Multiple voltage taps and a balanced load allow a near constant power operation, which shortens run time and thus minimizes cost.

Off-Gas Treatment System

In both the pilot-scale radioactive test and the large-scale systems, the off-gas containment and electrode support hood collects the off gas, provides a chamber for the combustion of released pyrolyzed organics, and supports the four electrodes embedded in the soil. Much of the heat generated during the ISV process is released to the off-gas stream. The heat is removed in the offgas treatment system, so that the temperature of the gas which exits after treatment is close to ambient.

There are three major kinds of treatment for the off-gas system (see Figure 2): first, the gases are scrubbed in two stages, with a quencher and Hydro-Sonic ${ }^{\circledR}$ scrubber. These scrubbers remove particles down through the submicron range. Second, the water in the saturated gas stream is removed by a vane separator and condenser followed by a vane separator, and then heated, insuring an unsaturated gas stream at a temperature well above the dewpoint. In the third stage the off yas is filtered with two stages of high efficiency particulate air (HEPA) filters. The off-gas treatment for the radioactive field system is similar to that of the large-scale system. Both systems are trailer mounted and therefore mobile.

The off gas from the engineering-scale system is treated by the air handling system of the facility in which it is located.

- Hydro-Sonic scrubber is a product of Hydro-Sonic Systems, Dallas, Texas. 


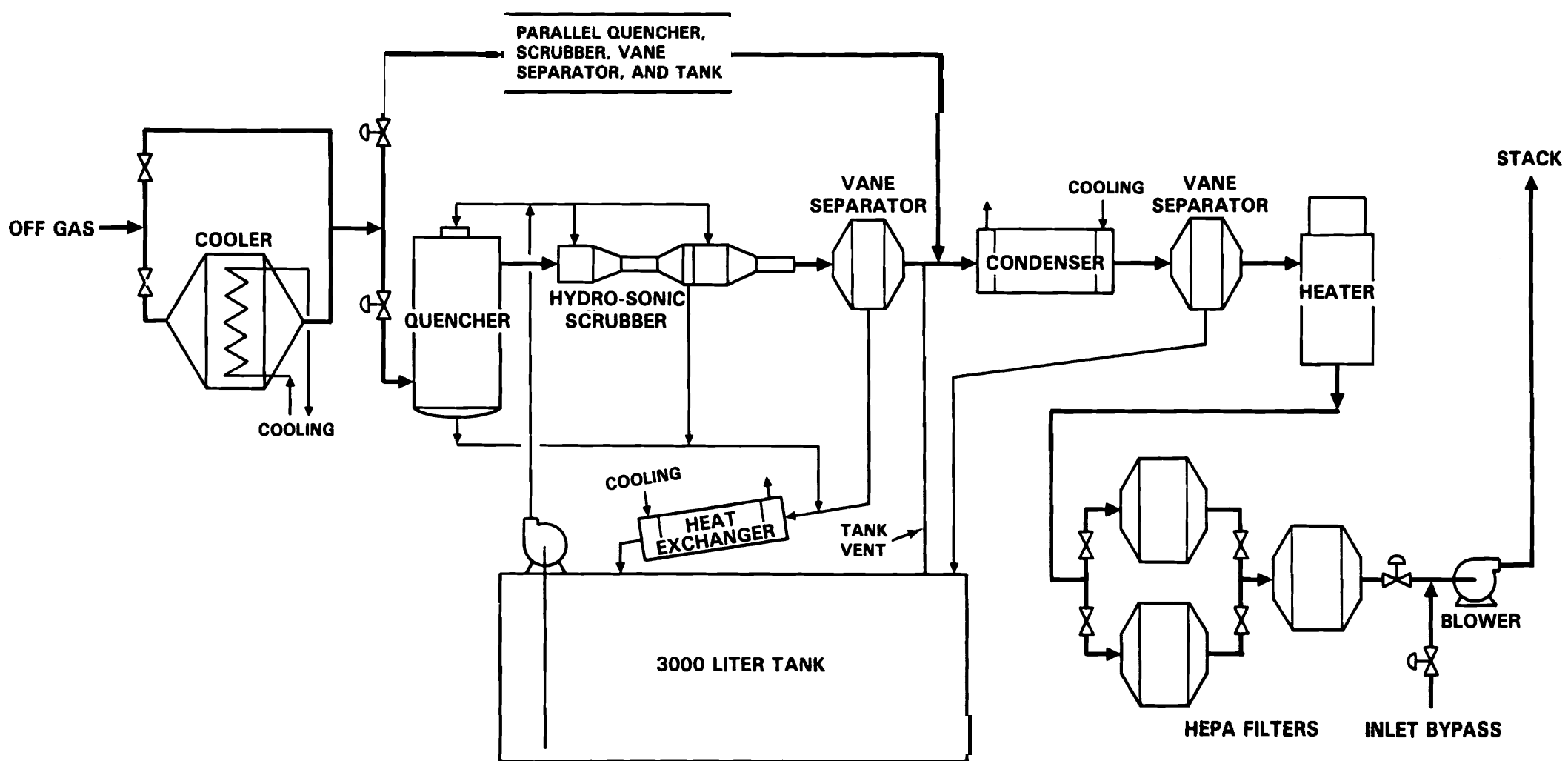

FIGURE 2. Schematic for the Large-Scale Off-Gas System 


\section{PERFORMANCE ANALYSIS}

The ability of the waste form to retain the encapsulated or incorporated radionuclides (some with very long half-lives) is of prime importance in the usefulness of the ISV process.

Vitrified soil blocks were analyzed to determine their chemical durability with a series of tests including 24 hour soxhlet leach tests. The soxhlet leach rate for all radionuclides was less than $1 \times 10^{-5} \mathrm{~g} / \mathrm{cm}^{2} /$ day, an acceptable value. These rates were comparable to those of Pyrex or granite, and much less than those of marble or bottle glass, as shown in Figure 3 .

A 28 day Materials Characterization Center test (MCC-1) (MCC 1981) was also conducted on a contaminated soil sample that was vitrified in the laboratory at $1600^{\circ} \mathrm{C}$. The overall leach rate of the vitrified soil is comparable to

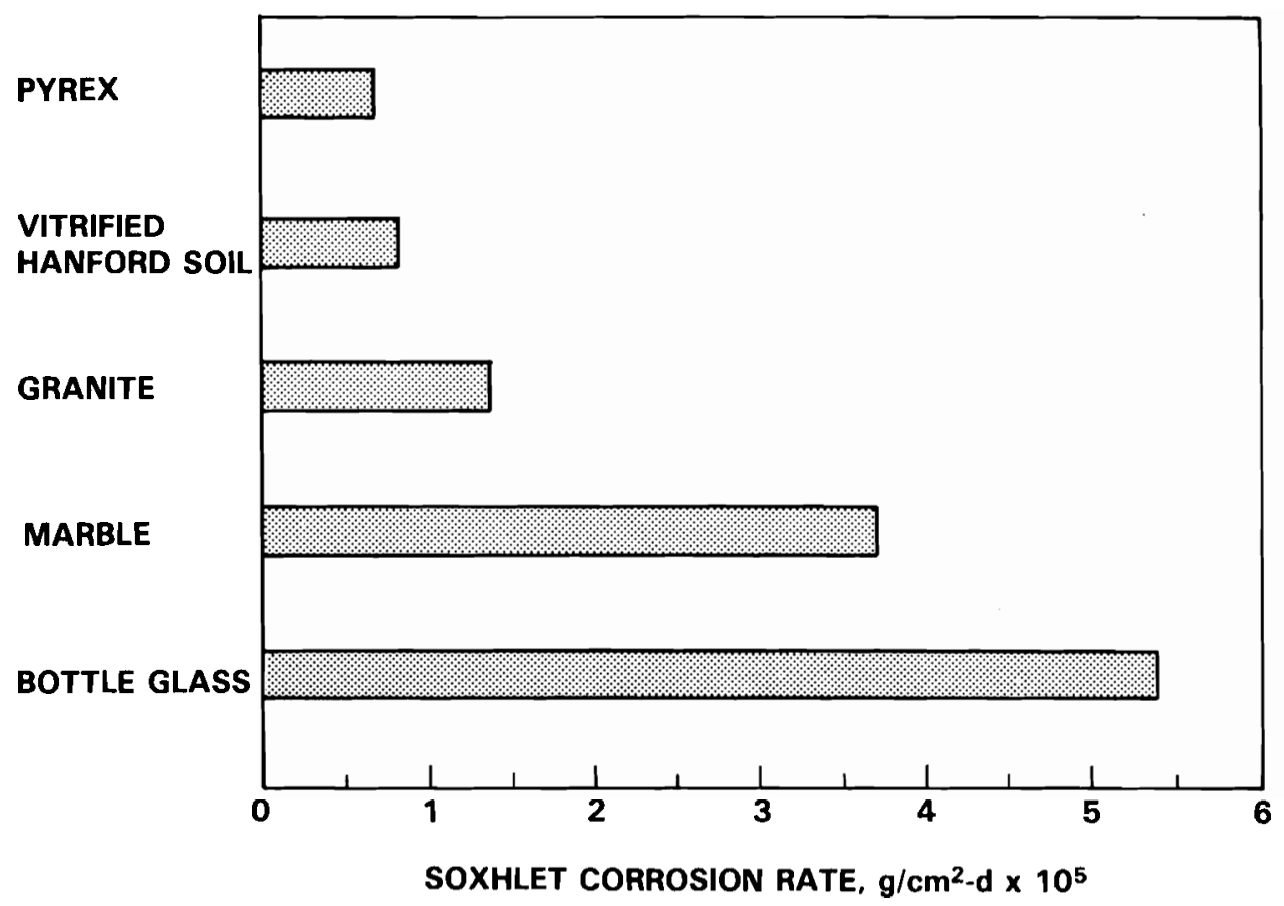

FIGURE 3. Leach Resistances of Selected Materials

(3) Pyrex is a registered trademark of Corning Glass Works, Corning, New York. 
the 76-68 glass and other TRU waste forms. The release rate of $\mathrm{Pu}$ from the vitrified soil $\left(2 \times 10^{-7} \mathrm{~g} / \mathrm{cm}^{2} /\right.$ day $)$ was higher than those for the borosilicate and aluminosilicate glasses. Higher vitrification temperatures like those experienced in the field are expected to lower the observed $\mathrm{Pu}$ leach rate.

Another indication of the durability of the ISV waste form is found in a study of the weathering of obsidian, a glasslike material physically and chemically similar to the ISV waste form (Ewing and Hoaker 1979). In the natural environment, obsidian weathers at a rate of 1 to $20 \mu \mathrm{m}^{2}$ per 1000 years (Laursen and Lanford 1978). A value of $10 \mu \mathrm{m}^{2}$ per 1000 years, assuming a linear weathering rate, yields a very conservative estimate of $1 \mathrm{~mm}$ of weathered ISV waste form for a 10,000 year time span.

Another important factor to consider in the waste form evaluation is the migration of the radionuclides once they are a part of the molten waste form. In the pilot-scale tests, the radionuclides did not move beyond the vitrified block. Furthermore, analysis of the blocks from the tests revealed that the radionuclides did not concentrate in the block, but instead were uniformly distributed.

- Also studied was the release of radionuclides to the off gas. The higher the decontamination factor (the mass of an element in the soil divided by the mass released to the off-gas treatment system), the less of the radionuclide that is released. Based on results from the pilot-scale system, it was estimated that for the large-scale system, soil-to-off-gas-hood DFs for less volatile elements such as $\mathrm{Pu}, \mathrm{Sr}$, and $\mathrm{U}$ will be $1 \times 10^{3}$ to $1 \times 10^{4}$. More volatile elements such as Cs, Co, and Te should have DFs of about $1 \times 10^{2}$. Element retention increases with depth of burial and the presence of a cold cap and decreases with the presence of gas generating materials. Decontamination factors for the off-gas treatment system (hood to stack) are as follows: for the semivolatiles (Cs, Co, and Te), $1 \times 10^{4}$, and for the less volatile nuclides $\mathrm{Sr}$ and Pu, $1 \times 10^{5}$. The soil-to-stack DFs are $1 \times 10^{6}$ for the semivolatiles and $1 \times 10^{8}$ to $1 \times 10^{9}$ for less volatile materials. For particulates the DFs are about $10^{11}$. In estimating plutonium DFs, Pu should be considered a nonvolatile in TRU contaminated soil sites, and a particulate in caissons and solid waste burial sites. 


\section{PROCESS PARAMETERS}

PNL studied the effects of soil properties such as chemical composition, thermal conductivity, fusion temperature, specific heat, electrical conductivity, viscosity, and bulk density on nine soils from waste sites all over the U.S. None of the minor variations in properties among the soils significantly impacts ISV operation. While soil moisture does affect the ISV process by increasiny the power requirements and run time, it is not a barrier to its use, having only a small effect on the attainable melt depth. Soil moisture is an economic penalty, not a process impediment.

The effect of materials buried with the waste itself, particularly those that are commonly found in radioactive waste sites, has been considered. These materials include metals, cements and ceramics, combustibles, and sealed containers. While there are some limitations to the ISV process due to waste inclusions, they are not significant.

The potential for criticality due to the presence of fissionable materials has been addressed. The Pu areal limit for the ISV process is approximately $1 \mathrm{~kg} \mathrm{Pu}$ per square meter of soil. Sites containing Pu levels approaching or surpassing this point should consider exhumation and recovery treatment prior to ISV as a stabilization option.

A mathematical model was devised to predict the behavior of the ISV system for waste burial sites with differing geometries and to assist in scale-up to the larye-scale system without the need for extensive field testing. The effects on process performance of changes in soil properties, power system capability, and waste site geometry were evaluated using the model. Information produced included energy consumption, mass vitrified, operating time, melt depth, and melt width for various ISV configurations. The model was also used to determine the effect of soil moisture on the ISV process. As part of the assessment of the effectiveness of the model as a predictive tool, model predictions were compared to results from the pilot-scale field tests, and the predicted and actual values were very close, with usually less than $10 \%$ variance. 


\section{ECONOMIC ANALYSIS}

The cost of using ISV as an in-place stabilization technique was estimated. For these estimates, two types of applications were considered: a TRU contaminated soil site and a burial trench.

The components that contribute to the cost of ISV are site preparation activities, annual equipment charges, operational costs such as labor, and consumable supplies such as electricity and electrodes. Five different configurations for TRU contaminated soil sites, employing the large-scale system, were evaluated, using the four basic cost-contributing categories. The results are provided in Table 1.

When using the cost figures in Table 1, it is recommended that ranges be employed for making cost estimates. For example, to estimate the cost of selectively vitrifying portions (a volume of $2900 \mathrm{~m}^{3}$ ) of the $216-Z-1 \mathrm{~A}$ site at Hanford, as shown in Figure 4, the lower boundary of the range should be case 3 (local power, above average manpower, average heat losses): $\$ 138 / \mathrm{m}^{3}$ of soil vitrified, for a total cost of $2900 \mathrm{~m}^{3} \times \$ 138 / \mathrm{m}^{3}$, or $\$ 400,200$, or $\$ 400 \mathrm{~K}$. The upper boundary of the range should be a combination of cases 1,2 , and 3 (local power, above average manpower, and high heat losses), which calculates to be $2900 \mathrm{~m}^{3} \times \$ 138 / \mathrm{m}^{3} \times[$ ratio of heat loss effects: 142 (case 1$) / 116$ (case 2$\left.)\right]=$ $\$ 489,900$, or $\$ 490 \mathrm{~K}$.

TABLE 1. Cost Estimates for Five ISV Large-Scale Configurations

\begin{tabular}{|c|c|c|c|c|c|}
\hline Number & Site & Power & Heat Loss & $\begin{array}{l}\text { Manpower } \\
\text { Level }\end{array}$ & $\begin{array}{l}\text { Total Cost, } \\
1982 \$ / \mathrm{m}^{3} \text { of } \\
\text { Soil Vitrified } \\
\end{array}$ \\
\hline 1 & Hanford & Local & $\mathrm{High}$ & Average & 142 \\
\hline 2 & Hanford & Local & Average & Average & 116 \\
\hline 3 & Hanford & Local & Average & Above Avg. & 138 \\
\hline 4 & Generic & Local & Average & Average & 135 \\
\hline 5 & Generic & Portable & Average & Average & 179 \\
\hline
\end{tabular}




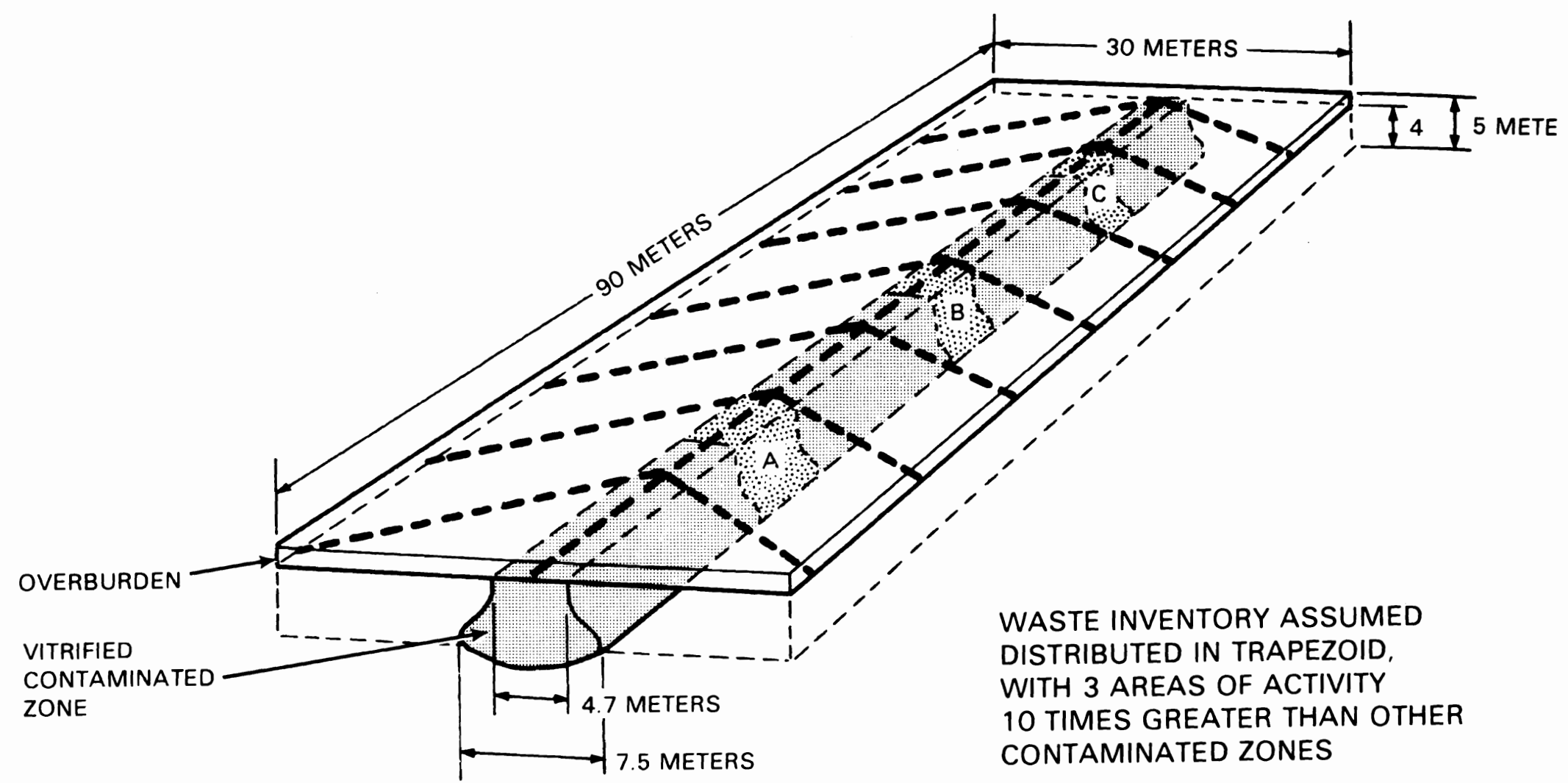

FIGURE 4. Waste Distribution in a $90 \times 4 \times 4 \mathrm{~m}$ Site 
The geometry of the site, cost of power, and soil moisture can have significant effects on cost. Data were developed to illustrate these effects by determining the cost of vitrifying an entire burial trench in an eastern and western U.S. site, assuming that the geometry of the trench was the same. Trench characteristics are given in Figure 5. The results of the evaluation are summarized in Table 2.

A comparison of the costs in Tables 1 and 2 shows that the effects of increased depth, site yeometry, and soil moisture are indeed significant. Here, geometry is a very important factor because the volume of waste vitrified does not equal the total volume vitrified, as it did in the previous case. Again, when using these values for planning purposes, ranges should be employed, making adjustments for heat losses and manpower levels.

For comparison, the charge for disposal of low level defense waste at Hanford is $\$ 145 / \mathrm{m}^{3}$, and the cost of placing TRU waste in 20 year retrievable storage is $\$ 370 / \mathrm{m}^{3}$. Estimates for exhumation, processing, certification, transportation, and emplacement at WIPP range from $\$ 12,000$ to $\$ 25,000 / \mathrm{m}^{3}$ (US DOE 1980; Bishoff and Hudson 1979), depending on the complexity of the site.

ANALYSIS OF OCCUPATIONAL AND PUBLIC SAFETY

To analyze the occupational and public safety of routine and nonroutine ISV operations for both the near and far term, a Hanford waste site (the 216-ZIA tile field in the 200 area) was selected as a reference. Radionuclide release rates from the soil during vitrification were estimated, and the 216-Z$1 \mathrm{~A}$ waste inventory reported by Owens (1981) was the basis for the radionuclide source term.

Tables 3 and 4 give the radiation doses from routine operations in the near term for both the ISV worker and the public, respectively. For all routine exposures, radiation doses are estimated to be well below federal guidelines set by DOE. Of all activities associated with ISV operations, the maximum occupational dose is expected to occur while the worker is placing electrodes. The low exposure levels can be seen in Table 3, where the occupational dose for this activity is compared to the dose that would be received 

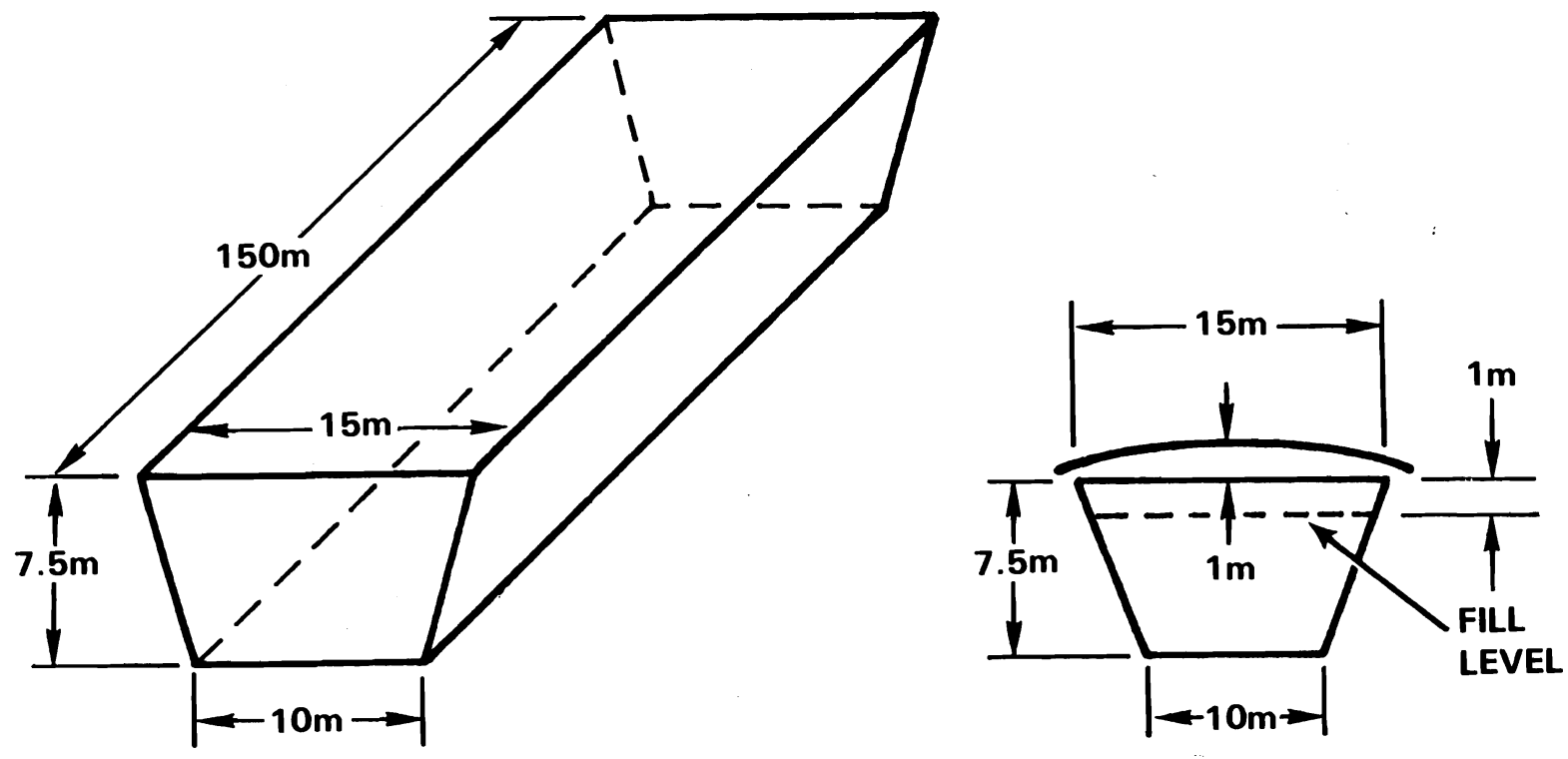

Trench dimensions $(L \times W \times D)$ Contaminated zone dimensions $(L \times W \times D)$ Soil moisture (dry weight bases)

\begin{tabular}{|c|c|}
\hline Hanford Site & Eastern Site \\
\hline $\begin{array}{r}150 \times 15 \times 7.5 \mathrm{~m} \\
151 \times 16 \times 8 \mathrm{~m} \\
5 \%\end{array}$ & $\begin{array}{l}150 \times 15 \times 7.5 \mathrm{~m} \\
152 \times 17 \times 8.5 \mathrm{~m} \\
25 \%\end{array}$ \\
\hline
\end{tabular}

FIGURE 5. Characteristics of a Generic waste Trench

TABLE 2. Cost Estimates for Vitrifying a Waste Trench

\begin{tabular}{|c|c|c|c|c|}
\hline Parameter & West 1 & West 2 & East 1 & East 2 \\
\hline Heat loss & High & Avg & $\mathrm{High}$ & Avg \\
\hline Power & Local & Local & Local & Local \\
\hline Manpower & Avg & Avg & Avg & Avg \\
\hline$\$ / \mathrm{m}^{3}$ waste & 276 & 199 & 506 & 300 \\
\hline
\end{tabular}

TABLE 3. Whole Body Radiation Doses from Routine Operations Occupational Dose (Electrode Emplacement)
All workers:
0.09 man-rem
Maximum exposed worker: 0.01 man-rem
Natural Background
Exposure rate: $\quad 7 \mu \mathrm{R} / \mathrm{h}$
Total $(1880 \mathrm{~h}): 0.01 \mathrm{rem}$ 
TABLE 4. Public Dose Commitments from Routine Operations

(critical organ)

\begin{tabular}{|c|c|c|}
\hline & $\begin{array}{l}\text { Max. Exposed } \\
\text { Indiv., rem }\end{array}$ & $\begin{array}{c}\text { Population, } \\
\text { man-rem }\end{array}$ \\
\hline 1st yr dose (lungs) & $3 \times 10^{-8}$ & $9 \times 10^{-3}$ \\
\hline 50 yr dose (bone) & $1 \times 10^{-5}$ & $5 \times 10^{-1}$ \\
\hline
\end{tabular}

during the same time period from natural background. The maximum exposed worker would receive a dose roughly the same as background radiation. The doses calculated for ISV operation at this reference site are substantially below the DOE regulations on exposure for routine operations to both workers and the general public [DOE Order 5480.1A, Chapter 11 (US DOE 1981a)].

Abnormal exposures for both the ISV worker and the public from the vitrification process were calculated using worst-case scenarios. The most serious abnormal condition is a break in the off-gas line. For the specific exposures calculated, see Tables 5 and 6 . While there are no standards for doses resulting from accidental releases, accidents that result in any individual receiving a total body dose $>25$ rem nust be reported immediately, and any that result in a dose $>5$ rem for the total body must be reported within 72 hours [DOE Order 5484.1 , Chapter 1 (US DOE 1981b)]. None of the public doses from potential accidents investigated for ISV application at site 216-Z-1A falls within these categories.

Far term (beyond institutional control) exposures were calculated for transients, inadvertent intruders, intentional intruders, and permanent residents in the vicinity of the waste site. Doses were calculated for these categories for individuals 1000 and 10,000 years in the future using three scenarios: doses resulting from a site that is 1) left in its present state, 2) covered with an engineered barrier, and 3) selectively vitrified in the highly contaminated areas and covered with an engineered barrier (see Table 7). Pathways of concern were determined and evaluated using the allowable residual contamination level (ARCL) techniques described by Napier (1982). The pathways are direct irradiation; inhalation of resuspended material; and ingestion of contaminated crops, yroundwater, and animal products. 
TABLE 5. Occupational Doses from Accidental Releases (120 hour run, 15 sets, concentrated inventory)

\begin{tabular}{|c|c|c|c|c|c|}
\hline \multirow[b]{2}{*}{ Accident } & \multirow{2}{*}{$\begin{array}{c}\begin{array}{c}\text { Number } \\
\text { of }\end{array} \\
\text { Personnel } \\
\end{array}$} & \multirow{2}{*}{$\begin{array}{c}\text { Length } \\
\text { of } \\
\text { Exposure } \\
\end{array}$} & \multicolumn{3}{|c|}{$\begin{array}{l}\text { 1st Year Dose Commitment } \\
\text { to Each Worker, rem }\end{array}$} \\
\hline & & & Total Body & Bone & Lung \\
\hline Uncontrolled venting & 1 & $1 \mathrm{~min}$ & $1 \times 10^{-3}$ & $2 \times 10^{-2}$ & $2 \times 10^{0}$ \\
\hline $\begin{array}{l}\text { Break in off-gas } \\
\text { line }\end{array}$ & 1 & $5 \min$ & $6 \times 10^{-3}$ & $1 \times 10^{-1}$ & $1 \times 10^{1}$ \\
\hline $\begin{array}{l}\text { Excess overburden } \\
\text { removal }\end{array}$ & 2 & $10 \min$ & $3 \times 10^{-3}$ & $4 \times 10^{-2}$ & $5 \times 10^{0}$ \\
\hline
\end{tabular}

TABLE 6. Public Dose Commitments from Postulated Abnormal Occurrences Maximum Exposed Individual, rem Population, man-rem

Uncontrolled Venting

1st year (lungs)

50 year (bone)

Off-Gas Line Break

1st year (lungs)

50 year (bone)
$5 \times 10^{-5}$

$5 \times 10^{-4}$

$3 \times 10^{-2}$

$3 \times 10^{-1}$
$2 \times 10^{-1}$

$2 \times 10^{0}$

$1 \times 10^{2}$

$1 \times 10^{3}$

Excessive Overburden Removal
1st year (1ungs)
$1 \times 10^{-2}$
$3 \times 10^{1}$
50 year (bone)
$9 \times 10^{-2}$
$3 \times 10^{2}$

For transients the undisturbed site does not pose a direct radiation hazard at the surface because the radiation levels are at background. This is true even for the unaltered site due to the shielding properties of the soil cover. However, for permanent residents the growing of gardens and eating of the garden produce could cause an exposure of $10 \mathrm{rem} / \mathrm{yr}$ from the unaltered site for both the 1000 and 10,000 year scenario. With an engineered barrier and selective vitrification, the dose would be reduced to $1 \times 10^{-2} \mathrm{rem} / \mathrm{yr}$, as shown in Table 7 .

The scenarios that best distinguish the capabilities of the selectively vitrified sites from unaltered sites and barrier sites involve intentional and 
IABLE 7. Public Dose Estimates for Far-Term Routine Scenarios

\begin{tabular}{|c|c|c|}
\hline Direct Irradiation & $\frac{\text { Year } 1,000}{\text { Maximum Annual }}$ & Total $\frac{\text { Year } 10,000}{\text { Body Dose }}$ \\
\hline Unmodified site & Background & Background \\
\hline $\begin{array}{l}\text { Vitrification and } \\
\text { engineered barrier }\end{array}$ & Background & Background \\
\hline Engineered barrier & Background & Background \\
\hline Inyestion & Maximum Annual & Bone Dose, rem \\
\hline Unmodified site & 10 & 10 \\
\hline $\begin{array}{l}\text { Vitrification and } \\
\text { Engineered barrier }\end{array}$ & 0.01 & 0.01 \\
\hline Engineered barrier & 0.01 & 0.01 \\
\hline
\end{tabular}

unintentional human intrusion (see Table 8). For a vitrified site, the worst case is drilling into the glass block because the relatively large quantity of respirable fines generated may result in the inhalation of the resuspended particles.

The worst case for the nonvitrified material with or without a barrier is excavation into the waste zone, shown in Table 8. While the barriers are designed to prevent surface erosion and plant or animal intrusion into the site, there is no way to predict whether future human populations may intrude into the waste zone. Although ISV cannot prevent an intrusion, it can mitigate its consequences.

\section{ASSESSMENT OF WASTE SITE APPLICATIONS}

Preliminary studies (Kennedy et al. 1982) indicate that a combination of selective vitrification and appropriately scaled barriers can be a cost effective in-place stabilization technique for those Hanford TRU sites requiring remedial action. This approach is consistent with the findings of the National Acadenly of Sciences (NAS 1978), which stated that retrieval of buried TRU for disposal in a geologic repository could be more hazardous than disposing the waste in place. This approach is also consistent with the long-range master plan for defense transuranic waste management (US DOE 1983), which states that "deep geologic disposal may not be the most economical means 
TABLE 8. Public Dose Commitments for Far-Term Intrusion, rem

$\frac{\text { Year } 1,000}{\underline{1 \text { st Year (a) }} 50 \text { Year (b) }} \quad \frac{\text { Year } 10,000}{1 \text { st Year }{ }^{(a)} 50 \text { Year }{ }^{(b)}}$

$\begin{array}{lcccc}\text { Drilling } & & & \\ \quad \text { Unmodified site } & 24 & 880 & 16 & 550 \\ \begin{array}{l}\text { Vitrification and } \\ \text { engineered barrier }\end{array} & 6 & 15 & 3 & 8 \\ \begin{array}{l}\text { Engineered barrier } \\ \begin{array}{l}\text { Excavation } \\ \text { Unmodified site }\end{array}\end{array} & 24 & 880 & 16 & 550 \\ \begin{array}{l}\text { Vitrification and } \\ \text { enyineered barrier }\end{array} & 0.006 & 1600 & 33 & 1100 \\ \text { Engineered barrier } & 48 & 0.02 & 0.003 & 0.008 \\ \text { Vitrified curio(c) } & 0.2 & 1600 & 33 & 1100 \\ \end{array}$

\footnotetext{
(a) Lung dose.

(b) Bone dose.

(c) Total body dose.
}

of safe disposal for all TRU wastes." DOE Order 5820.1 (US DOE 1982) allows field organizations to establish new or alternative TRU waste management practices. ISV is one of the engineered permanent disposal alternatives being examined for greater confinement than shallow land burial, also referred to as greater confinement disposal.

Within the context of greater confinement disposal, the TRU sites at Hanford were reviewed, and a list of candidate sites that may require in-place remedial action was compiled. These candidate sites include TRU contaminated soils, caissons, and solid burial grounds. More detailed evaluations to confirm the need for remedial action and the appropriateness of in-place stabilization are in progress.

The followiny recommendations have been made in regard to the future direction of the program: 
- Continue the design and deployment of the large-scale ISV system.

- Perform a systematic analysis to determine which TRU sites can benefit from in-place stabilization using ISV. Assist the appropriate operating contractors in finalizing the list by cost-benefit and public and occupational exposure analyses.

- Continue engineering- and pilot-scale testing to verify:

- electrode corrosion resistance

- computer modeling predictions

- the dynamic characteristics of the melt

- application to special geometries

- adequacy for processing combustible/hazardous chemicals. 


\section{INTRODUCTION}




\section{INTRODUCTION}

Development of vitrification technology for radioactive wastes has been underway at Pacific Northwest Laboratory (PNL) for over two decades. Since 1973, melting by joule heating or dissipation of electric current in the waste/glass mixture has been extensively researched, especially for high-level waste.

The in situ vitrification (ISV) concept for converting buried radioactive and nonradioactive hazardous wastes to an inert crystalline and glass form using joule heating was first tested in August 1980. In the ISV process, electrical current is passed among an array of four electrodes inserted in the ground around the waste to be stabilized. Heat from the process melts the soil, thus encapsulating the radioactive contaminants. This program has been sponsored by the U.S. Department of Energy's (DOE's) Richland Operations Office for application to Hanford sites. Additional support has been provided by the National Transuranic Waste Management Program since FY 1982.

Evaluations of 18 initial tests, performed with an engineering-scale laboratory test (ESLT) unit having a $36 \mathrm{~cm}$ distance between electrodes on a side, indicated that scale-up was technically feasible and would improve the costeffectiveness of the process. The objective of the initial engineering-scale laboratory tests was to develop reliable electrode designs, power systems, startup techniques, operating sequences and scale-up correlations. Later tests were used to evaluate process limitations and improve power system design. Table 9 lists a brief summary of the engineering-scale laboratory tests performed through June 1983.

Encouraging results from the early engineering-scale tests led to the design and construction of a stationary pilot-scale field test unit during the second half of FY 1981. This system operates with four electrodes in a square pattern $1.2 \mathrm{~m}$ on a side and has been used to conduct a series of four nonradioactive tests. Table 10 lists a summary of these tests. During pilot-scale field testing, a scale-up of 200 in vitrified mass over engineering-scale laboratory tests was realized. 
TABLE 9. Summary of Results of Engineering-Scale Laboratory Tests

$\begin{array}{ll}\frac{\text { Test }}{\text { ESLT } 1} & \frac{\text { Objectives }}{\text { Verify concept feasibility }} \\ \text { ESLT } 2 & \text { Vitrify simulated waste box } \\ \text { ESLT } 3 & \text { Vitrify simulated waste box } \\ \text { ESLT } 4 & \text { Evaluate test startup techniques } \\ & \text { Evaluate soil moisture effects }\end{array}$

ESLT 5 Obtain heat transfer data

Evaluate void formation

ESLT 6 Test graphite electrodes

ESLT $7 \quad$ Test graphite electrodes connection

ESLT 8 Test Na additions to increase soil conductivity

ESLT 9 Test graphite electrodes and vitrify simulated contaminated soil

ESLT $10 \quad$ Vitrify metal container (35\% of full electrical short)

ESLT 11 Vitrify simulated waste can of combustibles

ESLT 12 Vitrify metal containers (707 of full electrical short)

ESLT 13 Vitrify metal canister using increased power

ESLT 14 Vitrify concrete canister

ESLT 15 Vitrify concrete and cement monoliths

ESLT 16 Test Scott-Tee (Lazar 1977) power systen

ESLT 17 Test saturable reactor power control

ESLT 18 Test controller multi-tapped Scott-Tee power system

Results

Successful vitrification of $130 \mathrm{~kg}$ of soil

Incomplete test: electrode extension failed

Successful test

Surface startup successful in reducing 00 generation

Performance not limited by increased moisture

Data confirms predictions

Voids caused by subsidence of molten soil from cold cap

Incomplete test: electrical connection failure

Successful test

Sodium in soil too conductive; melt zone would not grow

Successful test

Successful test

Successful test

Successful test; no limit imposed by 5 wty metal occupying $70 \%$ of full electrical short

Successful test

Successful test

Successful test; no limits identified

Successful test

Successful test

Successful test 
TABLE 10. Summary of Results of Pilot-Scale Field Tests (stationary system)

\begin{tabular}{|c|c|c|}
\hline Test & Objectives & Results \\
\hline PSFT 1 & Verify process scale-up & $\begin{array}{l}\text { Successful vitrification of } \\
5670 \mathrm{~kg} \text { of soil }\end{array}$ \\
\hline PSFT 2 & $\begin{array}{l}\text { Evaluate migration and volatili- } \\
\text { zation of simulated hazardous } \\
\text { species }\end{array}$ & $\begin{array}{l}\text { No migration outside of } \\
\text { vitrified zone and very low } \\
\text { element volatilizations }\end{array}$ \\
\hline PSFT 3 & $\begin{array}{l}\text { Vitrify } 208 \text { L ( } 55 \text { yal) waste drum } \\
\text { containing soil and simulated } \\
\text { combustible wastes }\end{array}$ & $\begin{array}{l}\text { Successful vitrification } \\
\text { of drum and contents. } \\
\text { Temporary system shutdown } \\
\text { due to high off-gas par- } \\
\text { ticulate loading. Successful } \\
\text { restart on one pair of } \\
\text { electrodes. }\end{array}$ \\
\hline \multirow[t]{2}{*}{ PSFT 4} & $\begin{array}{l}\text { Test two side-by-side vit- } \\
\text { rification operations (PSFT } 4 A \text { and } \\
\text { PSFT 4B) }\end{array}$ & $\begin{array}{l}\text { Successful vitrification of } \\
25,400 \mathrm{~kg} \text { of soil }\end{array}$ \\
\hline & $\begin{array}{l}\text { Vitrify various combustible and } \\
\text { noncombustible waste packages }\end{array}$ & Successful test \\
\hline
\end{tabular}

Migration and volatilization of simulated hazardous species mixed with soil and combustible wastes were studied during PSFTs 2, 3, and 4. The fourth test was a two-part operation (PSFTs $4 A$ and $4 B$ ) verifying side-by-side vitrification and fusion into one monolith, which would be required to solidify many actual waste sites such as solid waste trenches or TRU contaminated soil cribs.

The next major objective of the program was to vitrify actual radioactive materials in place. To accomplish this, a mobile pilot-scale off-gas treatment unit for the radioactive field test was constructed in a semi-trailer. The power system and off-gas treatment system were improved designs, building upon experience gained with the pilot-scale field test system. 'Two nonradioactive tests were performed to provide equipment checkout and operator training prior to the radioactive field test. These tests are referred to as pilot-scale cold tests (PSCTs 1 and 2 ). A successful pilot-scale radioactive test (PSRT) was performed in June 1983, using a makeup site containing known quantities of ${ }^{239} \mathrm{Pu},{ }^{137} \mathrm{Cs},{ }^{60} \mathrm{Co},{ }^{106} \mathrm{Ru}$, and ${ }^{90} \mathrm{Sr}$. Table 11 summarizes the results of the 
TABLE 11. Summary of Results of Pilot-Scale Cold and Radioactive Tests (mobile system)

Test

PSCT 1
Objectives

Vitrify simulated waste
package

Perform operator training and equipment checkout

PSCT 2 Vitrify simulated waste package
Results

Successful vitrification of waste package. off-gas system maintained total containment of volatile elements. Identification of items requiring upgrade.

Successful test of system upgrade

Verify correct operation of system upgrade

PSRT Vitrify a makeup site containing known quantities of radionuclides
Successful vitrification with no release of radioactivity

three pilot-scale field tests. Analysis of the data at the time of this reporting shows that total containment of the radioactive material in the melt zone and within the off-yas treatment system can be achieved by ISV. No release of radioactive material to the environment was detected during the actual processing or during the cooldown period, even with $600 \mathrm{nCi} / \mathrm{g}$ transuranic (TRU) waste and $30,000 \mathrm{nCi} / \mathrm{g}$ mixed fission products in the initial $19 \mathrm{~L}$ waste package of soil.

An occupational safety assessment and an economic analysis were performed for the ISV process during FY 1983. These studies showed that a large-scale ISV process would reduce occupational exposures and decrease the cost per volume vitrified. Based on the safety of ISV, economic incentives, and the successful pilot-scale radioactive test, work has proceeded on development of a large-scale ISV system. At the date of this writing, the large-scale conceptual design has been completed and detailed design is in progress, with construction to follow. An operational test of the new system is scheduled for FY 1985 with radioactive field tests scheduled for FY 1986 and following years.

This report contains a systems evaluation and applications assessment of the ISV process. The systems evaluation includes a detailed description of the engineering-, pilot-, and large-scale units as well as ISV performance data. Parameters that affect ISV processing are discussed as well as the long-term 
durability of the waste form. The applications assessment consists of an economic analysis, occupational and public safety analysis, and a review of waste sites for potential ISV application. Part of the information presented within this report is an extension of previous work performed as part of an applications analysis for stabilization of transuranic wastes using ISV (Oma, Farnsworth, and Rusin 1982). 
CONCLUSIONS AND RECOMMENDATIONS 


\section{CONCLUSIONS AND RECOMMENDATIONS}

In situ vitrification is an emerging technology, suitable for the stabilization of buried radioactive wastes requiring in-place stabilization. The following conclusions have been made reyarding ISV performance and the applicability of solidifying TRU wastes at Hanford and other DOE sites.

\section{SYSTEM AND WASTE FORM PERFORMANCE}

- The predicted depth limit of a large-scale ISV system is 10 to $13 \mathrm{~m}$ in Hanford soils. The electrode separation, which determines maximum melt depth, can be adjusted from 3.5 to slightly over $6 \mathrm{~m}$; the $3.5 \mathrm{~m}$ separation is required to obtain maximum depth. The peak flow capacity of the off-gas treatment system is $104 \mathrm{~m}^{3} / \mathrm{min}$, which is adequate to contain gaseous releases from buried combustibles and sealed containers.

- Radionuclides are retained in the melt. Areas of high concentration are diluted via convection currents. When gas venting occurs on encountering combustibles that are contaminated, only small quantities of contaminants associated with the combustibles are available for release to the off-gas system. Those releases are acceptably low.

- Metal inclusions do not significantly affect ISV unless a full electrical short circuit is approached. During an engineering-scale ISV test, metal occupying over $70 \%$ of the electrode spacing, and accounting for $5 \%$ of the final block weight, was successfully vitrified.

- Two adjacent melts have been fused into a single monolith, with a minimum of nuclide migration between melts.

- Two engineering-scale tests have verified that there is complete dissolution of cement inclusions within the glass waste form. Cement and concrete inclusions within a waste site fracture as they 
are heated during ISV. Strong convective currents within the melt promote distribution and dissolution of the fragmented pieces.

- ISV is capable of processing soils at DOE sites. Soils from nine different U.S. locations were tested and found to be similar in the properties which could affect the ISV process.

- Transuranic waste sites with areal Pu concentrations of $<1.0 \mathrm{~kg} / \mathrm{m}^{2}$ can be vitrified safely without a criticality. Sites which contain hydrogenated organics in waste containers are limited to an areal $\mathrm{Pu}$ concentration of $<0.8 \mathrm{~kg} / \mathrm{m}^{2}$.

- No credible concentration mechanism for ${ }^{239} \mathrm{Pu}$ or other TRU fissionable isotopes has been identified. The ISV melt zone has strong convective currents which promote dilution and thorough mixing of waste species.

- Leachability of vitrified soil from Hanford is estimated to be $<1 x$ $10^{-5}$ parts per year.

\section{ECONOMICS AND SAFETY}

- Operational and consumable costs are dominant, accounting for $>80 \%$ of the total cost. Other cost elements are site preparation activities and annual equipment charges.

- Costs were developed for 12 different ISV configurations. Six of the configurations were for TRU contaminated soil sites and six were for burial trenches. Costs for TRU contaminated soil sites ranged from $\$ 116 / \mathrm{m}^{3}$ to $\$ 142 / \mathrm{m}^{3}$ of soil vitrified where local power was available; the cost increased to $\$ 179 / \mathrm{m}^{3}$ when a diesel generator was used as the power source. The cost for a typical trench in the western U.S. ranged from $\$ 199$ to $\$ 276 / \mathrm{m}^{3}$, and in the eastern U.S. from $\$ 300$ to $\$ 506 / \mathrm{m}^{3}$.

The costs of electricity and increased power and processing time were the principal contributors to the eastern versus western trench 
costs. The difference between the western TRU contaminated soil sites and trenches is attributed to the decrease in processing efficiency when going to greater depths.

- Soil moisture increases the time and power required to vitrify a waste site; however, the effect on the maximum attainable geometric limits of ISV is small. Soil moisture is an economic penalty, not a process impediment.

- The stabilization of a typical crib and tile field at Hanford was estimated using selective ISV. Solidifying $2900 \mathrm{~m}^{3}$ of highly contaminated soil using ISV is estimated to cost between $\$ 400,000$ and $\$ 490,000$.

- Public and occupational exposures for routine operations are acceptably low. The first year dose commitment for the maximum exposed individual is $3 \times 10^{-8}$ rem, and the 50 year dose commitment is $1 \times$ $10^{-5}$ rem. The maximum occupational dose is $0.01 \mathrm{rem}$.

- Occupational doses for postulated abnormal occurrences range from 2 to 10 rem. Public dose commitments for these same scenarios range from $5 \times 10^{-5}$ to $3 \times 10^{-2}$ rem for the first year dose to the maximum exposed individual.

- Far-term radiation exposure calculations clearly showed that although ISV cannot prevent intrusion, it may mitigate the consequences. Future dose performance assessments were developed using a variety of scenarios for 1000 and 10,000 years in the future (after institutional control). Human intrusion, both inadvertent and deliberate, produced the highest exposures.

\section{APPLICATION OF ISV}

- For Hanford, selective ISV in combination with barriers can be a cost effective in-place disposal option. Sites at Hanford being considered for in-place stabilization include TRU contaminated soil sites, caissons, and solid waste burial trenches. 
- Whenever exhumation of buried radioactive wastes is considered, ISV should be evaluated as an option. In special cases, ISV can be an aid or precursor to exhumation.

- Most pre-1970 solid waste burial grounds that would require in-place stabilization can be processed by ISV. Site characterization is a necessary precursor; however, characterization costs would be modest when compared to the alternative of exhumation, processing, certification, shipping, and storage in geologic repositories. The public and occupational exposure would be significantly less for the ISV option.

- TRU contaminated soil sites that would require in-place stabilization could be processed by ISV. With the exception of several deep reverse wells at Hanford, no major process limits have been identified.

\section{RECOMMENDATIONS}

The following recommendations have been made in regard to the future direction of the program:

- Continue the design and deployment of the large-scale ISV system. Also continue the technology transfer activities at Hanford, verifying the stabilization of at least two actual TRU sites (tentatively one TRU contaminated soil site and one caisson).

- Perform a systematic analysis at Hanford to determine which TRU sites can benefit from in-place stabilization using ISV. Assist the appropriate operating contractor in finalizing the list by costbenefit and public and occupational exposure analyses. A limited number of onsite field tests and/or experiments may be required to evaluate special situations. 
- Continue engineering- and pilot-scale testing to verify:

- electrode corrosion resistance

- computer modeling predictions

- the dynamic characteristics of the melt

- application to special geometries

- adequacy for processing combustible/hazardous chemicals. 


\section{PROCESS DESCRIPTION}

$\because$ 


\section{PROCESS DESCRIPTION}

During ISV, buried waste and surrounding contaminated soil are stabilized by inserting electrodes in the soil and establishing an electric current between the electrodes. Figure 6 illustrates the process sequence. For startup, a small amount of specially prepared graphite is placed in paths between the electrodes on the soil's surface. Dissipation of power through the starter material creates temperatures high enough to melt a layer of soil, thereby establishing a molten, conductive path. This molten zone continues to grow in size, provided sufficient power is supplied to overcome heat losses. At the high temperatures $\left(>1700^{\circ} \mathrm{C}\right)$ created, organic materials pyrolyze; and the remaining ash, along with other noncombustible waste materials, dissolves or becomes encapsulated in the molten soil. Natural convective currents in the molten soil help distribute the waste materials uniformly. Upon cooling, a durable glass and crystalline waste form is created. Off gas from the process is collected and treated. If ground subsidence occurs during ISV, uncontaminated soil can be backfilled over the site.

The process operation is based on extensive joule-heated melter work performed at PNL for various nuclear waste immobilization projects (Buelt et al. 1979). The joule-heating principle operates by internal resistance heating of the conducting material as an electric current passes through the molten media. In ISV, the resistance decreases as the molten mass grows; therefore, to maintain a power level high enough (according to the formula $P=I^{2} R$ ) to

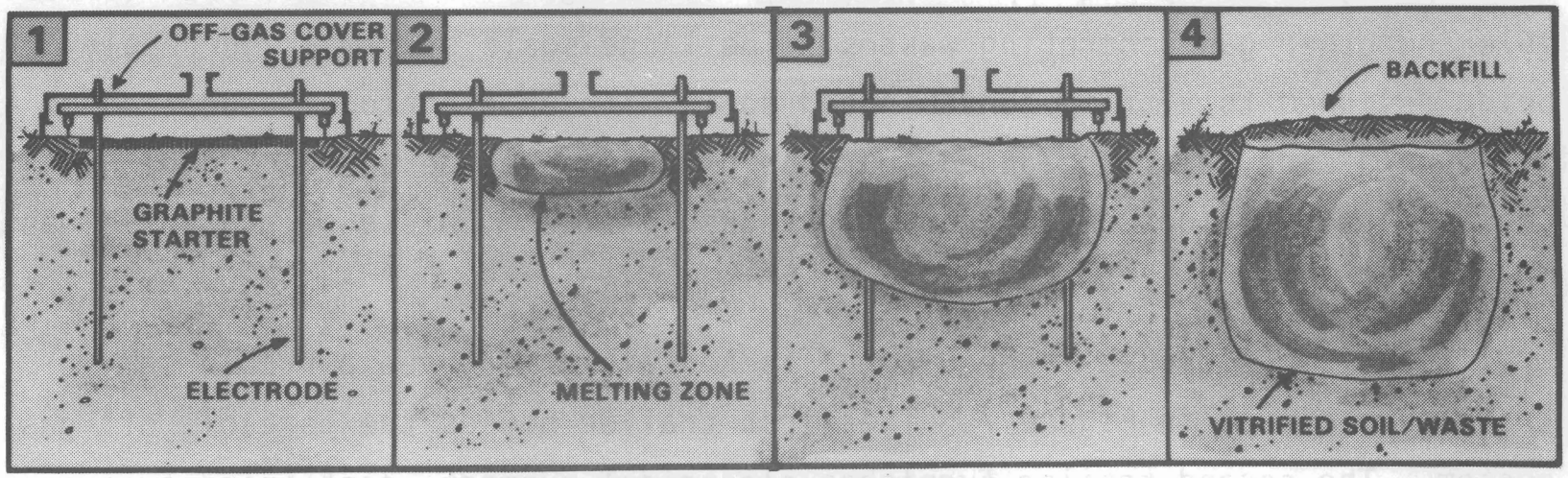

FIGURE 6. In Situ Vitrification Process Sequence 
continue melting more soil, the current must be increased. With a given power supply input, the amperage is increased by a transformer with multiple voltage taps.

The ISV process is started using a higher voltage potential and lower amperage. As the melt progresses and resistance decreases, lower voltage taps allow increased amperage to the melt, thus maintaining the power into the melt at nearly the maximum level. The process continues until the heat losses from the melt approach the energy delivered to the molten soil via the electrodes.

A hood over the vitrification zone is maintained under a slight vacuum to contain any hazardous gases or particulates that may be released. This hood also provides support for the electrodes. The vacuum on the hood is supplied by the off-gas treatment system, which also scrubs and filters any hazardous components from the off-gas stream.

This section describes components for the four ISV systems: large scale, pilot-scale radioactive test, pilot-scale field tests, and engineering scale.

\section{LARGE-SCALE SYSTEM}

Development and deployment of the large-scale ISV system is the goal of the ISV program. The large-scale system is less costly and more adaptable to numerous types of waste sites than the pilot-scale system. The cost of vitrifying a given waste volume with the large-scale system is one-seventh that of the pilot-scale system. The large-scale system is more adaptable because its high capacity off-gas system, which can process off gas at a rate of $104 \mathrm{~m}^{3} / \mathrm{min}$, is better equipped to contain sudden gaseous releases from combustible and other gas-generating wastes. The large-scale system is currently being designed to vitrify contaminated soils with an electrode separation of $5.5 \mathrm{~m}$ on a side. It is planned that the process could be applied to highly contaminated portions of TRU contaminated soil sites, caissons, and solid waste burial sites.

The off-gas processing equipment is contained in three portable semitrailers depicted in Figure 7. The first trailer houses the portable off-gas system. The second trailer furnishes electrical support, containing a power 


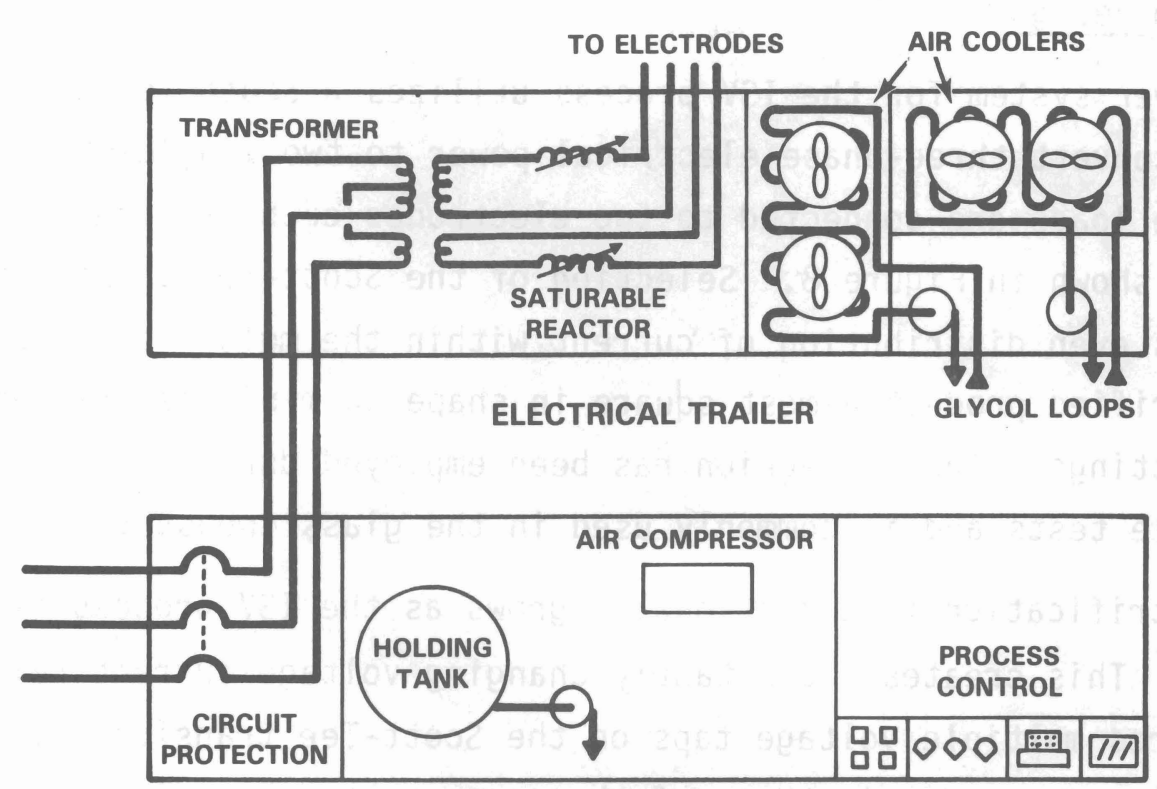

PROCESS CONTROL TRAILER

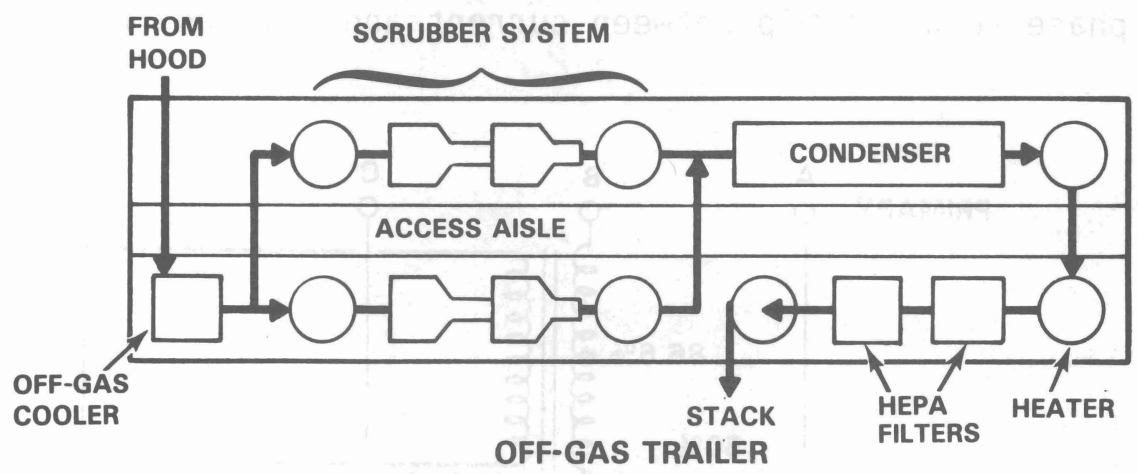

FIGURE 7. Three Portable Semi-Trailers for the Large-Scale System

system providing the electrical energy distributed to the electrodes. The second trailer also contains the air cooled heat exchangers, which cool the gases in the portable off-gas system. The entire process is monitored and operated from a control trailer, which houses the circuit protection equipment for the electrical system, the motor control center for the off-gas and cooling systems, and the instrument readout and control station. The control trailer also houses a holding tank for additional scrub water and an air compressor for actuation of pneumatic valves in the off-gas system. 
Power System Design

The power system for the ISV process utilizes a Scott-Tee transformer connection to convert three-phase electrical power to two single-phase loads. The single-phase loads are connected to two electrodes each, arranged in a square pattern, as shown in Figure 8. Selection of the Scott-Tee transformer was based on its even distribution of current within the molten soil, which produces a vitrified product almost square in shape to minimize overlap among adjacent settings. The connection has been employed during pilot- and engineering-scale tests and is commonly used in the glass industry.

The vitrification zone continually grows as the ISV process is supplied with power. This creates a constantly changing voltage/current relationship which requires multiple voltage taps on the Scott-Tee transformer. The multiple taps allow more efficient use of the power system by maintaining the power factor (the phase relationship between current and voltage) near maximum, which

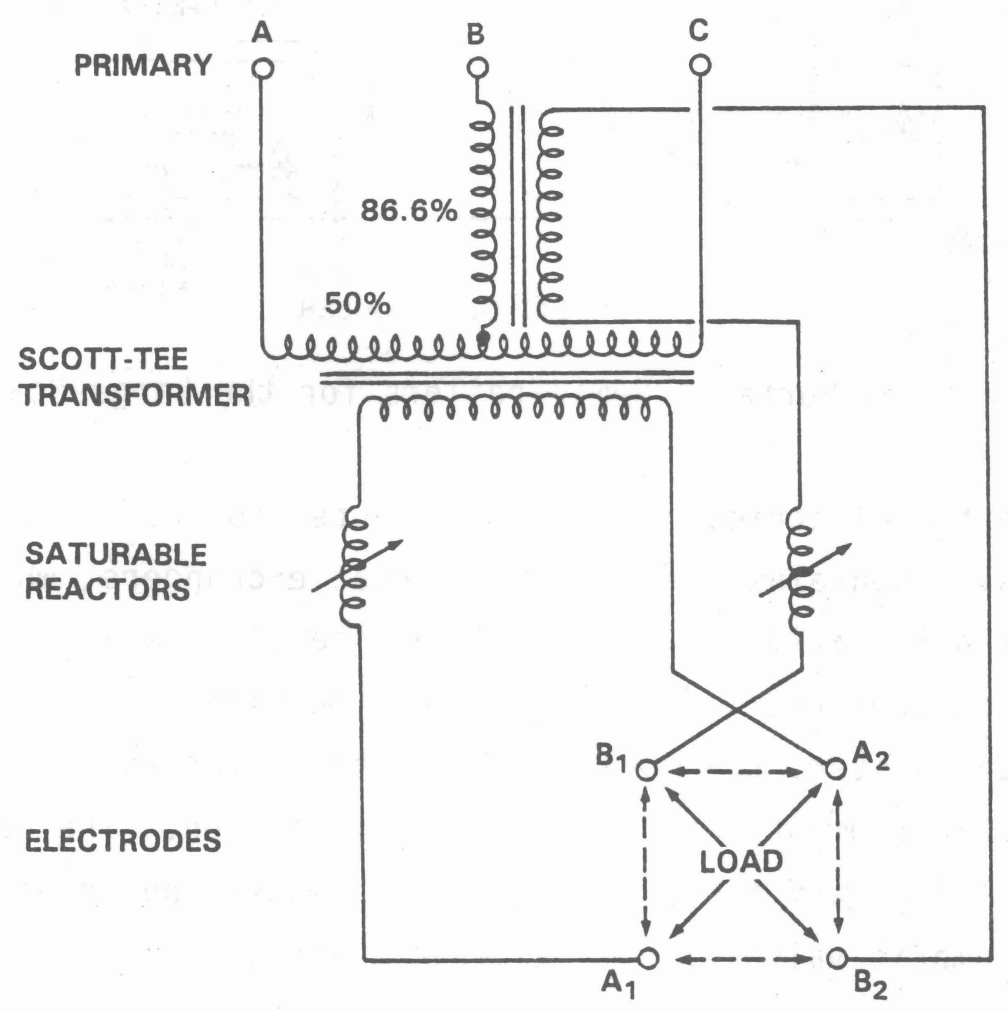

FIGURE 8. Scott-Tee Transformer Design for the Large-Scale System 
is $3750 \mathrm{~kW}$ for the large-scale system. Figure 9 shows the increase in the average power input when using 16 transformer taps rather than 4. Average power is $2900 \mathrm{~kW}$ when 4 voltage taps are utilized. With 16 voltage taps the average power has been increased to $3500 \mathrm{~kW}$, which is much closer to the maximum power.

To control the current and/or voltage being introduced into the electrodes, saturable reactors with their respective control windings are used for the large-scale system. Saturable reactors have been used extensively for power control systems in various applications. Their principle of operation is similar to a variable inductor in series with the load, as shown in Figure 8. By changing the control winding current to the saturable reactor, the level of saturation of the saturable reactor's core is varied. This changes the inductance in series with the load of the system. By decreasing the level of saturation, a higher voltage drop is attained across the saturable reactor, leaving less voltage and current available to the load, thus controlling the power to the load.

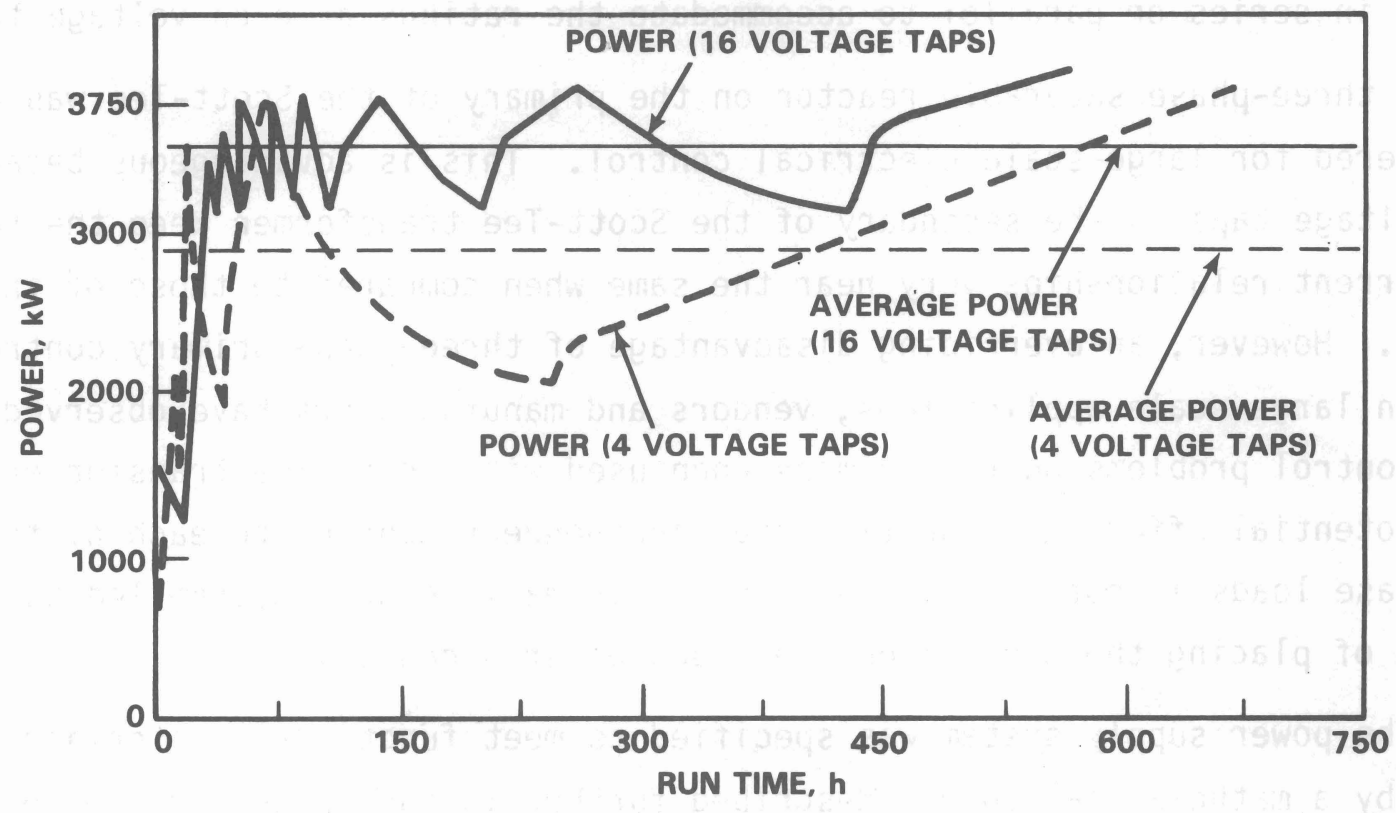

FIGURE 9. Effect of Increased Number of Voltage Taps on Average Power Output 
Saturable reactors were selected rather than solid-state components for large-scale operation because solid-state components are not available above $600 \mathrm{~V}$, unless operated in series. Saturable reactors also introduce fewer harmonic frequencies into the grid system. The saturable reactors do, however, have a detrimental effect on power factor. Power factor is the cosine of the phase angle between the current and voltage waveforms distributed to the power system. A power factor much less than 1 generally results in cost penalties to the user, and is discouraged by both power generation and transmission people. This problem can be overcome by using up to 16 multiple taps on the Scott-Tee transformer, which keeps the average predicted power factor for the large-scale system high (near 0.9 ), well within the acceptable range.

The proposed control scheme is the use of two or more saturable reactors on the secondary side of the Scott-Tee transformer. This has the advantage of independently controlling the power to each of the single-phase loads. However, the saturable reactors must be designed to accommodate the full voltage and current ranges due to the variable resistance of the melt in this batch operation process. This requires one full range reactor for each phase rated at maximum load voltage and current or many smaller reactors that can be connected in series or parallel to accommodate the ratings at each voltage tap.

A three-phase saturable reactor on the primary of the Scott-Tee was also considered for large-scale electrical control. This is advantageous because the voltage taps on the secondary of the Scott-Tee transformer keep the voltage and current relationships very near the same when compared to those of the secondary. However, an overriding disadvantage of three-phase primary control is that in large-scale applications, vendors and manufacturers have observed balance control problems on the primary when used with Scott-Tee transformers. This potential effect and the fact that independent control to each of the single-phase loads is not achievable with the primary control system led to the choice of placing the control on the transformer secondary.

The power supply system was specified to meet functional criteria determined by a mathematical model, described further in the Process Parameters chapter later in this report. From the mathematical simulations, a $3750 \mathrm{~kW}$ power supply was selected for the large-scale system. The modeling predictions 
also stipulate that to meet the functional criteria, a load voltage of between 4160 to $400 \mathrm{~V}$ be supplied with a corresponding current capacity on each of the two secondary phases between 450 and 4000 A, respectively.

Excluding circuit protection, the power supply system is $\sim 4 \mathrm{~m}$ long by $2 \mathrm{~m}$ wide by $3 \mathrm{~m} \mathrm{tall}$, with a total weight of about 20 metric tons. The power system is therefore well suited for mounting on a flat bed semi-trailer, leaving enough room for the air cooled glycol heat exchangers.

Off-Gas Containment and Electrode Support Hood

A stainless steel off-gas hood is placed over the vitrification zone to contain any gaseous and radioactive effluents from the process and to direct them to the portable off-gas treatment system. Shown in Figure 10, the hood is kept under a slightly negative pressure $(2.5$ to $10 \mathrm{~cm}$ water).

The hood is constructed of $2.4 \times 1.2 \mathrm{~m}$ panels which can be dismantled and stored in type $A^{(a)}$ transportation containers. Because of the high heat load from burning combustible wastes at the vitrification surface, the off-gas hood is constructed of materials capable of withstanding $900^{\circ} \mathrm{C}$. A non-welded (bolted) hood design was favored for the large-scale system because thermal expansion from ambient temperature to $900^{\circ} \mathrm{C}$ creates $>2.5 \mathrm{~cm}$ expansion in any direction. The panels are assembled in such a manner to relieve stresses that might occur from thermal expansion.

The hood is sealed to the surface of the soil surrounding the zone to be vitrified by a flexible skirt of tightly woven, high-temperature resistant fiber covered with a few centimeters of dirt. The skirt maintains a seal during processing, which normally tends to dry out the dirt around the hood, increasing air inleakage.

The buss bars connected to the graphite electrodes protrude through the hood and are surrounded by electrically insulated sleeves which allow adjustment of the electrode position (Figure 11). The electrodes and buss bars are supported by insulators above the sleeve. The insulators are designed to

(a) Hanford radioactive shipment classification. 

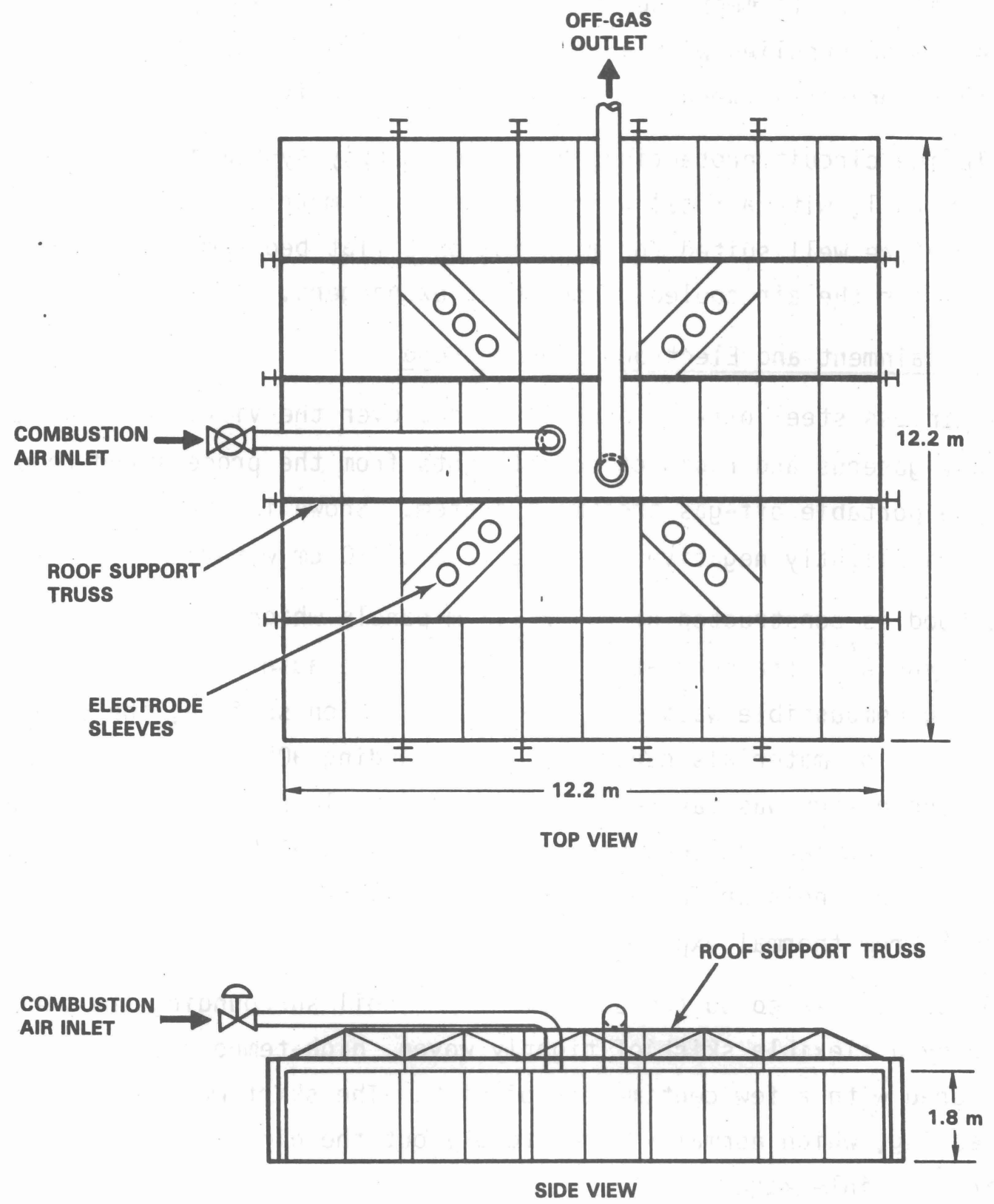

FIGURE 10. Off-Gas Containment Hood for the Large-Scale System

withstand any movement of the molten mass against the electrodes from convective currents and the gravitational and buoyant forces exerted on the electrodes. 


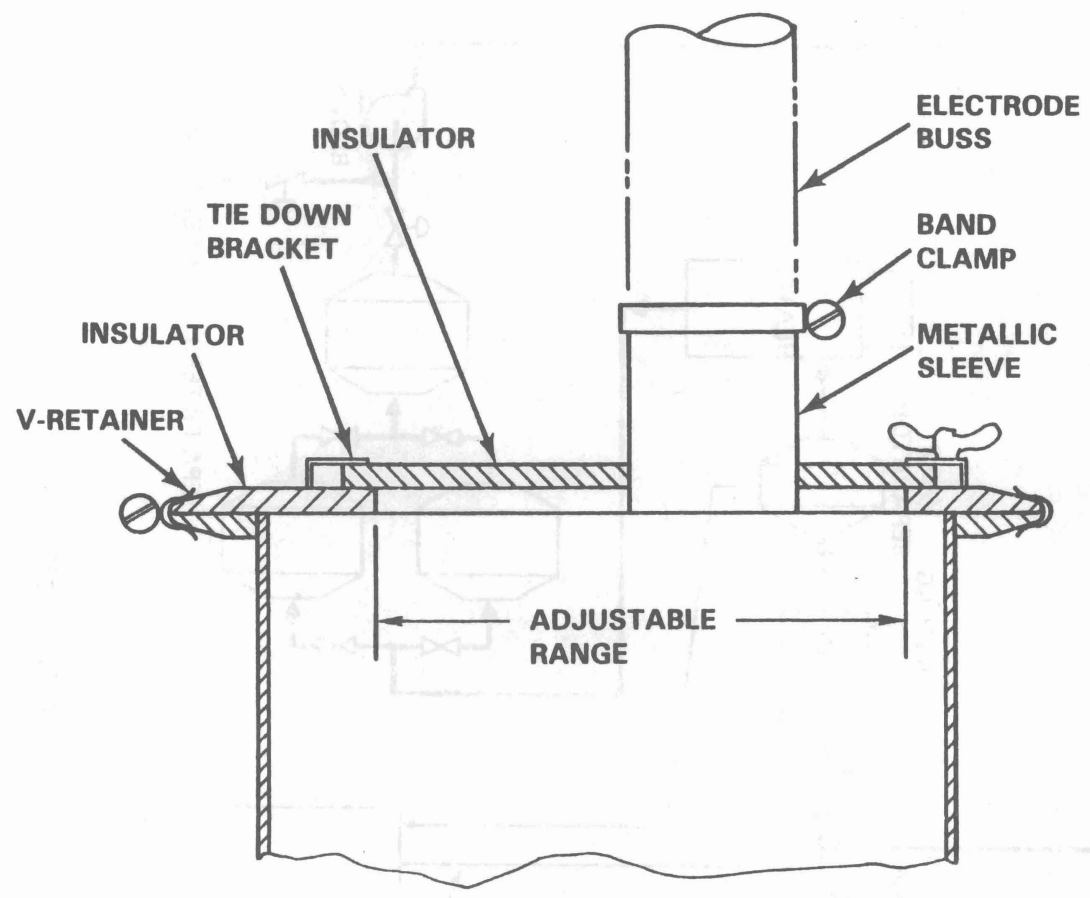

FIGURE 11. Design of Hood Feed-Through for Electrode Buss Bar

\section{Off-Gas Treatment System}

The large-scale off-gas treatment system shown in Figure 12 is modeled after the pilot-scale off-gas system. The off gas is directed from the hood to the off-gas treatment system through five $3-m$ sections of $40 \mathrm{~cm}$ dia pipe. When highly combustible material is being processed, the off gas may exit the hood at temperatures up to $900^{\circ} \mathrm{C}$ and enter the off-gas trailer at $750^{\circ} \mathrm{C}$. The off gas is cooled to $300^{\circ} \mathrm{C}$ by a finned heat exchanger, which is cooled with a glycol solution. The heat exchanger, which can remove up to $1060 \mathrm{~kW}$ (3.6 million Btu/h), is bypassable and is equipped with an automatic flushout system, should the heat fins accumulate scale or radioactive constituents. The off gases are then directed into two parallel wet scrubbing assemblies, which are required to accommodate the wide range of flows anticipated. Normal air inleakage through the hood would give a flow of $50 \mathrm{std} \mathrm{m}^{3} / \mathrm{min}$. However, when combustible wastes are present, combustion air requirements create a maximum off-gas flow of up to $104 \mathrm{std} \mathrm{m}^{3} / \mathrm{min}$. A single wet scrubbing system is not capable of operating within this range of flows, so parallel scrubbing assemblies were selected. 


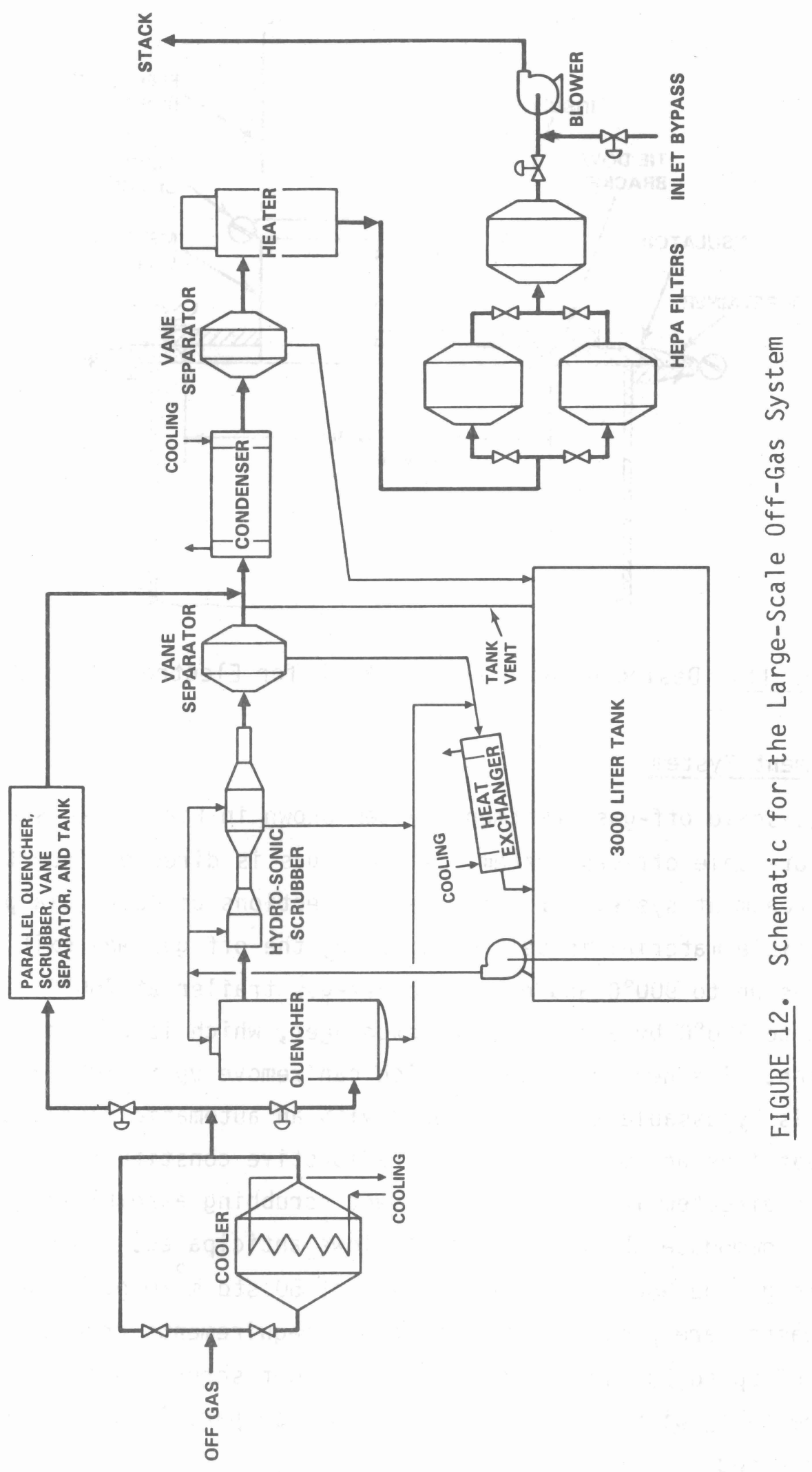


Each scrubbiny assembly consists of a quench tower that removes the remaining heat load in the off-gas system, a tandem-nozzle Hydro-Sonic scrubber, and a vane separator. The quench tower replaces the venturi-ejector scrubber of the pilot-scale unit because the quencher requires much less energy and water flow to reduce the heat load in the off gases from $300^{\circ} \mathrm{C}$ to $<100^{\circ} \mathrm{C}$. The Hydro-Sonic scrubber is designed to remove $90 \%$ of particulates $\geq 0.5 \mu \mathrm{m} \mathrm{dia}$. The vane separator is an impingement mist eliminator capable of removing all droplets $\geq 12 \mu \mathrm{m}$ dia. The temperature of the off gas exiting the vane separator at maximum heat load is expected to be about $60^{\circ} \mathrm{C}$. The off-gas temperature is reduced to $52^{\circ} \mathrm{C}$ by a condenser after the parallel flows from the Hydro-Sonic scrubbers are recombined.

The condenser removes an additional $335 \mathrm{~kW}(1.1 \mathrm{million} \mathrm{Btu} / \mathrm{h})$, thereby condensing more water vapor from the off gas. During maximum combustion, the remaining water vapor in the off gas after exiting the final vane separator should match the amount entering the off-gas system from moist soil and combustion products. This will avoid an accumulation or depletion of water in the two scrubbing tanks. To prevent the remaining moisture in the off gas leaving the second-stage vane separator from condensing in the HEPA filters, the off gas is reheated by $\sim 25^{\circ} \mathrm{C}$. By raising the temperature of the off gas above the dewpoint, condensation of moisture in the HEPA filters is eliminated. Following two stages of HEPA filters, the off gas is then discharged to the atmosphere through an induced-draft blower capable of operating at a $90^{\circ} \mathrm{C}$ inlet temperature.

The off-gas system is instrumented for observation and control. Differential pressures are recorded at various points in the off-gas train. The offgas system is monitored for radioactive buildup in the off-gas lines and the stack. A flowmeter is included in the stack to determine the total off-gas flow as well. An $0_{2}$ analyzer is included after the final stage HEPA filter to automatically control the combustion air inlet into the off-gas hood. If a lower $\mathrm{O}_{2}$ level is detected than prescribed by the operator, additional combustion air is automatically introduced into the hood to insure that no 
combustible, pyrolyzed gases gather downstream in the off-gas system. This control system will not interfere with the operation of the hood vacuum control system, which is also automated.

The conceptual design for the large-scale off-gas system, along with the hood and electrical system, has recently been completed. Upon approval, major pieces of equipment will be purchased for the off-gas and electrical systems. Following technical bid review of the vendors' proposals, the detailed design will commence. Construction should be completed in FY 1985 for the initial large-scale non radioactive test. A radioactive test at a Hanford waste site is currently scheduled for FY 1986.

\section{PILOT-SCALE RADIOACTIVE TEST SYSTEM}

Two different pilot-scale ISV systems have been tested and operated using four electrodes with a $1.2 \mathrm{~m}$ separation. The more advanced system, designed for vitrification of radioactive materials, is described in this section, while the pilot-scale field test (PSFT) system is discussed in the following section.

The pilot-scale radioactive test (PSRT) system consists of a power control unit, an off-gas containment hood over the waste site, and an off-gas treatment system housed in a portable semi-trailer. Prior to the PSRT, this same system was used on two nonradioactive tests: pilot-scale cold tests 1 and 2 (PSCTs 1 and 2).

Power System Design

Like the large-scale unit, the PSRT power system also utilizes a Scott-Tee connection to transform a three-phase input to a two-phase secondary load on diagonally opposed electrodes in a square pattern. The $500 \mathrm{~kW}$ power supply may be either voltage or current regulated. The alternating current primary is rated at $480 \mathrm{~V}, 600 \mathrm{~A}, 3$ phase, and $60 \mathrm{~Hz}$. The 3 phase input feeds a Scott-Tee connected transformer (see Figure 13) providing a 2 phase secondary. The transformer has four separate voltage tap settings--1000 V, $650 \mathrm{~V}, 430 \mathrm{~V}$, and $250 \mathrm{~V}$. Each voltage tap has a corresponding amperage rating of $250 \mathrm{~A}, 385 \mathrm{~A}$, $580 \mathrm{~A}$, and $1000 \mathrm{~A}$ per phase, respectively. The amount of 3 phase input 


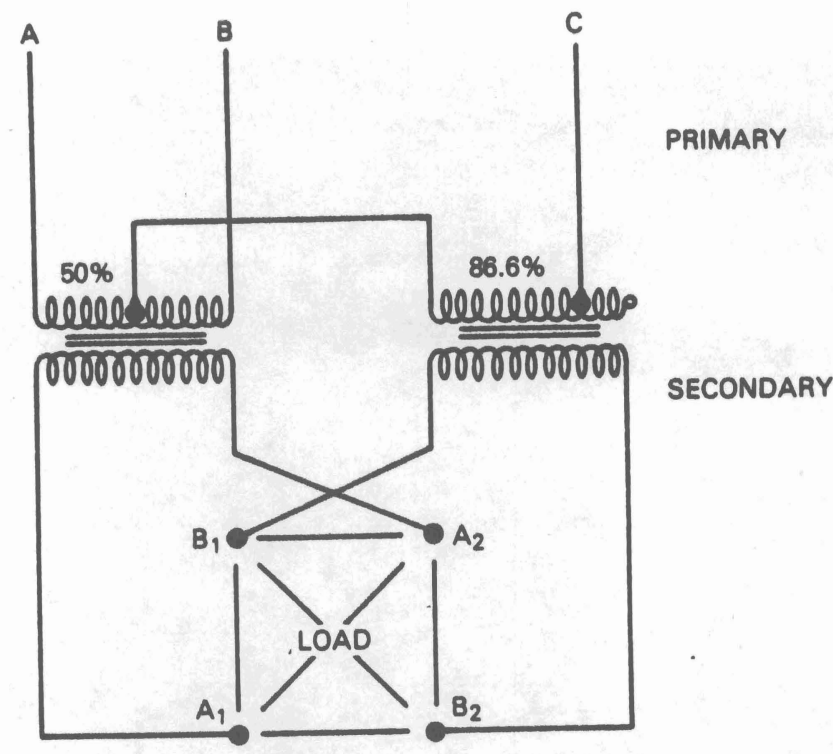

FIGURE 13. Scott-Tee Connection for the PSRT

power delivered to the transformer is controlled by adjusting the conduction anyle of the thyristor switches located in each of the three input lines. These switches, in conjunction with selectable taps on the transformer secondary, regulate the amount of output power deliverable to both secondary phases.

The Scott-Tee setup requires transformer taps at 50 and $86.6 \%$ of the primary transformer windings. The Scott-Tee connection provides an even power distribution when the molten zone approaches a uniform resistance load. The primary and secondary current is balanced for a Scott-Tee system when a balanced load exists. Duriny PSCTs 1 and 2 and the PSRT, this power system proved very effective in maintaining a balanced load to the electrodes. Off-Gas Containment and Electrode Support Hood

Constructed of 7 panels of 20 gauge stainless steel bolted together, the off-gas containment and electrode support hood (see Figure 14) is $3.05 \mathrm{~m}$ square by $0.9 \mathrm{~m} \mathrm{high}$. Four leveling supports attached to the side panel corners can also be unbolted. The hood is designed to withstand an $18 \mathrm{~cm}$ water vacuum. The off-gas containment and electrode support hood includes a viewing port and an access port. Built into the access port is a valve and HEPA filter 


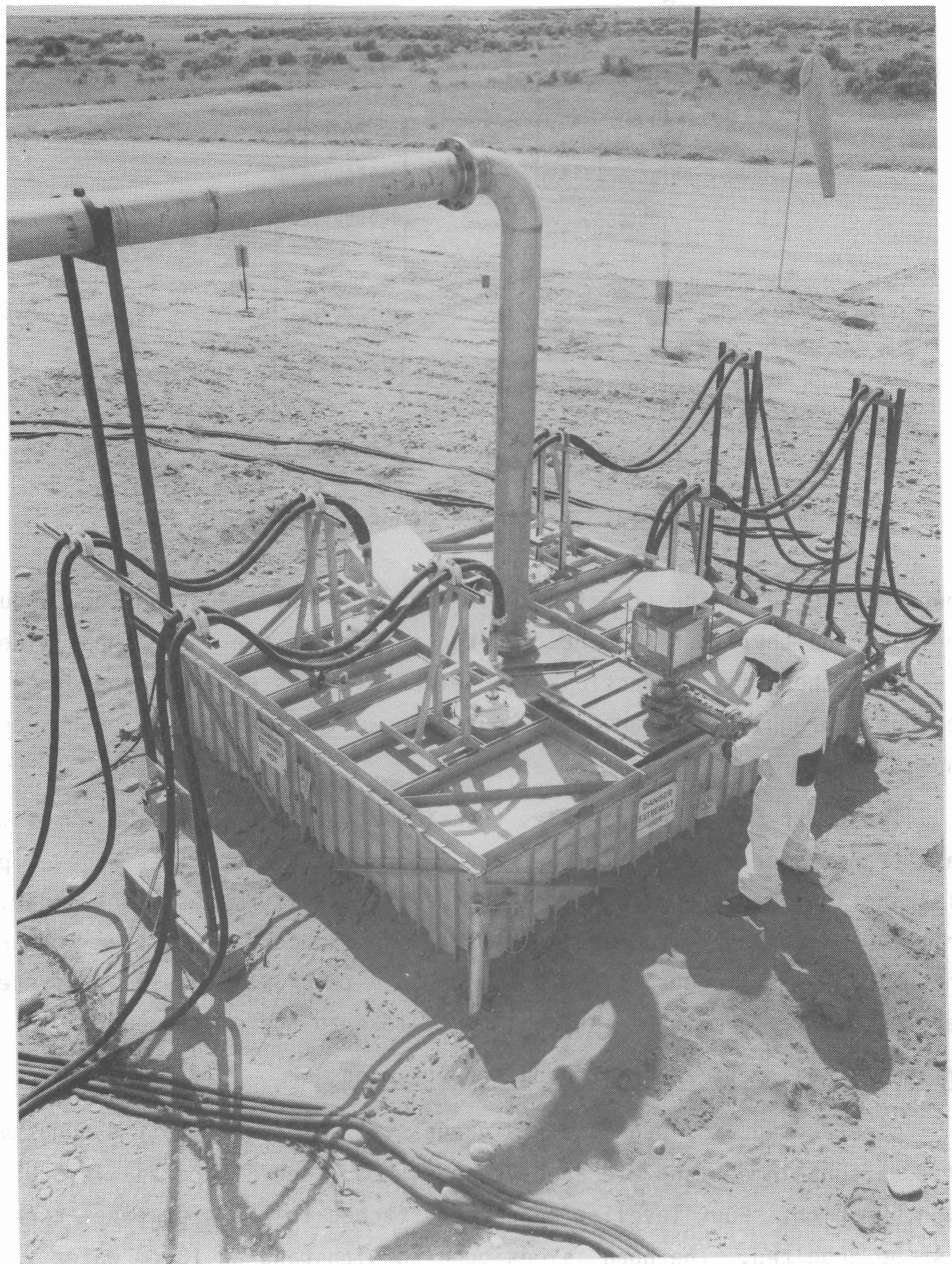

0

FIGURE 14. Off-Gas Containment and Electrode Support Hood for the PSRT 
assembly for regulating the vacuum on the hood. A center off-gas port allows for direct coupling of the hood to the processing van and off-gas treatment system. A skirt like the one used in the large-scale system is attached to the bottom of all side panels. This skirting extends $\sim 0.6 \mathrm{~m}$ away from the hood, allowing for a tight hood-to-ground seal when covered with a layer of soil. The same type of circular sealing plates designed for the large-scale system were used for the four electrical busses of the pilot-scale unit. The hood is equipped with a heat shield installed under the center top panel to protect the hood from the heat that radiates from the partially molten surface during processing.

\section{Off-Gas Treatment System}

The off-gas system designed for the PSRT is shown schematically in Figure 15. The off gas passes through a venturi-ejector scrubber and separator, Hydro-Sonic scrubber, separator, condenser, another separator, heater, two stages of HEPA filtration, and a blower. Liquid to the two wet scrubbers is supplied by two independent scrub recirculation tanks, each having a pump and heat exchanger. The entire off-gas system has been installed in a $13.7 \mathrm{~m}$ (45 ft) long semi-trailer to facilitate transport to a waste site. Equipment layout within the van is illustrated in Figure 16. All off-gas components except the HEPA filters and blower are housed within a removable containment module pictured in Figure 17, which has gloved access for remote operations and is maintained under a slight vacuum.

Heat is removed from the off gas by a closed loop cooling system, which consists of an air/liquid heat exchanger, a coolant storage tank, and a pump. A $50 \%$ water/ethylene glycol mix is pumped from the storage tank through the shell side of the condenser and the two scrub solution heat exchangers, then through the air/liquid exchanger, where heat is removed from the coolant.

The venturi-ejector scrubber is the same type as used on the pilot-scale field test (PSFT) off-gas system. This unit serves both as a quencher and high energy scrubber. The second scrubber is a two stage Hydro-Sonic scrubber (tandem nozzle fan drive) as illustrated in Figure 18. The first section condenses vapors, removes larger particles, and initiates growth of the finest particles so that they are more easily captured in the second stage. Particulate is 


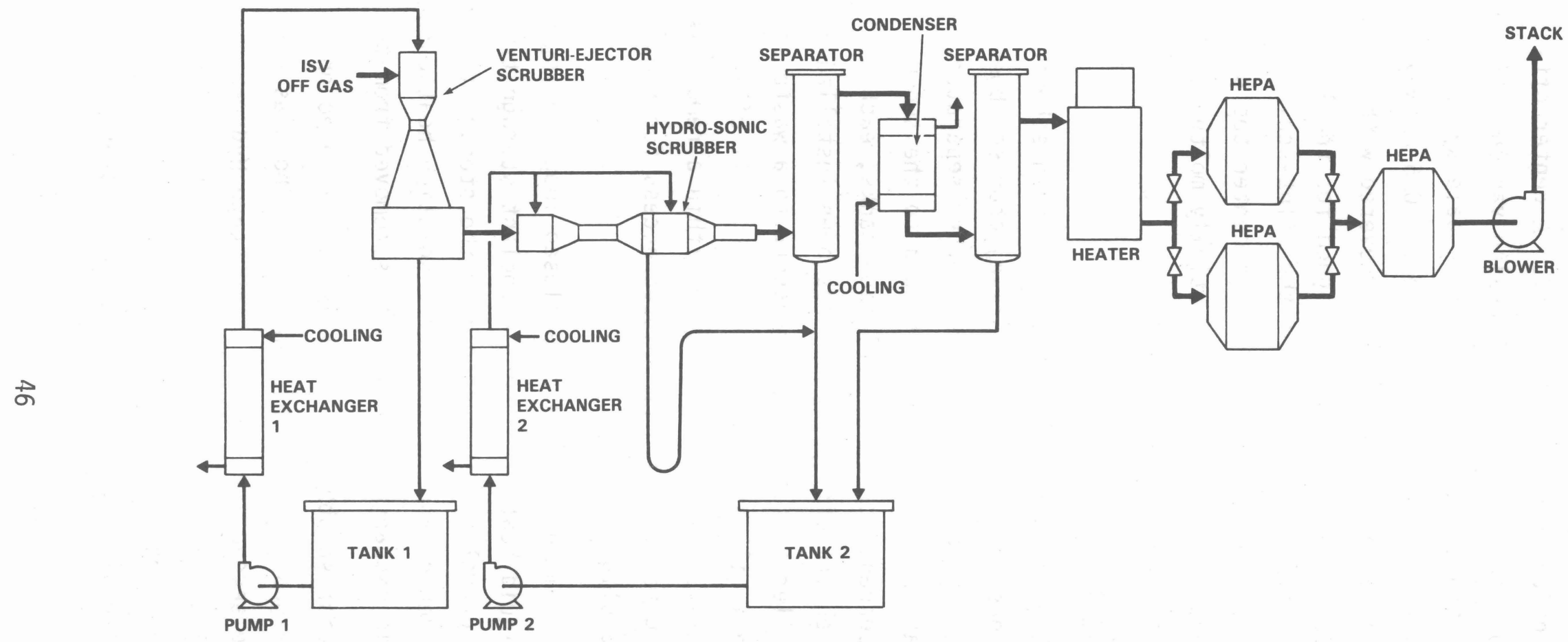

FIGURE 15. Off-Gas System Schematic for the PSRT 


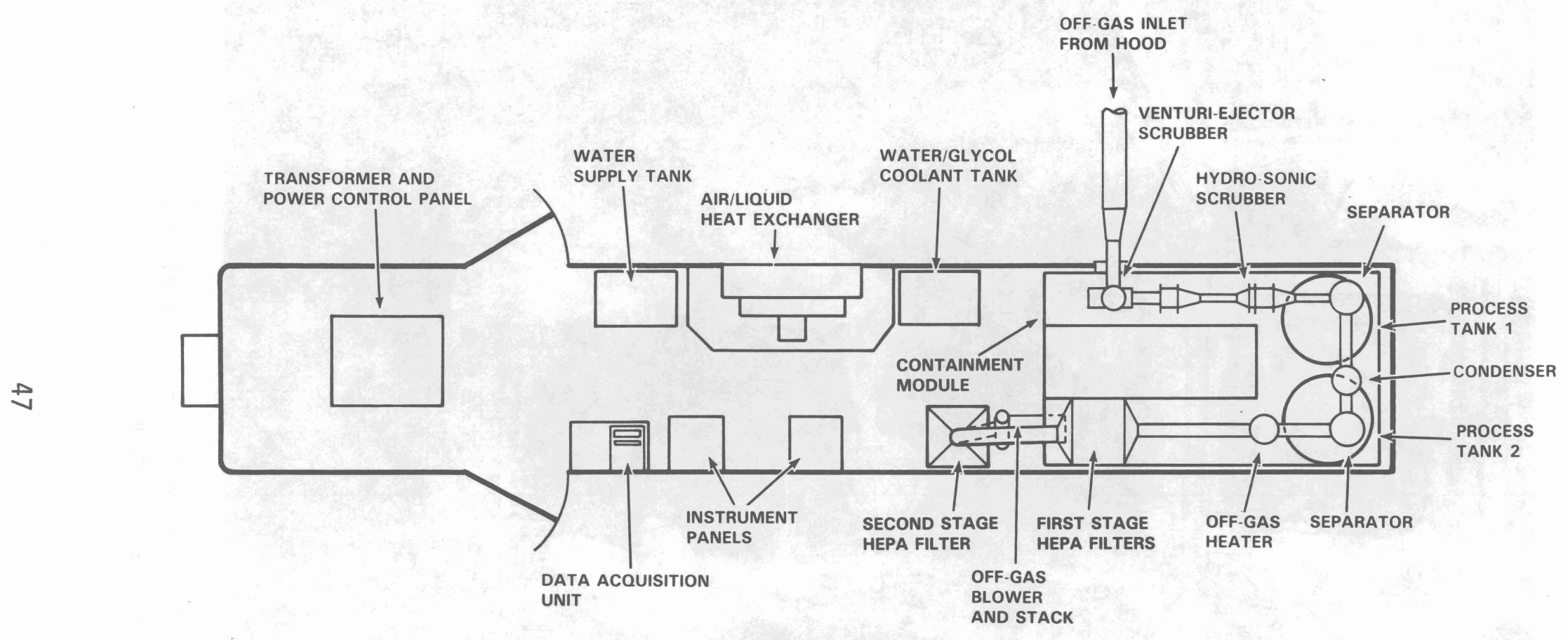

FIGURE 16. Plan View of Off-Gas System in Semi-Trailer for the PSRT 


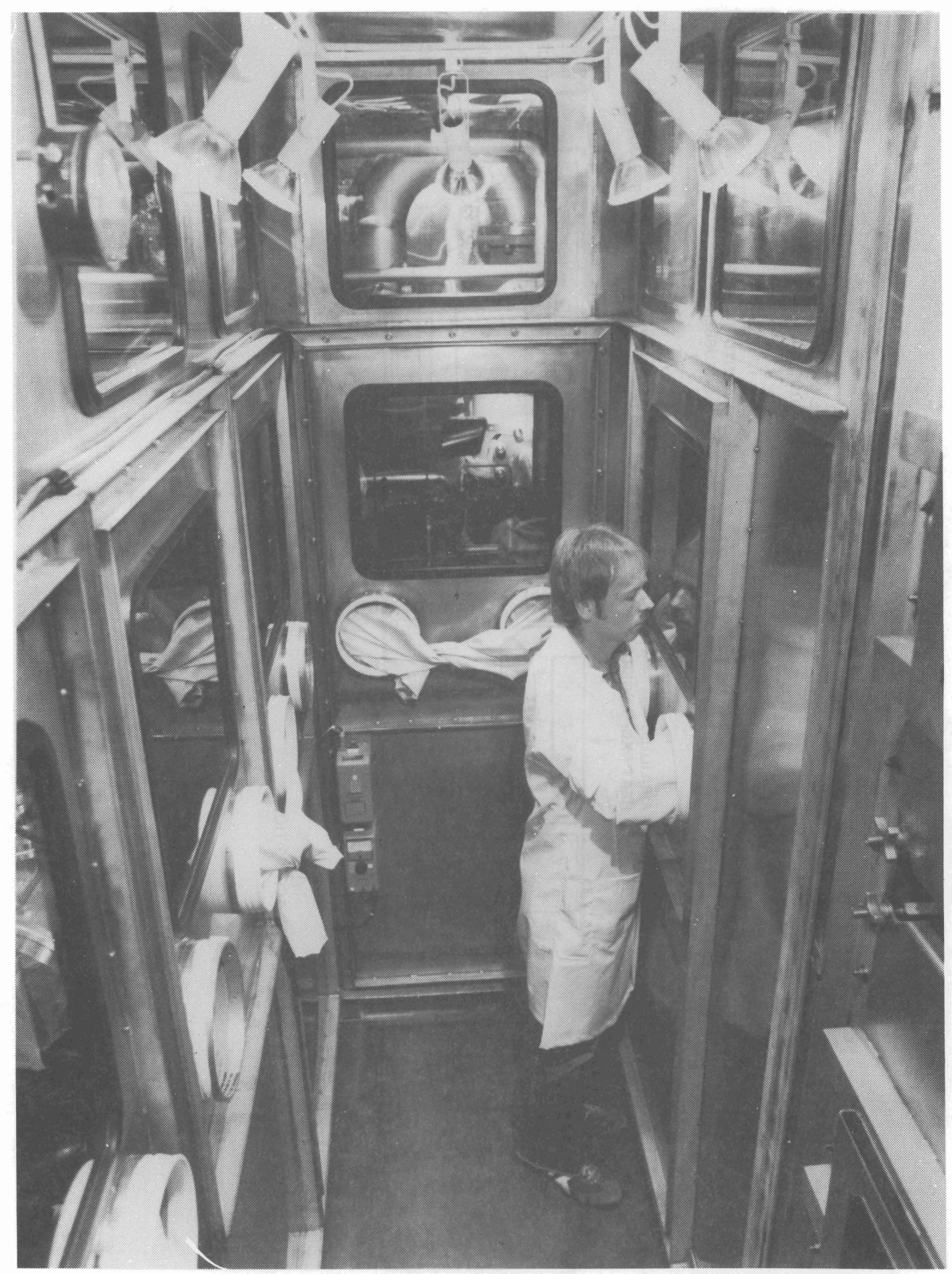

FIGURE 17. Removable Containment Module for the PSRT Off-Gas Treatment System 


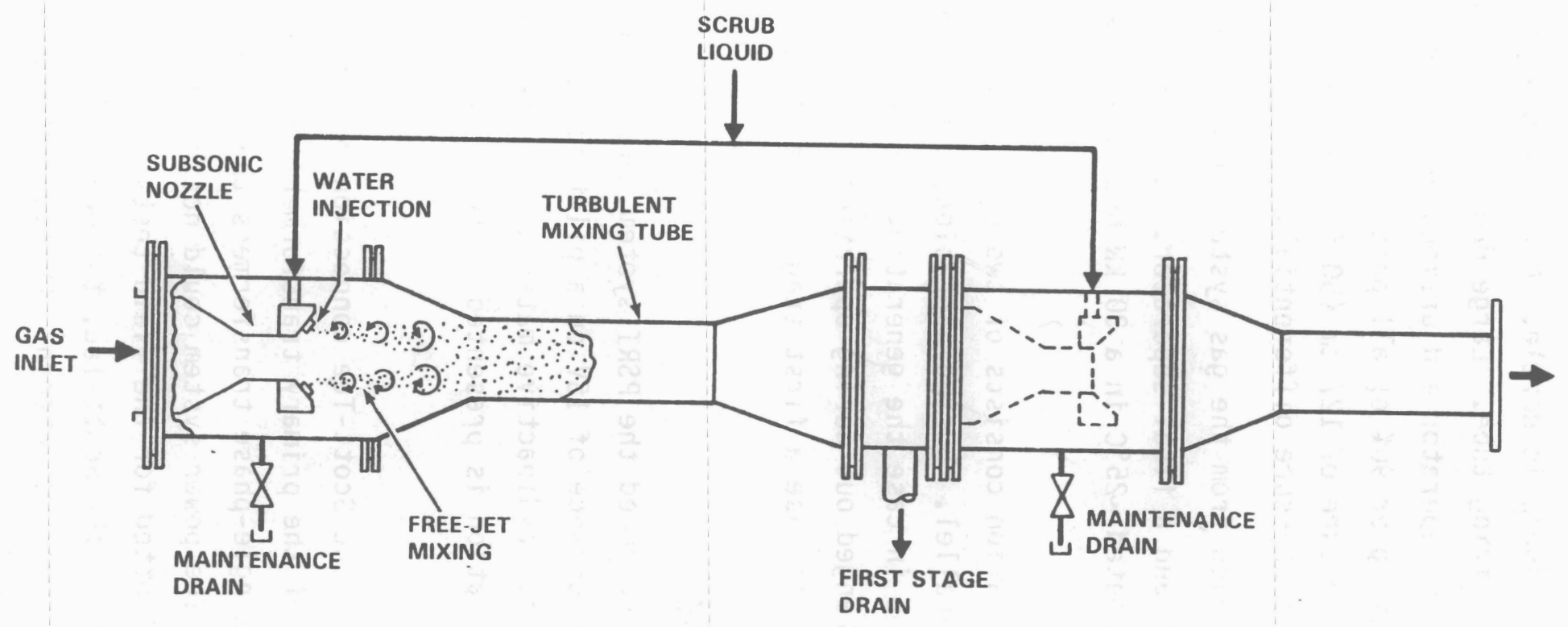

FIGURE 18. Tandem Nozzle Hydro-Sonic Scrubber 
captured when the gas is mixed with fine water droplets produced by spraying water into the exhaust of the subsonic nozzle. Mixing and droplet growth continue down the length of the mixing tube. Large droplets containing the particulate are then removed by a separator and drained back into the scrub tank. The unit is designed to remove over $90 \%$ of all particulates $>0.5 \mu \mathrm{m}$ dia when operated at a differential pressure of $127 \mathrm{~cm}$ (50 in.) water. Efficiency increases with an increase in pressure differential.

Additional water is removed from the gas system by a condenser having a heat exchange area of $8.9 \mathrm{~m}^{2}$ and a final separator. As with the large-scale unit, the gases are then reheated $\sim 25^{\circ} \mathrm{C}$ in a $30 \mathrm{~kW}$ heater to prevent condensate carryover to the filters.

The first stage of filtration consists of two $61 \times 61 \times 29 \mathrm{~cm}(24 \times 24 \times$ 11.5 in.) HEPA filters in parallel. During operation, one filter is used and the other remains as a backup in case the generating filter becomes loaded. The primary filter can be changed out during operation. The second stage HEPA filter also acts as a backup in case a first stage filter fails.

\section{PILOT-SCALE FIELD TEST SYSTEM}

The PSFT system, which preceded the PSRT system, originally tested the scale-up feasibility and performance of ISV on a pilot scale. It is not mobile and was not designed to contain radioactive materials. A detailed description of the equipment and its operation is presented in this section.

\section{Power System Design}

As described previously, the Scott-Tee connection requires specific transformer taps at 50 and $86.6 \%$ of the primary transformer windings. This is difficult to achieve with the single-phase transformers that were available for the PSFTs. Since the Scott-Tee power system could not be attained within the budget and time schedules allotted for the field tests, the open-delta electrical system was installed. Like the Scott-Tee, the open-delta design delivers power to four electrodes in a square pattern. However, the open-delta system can be assembled from two standard, single-phase electrical power supplies. A sketch of this system is depicted in Figure 19. 


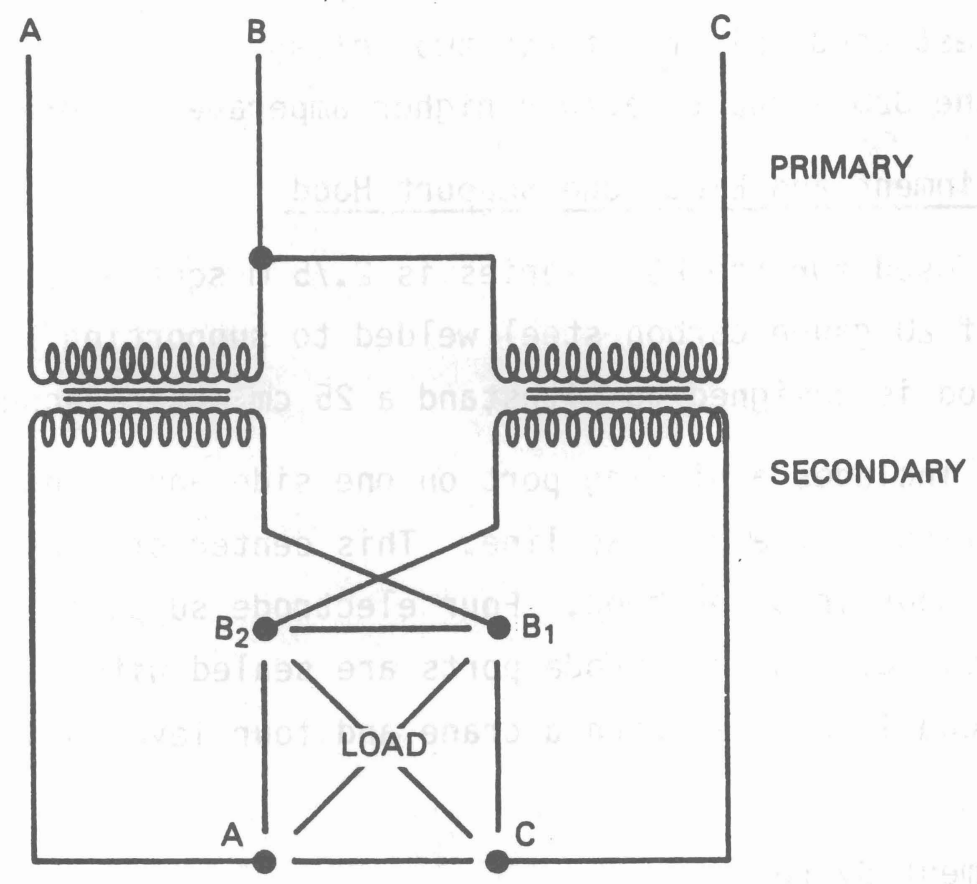

FIGURE 19. Open-Delta Connection for the PSFT Power System

The open-delta system differs from the Scott-Tee connections in two ways:

- For a balanced load, the primary side current is unbalanced.

- The power distribution varies slightly within the molten zone.

An unbalanced primary current, characteristic of the open-delta system, is of little concern for the pilot-scale field test unit. Application of the open delta to a larye-scale $3750 \mathrm{~kW}$ unit, however, would not be advisable due to line balancing and the possible introduction of harmonics into the power grid. Harmonics could disturb electrical systems of other electrical customers within the area.

The PSFT unit utilized a $400 \mathrm{~kW}$ power supply with each of the two pairs of electrodes capable of operating under the following voltage and amperage modes:

- $960 \mathrm{~V}, 208 \mathrm{~A} /$ phase

- $480 \mathrm{~V}, 416 \mathrm{~A} /$ phase

- $320 \mathrm{~V}, 600 \mathrm{~A} /$ phase.

This electrical system was used successfully in four PSFTs on Hanford soil. The initial test used only the first two voltage taps, while the final three tests added the $320 \mathrm{~V}$ tap to attain higher amperage and greater melt depth. 
This electrical system was used successfully in four PSFTs on Hanford soil. The initial test used only the first two voltage taps, while the final three tests added the $320 \mathrm{~V}$ tap to attain higher amperage and greater melt depth. Off-Gas Containment and Electrode Support Hood

The hood used for the PSFT series is $2.75 \mathrm{~m}$ square by $0.5 \mathrm{~m}$ high and is constructed of 20 gauge carbon steel welded to supporting I beams and angle iron. The hood is designed to withstand a $25 \mathrm{~cm}$ water vacuum.

The hood includes a viewing port on one side and a center port with a slip flange connection to the off-gas line. This center off-gas port is part of a hinged access door into the hood. Four electrode support frames and electrode ports are provided. The electrode ports are sealed with a nonconductive fiber board. The hood is aligned with a crane and four leveling supports welded to each corner.

Off-Gas Treatment System

Pilot-scale field test 1 was performed only to verify scale-up of the ISV process, so no simulated hazardous species were added to the test-site soil. The off-gas system during this test consisted of the containment hood, a nonflooded packed tower, and a blower. An upgraded off-gas system was used during PSFTs 2,3 and 4 to allow the safe testing of the behavior of simulated hazardous wastes and heavy metals during vitrification. This off-gas system, shown in Figure 20, includes a cyclonic-spray scrubber, venturi-ejector scrubber, demister, and blower. During operation of the ISV process, off gases are drawn from the containment hood through a $20 \mathrm{~cm}$ off-gas line to the scrubbing system. The cyclonic-spray scrubber acts both as a quencher and scrubber. The chamber, which is $36 \mathrm{~cm}$ dia and $250 \mathrm{~cm}$ tall, has a central pipe with 52 fine atomizing nozzles that spray scrub solution radially outward to the walls of the vessel. The hot off gas enters tangentially at the top through a $9 \mathrm{~cm}$ dia inlet, creating a cyclonic action that enhances particle removal and liquid deentrainment. Gases, saturated with water vapor, typically exit at $\sim 50^{\circ} \mathrm{C}$. The gases then pass through a $15 \mathrm{~cm}$ Ametek model $7014^{\circledR}$ venturi-ejector

(3) Ametek model 7014 is a product of Ametek Process Systems, Durham, North Carolina. 


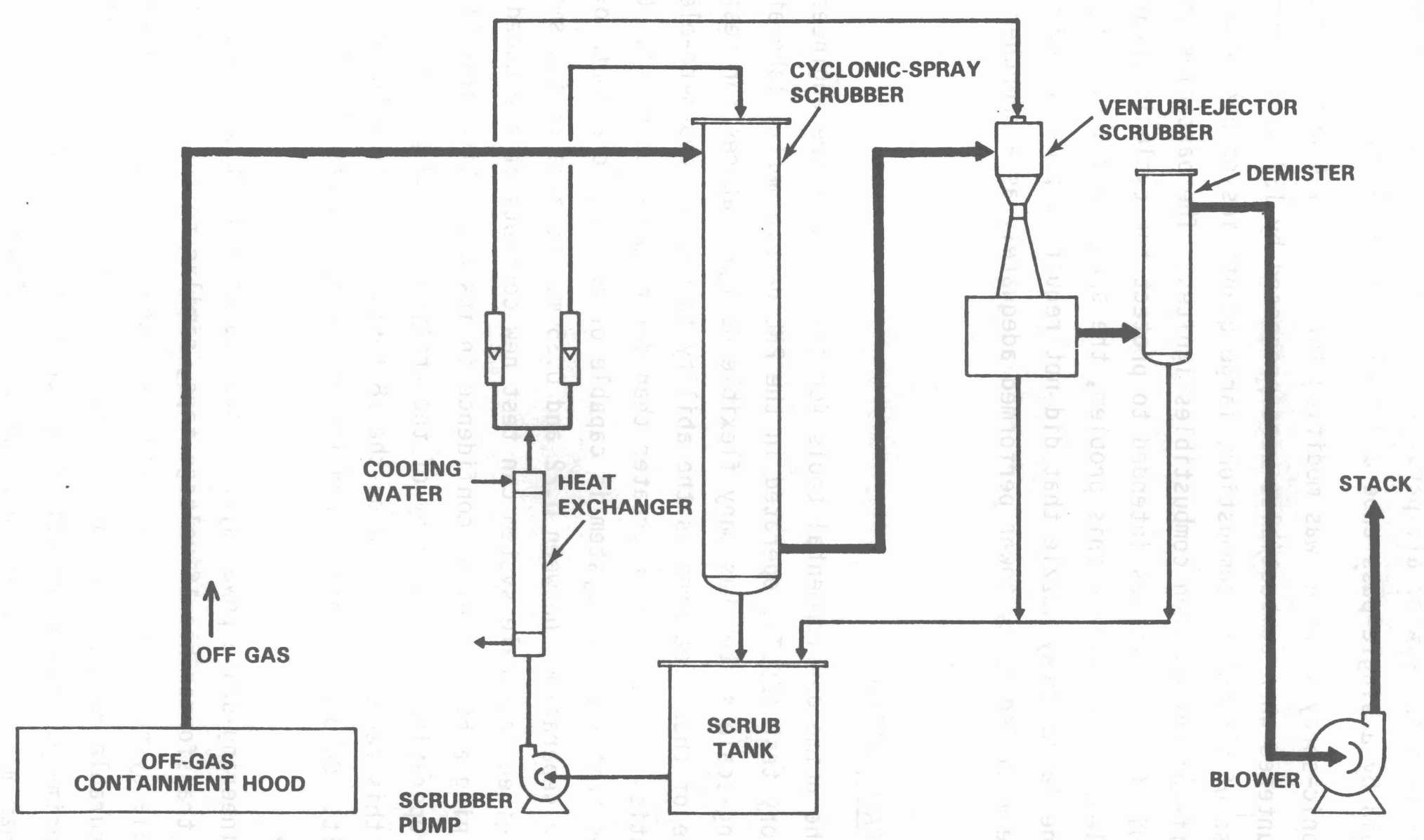

FIGURE 20. Off-Gas System Schematic for the PSFTs 
scrubber, which removes $>90 \%$ of all particles $>2 \mu \mathrm{m}$ dia. Heat is removed from the scrub liquid by a single-pass tube and shell heat exchanger.

The cyclonic-spray scrubber was modified for the PSFT 4 due to operational problems encountered when combustibles were processed by ISV during previous PSFTs. Because of incomplete combustion, large quantities of particles had entered the off-gas system when combustibles ignited. The particles in turn plugged a liquid filter that was intended to protect the cyclonic-spray scrubber nozzles. To eliminate this problem, the spray nozzle assembly was replaced by one large spray nozzle that did not require a prefiltered scrub solution. The modified spray tower performed adequately as a quencher and scrubber.

\section{ENGINEERING-SCALE SYSTEM}

One of the prime developmental tools for ISV has been the engineeringscale laboratory test (ESLT), operated in the PNL developmental laboratory. The engineering-scale system has many flexible design features for testing new concepts. One of these features is the ability to melt at depth-to-electrode separation ratios that were much greater than during previous PSFTs. Computer modeling shows that the ESLT system is capable of melting to a depth of $1.8 \mathrm{~m}$ with electrode separations between 0.22 and $0.35 \mathrm{~m}$. Because of its smaller scale, the engineering-scale system can test new concepts at a reduced cost while maintaining a high level of confidence in its predictive capabilities for larger-scale operations. Also, many of the analyses of ISV process limits described in this report are based on the 18 tests conducted with the engineering-scale unit. Cold cap behavior and its governing factors are also being investigated.

The engineering-scale power system consists of a $30 \mathrm{~kW}$ Scott-Tee transformer. The transformer has 16 voltage taps, similar to those described for the large-scale system. It can be wired for either primary or secondary control with saturable reactors or solid-state, silicon controlled rectifier control on the primary. The vitrification process is conducted inside a sealed metal container measuring $1.8 \mathrm{~m}$ dia $\times 2.4 \mathrm{~m}$ tall (Figure 21). 


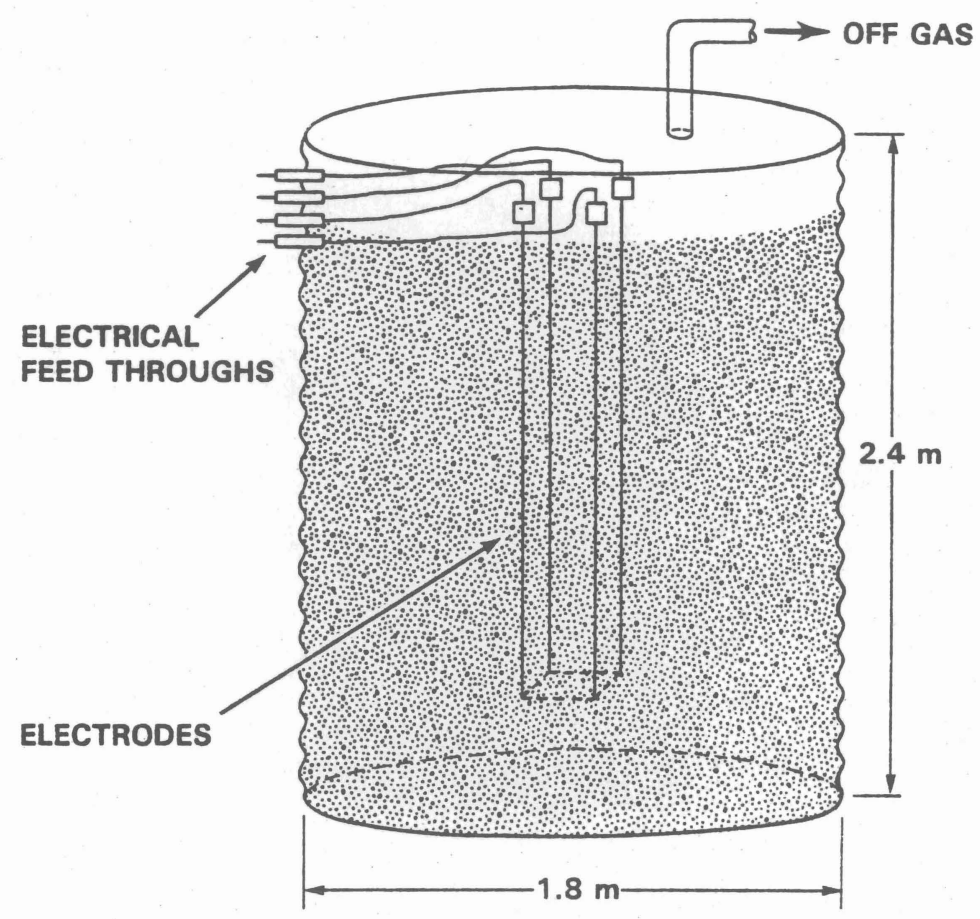

FIGURE 21. Engineering-Scale System

Much of the data on process limits was gathered from an earlier version of the engineering-scale unit equipped with a single-phase electrode power supply. This unit was installed in a sealed metal container measuring $2 \mathrm{~m} \mathrm{dia} \times 0.8 \mathrm{~m}$ tall. The hood was maintained under a slight vacuum by a facility off-gas system. Although less flexible than the present unit, it provided much of the data for the process limits analysis on combustible, metal, and ceramic inclusions. 


\section{PERFORMANCE ANALYSIS}




\section{PERFORMANCE ANALYSIS}

The performance of the ISV process has been evaluated using the engineering- and pilot-scale systems described previously. The performance of the process equipment, processing factors, and the waste form itself is described and evaluated in this section.

\section{EQUIPMENT PERFORMANCE}

The power system, off-gas containment hood, and off-gas treatment system were evaluated to determine their effectiveness in vitrifying and containing hazardous components within the glass product. This section summarizes the performance assessment of these equipment components for the pilot-scale system.

\section{Power System}

The power system performed well during all field tests. In all but one case, no further adjustments were necessary once the graphite starter material was placed. No signs of unstable melting behavior such as arcing, hot spots, or disruptions in continuity were detected during the startup phases. However, during a restart attempt in PSFT 3, continuous conduction between one diagonal pair of electrodes was not reestablished. Therefore, if conduction among the electrodes is lost for a significant length of time, allowing the molten soil to cool, the process would have to be restarted using a new graphite path.

The electrical resistance of the vitrification zone was lower than originally predicted by a mathematical model based on one dimensional heat transfer because of the interaction between the second pair of electrodes used in the four electrode field-test system. As a result, the initial pilot-scale (PSFT 1) power system design provided only enough current to melt the soil to a depth of $\sim 1.1 \mathrm{~m}$, which was less than originally anticipated. Power input during the final hours of the test was current limited. To increase power (according to the $I^{2} R$ relationship), higher current input was needed to compensate for the lower resistance in order to increase the depth of the melt zone. For PSFTs 2, 3, and 4, the maximum operating current was increased by $~ 50 \%$ with the addition of a $320 \mathrm{~V}$ transformer tap setting. This increased current and 
power allowed the melt depth to reach $1.5 \mathrm{~m}$. Additional lower voltage taps and electrode extensions could allow the PSFT system to achieve even greater depths.

The burial of a $208 \mathrm{~L}$ (55 gal) metal drum filled with materials resulted in only a $10 \%$ drop in electrical resistance between the electrodes, which agreed well with engineering-scale laboratory test (ESLT) results. These smaller-scale tests show that much larger volumes of metal can be handled. The drums were completely melted during the tests, with their contents, the contaminated soil, and the ash from the combustible waste distributed throughout the glass block.

Three tests have been made with the pilot-scale radioactive test power system--two nonradioactive operational tests (PSCTs 1 and 2) and one radioactive containment test (PSRT) (see Table 12). This Scott-Tee transformer system performed to expectations, providing a balanced supply of power to the melt. The performance comparison among the three tests indicates the effects on melting efficiency (energy/mass ratio). The ratio from the first cold test (PSCT 1) was higher than previously measured because the soil moisture was greater and the power supply system was not operating under optimum conditions. The estimated energy/mass ratio during PSCT 2 was also high, due to 3 hours of downtime as a result of blown fuses. When the system operates without interruptions, as was the case in the PSRT, an improved power efficiency $(0.8 \mathrm{kWh} / \mathrm{kg})$ was achieved, comparable with similar test operations PSFTs 1 and 4 (see Table 13).

Off-Gas Containment Hood

The hood covering the vitrification zone maintained a vacuum seal over the molten area throughout most of the tests. Brief moments of reduced vacuum were experienced when the dirt seal around the base of the hood dried and partially subsided. A skirting made of high-temperature resistant cloth effectively eliminated the effects of soil subsidence on the hood vacuum.

Structurally, the hood has maintained its integrity through all the tests. The pilot-scale hood was designed to withstand an $18 \mathrm{~cm}$ water vacuum. A HEPA filtered air inlet system with a slide valve was installed on the hood to insure that the vacuum supply never exceeded the hood's structural limitations. 
TABLE 12. Comparison of Power System Performance of Three Pilot-Scale

\begin{tabular}{|c|c|c|c|}
\hline Parameter & PSCT 1 & PSCT 2 & PSRT \\
\hline Processing time, $h$ & 36 & 27 & 23 \\
\hline Soil solidified, $\mathrm{kg}$ & 9270 & $8000^{(b)}$ & $8600^{(b)}$ \\
\hline $\begin{array}{l}\text { Approximate dimen- } \\
\text { sions of solidifi- } \\
\text { cation zone, } m\end{array}$ & $1.8 \times 1.8 \times 1.5$ & $1.8 \times 1.8 \times 1.4^{(b)}$ & $1.8 \times 1.8 \times 1.5^{(b)}$ \\
\hline $\begin{array}{l}\text { Approximate volume } \\
\text { of solidification } \\
\text { zone, } \mathrm{m}^{3}\end{array}$ & 4.9 & $4.5^{(b)}$ & $4.9^{(b)}$ \\
\hline $\begin{array}{l}\text { Total energy consumed, } \\
\text { kWh }\end{array}$ & 9920 & 9500 & 6900 \\
\hline Average power, kW & 275 & 315 & 300 \\
\hline Maximum power, kW & 410 & 410 & 375 \\
\hline Energy/mass, kWh/kg & 1.07 & $1.06^{(b)}$ & $0.80^{(b)}$ \\
\hline
\end{tabular}

(a) Graphite electrodes used with $1.22 \mathrm{~m} \times 1.22 \mathrm{~m}$ separation. (b) Estimated (blocks still in the ground).

Heat related stresses have created small cracks in the hood in the region directly above the melt zone. A radiative heat shield has been installed over the central region of the hood and has substantially reduced these temperature stresses to the metal hood. No new cracks have developed in the hood since the installation of the shield.

Overall the hood has effectively contained off gases from the melt and supported the electrodes under varying thermal conditions. This effective containment was highlighted and proven in the PSRT, in which no airborne radioactive contaminants were detected outside the off-gas hood.

Off-Gas Treatment System

Operating parameters for the off-gas system used during the PSFTs, PSCTs, and the PSRT are summarized in Table 14. The removal efficiency of the off-gas 
TABLE 13. Comparison of Power System Performance for the Pilot-Scale Field Tests

\begin{tabular}{|c|c|c|c|c|}
\hline Parameter & PSFT 1 & PSFT 2 & PSFT 3 & PSFT ${ }_{4}(\mathrm{a})$ \\
\hline Run time, $h$ & 21 & 39 & $\begin{array}{l}38 \text { ( } 49 \\
\text { including } \\
\text { down time) }\end{array}$ & $\begin{array}{l}80 \text { ( } 89 \\
\text { including equip- } \\
\text { ment transfer } \\
\text { between melts) }\end{array}$ \\
\hline Soil solidified, $\mathrm{kg}$ & 5670 & 9070 & 6240 & 25,400 \\
\hline $\begin{array}{l}\text { Approximate dimen- } \\
\text { sions of solidifi- } \\
\text { cation zone, m }\end{array}$ & $\begin{array}{c}1.8 \times 1.8 \times \\
1.1\end{array}$ & $2.1 \times 2.1 \times$ & $2.1 \times 1.2 \times$ & $\begin{array}{c}4.6 \times 2.8 \times \\
1.5\end{array}$ \\
\hline $\begin{array}{l}\text { Approximate volume } \\
\text { of solidifica- } \\
\text { tion zone, } \mathrm{m}^{3}\end{array}$ & 3.6 & 6.2 & 3.8 & 19.3 \\
\hline Electrode material & Molybdenum & Graphite & Graphite & Graphite \\
\hline $\begin{array}{l}\text { Electrode separa- } \\
\text { tion, } m\end{array}$ & $1.19 \times 1.12$ & $1.22 \times 1.22$ & $1.22 \times 1.22$ & $1.22 \times 1.22$ \\
\hline $\begin{array}{l}\text { Total energy } \\
\text { consumed, kWh }\end{array}$ & 4300 & 9400 & 5270 & 19,590 \\
\hline Average power, $\mathrm{kW}$ & 205 & 240 & 140 & 245 \\
\hline Maximum power, $\mathrm{kW}$ & 300 & 360 & 275 & 350 \\
\hline Energy/mass, kWh/kg & 0.76 & 1.04 & 0.84 & 0.77 \\
\hline
\end{tabular}

(a) An adjacent melt producing a double block.

system was determined by comparing particulate mass loadings measured at the hood outlet to those at the blower inlet during PSFTs 3 and 4 . During test 3 , the efficiency averaged $65 \%$, while the efficiency averaged $80 \%$ during test 4 . The reduced off-gas efficiency during PSFT 3 resulted from the shutdown of the cyclonic spray tower after a combustible release plugged a scrub recycle filter.

Removal efficiencies for the PSCT off-gas system were determined from scrub liquid and HEPA filter sample analysis. The venturi-ejector scrubber effectively removed from 81 to $92 \%$ of several of the nonvolatile soil 
TABLE 14. Operating Parameters for the Pilot-Scale Off-Gas System Typical Operating Range

\begin{tabular}{|c|c|c|}
\hline Parameter & Field Tests (a) & Radioactive Field Test ${ }^{(b)}$ \\
\hline Off-gas flow, std $\mathrm{m}^{3} / \mathrm{min}$ & 8 to 12 & 8 to 13 \\
\hline Hood vacuum, $\mathrm{cm}$ water & 0.5 to 1.5 & 3 to 4.5 \\
\hline \multicolumn{3}{|l|}{ Scrub liquid flows, L/min: } \\
\hline Cyclonic-spray scrubber & 40 & (c) \\
\hline Venturi-ejector scrubber & 110 & 160 \\
\hline Hydro-Sonic scrubber & (c) & 60 to 90 \\
\hline \multicolumn{3}{|l|}{ Scrubber delta $P, \mathrm{~cm}$ water: } \\
\hline Cyclonic-spray scrubber & -10 to -13 & (c) \\
\hline Venturi-ejector scrubber & +1 & +3 \\
\hline Hydro-Sonic scrubber & (c) & -150 to -230 \\
\hline
\end{tabular}

a) PSFTs 2,3 and 4 .

b) PSCT 1,2 and PSRT.

c) Scrubber not present.

components ( $\mathrm{Al}, \mathrm{Ca}$, and $\mathrm{Fe}$ ) during PSCT 1, as shown in Table 15. Semivolatile elements including $\mathrm{Cs}, \mathrm{K}$, and $\mathrm{Na}$ were more uniformly collected by the venturiejector and Hydro-Sonic scrubbers. The venturi-ejector scrubber was least efficient at removal of $\mathrm{Zn}(20 \%)$, the only heavy metal which appeared in quantity. However, the Hydro-Sonic scrubber and HEPA filters were effective at removing the residual $\mathrm{Zn}$ as well as the other elements entrained in the off gas. Carryover of most elements to the HEPA filter can be attributed to the extremely small particles, which are not easily removed by the scrubbers and condenser. During normal ISV operations, the mass mean particle diameter ranges from $<0.1$ to $0.8 \mu \mathrm{m}$. When combustible wastes are present, the entrained particle size is larger, averaging $1.4 \mu \mathrm{m}$, which can be more easily scrubbed. The HEPA filters have shown ample capacity to handle the off-gas solids loading they receive.

The secondary cooling loop is very effective at removing heat from the incoming off gas. During the PSCTs the gas inlet temperature averaged $250^{\circ} \mathrm{C}$. By the time the off gas exited the condenser, it had been cooled to within 8 to 
TABLE 15. Element Removal by Off-Gas System During PSCT 1

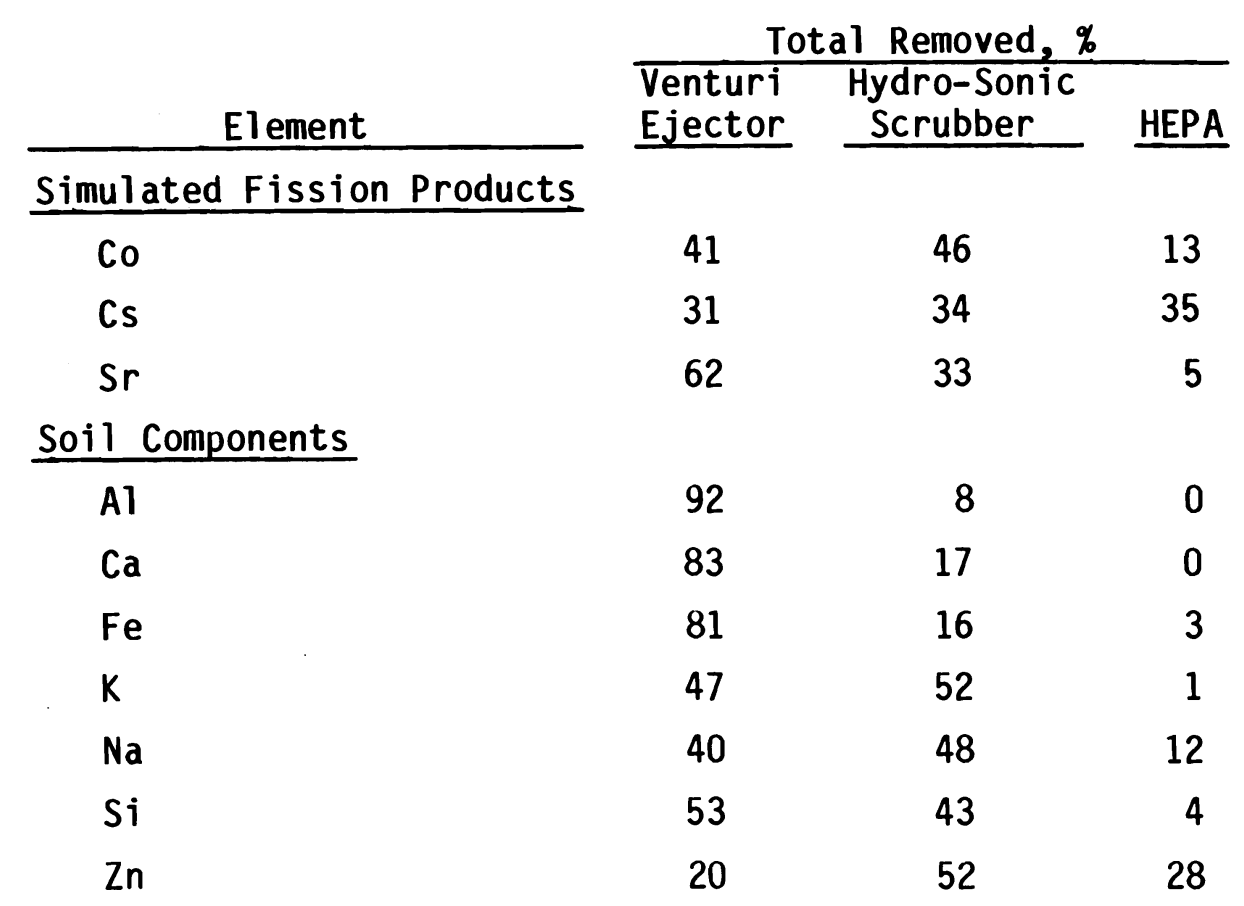

$12^{\circ} \mathrm{C}$ of the ambient air. Typically $90 \%$ of the temperature drop occurs in the venturi-ejector scrubber. Gas exiting the condenser has been cooled to below its original dewpoint, as indicated by a gradual buildup of condensate in the process tanks during operation. The amount of condensate is dependent on several factors including soil moisture, relative humidity, temperature of the ambient air, off-gas flow rate, and off-gas temperature.

\section{PROCESSING PERFORMANCE}

This section presents data on element retention within the vitrified soil, discusses melt depth monitoring, and describes a technique for extending the life of graphite electrodes.

Element Retention

Retention of simulated hazardous species within the vitrified zone was determined by chemical analysis of the soil adjacent to the solidified block and element releases to the off-gas system. No migration into the surrounding soil was found during pilot-scale tests, so releases to the off gas were the 
sole source of element losses from the vitrified zone. Releases to the off-gas system were ascertained by chemical analysis of scrub tank solutions, filter solids, and any solids which had accumulated on the hood and off-gas line walls. From these data, soil-to-off-gas decontamination factors (DFs) (a) were calculated, which helped determine the effects of waste type, operating mode, and burial depth on the retention of selected elements.

Retention of radioactive elements during large-scale ISV is predicted to be very high, based on pilot-scale retention data. Table 16 lists predicted DFs for the large-scale system assuming that the waste elements are at a burial depth of $1 \mathrm{~m}$. Plutonium, $\mathrm{Sr}$, and $U$ are expected to have the highest DFs $\left(10^{3}\right.$ to $10^{4}$ ). Decontamination factors for the more volatile elements such as Cs and $\mathrm{Sb}$ should average $1 \times 10^{2}$ or greater. Tellurium is expected to be slightly more volatile, with a DF of $1 \times 10^{1}$. These DFs are expected to increase for wastes at greater burial depths.

TABLE 16. Predicted Soi1-to-0ff-Gas Decontamination Factors for the Large-Scale System

\begin{tabular}{cc} 
Element (a) & DF \\
\cline { 2 - 3 } Co & $1 \times 10^{2}$ \\
Cs & $1 \times 10^{2}$ \\
$\mathrm{Pu}$ & $1 \times 10^{3}$ \\
$\mathrm{Sb}$ & $1 \times 10^{2}$ \\
$\mathrm{Sr}$ & $1 \times 10^{4}$ \\
$\mathrm{Te}$ & $1 \times 10^{1}$ \\
$\mathrm{U}$ & $1 \times 10^{3}$
\end{tabular}

(a) Waste elements are assumed to be buried at $1 \mathrm{~m}$ depth.

(a) Decontamination factor is the mass of an element in the soil divided by the mass released to the off-gas treatment system. 
A summary of soil-to-off-gas DFs for the pilot-scale tests is presented in Table 17. These data illustrate that most species are retained quite well (i.e., have high DFs) by the molten soil. Decontamination factors for simulated nonvolatile fission products ( $\mathrm{CO}, \mathrm{Mo}$, and $\mathrm{Sr}$ ) and simulated transuranics (Ce, La, and $\mathrm{Nd}$ ) are very high, ranging from $\sim 1 \times 10^{2}$ to over $1 \times 10^{4}$. Retention of Cs was also quite good, with DFs ranging from $3 \times 10^{1}$ to $2 \times 10^{3}$, depending on burial depth and operating condition. Cadmium, however, consistently exhibited a high loss (DF of 3 to 4 ) due to its volatile nature at the high temperatures $\left(>1700^{\circ} \mathrm{C}\right)$ of the molten soil. Tellurium was retained well

\section{TABLE 17. Soil-to-0ff-Gas Decontamination Factors for Nonradioactive Pilot-Scale Tests}

Trace Element

Simulated Fission Products
Nonvolatile

Co

Mo

$\mathrm{Sr}$

Semivolatile

Cs

$\mathrm{Sb}$

$\mathrm{Te}$

Simulated Transuranics

Ce

La

$\mathrm{Nd}$ (a)

(a)

$5 \times 10^{4}$

Decontamination Factors

PSFT 2 PSFT 3 PSFT 4A PSFT 4B PSCT 1


when buried at a depth of $1.35 \mathrm{~m}$ during PSFT $4 \mathrm{~A}$ but exhibited a high loss during test $4 B$, when it was buried at a relatively shallow depth of $0.4 \mathrm{~m}$. Despite the high releases of these two elements from the soil, they were efficiently removed from the off-gas stream by wet scrubbing and condensing in the off-gas treatment system.

Element releases to the off gas were dependent on burial depth, cold cap condition, and gas generation within the melt zone. The effect of depth on element retention can be seen from the data for PSFTs 3 and 4 presented in Figure 22. At depths of $\geq 0.5 \mathrm{~m}, 99 \%$ of the nonvolatile species were retained. Simulated semivolatile fission products $C S, S b$, and Te showed the lowest retention; however, their retention increased to $>99 \%$ at a $1.35 \mathrm{~m}$ burial depth. Over $99.9 \%$ of the nonvolatile elements are retained at the greater burial depth. In large-scale operations, it is expected that the vast majority of hazardous species will be buried deeper than $1.35 \mathrm{~m}$. Contaminant levels in secondary wastes such as scrub liquid and HEPA filters will be minimized, increasing the ease of contamination control and disposal.

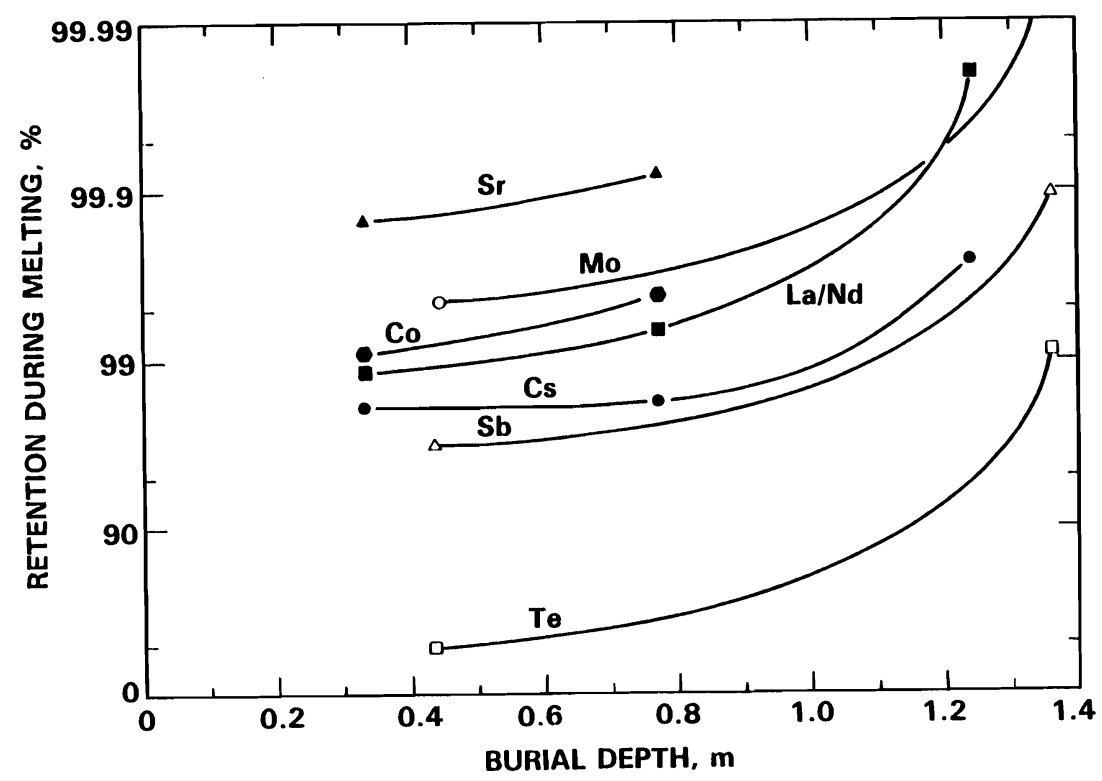

FIGURE 22. Effect of Burial Depth on the Retention of Selected Species Within the Vitrification Zone 
The effect of the cold cap on element releases was revealed during PSFT 2, in which the cold cap subsided and melted, exposing the molten surface. Figure 23 shows the cumulative releases of $C s$ and $S r$ to the off gas as a function of run time during this test. As the cold cap began to subside (21 hours into the test), the Cs release began to increase steadily, to a total loss of $0.047 \%$. Because of its nonvolatile nature, $\mathrm{Sr}$ was not released to the same extent. The same type of behavior was observed for simulated TRU elements (lanthanide series) in that the effect of the cold cap is much less pronounced for the nonvolatile elements. Releases of these elements are more a function of rapid gas releases from the molten soil due to the decomposition of combustibles or other gas generating substances.

Element releases due to rapid gas generation from combustible wastes were best illustrated during PSFT 3. The sequence of events follows. Buried combustibles pyrolyze due to the high temperatures and insufficient supply of oxygen within the soil. These pyrolyzed gases move upward through the molten zone and burn on contact with air at the surface. This upward movement of gas increases the entrainment of particles and creates a direct pathway for the release of the more volatile elements. Figure 24 shows the cumulative releases of Cs, Sr, and the lanthanides during PSFTs 3, 4A, and 4B. Periods of active gas release are also indicated. Figure 25 shows similar release data for the

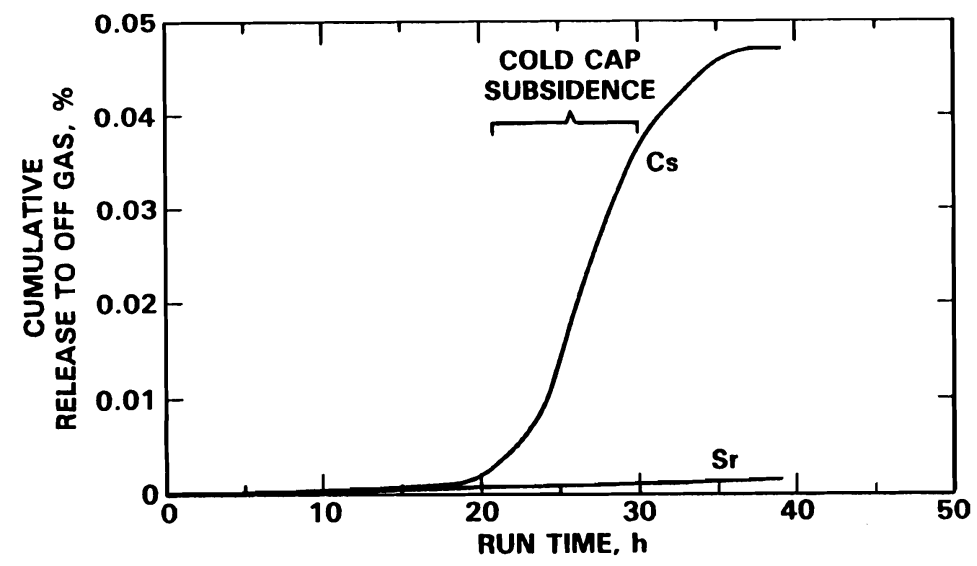

FIGURE 23. Effect of Cold Cap on the Release of Cs and Sr to the Off Gas During PSFT 2 


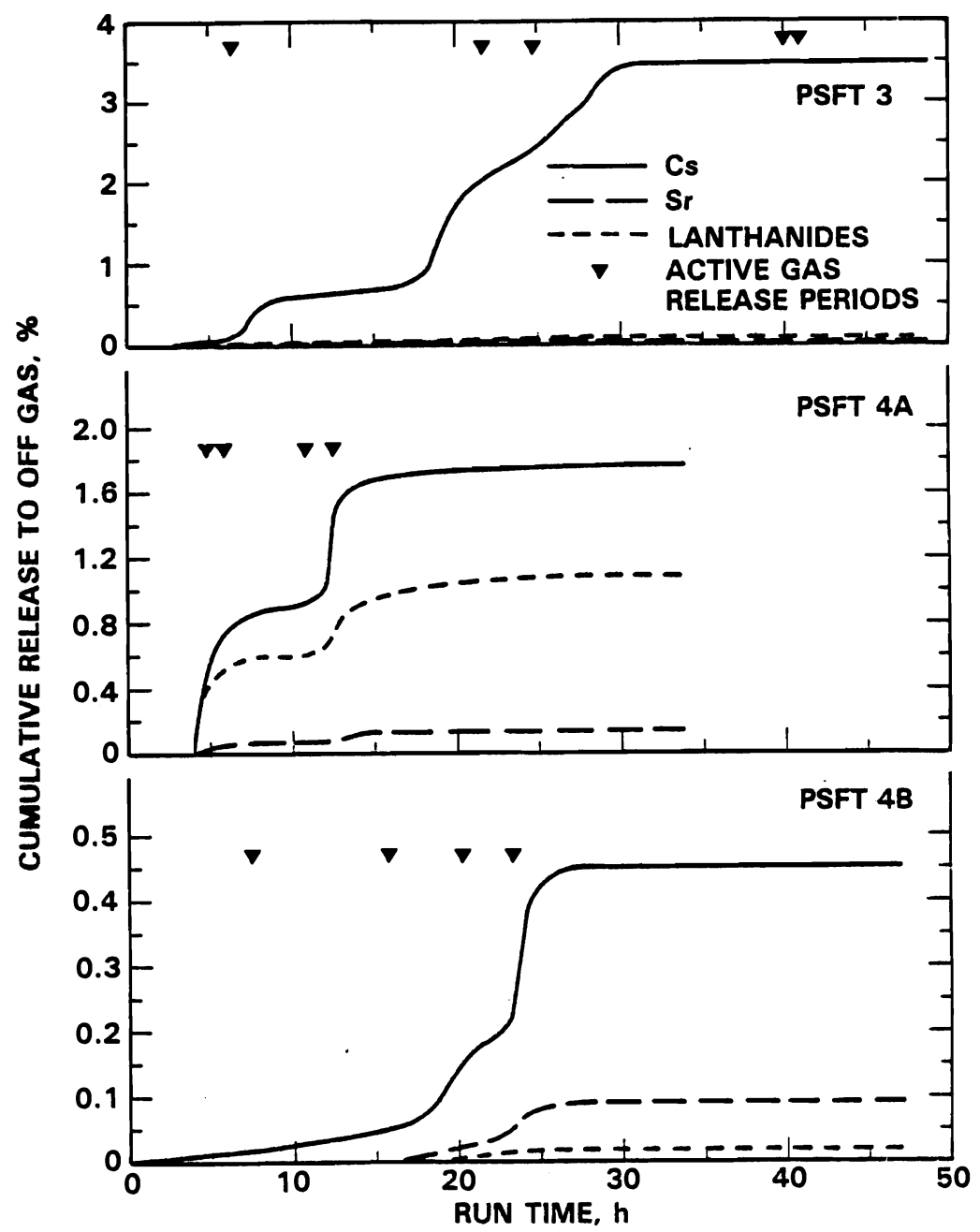

FIGURE 24. Effect of Gas Generation on the Release of Cs, Sr, and Lanthanides to the off Gas During PSFTs 3, 4A, and 4B

heavy metals $\mathrm{Cd}$ and $\mathrm{Pb}$. For most elements, a notable increase in their release to the off-gas system occurred during the rapid gas release periods. However, off-gas losses of $\mathrm{Cd}$ and $\mathrm{Pb}$ were not as strongly dependent on the gas releases during PSFTs 3 and $4 A$ as the losses of Cs, Sr, and the lanthanides were. Cadmium and $\mathrm{Pb}$, which are volatile at the processing temperatures, were released continuously throughout PSFT $4 A$, showing little or no dependence on rapid gas generation periods. Releases during PSFT 4B, however, showed some dependence on gas generation periods, since a higher combustibles loading resulted in more intense gas releases. 


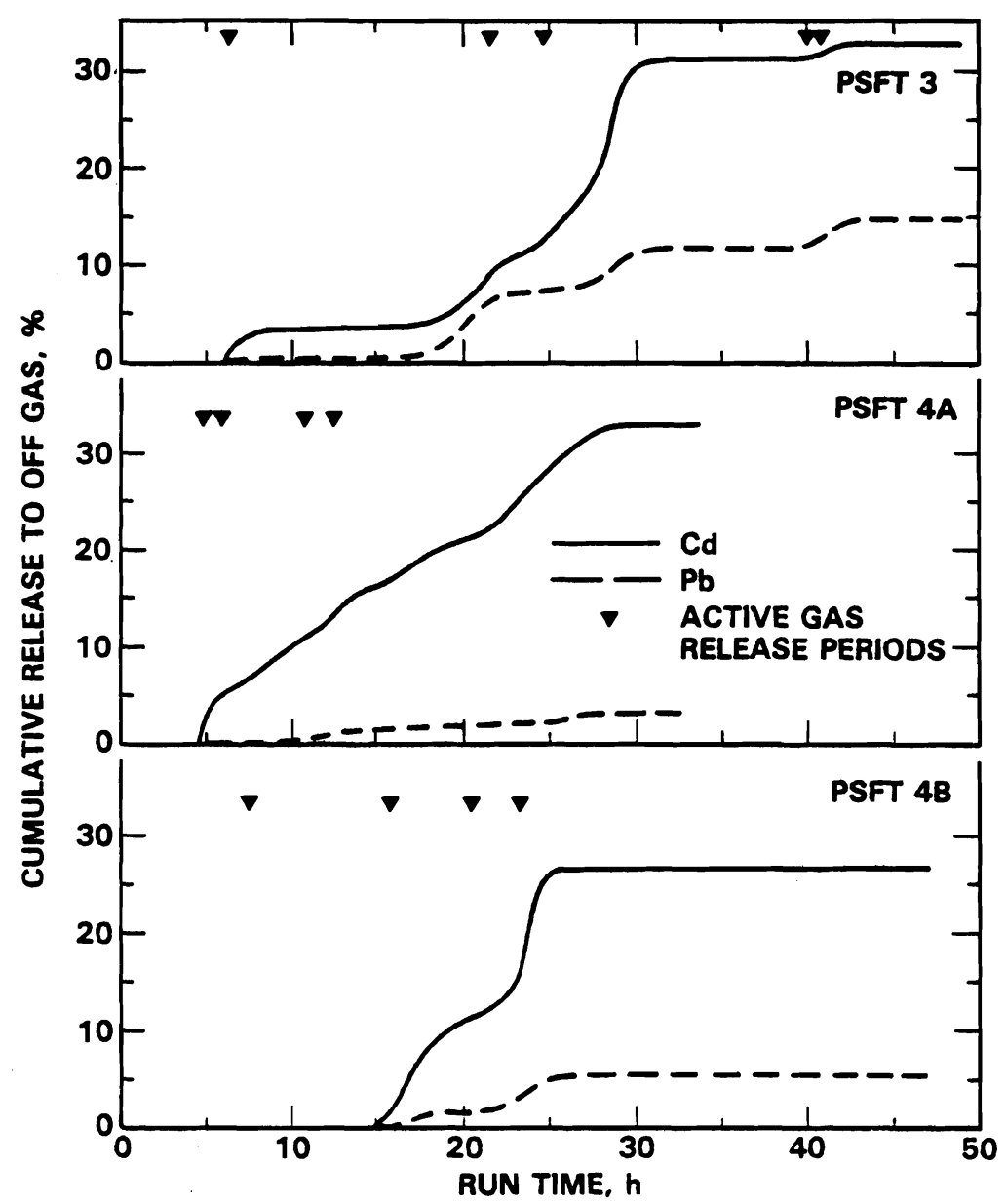

FIGURE 25. Effect of Gas Generation on the Release of Heavy Metals to the off Gas During PSFTs $3,4 A$, and $4 B$

The chemical form of a hazardous species affects the quantity released from the vitrification zone to the off gas. This was best illustrated during PSCT 1, in which Cs, Co, and Sr were placed in a simulated waste canister. The element releases to the off gas as a function of run time lapsed are illustrated in Figure 26. Cesium and Sr were primarily released during the initial glass penetration of the waste canister at 10 hours into the run. They were both present as nitrates which decompose during vitrification. Cobalt, added as an oxide, did not release until the cold cap had thinned. Cesium also continued to release gradually after cold cap thinning occurred; however, Sr showed no signs of release after the initial glass penetration period. Transuranic elements are expected to behave similarly to Sr. 


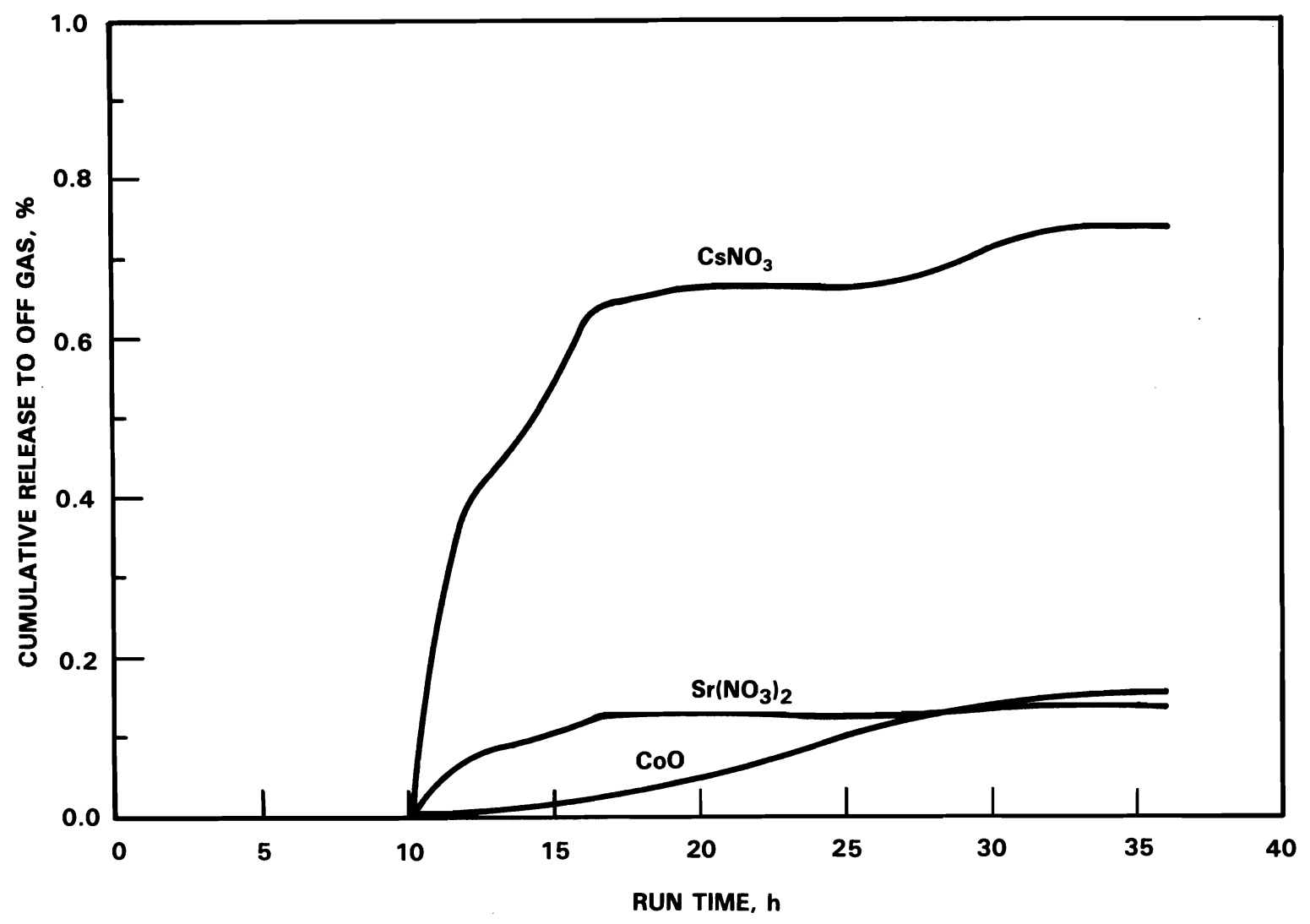

FIGURE 26. Effect of Chemical Form on the Release of Simulated Fission Products to the off Gas in PSCT 1

Depth Monitoring

During the engineering- and pilot-scale development phase, growth of the vitrification zone was monitored by thermocouples placed in the soil at designated positions. These in-ground thermocouples are not considered feasible for monitoring vitrification depth at a radioactive waste site. Therefore, various monitoring methods having the potential to indicate melt depth were investigated.

Depth Transmitter Concept

A depth transmitter system has shown the most promise for economical and reliable monitoring of the vitrification zone depth. The depth transmitter method for monitoring is passive in the sense that it does not require transmission of energy into the melt volume. Its operation necessitates that an electrical circuit and transmitter be mounted beneath one or more of the 
graphite electrodes. For operation, several sensors connected to the electronic package are installed at different depths alongside the electrodes. As the melt progresses downward, the sensors indicate when the melt has reached that depth. This event is transmitted to a receiver at the ground surface by a low-powered radio transmitter mounted beneath the electrodes.

The depth transmitter technique has been tested during PSFT 4, PSCT 1, and PSCT 2. A different electronic design was used for each test; however, the configuration was similar for all tests as illustrated in Figure 27 .

The depth sensor design which worked well during field tests is shown in Figure 28. The system operates as a thermal switch, closing a circuit when the temperature reaches a specified level. Coiled silver solder is placed in a

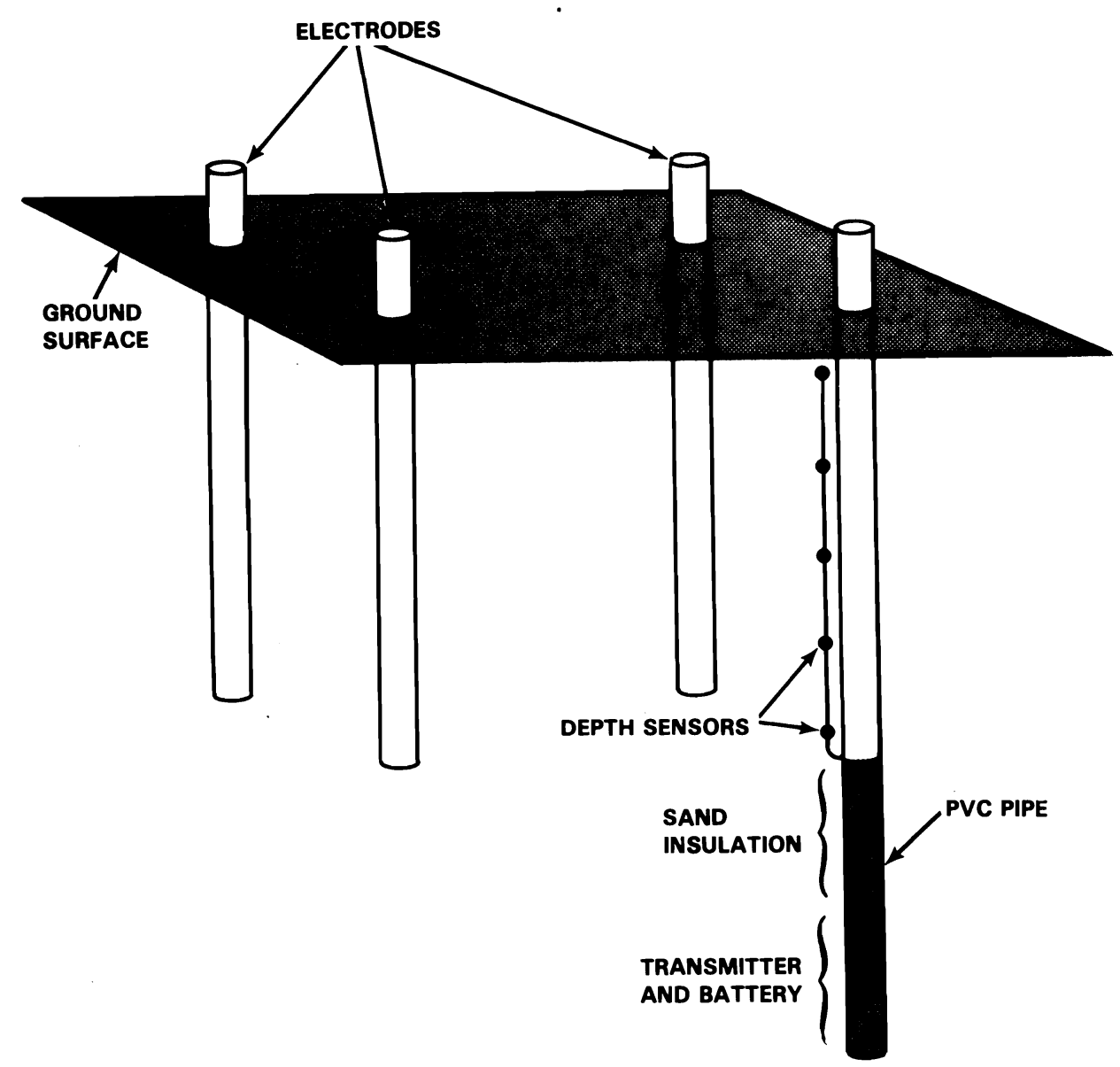

FIGURE 27. Depth Transmitter System Configuration for Monitoring Melt Depth 


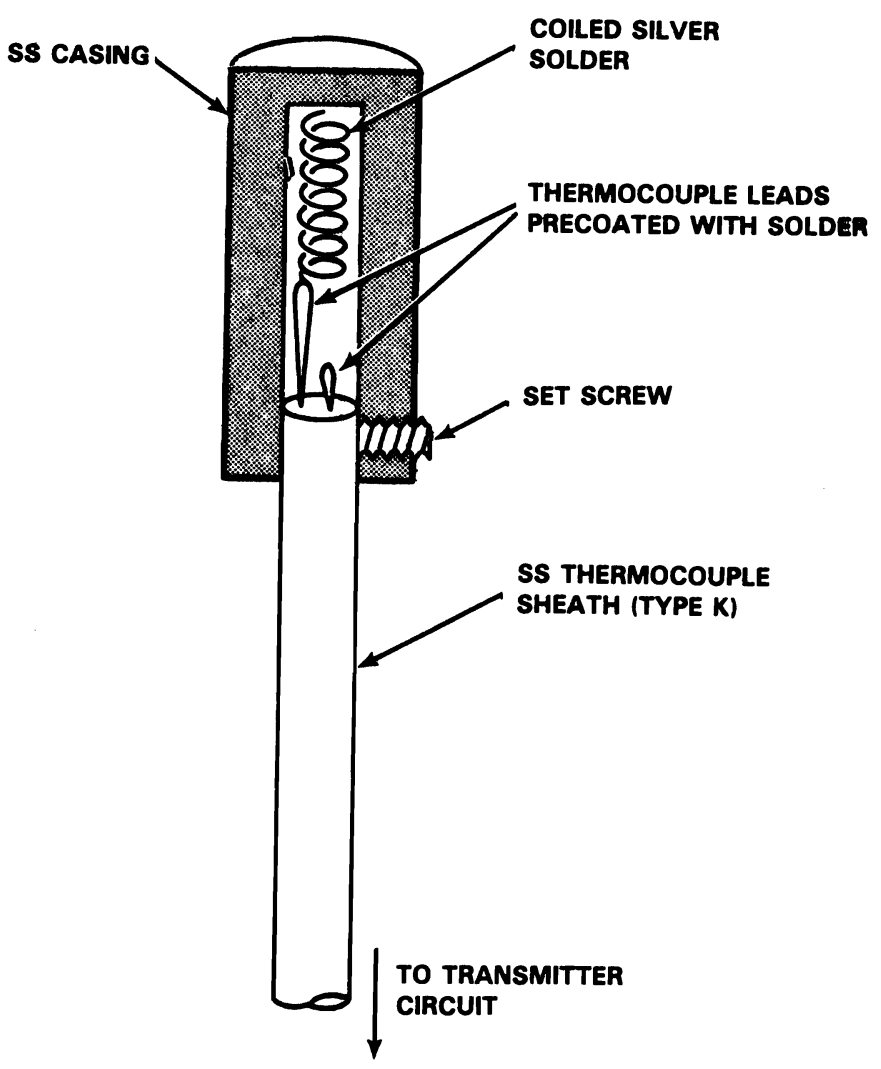

FIGURE 28. Design of Thermal Switch Depth Sensor

casing and affixed to the end of a Type $K$ thermocouple with leads disconnected and positioned as shown. When the glass approaches the probe, the solder melts, closing the circuit and thus becoming detectable by the transmitter electronics. The solder selected had a melting point of $645^{\circ} \mathrm{C}$, which is cooler than the melting point of soil. The thermal gradient near the melt zone is so steep that the low melting solder alters the predicted melt depth by less than $5 \mathrm{~cm}$ from the actual. Solders or other metals with even higher melting points could be used to increase the sensor accuracy.

Optical file sensors of the design shown in Figure 29, although not yet tested, are being considered as a replacement to the thermal switch concept. The advantages of the optical probes are that they are less expensive, substantially simpler, and will not conduct electricity from the melt or electrode to the transmitting electronics. The probes function as optical pyrometers using a quartz fiber rather than an air path between measurement zone and detector. 


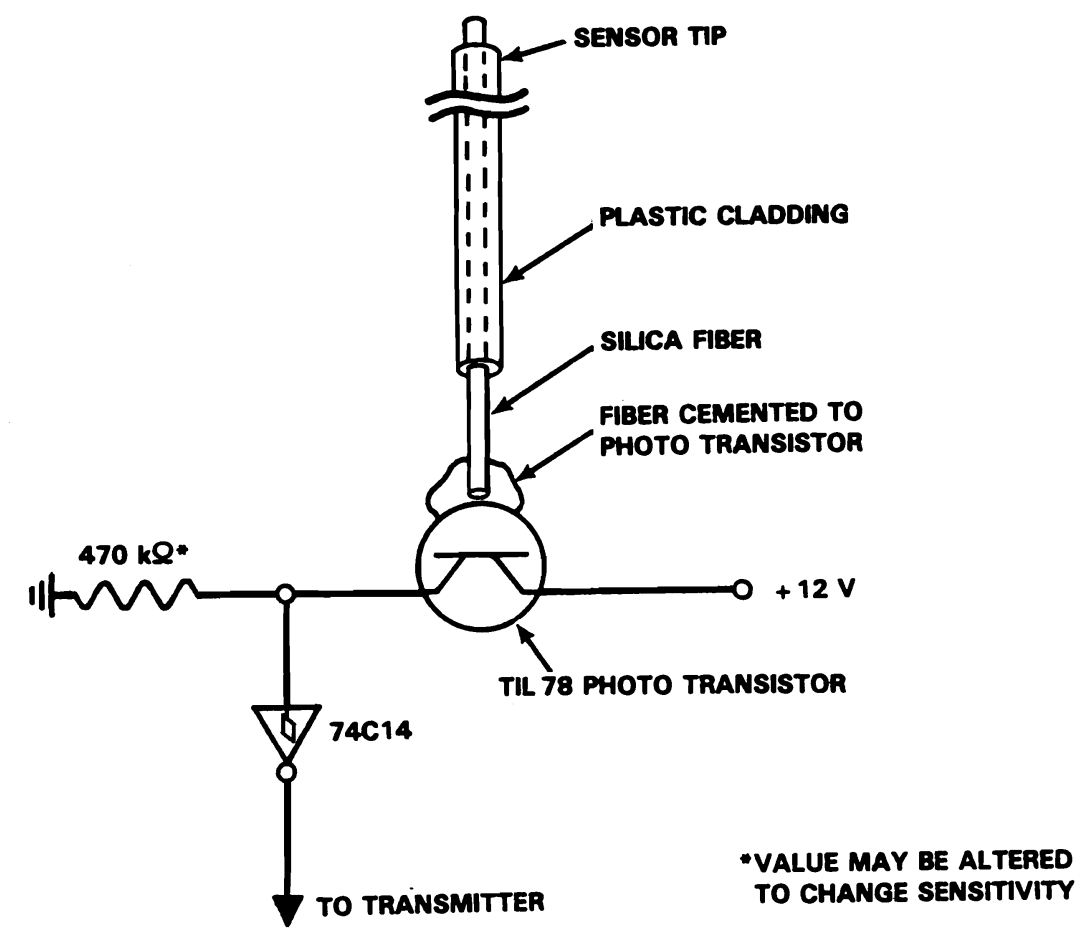

FIGURE 29. Design of Optical Fiber Depth Sensor

Plastic clad silica (quartz) optical fiber of a type commonly used for data communication is cemented to a silicon photodiode detector, which in laboratory tests reliably detects temperatures above $1200^{\circ} \mathrm{C}$ at the fiber end. As the fiber is heated above $1000^{\circ} \mathrm{C}$, infrared emission and thus radiation down the fiber increases rapidly in the wavelength region to which the phototransistor is sensitive $(<1 \mu \mathrm{m})$. Figure 30 shows the effect of fiber end temperature on phototransistor output. Tests with a gas flame showed a clear, reliable response as the fiber end began to glow. Severe charring of up to $15 \mathrm{~cm}$ of the plastic fiber jacket shifted the apparent response temperature upward as the jacket material absorbed light from the fiber, but a clear indication was still obtained at fiber temperatures estimated at 1200 to $1400^{\circ} \mathrm{C}$ (the softening point of the quartz).

Graphite electrodes are much better thermal conductors than soil, so the melt depth close to the electrodes exceeds the average depth by several centimeters. Depth sensors directly contacting the graphite will indicate a depth 


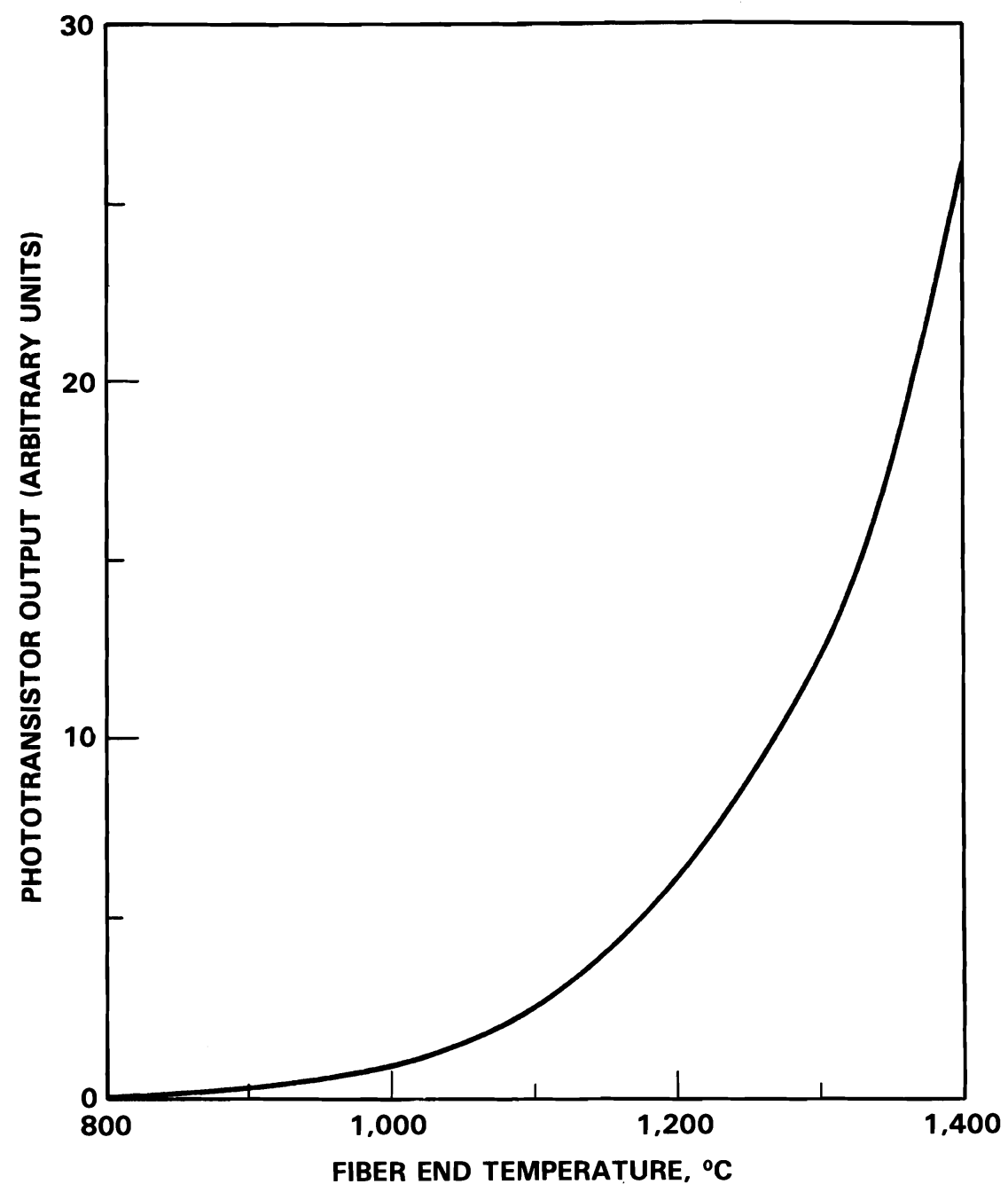

FIGURE 30. Effect of Silica Fiber End Temperature on Phototransistor 0utput

greater than the actual. To minimize this effect an insulative spacer should be placed between the sensors and electrodes.

\section{Other Monitoring Concepts}

Other depth monitoring concepts evaluated prior to selection of the depth transmitter system were infrared sensing, ultrasonics, power/design parameters, acoustics, and ground penetrating radar.

The infrared technique has little or no value for monitoring vitrification growth. Infrared sensing is strictly a surface-mapping technique and as such, cannot directly measure vitrification depth. 
The ultrasonic method involves transmitting ultrasonic pulses through a waveguide coupled to the molten glass and measuring the travel time of the reflected pulse to determine melt depth. To do this, the waveguide must be extended through the porous cold cap and rock layer into the molten glass during processing because these upper regions are too attenuative for transmission. The waveguide is not capable of withstanding the high temperature $\left(1800^{\circ} \mathrm{C}\right)$ of the molten glass. Moreover, the glass attenuation is too high for practical use of the ultrasonic technique.

Power input and system design parameters combined with mathematical modeling is not a direct method of measurement. Substantial data on the soil and waste properties would be required before this method would be reliable for depth predictions.

Data obtained by the acoustic and ground penetrating radar methods are complex and require computer aided interpretation. Subsurface geologic features complicate data analysis by altering the acoustic velocity and radar images. Both techniques are also subject to interference. The best results for monitoring depth by acoustic methods employ subsurface or downhole sensors. This would necessitate drilling an additional shaft in potentially contaminated soil, producing additional exposure and the spreading of contaminants. Graphite Electrodes

Based on an ISV electrode evaluation study, graphite was selected as the electrode material for future development. Through engineering- and pilotscale tests, graphite oxidized at a rate which is acceptable for the smallerscale tests but unacceptable for a large-scale operation, which may require over 400 hours to complete. Methods to extend the life of graphite electrodes have been investigated including using more durable graphite material, protective coatings, and diffusion barriers.

During PSCTs 1 and 2, the cold cap thinned and the surface, particularly around the electrode, became quite hot. Temperatures at the electrode/glass interface ranged from about 1000 to $1200^{\circ} \mathrm{C}$. Glass temperatures near the electrode were sometimes $>1300^{\circ} \mathrm{C}$. The high temperatures at the electrodes (which accelerate oxidation) were caused by two mechanisms. First, the power density 
at the electrodes is higher than at other points in the melt because all the current must converge on each electrode from a more evenly distributed state in the melt zone. Secondly, graphite is an excellent heat conductor, transmitting thermal energy to the upper portion of the electrode where oxidation can occur. The thermal conductivity of graphite is 5 to 10 times higher than that of molten soil at $2000^{\circ} \mathrm{C}$.

A thermal analysis was performed to predict the temperature profile of an electrode protruding above the melt zone during ISV. For the analysis the temperature of the plenum gas was $300^{\circ} \mathrm{C}$, and the temperature of the electrode at the surface of the cold cap was $1200^{\circ} \mathrm{C}$. A plot of the temperature profile for graphite is shown in Figure 26, along with stainless steel, carbon steel, and copper for comparison. As shown, the graphite is an extremely good conductor of heat, with its performance falling between those of carbon steel and copper. Temperatures within $0.4 \mathrm{~m}$ of the surface are predicted to be $>1000^{\circ} \mathrm{C}$ for a rod $1.2 \mathrm{~m}$ in height. During controlled air tests, graphite ignited and burned at $\sim 1100^{\circ} \mathrm{C}$. This predicted behavior (see Figure 31 ) has been observed during pilot-scale tests.

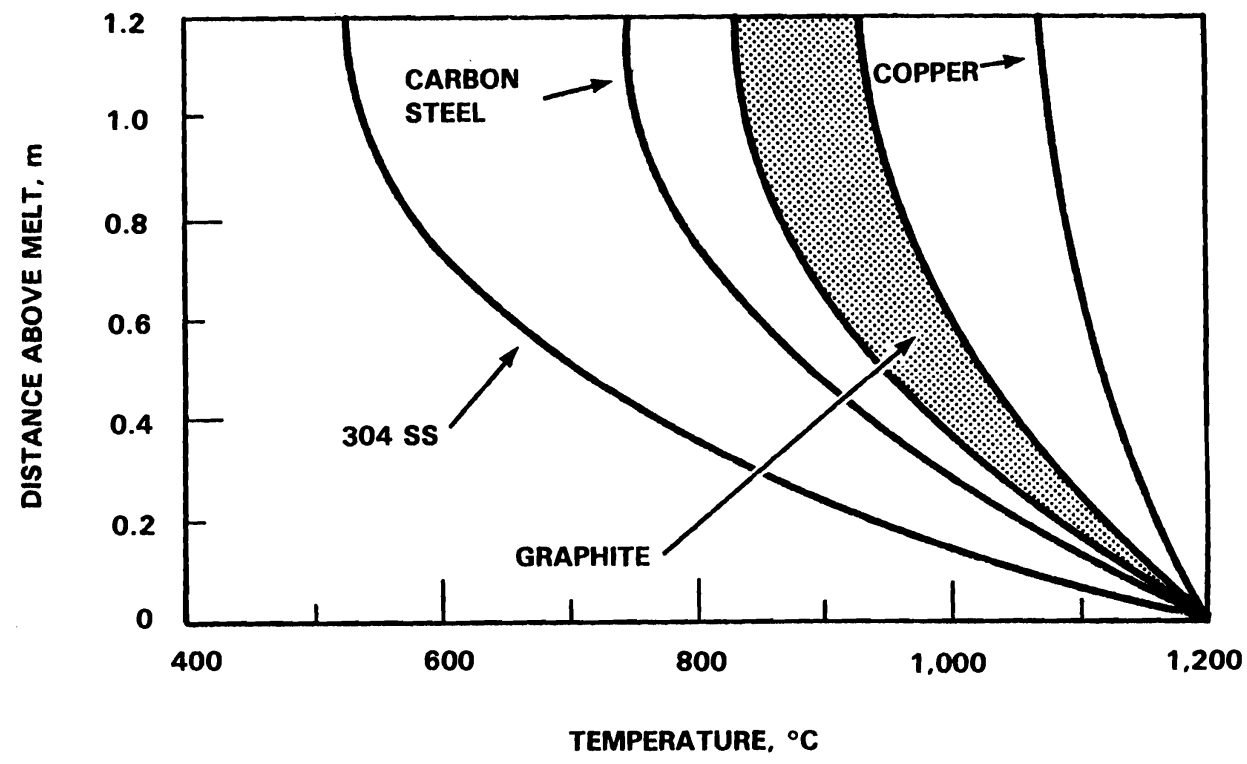

FIGURE 31. Calculated Thermal Profile of Vertical Rods $15 \mathrm{~cm}$ dia by $1.2 \mathrm{~m}$ Long with a Bottom End Temperature of $1200^{\circ} \mathrm{C}$ 
A study was conducted to evaluate parameters which affect graphite oxidation. Six different grades of graphite were assessed. Differences in graphite density and purity did not significantly affect the rate of graphite oxidation in air at $1000^{\circ} \mathrm{C}$. The HPC grade, with the largest grain size, oxidized at a slightly reduced rate, probably due to the smaller surface area available for reaction. Because HPC was also low in price, it was chosen as the reference ISV electrode material.

Coatings of silicon carbide and KNOX (phosphate impregnated) were also tested. The KNOX coating did not slow the rate of graphite oxidation in the controlled oxidation tests. The silicon carbide coating, however, eliminated oxidation on graphite grades HPC, CS, and SIC-6 (a special graphite with properties compatible to the silicon carbide coating) when applied in a layer $250 \mu \mathrm{m}(10 \mathrm{mil})$ thick.

An economic analysis was prepared, comparing costs of different electrode systems for a large-scale, $5 \mathrm{~m}$ deep operation. The graphite electrode configuration, shown in Figure 32 , consists of a $0.6 \mathrm{~m}$ electrical coupling section, two $0.6 \mathrm{~m}$ silicon carbide-coated sections, and the balance of $1.8 \mathrm{~m}$ standard sections. Based on the parametric study results, HPC grade graphite was used as the standard electrode material. Another graphite electrode configuration, using HPC with silicon carbide-coated SIC- 6 graphite, was also evaluated. If thermal cycling should cause silicon carbide to crack on the larger specimens of HPC, then SIC- 6 , which is compatible with the coating, would be required. Electrodes of HPC, having a $1.2 \mathrm{~m}$ silicon carbide-coated section at the glass/soil interface, are estimated to cost $\$ 4330$ per set of 4 . By replacing the $1.2 \mathrm{~m}$ silicon carbide coated HPC section with silicon carbide coated SIC-6, the total cost increases by $52 \%$ to $\$ 6600$ per electrode set. For comparison, the costs of using molybdenum electrodes were estimated to be $\$ 21,300$, or nearly 5 times the cost of the all-HPC option.

\section{WASTE FORM PERFORMANCE}

This section includes a discussion of the analyses performed on the soil surrounding the vitrified blocks to determine waste element migration. The 


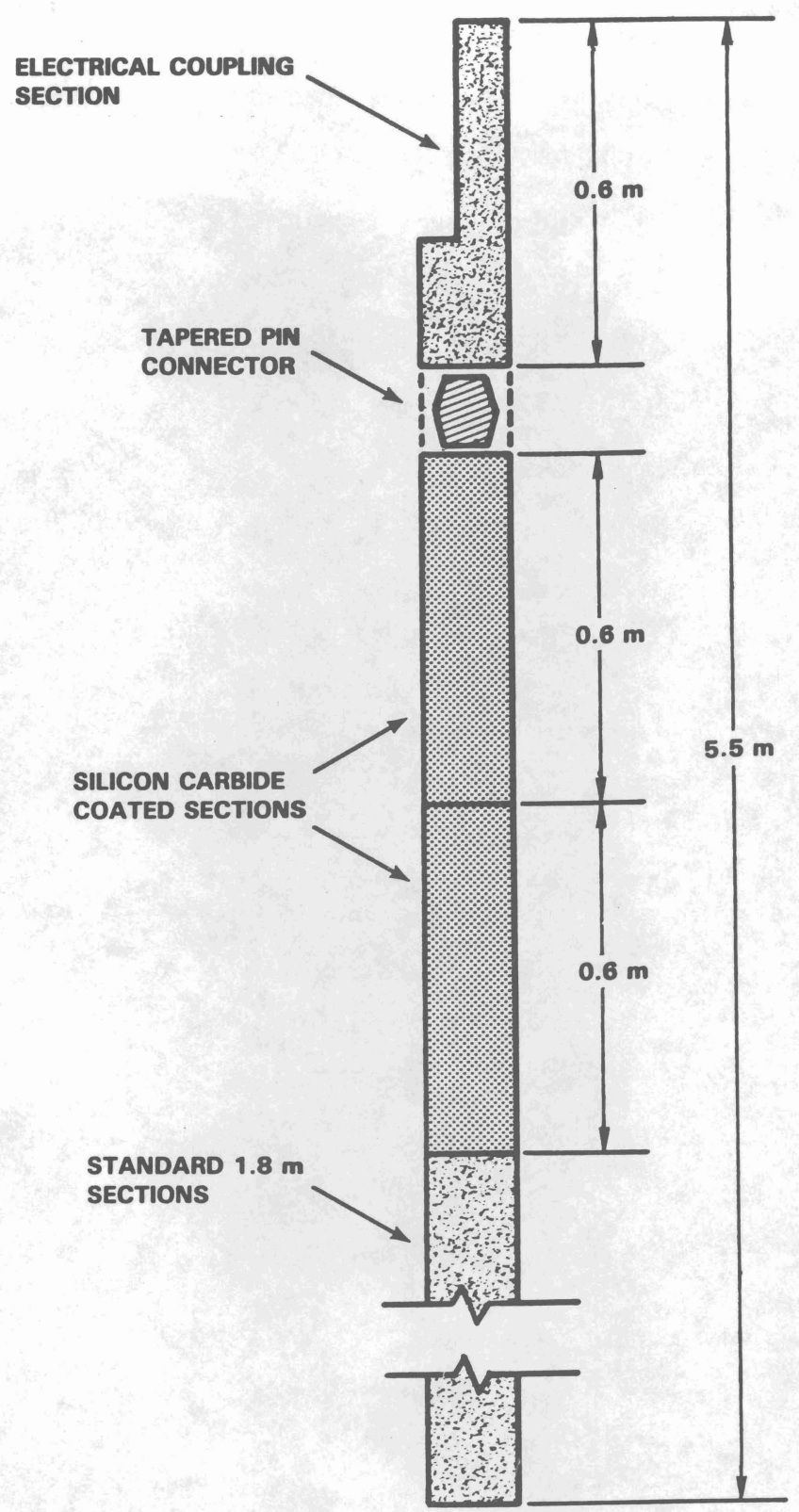

FIGURE 32. Typical Configuration for a Graphite Electrode

vitrified blocks themselves were also analyzed to trace the distribution of simulated waste elements. In addition, the durability of the glass product has been assessed.

Examination of the three layers in each vitrified block revealed that differing density materials were formed in each test (see Figure 33). An upper, low-density $(0.75 \mathrm{~kg} / \mathrm{L})$ porous layer was created from the cooler, cold-cap, 


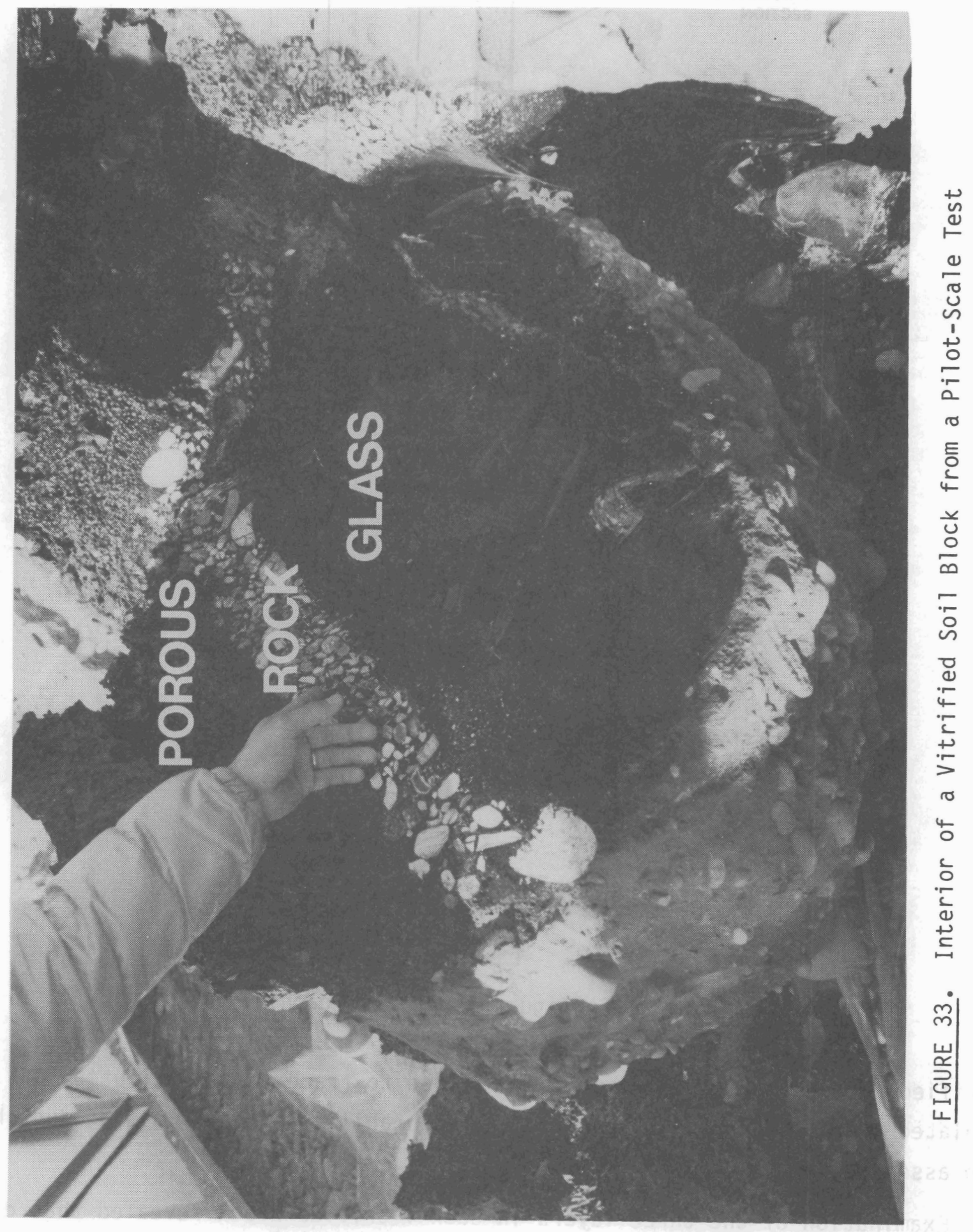


surface glass. Rocks fully encompassed by the lower melt region had floated to below the porous zone and formed a rock layer having a density of $2.2 \mathrm{~kg} / \mathrm{L}$. Finally, the lower glass layer constituted the major mass and volume of the melt. This vitreous region was also the most dense $(2.7 \mathrm{~kg} / \mathrm{L})$.

Migration Analysis

Most of the soil sample analyses for the PSFTs showed no migration of simulated contaminant elements beyond the vitrification zone. Even the partially fused soil at the molten edge approached the detection limits of these elements. Thus the high viscosity of this region apparently prevents the migration of simulated contaminants outside the vitreous block. An anomalous migration of Cs and Sr to the small region directly below the center of the melt did occur in PSFT 2. No other ISV test has detected contaminant migration beyond the vitrified block. Detection sensitivity of radionuclide migration will be improved with the analysis of soil surrounding the glass block from the radioactive field test. This analysis will be used to determine any species migration.

The contaminants were uniformly distributed throughout the vitrified soil blocks in all pilot-scale tests, indicating extensive convective mixing during operation. Concentration profiles show that near the edge of the vitrification zone the contaminant concentrations decrease to natural soil levels.

Concentration plots have also shown that within the dense glass layer of the melt the contaminant concentrations reach their respective, evenly distributed amounts. In one pilot-scale test, for example, the $\mathrm{CsO}_{2}$ concentration was $0.04 \mathrm{wt} \%$, the strontium oxide concentration was $0.08 \mathrm{wt} \%$, and the lanthanum oxide concentration was 0.05 wt\% within the inner glass zone. These values correspond closely with the predicted homogeneous values of $0.04,0.08$ and $0.04 \mathrm{wt} \%$, respectively. Apparently, convective mixing and an even distribution of these compounds occur within the molten core. Contaminant concentrations in the rock layer are lower due to the dilution effects of the rocks. Samples from the uppermost, porous layer show the same relative distributions and concentrations of the contaminants as in the glass region of the melt; however, the porous region only encompasses a small ( $<5 \mathrm{wt} \%$ ) portion of the vitrified block. 
While Cs selectively migrated upward in some engineering-scale tests, there was no evidence of this movement in the pilot-scale tests. Pilot-scale results indicate that the convective mixing patterns may dominate the diffusion mechanisms through the molten soil and provide a uniform distribution of contaminants. An example of a typical distribution pattern for rare earths is provided in Figure 34 for Ce (Oma, Farnsworth, and Rusin 1982). Final concentration of Ce was 14 times less than its initial concentration. This uniform distribution of the rare earths (Ce, La, and Nd) suggests that actinides such as $\mathrm{Pu}$, which the rare earth elements simulate, would not migrate either. Selective migration (mainly settling) of Pu has been of concern because of its criticality potential. This final distribution of $\mathrm{Ce}$ and other elements aids in dispelling the concerns over selective migration effects.

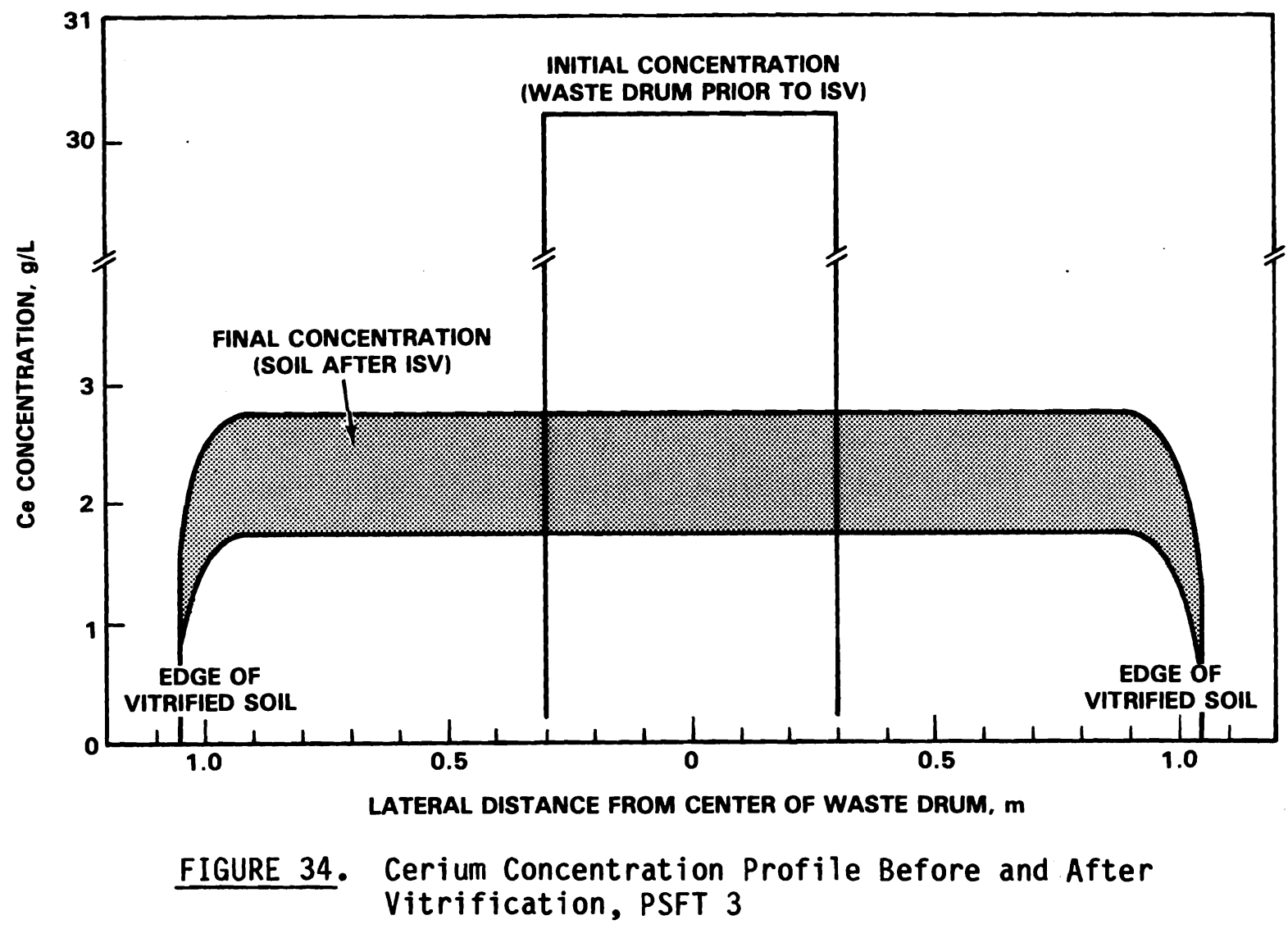




\section{Product Durability}

After each field test, the vitrified blocks were removed from the test area and sectioned for evaluation. The vitrified soil from each of the tests has remained a solid, nearly crack-free block until fractured open for analysis. In general, the interior of the block was a nonporous glass similar to natural obsidian (Figure 33 ).

Leaching studies of the vitrified Hanford soil were conducted to determine its chemical durability. Two types of leach tests have been performed on ISV field test products: a 24 hour soxhlet test in $99^{\circ} \mathrm{C}$ deionized water and a 28 day Materials Characterization Center Test-1 (MCC-1) (MCC 1981) in $90^{\circ} \mathrm{C}$ solutions of deionized water, silicate water, and brine. A comparison of the resulting corrosion rate during soxhlet leaching with published data (Platt 1973; MCElroy 1975) is provided in Figure 35, showing that the bulk leach rate of vitrified soil is significantly less than that of marble or bottle glass and is comparable to Pyrex and granite.

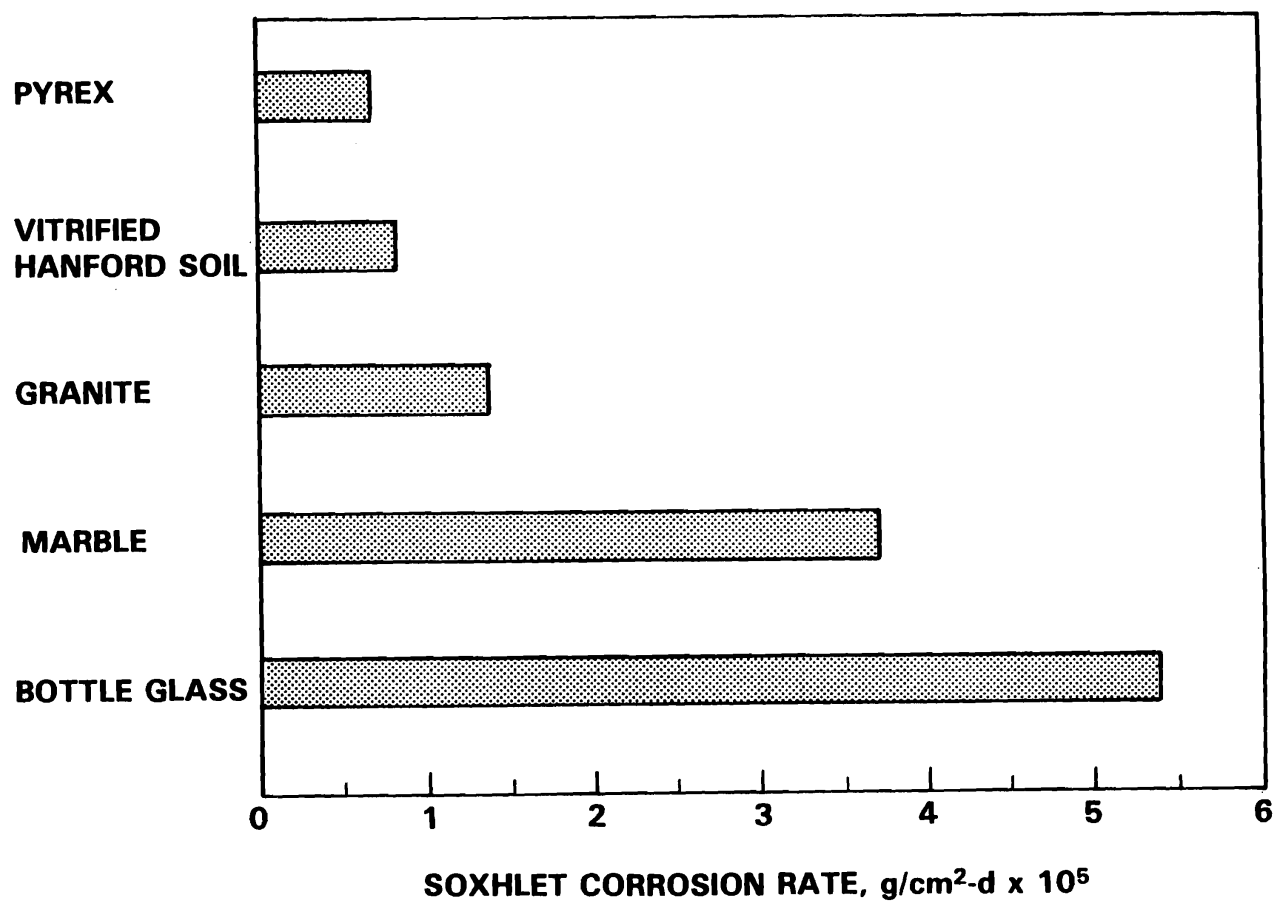

FIGURE 35. Leach Resistances of Selected Materials 
Samples of the porous, rock, and glass layers from PSFTs 1 and 2 were soxhlet leach tested. The second field test product also formed vitreous and crystalline phases which were leach tested. These soxhlet leach results are presented in Table 18. Other materials and their respective leach losses are listed below the ISV samples for comparison. Comparable leach losses are shown between the first two field test products and the various layers formed. Soxhlet leach results show that the leach resistances of ISV products are better than those of other waste glasses. This is primarily due to the high silica and alumina and low alkali content in the ISV glass. The soxhlet results also indicate that ISV glass containing a crystalline phase exhibits a slightly improved leach resistance. These results indicate that crystallization of ISV glass may actually enhance waste form durability.

In the 28-day MCC-1 leach tests, glasses with and without a crystalline phase were examined. Their leach resistances are shown in Table 19. Glass containing an observable crystalline phase, formed from nucleation site growth and slow cooling (Timmerman and Lokken 1983), exhibits equal or better leach resistance than the single-phase glass. This is consistent with the soxhlet

TABLE 18. Soxhlet Leach Test Results for PSFTs 1 and 2

\begin{tabular}{lc} 
PSFT 1 Samples & Wt\% Loss \\
\cline { 2 - 2 } Surface & 0.36 \\
Porous layer & 0.40 \\
Rock layer & 0.38 \\
Glass layer & 0.41 \\
PSFT 2 Samples & \\
\hline Porous layer & 0.32 \\
Rock/porous interface & 0.26 \\
Glass layer & 0.26 \\
Glass with crystalline & 0.21 \\
Comparison with Glass Samples & \\
\hline Commercial waste glass (PNL 76-68) & 1.6 \\
Defense waste glass (SRL-131) & 2.0 to 3.5
\end{tabular}


TABLE 19. Comparison of ISV Glass/Crystalline Leach Resistances with Commercial Waste Glass PNL 76-68

\begin{tabular}{|c|c|c|c|}
\hline \multirow[b]{2}{*}{ El ement } & \multicolumn{3}{|c|}{ Normalized El emental Loss, $\mathrm{g} / \mathrm{m}^{2}(\mathrm{a})$} \\
\hline & ISV Glass & Crystals & PNL $76-68$ (b) \\
\hline Al & 4 & 2 & -- \\
\hline $\mathrm{Ba}$ & 2 & 2 & $<0.05$ \\
\hline $\mathrm{Ca}$ & 4 & 3 & 0.3 \\
\hline $\mathrm{Fe}$ & 0.1 & 0.5 & $<0.01$ \\
\hline $\mathrm{Mg}$ & 4 & 3 & -- \\
\hline $\mathrm{Na}$ & 5 & 3 & 55 \\
\hline $\mathrm{Si}$ & 4 & 3 & 36 \\
\hline $\mathrm{Sr}$ & 3 & 3 & 0.3 \\
\hline Cs & 6 & 4 & 64 \\
\hline La & $<0.01$ & $<0.01$ & -- \\
\hline $\mathrm{Nd}$ & $<0.02$ & $<0.02$ & -- \\
\hline
\end{tabular}

(a) MCC-1 leach fest in $90^{\circ} \mathrm{C}$ deionized water, $S A / V=10 \mathrm{~m}^{-1}$ for 28 days.

(b) Strachan, Turcotte, and Barnes (1980).

weight losses. Glass leach rates for the majority of elements listed are significantly less than those of the commercial high-level waste glass

PNL 76-68. Cesium yielded the highest leach rate (although still low), while the rare earths leached less than the analytical detection limits. The leach resistance observed in the other pilot-scale tests is similar to that shown in Table 19.

Leach tests were also conducted on vitrified Z-12 soil samples using the MCC-1 test method. A $200 \mathrm{~g}$ soil sample was obtained from well drilling Hanford Z-12 crib No. 182 (Kasper 1981). The soil was vitrified at $1600^{\circ} \mathrm{C}$ in a crucible placed within a resistance-heated laboratory furnace. The vitrified melt was radioactively nonsmearable and free of major cracks, allowing easy cutting of the samples for the MCC-1 leach test.

Table 20 lists other MCC-1 leach test results, giving the normalized elemental releases from the vitrified Z-12 crib soil, borosilicate glass, 
TABLE 20. MCC-1 Leach Test Results for TRU Waste Forms

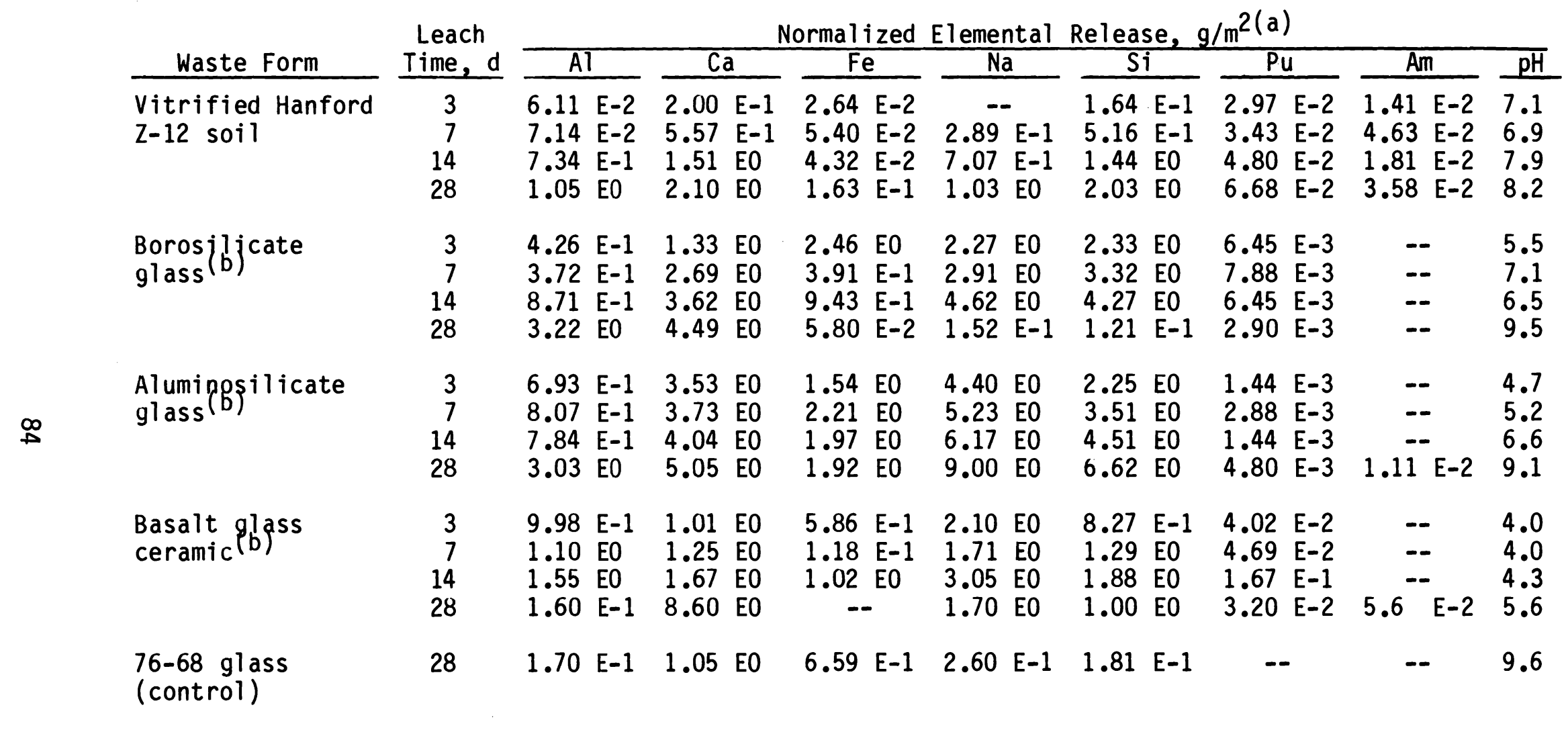

(a) Leached in deionized water at $90^{\circ} \mathrm{C}$.

(b) Ross et al. (1982). 
aluminosilicate glass, basalt-glass ceramic, and glass PNL 76-68 (Ross et al. 1982). This comparison with other waste forms allows an evaluation of the relative benefits from ISV of Z-12 soil. The overall leach rate of the vitrified Z-12 soil is comparable to the 76-68 glass and other TRU waste forms. However, the release of $\mathrm{Pu}$ is higher from the vitrified Z-12 soil than from the borosilicate and aluminosilicate glasses. The similarity between $\mathrm{Pu}$ releases from the vitrified $Z-12$ crib soil and the basalt glass ceramic indicates that the $\mathrm{Pu}$ in both waste forms may be in a crystalline form that may be more readily leached. This may be due to the $1600^{\circ} \mathrm{C}$ crucible melt temperature, which is less than the 1800 to $2000^{\circ} \mathrm{C}$ temperatures obtained during ISV. Thus some unmelted or crystalline material might be present in the crucible melt, making Pu less leach resistant. However, leach resistance studies presented above on nonradioactive, vitrified soil containing large fractions of crystalline products have indicated that the crystalline phases are not detrimental to overall leach resistance, as is also indicated in Table 20, which gives releases for other elements.

The durability of the ISV waste form can also be estimated by examining the durability of obsidian, which is a naturally occurring glass with similar physical properties and chemical composition (Ewing and Hoaker 1979). Obsidian is formed as a result of cooling of volcanic lava which has lost heat too quickly to permit crystallization. The weathering process of obsidian in a natural environment not saturated with free water involves hydration of atmospheric water that is chemically absorbed on the surface. The water then diffuses into the obsidian as a function of time and temperature. This type of weathering would be expected for the ISV waste form at Hanford because of its chemical and physical similarity to obsidian.

The rate of hydration is expected to be limited by diffusion, with the thickness of the hydration profile increasing proportionally to the square root of the hydration time. Laursen and Lanford (1978) report that archaeological evidence shows that hydration rate varies from 1 to $20 \mu^{2}$ per 1000 years. If a fresh fracture surface is exposed for 1 year at a hydration rate of $10 \mu \mathrm{m}^{2}$ per 1000 years, assuming a linear weathering rate, the resulting hydration layer will be $1 \times 10^{-5} \mathrm{~cm}$ thick. 
A very conservative estimate that assumes that the hydrated glass formed during each 1 year period has no effect on the hydration rate of adjacent fresh material would result in a hydration thickness of only $1 \mathrm{~mm}$ in 10,000 years. Therefore, under environmental conditions expected at Hanford, the ISV waste form would be expected to remain virtually unweathered for time frames much greater than 10,000 years. Thus leach testing and a long-term geologic comparison have shown that the ISV process generates a highly durable waste form.

\section{CONCLUSIONS}

Performance of the ISV equipment, the ISV process, and the waste form has been discussed in this section. The power system has proven to be reliable and correctly designed. Startup and normal operation have been conducted with no signs of unstable behavior such as arcing, hot spots, or significant imbalance of the power load. The off-gas containment hood, developed for the PSRT system, has maintained a vacuum seal over the vitrification zone to prevent radionuclide losses outside the hood. The hood design incorporates a skirting of high-temperature resistant cloth which improves the seal around the edge. The off-gas system also performed very well. The system effectively contained off gases and removed all radioactive species during the radioactive field test.

Retention of elements within the vitrification zone has been high during pilot-scale tests. Retention during large-scale ISV operations is predicted to equal or exceed the pilot-scale performance because the waste elements will normally be buried deeper. During large-scale ISV, soil-to-off-gas DFs for less volatile elements such as $\mathrm{Pu}, \mathrm{Sr}$, and $U$ are expected to be $1 \times 10^{3}$ to $1 \times$ $10^{4}$. More volatile elements such as Cs and Sb should have DFs of $1 \times 10^{2}$ or greater. These values will vary depending on waste burial depth, the presence of a cold cap, and the presence of gas generators within the melt zone. Element retention increases with burial depth, decreases with the presence of gas generators, and increases slightly with the presence of a protective cold cap.

A depth transmitter system has been tested and shows promise for economical and reliable monitoring of the vitrification zone depth. The system con- 
sists of a series of sensors attached along the length of an electrode and connected to a transmitter device at the bottom of the electrode. During the ISV operation, the molten glass is detected by the sensors and the information is transmitted to an above-ground receiver, giving an operator the melt depth information. The system is still in the developmental stage and must be verified.

Graphite electrodes are economical and have performed well during engineering- and pilot-scale testing; however, oxidation of the graphite does occur directly above the molten zone surface. The oxidation rate, while acceptably low for the smaller-scale systems, is not acceptable for a large-scale operation, which may require over 400 hours to complete. Silicon carbide was identified as a coating which could potentially eliminate electrode oxidation. During laboratory tests the coating performed very well on graphite at $1000^{\circ} \mathrm{C}$, and is planned to be tested during actual ISV operations.

Migration of simulated radioactive elements outside of the vitrification zone was not detected during three of the four PSFTs. Even the partially fused soil at the boundary of the molten area contained minimally detectable amounts of these elements. Migration will be further evaluated during the post-run analysis of the PSRT, where the increased detection sensitivity possible with radioactive contaminants will determine whether any element migration has occurred. Contaminants were uniformly distributed throughout the vitrified soil blocks in all pilot-scale tests, indicating extensive convective mixing during operation.

The vitrified soil from each of the tests has remained a solid, nearly crack-free block with an interior of nonporous glass similar to natural obsidian. Leach testing has shown that the ISV process generates a highly durable waste form, comparable to Pyrex and granite. The weathering rate is predicted to be only $1 \mathrm{~mm}$ in 10,000 years, based on geologic data from the weathering of obsidian, which is chemically similar to the ISV glass. 


\section{PROCESS PARAMETERS}




\section{PROCESS PARAMETERS}

Parameters which may affect ISV operation are addressed in this section. These parameters include soil properties, site geometry, and waste inclusions.

\section{INFLUENCE OF SOIL PROPERTIES}

Hanford soil which includes simulated and actual radionuclides has been successfully vitrified in place. Since the properties of soils will vary among the different waste sites where ISV could be applied, it is necessary to investigate potential process limitations due to soil characteristics. The soil properties most relevant to the ISV process are:

- chemical composition

- thermal conductivity

- fusion temperature

- specific heat

- electrical conductivity

- viscosity

- bulk density.

Fusion temperature, specific heat, electrical conductivity, and viscosity are dependent on soil composition. Thermal conductivity is dependent on both composition and soil morphology. The bulk density of the soil depends on its morphology. The density of the vitrified material is relatively insensitive to compositional variations.

Soil property data were obtained from literature surveys and laboratory characterization tests on soil from Barnwell, South Carolina; Hanford, Washington; Idaho National Engineering Laboratory (INEL), Idaho; Los Al amos National Laboratory (LANL), New Mexico; Maxey Flats, Kentucky; the Nevada Test Site (NTS), Nevada; Oak Ridge National Laboratory (ORNL), Tennessee; Sheffield, Illinois; and West Valley Nuclear Services Co., Inc., West Valley, New York.

A description is given below of the effects of changes in the soil properties listed above. 


\section{Chemical Composition}

The chemical compositions of soils from potential ISV sites were determined using induction-coupled plasma (ICP) spectroscopy. These results are shown in Table 21. All soils were composed primarily of $\mathrm{SiO}_{2}$ and $\mathrm{Al}_{2} \mathrm{O}_{3}$. Higher levels of these oxides tend to increase the chemical durability of the resulting glass, but have the negative effects of increasing viscosity and decreasing electrical conductivity. All of the soils also contained significant amounts of $\mathrm{Na}_{2} \mathrm{O}$ and $\mathrm{K}_{2} \mathrm{O}$, which act as the primary charge carriers in molten soil. A number also contained significant amounts of $\mathrm{CaO}$ and $\mathrm{MgO}$, oxides which tend to suppress the electrical conductivities of molten silicates (Stanek 1977).

Thermal Conductivity

Variations in the thermal conductivities of soil can influence the maximum temperature that can be reached by the molten zone and the rate at which heat energy can be transferred to the unmelted soil. A lower thermal conductivity will result in a higher molten zone temperature for a given rate of melt propagation. However, thermal conductivity variations within the molten zone will not significantly affect the temperature profile since convective mixing produces a relatively flat temperature profile. Variations in thermal conductivity mainly affect the boundary layer between the soil fusion zone and soil at ambient temperature.

Thermal conductivities of soils at ambient temperature are very low, ranging from 0.08 to $0.16 \mathrm{~W} / \mathrm{m}^{\circ} \mathrm{K}$ (Table 22). These low conductivities result from the small particle sizes present in the majority of the soils, which increase grain-to-grain contact resistance. Conduction by the gas phase is low because of the extremely small effective pore size of these materials. The small pore size eliminates convective heat transfer and effectively reduces conduction within pores (Parrott and Stuckes 1975). Soils which contained rocks and pebbles, such as certain samples from Hanford and NTS, had higher conductivities. This was expected, as conduction through solid materials is much higher than through porous, fine-grained soil. 
TABLE 21. Oxide Composition of Soils

\begin{tabular}{|c|c|c|c|c|c|c|c|c|c|c|c|c|}
\hline & & & & & & & Wt\% & & & & & \\
\hline Soil Location & Soil Type & Depth, cm & $\underline{\mathrm{Na}}_{2} \mathrm{O}$ & $\underline{K}_{2} 0$ & $\mathrm{Fe}_{2} \mathrm{O}_{3}$ & $\mathrm{Al}_{2} \mathrm{O}_{3}$ & $\mathrm{SiO}_{2}$ & $\mathrm{CaO}$ & $\mathrm{Mg0}$ & $\mathrm{TiO}_{2}$ & $2 \mathrm{rO}_{2}$ & $\mathrm{P}_{2} \mathrm{O}_{5}$ \\
\hline Barnwell, SC & Fuquay & $\begin{array}{c}0-15 \\
15-76 \\
76-107 \\
396-427\end{array}$ & $\begin{array}{l}0.23 \\
0.23 \\
0.25 \\
0.26\end{array}$ & $\begin{array}{l}0.19 \\
0.19 \\
0.24 \\
0.18\end{array}$ & $\begin{array}{l}0.68 \\
0.57 \\
5.04 \\
4.69\end{array}$ & $\begin{array}{l}2.10 \\
1.65 \\
16.3 \\
17.0\end{array}$ & $\begin{array}{l}96.2 \\
96.8 \\
77.1 \\
76.8\end{array}$ & $\begin{array}{l}0.08 \\
0.03 \\
0.02 \\
0.02\end{array}$ & $\begin{array}{l}0.08 \\
0.09 \\
0.16 \\
0.13\end{array}$ & $\begin{array}{l}0.42 \\
0.45 \\
0.71 \\
0.68\end{array}$ & $\begin{array}{l}0.03 \\
0.03 \\
0.03 \\
0.03\end{array}$ & $\begin{array}{l}-- \\
-- \\
0.14 \\
0.17\end{array}$ \\
\hline Hanford, WA & $\begin{array}{l}(\mathrm{a}) \\
\text { PSFT } 1(\mathrm{~b}) \\
\text { PSFT } 4(b)\end{array}$ & $\begin{array}{c}\text { Surface } \\
\text { N/D } \\
\text { N/D }\end{array}$ & $\begin{array}{l}3.14 \\
2.87 \\
2.69\end{array}$ & $\begin{array}{l}1.57 \\
1.43 \\
1.56\end{array}$ & $\begin{array}{c}11.5 \\
8.16 \\
9.86\end{array}$ & $\begin{array}{l}12.5 \\
13.6 \\
13.9\end{array}$ & $\begin{array}{l}58.0 \\
64.4 \\
60.1\end{array}$ & $\begin{array}{l}6.81 \\
5.37 \\
6.41\end{array}$ & $\begin{array}{l}3.40 \\
2.51 \\
3.02\end{array}$ & $\begin{array}{l}2.06 \\
1.39 \\
1.60\end{array}$ & $\begin{array}{l}0.03 \\
-- \\
--\end{array}$ & $\begin{array}{c}0.47 \\
-- \\
0.52\end{array}$ \\
\hline LANL, NM & Carjo & $\begin{array}{r}0-5 \\
5-15 \\
15-25\end{array}$ & $\begin{array}{l}2.54 \\
2.79 \\
2.86\end{array}$ & $\begin{array}{l}2.68 \\
2.80 \\
2.97\end{array}$ & $\begin{array}{l}2.67 \\
2.93 \\
3.18\end{array}$ & $\begin{array}{l}12.2 \\
12.4 \\
12.5\end{array}$ & $\begin{array}{l}77.5 \\
76.8 \\
76.2\end{array}$ & $\begin{array}{l}0.98 \\
0.93 \\
0.91\end{array}$ & $\begin{array}{l}0.62 \\
0.59 \\
0.59\end{array}$ & $\begin{array}{l}0.60 \\
0.62 \\
0.65\end{array}$ & $\begin{array}{l}0.04 \\
0.06 \\
0.13\end{array}$ & $\begin{array}{c}0.13 \\
0.11 \\
--\end{array}$ \\
\hline & Puye & $\begin{array}{r}0-10 \\
10-41\end{array}$ & $\begin{array}{l}3.85 \\
3.88\end{array}$ & $\begin{array}{l}2.96 \\
3.81\end{array}$ & $\begin{array}{l}2.13 \\
2.63\end{array}$ & $\begin{array}{l}12.6 \\
13.3\end{array}$ & $\begin{array}{l}77.2 \\
75.0\end{array}$ & $\begin{array}{l}0.45 \\
0.57\end{array}$ & $\begin{array}{l}0.31 \\
0.42\end{array}$ & $\begin{array}{l}0.27 \\
0.36\end{array}$ & $\begin{array}{l}0.05 \\
0.05\end{array}$ & $\begin{array}{c}0.16 \\
--\end{array}$ \\
\hline & Tuff & $N / D$ & 4.44 & 4.44 & 1.23 & 12.3 & 76.9 & 0.46 & -- & 0.09 & 0.07 & -- \\
\hline Maxey Flats, KY & Tilsit & $\begin{array}{c}0-18 \\
18-61 \\
61-142 \\
142\end{array}$ & $\begin{array}{l}0.45 \\
0.47 \\
0.39 \\
0.44\end{array}$ & $\begin{array}{l}0.89 \\
1.10 \\
0.89 \\
1.61\end{array}$ & $\begin{array}{l}2.17 \\
3.66 \\
2.63 \\
4.07\end{array}$ & $\begin{array}{c}5.58 \\
7.85 \\
7.22 \\
10.5\end{array}$ & $\begin{array}{l}89.0 \\
84.9 \\
87.0 \\
81.2\end{array}$ & $\begin{array}{l}0.10 \\
0.07 \\
0.04 \\
0.03\end{array}$ & $\begin{array}{l}0.23 \\
0.40 \\
0.41 \\
0.69\end{array}$ & $\begin{array}{l}1.37 \\
1.33 \\
1.32 \\
1.29\end{array}$ & $\begin{array}{l}0.08 \\
0.07 \\
0.06 \\
0.06\end{array}$ & $\begin{array}{l}0.12 \\
0.10 \\
0.09 \\
0.20\end{array}$ \\
\hline NTS, NV & Beatty & $\begin{array}{c}0-10 \\
10-36 \\
36-53 \\
53-122\end{array}$ & $\begin{array}{l}3.38 \\
3.39 \\
3.27 \\
4.10\end{array}$ & $\begin{array}{l}3.66 \\
4.03 \\
3.86 \\
3.98\end{array}$ & $\begin{array}{l}2.87 \\
3.01 \\
2.87 \\
2.73\end{array}$ & $\begin{array}{l}13.8 \\
13.6 \\
13.6 \\
13.2\end{array}$ & $\begin{array}{l}70.7 \\
69.9 \\
71.0 \\
73.5\end{array}$ & $\begin{array}{l}3.19 \\
3.77 \\
3.24 \\
1.37\end{array}$ & $\begin{array}{l}1.54 \\
1.44 \\
1.39 \\
0.61\end{array}$ & $\begin{array}{l}0.55 \\
0.56 \\
0.53 \\
0.50\end{array}$ & $\begin{array}{l}0.03 \\
0.04 \\
0.04 \\
0.05\end{array}$ & $\begin{array}{c}0.26 \\
0.20 \\
0.20 \\
--\end{array}$ \\
\hline ORNL, TN & (a) & Surface & 0.32 & 2.55 & 11.0 & 17.3 & 66.5 & 0.11 & 0.97 & 0.97 & 0.05 & 0.26 \\
\hline Sheffield, IL & Fayette & $\begin{array}{ll} & 0-18 \\
& 25-102 \\
C & \text { Horizon }\end{array}$ & $\begin{array}{l}1.61 \\
1.49 \\
1.71\end{array}$ & $\begin{array}{l}2.01 \\
1.99 \\
1.90\end{array}$ & $\begin{array}{l}2.55 \\
4.44 \\
4.48\end{array}$ & $\begin{array}{l}9.09 \\
12.0 \\
11.3\end{array}$ & $\begin{array}{l}82.4 \\
77.3 \\
77.7\end{array}$ & $\begin{array}{l}0.83 \\
0.62 \\
0.89\end{array}$ & $\begin{array}{l}0.64 \\
0.99 \\
0.98\end{array}$ & $\begin{array}{l}0.82 \\
0.78 \\
0.72\end{array}$ & $\begin{array}{l}0.05 \\
0.06 \\
0.04\end{array}$ & $\begin{array}{l}-- \\
0.20 \\
0.21\end{array}$ \\
\hline West Valley, NY & Churchville & $\begin{array}{c}0-10 \\
10-30 \\
30-97 \\
97-157 \\
>157\end{array}$ & $\begin{array}{l}1.10 \\
1.00 \\
1.08 \\
1.14 \\
1.11\end{array}$ & $\begin{array}{l}2.08 \\
2.11 \\
3.08 \\
3.13 \\
3.05\end{array}$ & $\begin{array}{l}1.59 \\
5.30 \\
6.01 \\
6.03 \\
6.14\end{array}$ & $\begin{array}{l}12.8 \\
12.9 \\
14.5 \\
15.3 \\
15.7\end{array}$ & $\begin{array}{l}79.4 \\
75.9 \\
66.9 \\
65.0 \\
65.0\end{array}$ & $\begin{array}{l}0.53 \\
0.39 \\
4.60 \\
5.50 \\
5.10\end{array}$ & $\begin{array}{l}0.98 \\
1.08 \\
2.70 \\
2.69 \\
2.72\end{array}$ & $\begin{array}{l}1.22 \\
1.10 \\
0.89 \\
0.90 \\
0.92\end{array}$ & $\begin{array}{l}0.05 \\
0.06 \\
0.04 \\
0.06 \\
0.03\end{array}$ & $\begin{array}{l}0.24 \\
0.15 \\
0.28 \\
0.28 \\
0.25\end{array}$ \\
\hline
\end{tabular}


TABLE 22. Thermal Conductivities of Soils at Ambient Temperature

\begin{tabular}{|c|c|c|c|c|}
\hline Soil Location & Soil Type & Depth, cm & $\begin{array}{c}\text { Thermal } \\
\text { Conductivity, } \\
W / \mathrm{m}^{\circ} \mathrm{K}\end{array}$ & $\begin{array}{l}\text { Standard } \\
\text { Deviation }\end{array}$ \\
\hline \multirow[t]{2}{*}{ Barnwell, SC } & Fuquay & $76-107$ & 0.147 & \\
\hline & & $396-427$ & 0.154 & \\
\hline \multirow{6}{*}{$\begin{array}{l}\text { Hanford, WA } \\
\text { LANL, NM }\end{array}$} & (a) & Surface & 0.131 & \\
\hline & Carjo & $5-15$ & 0.121 & \\
\hline & & $15-25$ & 0.096 (b) & 0.005 \\
\hline & Puye & $0-10$ & $0.118^{(b)}$ & 0.016 \\
\hline & & $10-41$ & 0.097 & \\
\hline & Tuff & (c) & (c) & \\
\hline \multirow[t]{4}{*}{ Maxey Flats, KY } & Tilsit & $0-18$ & 0.107 & \\
\hline & & $18-61$ & 0.161 & \\
\hline & & $61-142$ & 0.157 & \\
\hline & & $>142$ & 0.083 & \\
\hline \multirow[t]{4}{*}{ NTS, NV } & Beatty & $0-10$ & 0.112 & \\
\hline & & $10-36$ & 0.121 & \\
\hline & & $36-53$ & $0.096^{(b)}$ & 0.008 \\
\hline & & $53-122$ & 0.138 & \\
\hline ORNL, TN & (a) & Surface & 0.104 & \\
\hline Sheffield, IL & Fayette & C Horizon & 0.095 & \\
\hline \multirow[t]{4}{*}{ West Valley, NY } & Churchville & $0-10$ & 0.116 & \\
\hline & & $30-97$ & 0.093 & \\
\hline & & $97-157$ & $0.117^{(b)}$ & 0.012 \\
\hline & & $>157$ & 0.100 & \\
\hline
\end{tabular}

\footnotetext{
(a) Soil type not identified.

(b) Average value and standard deviation calculated from multiple replicate measurements.

(c) Not determined.
} 
Measured and anticipated values for the thermal conductivities of Hanford soil are shown in Figure 36 . The conductivities of all soils that were measured (NTS, Maxey Flats, Hanford, and West Valley) approximately doubled when heated from 200 to $800^{\circ} \mathrm{C}$. This increase was due primarily to an increase in conductivity of the porous phase. The initial increase in conductivity above $800^{\circ} \mathrm{C}$ is caused by a decrease in grain-to-grain contact resistance due to the onset of soil fusion. Measurements could not be made at temperatures above $1000^{\circ} \mathrm{C}$. At these temperatures, however, increasing conductivity with increasing temperatures is caused by radiative conduction (Bates 1975). This contribution to conductivity increases with temperature ${ }^{3}\left(T^{3}\right)$. The values above $1000^{\circ} \mathrm{C}$ were calculated using this $\mathrm{T}^{3}$ relationship and the conductivity of a portion of fused Hanford soil at $1000^{\circ} \mathrm{C}$. Because of the uncertainties

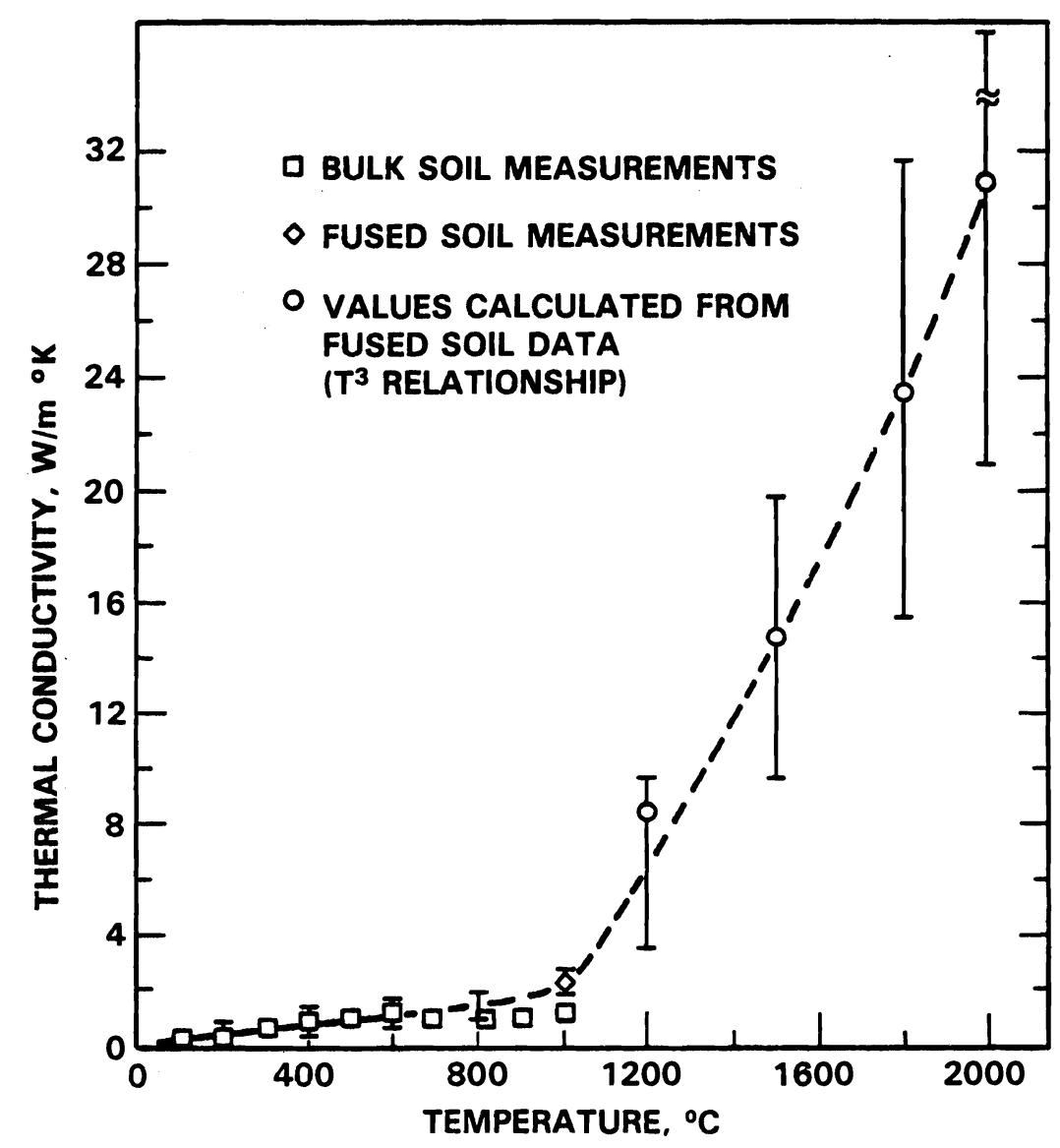

FIGURE 36. Thermal Conductivities of Hanford Soil 
inherent in this calculation, the error bars on the curve are fairly large. Similar behavior is expected from the remaining soil samples.

Fusion Temperature

The temperatures at which soils initially fused were determined from thermal conductivity measurements. These data were available for the Maxey Flats Tilsit, the NTS Beatty, and the West Valley Churchville soils. The initial fusion point was assumed to be the temperature at which the conductivity began to increase at a much higher rate than it had at lower temperatures. The temperature at which the the soil would completely fuse was assumed to be $\sim 200^{\circ} \mathrm{C}$ higher than this initial fusion temperature. Anticipated fusion temperatures of the other soils were calculated by comparing their $\mathrm{SiO}_{2}+\mathrm{Al}_{2} \mathrm{O}_{3}, \mathrm{~K}_{2} \mathrm{O}+\mathrm{Na}_{2} \mathrm{O}$, and $\mathrm{CaO}+\mathrm{MgO}$ levels with those of the three previously measured soils. The fusion temperatures of the soils are listed in Table 23. Fusion temperatures for all soils tested ranged from 1100 to $1400^{\circ} \mathrm{C}$, too low to impose any process limit. Glass temperatures observed during pilot-scale tests have exceeded $1700^{\circ} \mathrm{C}$, well above the fusion point.

Specific Heat

Knowing the specific heat $(C p)$ of a soil is important in determining the power required to melt it. A high specific heat is undesirable because it increases the energy needed to heat the soil to vitrification and also slows the vitrification rate.

The $C p$ values of the soils listed in Table 24 were measured at temperatures from 150 to $550^{\circ} \mathrm{C}$ using differential scanning calorimetry. Most soils had $C p$ values in the range of 0.17 to $0.22 \mathrm{cal} / \mathrm{g}^{\circ} \mathrm{C}$. Soil from Maxey $\mathrm{Flats}$ was higher, at 0.24 to $0.27 \mathrm{cal} / \mathrm{g}^{\circ} \mathrm{C}$. These values are consistent with those found for other ceramic materials (Norton 1968). The variation in Cp among the soils is not considered an ISV process limit.

At higher temperatures $\left(1500\right.$ to $2000^{\circ} \mathrm{C}$ ), a $\mathrm{Cp}$ value of 0.25 to $0.28 \mathrm{cal} / \mathrm{g}^{\circ} \mathrm{C}$ will be reached by most soils. The measured and anticipated $\mathrm{Cp}$ values of a Hanford soil in the temperature range of 25 to $2000^{\circ} \mathrm{C}$ are shown in Figure 37. Since measurements could not be made at temperatures over $600^{\circ} \mathrm{C}$ due to equipment limitations, it was assumed that above $400^{\circ} \mathrm{C}$, the $\mathrm{Cp}$ would 
TABLE 23. Fusion Temperatures of Soils

Fusion

\begin{tabular}{|c|c|c|}
\hline Soil Location & Soil Type & Temperature, $^{\circ}$ \\
\hline Barnwell, SC & Fuquay & $1400^{(a)}$ \\
\hline Hanford, WA & (b) & $1100(a)$ \\
\hline INEL, ID & (b) & $1100^{(a)}$ \\
\hline \multirow{3}{*}{ LANL, NM } & Puye & $1100(a)$ \\
\hline & Carjo & $1200^{(a)}$ \\
\hline & Tuff & $1300(a)$ \\
\hline Maxey Flats, KY & Tilsit & 1300 \\
\hline \multirow[t]{2}{*}{ NTS, NV } & Beatty & $1100-1200$ \\
\hline & Tuff & $1300^{(a)}$ \\
\hline ORNL, TN & (b) & $1100(a)$ \\
\hline Sheffield, IL & Fayette & $1100^{(a)}$ \\
\hline West Valley, NY & Churchville & 1100 \\
\hline
\end{tabular}

increase linearly with temperature, and at higher temperatures should exceed $5.96 \mathrm{cal} / \mathrm{g}$ atom. ${ }^{\circ} \mathrm{C}$ (Kingery 1960 ). This is equal to $0.26 \mathrm{cal} / \mathrm{g}^{\circ} \mathrm{C}$ for Hanford soil.

\section{Electrical Conductivity}

Variations in the electrical conductivities of molten soils will impact the operating voltage of an ISV system. Low-conductance soils may limit the electrode separation attainable if the soil voltage required during startup exceeds the available supply voltage. The reference full-scale ISV system has a maximum supply voltage of $4160 \mathrm{~V}$, a standard but arbitrarily selected limit.

The electrical conductivities of three molten soils were measured using a two probe method. The values obtained are shown in Figure 38. At high temperatures the Hanford and NTS tuff materials had very similar conductivities. The Maxey $\mathrm{Flats}$ Tilsit soil had a conductivity approximately an order of magnitude lower. This is primarily due to its lower alkali oxide $\left(\mathrm{Na}_{2} \mathrm{O}+\mathrm{K}_{2} \mathrm{O}\right)$ content. 
TABLE 24. Specific Heats of Various Soil Types, cal $/ \mathrm{g}^{\circ} \mathrm{C}$

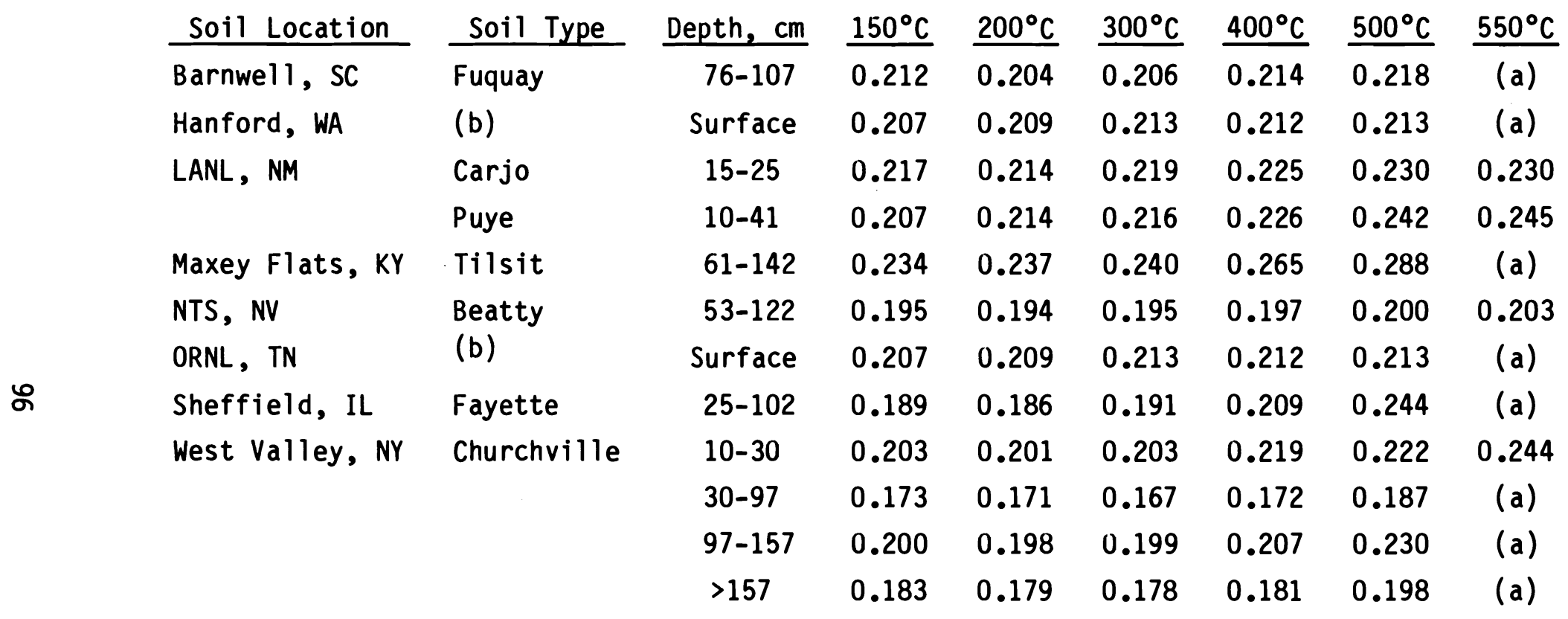

(a) Not determined.

(b) Soil type not identified. 


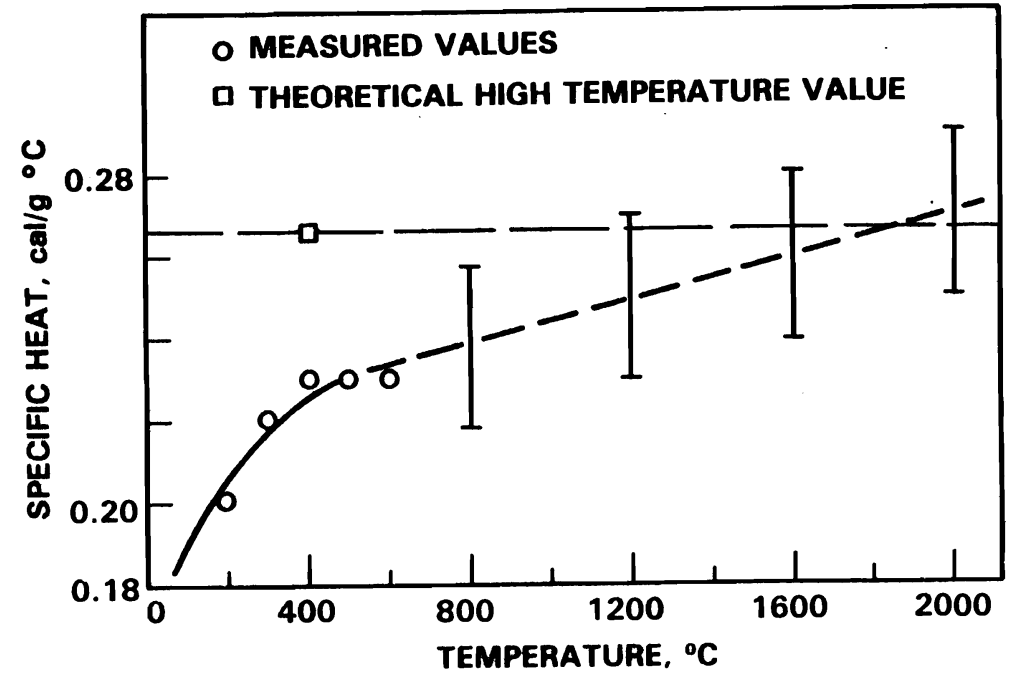

FIGURE 37. Specific Heat of Hanford Soil 28-2 at Various Temperatures

Before the capability to measure high-temperature $\left(>1600^{\circ} \mathrm{C}\right)$ electrical conductivities existed, five soils were chosen for measurement using the two probe method in a lower temperature system. Due to the high melting temperatures of the soils, $10 \mathrm{wt} \% \mathrm{Na}_{2} \mathrm{O}$ was added to each sample to reduce the melting time and temperature. The calculated conductivities, corrected for the $\mathrm{Na}_{2} \mathrm{O}$ addition, are also shown in Figure 38. It can be seen that, with the exception of the Maxey Flats Tilsit, all of the measured and calculated electrical conductivities fall within a narrow range. The conductivities of other soils will depend, of course, on their compositions. Alkali oxides $\left(\mathrm{Na}_{2} \mathrm{O}, \mathrm{K}_{2} \mathrm{O}, \mathrm{Li}_{2} \mathrm{O}\right)$ increase conductivity, while the alkaline earths ( $\mathrm{CaO}, \mathrm{MgO})$ tend to decrease conductivity (Stanek 1977). Soil with higher amounts of refractory oxides $\left(\mathrm{SiO}_{2}, \mathrm{Al}_{2} \mathrm{O}_{3}\right)$ has a higher viscosity and therefore a lower electrical conductivity due to decreased conduction ion mobility. Based on comparison of soil compositions, all other soils in this study are expected to fall within the range shown in Figure 38 . 


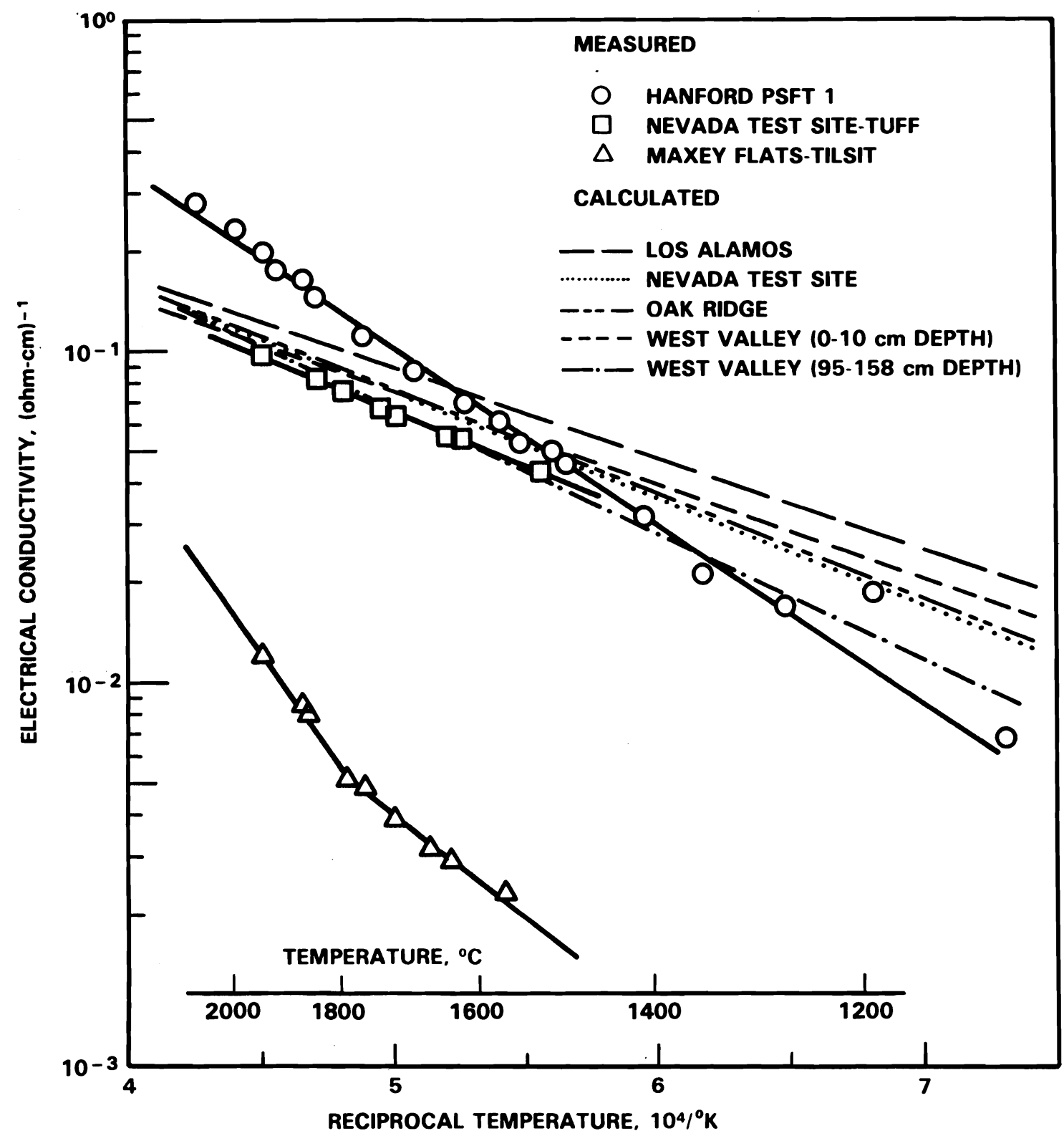

FIGURE 38. Electrical Conductivities of Molten Soils

The variation in electrical conductivity among the soils tested, even including that of the Tilsit, does not limit the application of the ISV process. Such variation can easily be compensated for by modification of the startup technique. Voltage during startup is dependent on the graphite-frit startup mixture, not on soil conductivity. Once the graphite startup material has burned, the voltage reaches its maximum, which is dependent on the crosssectional area and conductivity of the molten path. Beyond this point, voltage 
decreases as the molten zone expands. If the maximum startup voltage exceeds the supply voltage because the soil conductivity is low, the startup voltage can be lowered by increasing the width and depth of the graphite-frit path and by choosing a frit which is highly conductive. These actions will increase the cross-sectional area of the molten path and the glass conductivity in that path, thus decreasing the maximum voltage during the startup period.

Figure 39 shows the anticipated electrical conductivity of Hanford soil during the heating portion of the process. At temperatures below $200^{\circ} \mathrm{C}$ the soil will not have fused at all and its conductivity will be essentially zero $\left(10^{-15}\right.$ or $\left.10^{-16} \mathrm{ohm}-\mathrm{cm}\right)$. Once the soil begins to fuse it will start to conduct, and this conductivity will increase rapidly until the soil is completely molten. The dashed line in Figure 39 represents a possible behavior of the soil in this region. Similar behavior is expected of the other soils studied in this work. At temperatures above 1200 to $1300^{\circ} \mathrm{C}$ the soil should be completely melted. At these temperatures the conductivity will be the same as that of the vitrified soils whose measurements are shown in Figure 38 .

\section{$\underline{\text { Viscosity }}$}

A molten soil's viscosity will affect 1 ) the time required for melting at a particular temperature and 2) the temperature gradients within the molten portion of the process. A more fluid medium will generally melt more quickly and will have smaller temperature gradients due to greater convective mixing in the melt.

The viscosities of four molten soils were measured using a rotating spindle technique. One sample each was obtained from PSFTs 1 and 4 . The other two soils were portions of Maxey Flats Tilsit and NTS tuff. Their viscosities are shown in Figure 40 .

The viscosities of the tuff and Tilsit are similar and about 2 orders of magnitude higher than those of the Hanford samples. This is due to the higher $\mathrm{SiO}_{2}+\mathrm{Al}_{2} \mathrm{O}_{3}$ and lower $\mathrm{Na}_{2} \mathrm{O}+\mathrm{K}_{2} \mathrm{O}$ content of the tuff and Tilsit. The higher $\mathrm{Fe}_{2} \mathrm{O}_{3}$ content in the Hanford material also contributed to its lower viscosity. Based on the compositions of the other soils in this study, it is anticipated that all will have viscosities within the range found in Figure 40 . 


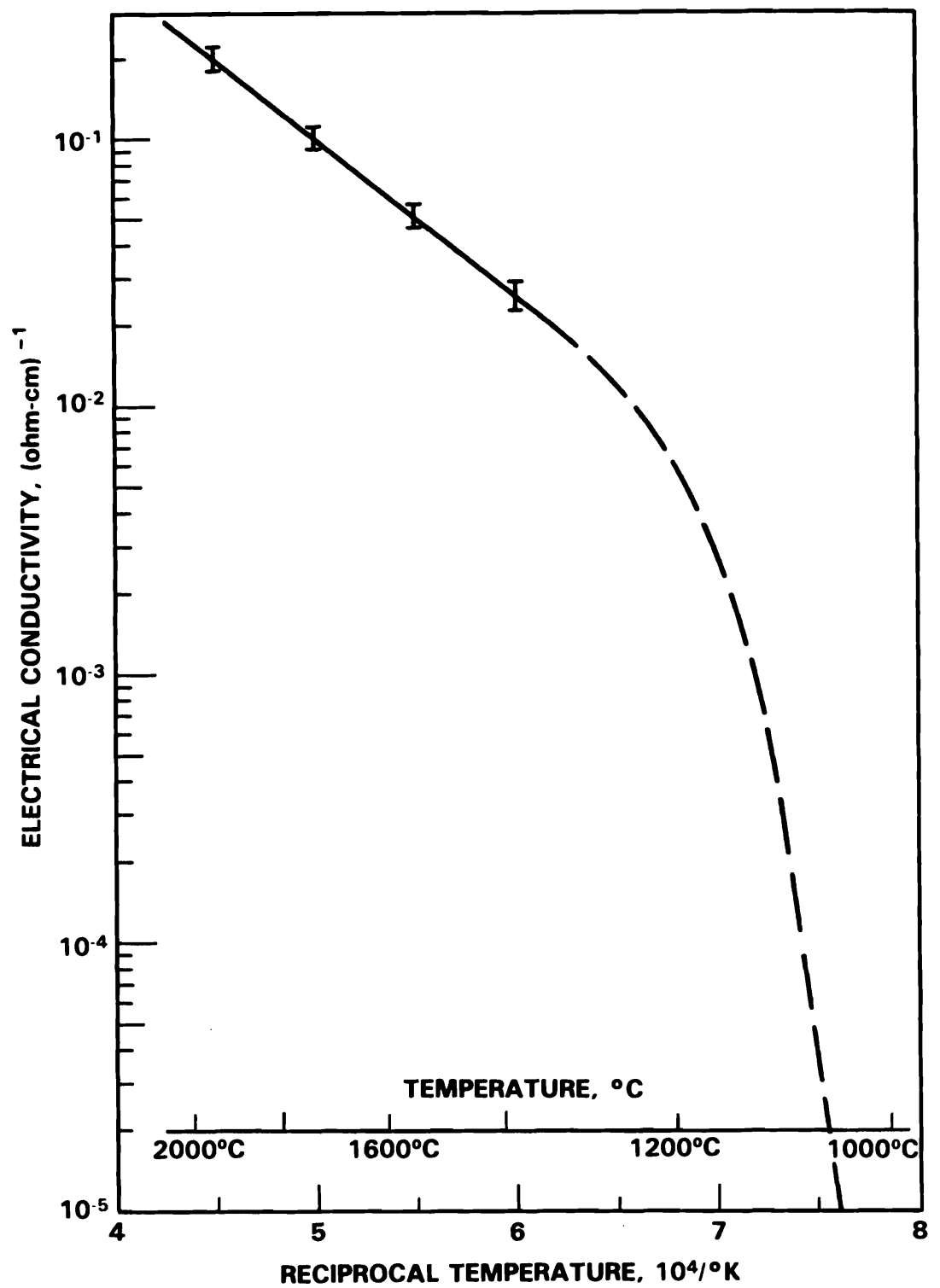

FIGURE 39. Electrical Conductivities at $40 \mathrm{~Hz}$ of Vitrified Hanford Soil from PSFT 4

While complete vitrification of materials such as tuff and Tilsit may require somewhat higher melt temperatures and longer melt times, melting can still be accomplished.

Density

The decrease in soil volume due to vitrification is determined by the soil density values before and after melting. The bulk densities of a number of unmelted soils are shown in Table 25. These densities are most strongly 


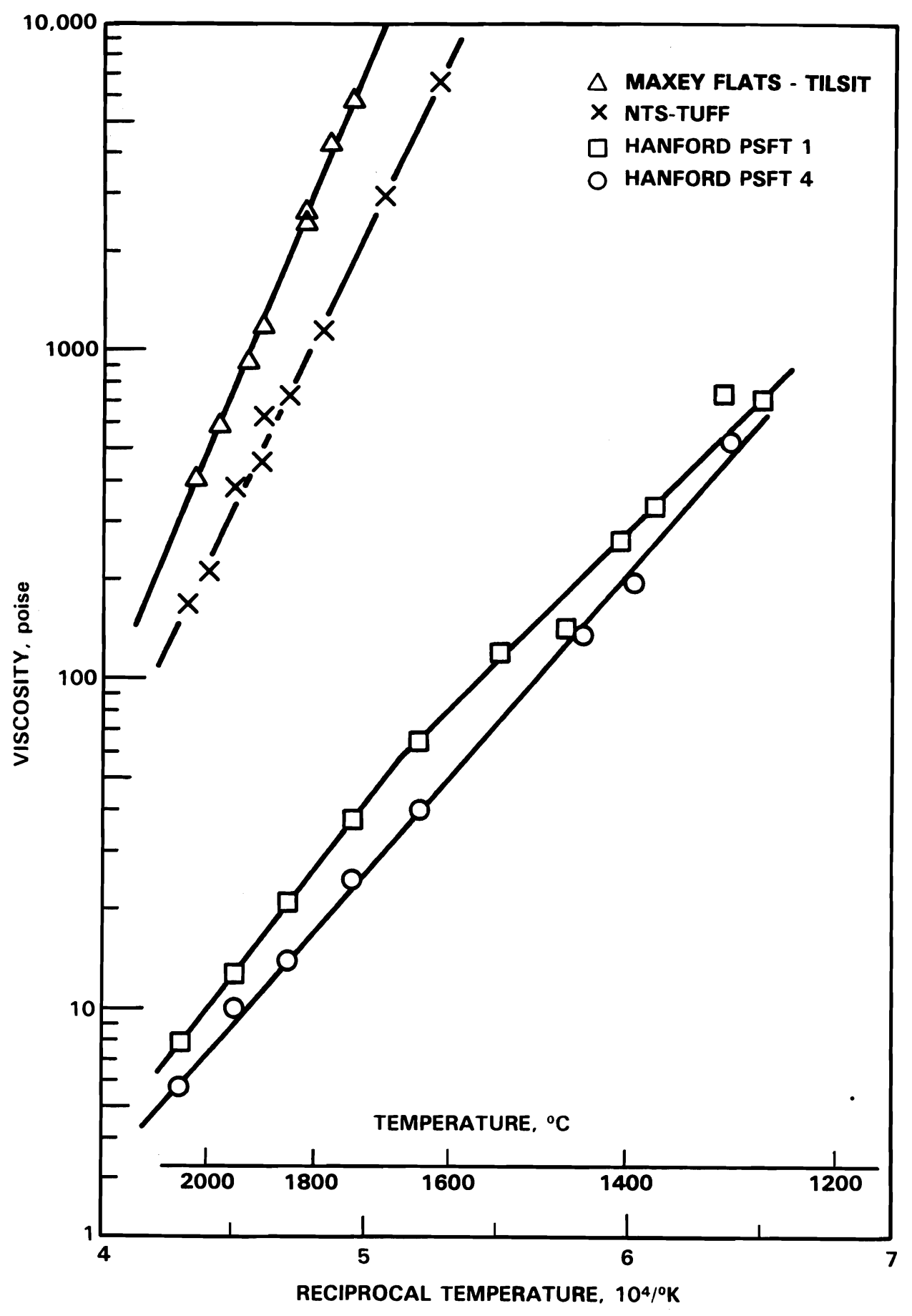

FIGURE 40. Viscosities of Molten Soils

affected by soil morphology and particle size, as well as the degree to which the site's soil has been disturbed. Also shown are the room temperature densities of three melted soils. Although the initial soil densities vary significantly, the final densities of the melted materials are very similar. 
IABLE 25. Bulk Density of Unmelted Soil and Density of Vitrified Soil

\begin{tabular}{|c|c|c|c|c|}
\hline Soil Location & Soil Type & Depth, cm & $\begin{array}{c}\text { Bulk } \\
\text { Densiţy, } \\
\mathrm{g} / \mathrm{cm}^{3} \\
\end{array}$ & $\begin{array}{c}\text { Vitrified } \\
\text { Density, } \\
\mathrm{g} / \mathrm{cm}^{3} \\
\end{array}$ \\
\hline \multirow[t]{2}{*}{ Barnwell, SC } & Fuquay & $76-107$ & 0.95 & (a) \\
\hline & & $396-427$ & 0.97 & (a) \\
\hline Hanford, WA & (b) & Surface & 1.65 & 2.43 \\
\hline \multirow[t]{5}{*}{ LANL, NM } & Carjo & $5-15$ & 1.07 & (a) \\
\hline & & $15-25$ & 1.07 & (a) \\
\hline & Puye & $0-10$ & 1.10 & (a) \\
\hline & & $10-41$ & 0.94 & (a) \\
\hline & Tuff & (a) & 1.70 & 2.33 \\
\hline \multirow[t]{4}{*}{ Maxey Flats, KY } & Tilsit & $0-18$ & 0.94 & (a) \\
\hline & & $18-61$ & 1.04 & (a) \\
\hline & & $61-142$ & 1.12 & 2.30 \\
\hline & & $>142$ & 1.08 & (a) \\
\hline \multirow[t]{4}{*}{ NTS, NV } & Beatty & $0-10$ & 1.20 & (a) \\
\hline & & $10-36$ & 1.20 & (a) \\
\hline & & $36-53$ & 1.18 & (a) \\
\hline & & $53-122$ & 1.41 & (a) \\
\hline ORNL, TN & (b) & Surface & 0.93 & (a) \\
\hline Sheffield, IL & Fayette & C Horizon & 0.91 & (a) \\
\hline \multirow[t]{4}{*}{ West Valley, NY } & Churchville & $0-10$ & 0.71 & (a) \\
\hline & & $30-97$ & 1.00 & (a) \\
\hline & & $97-157$ & 1.12 & (a) \\
\hline & & $>157$ & 1.12 & (a) \\
\hline
\end{tabular}

(a) Not determined.

(b) Soil type not identified.

Figure 41 shows the way in which a typical soil's density might change during processing. Hanford soil is used as an example. During heating, no density change will be seen until the soil begins to fuse at 700 to $900^{\circ} \mathrm{C}$. The density will then increase until the soil is completely fused at $\sim 1400^{\circ} \mathrm{C}$. A decrease in density will occur at higher temperatures due to the thermal 


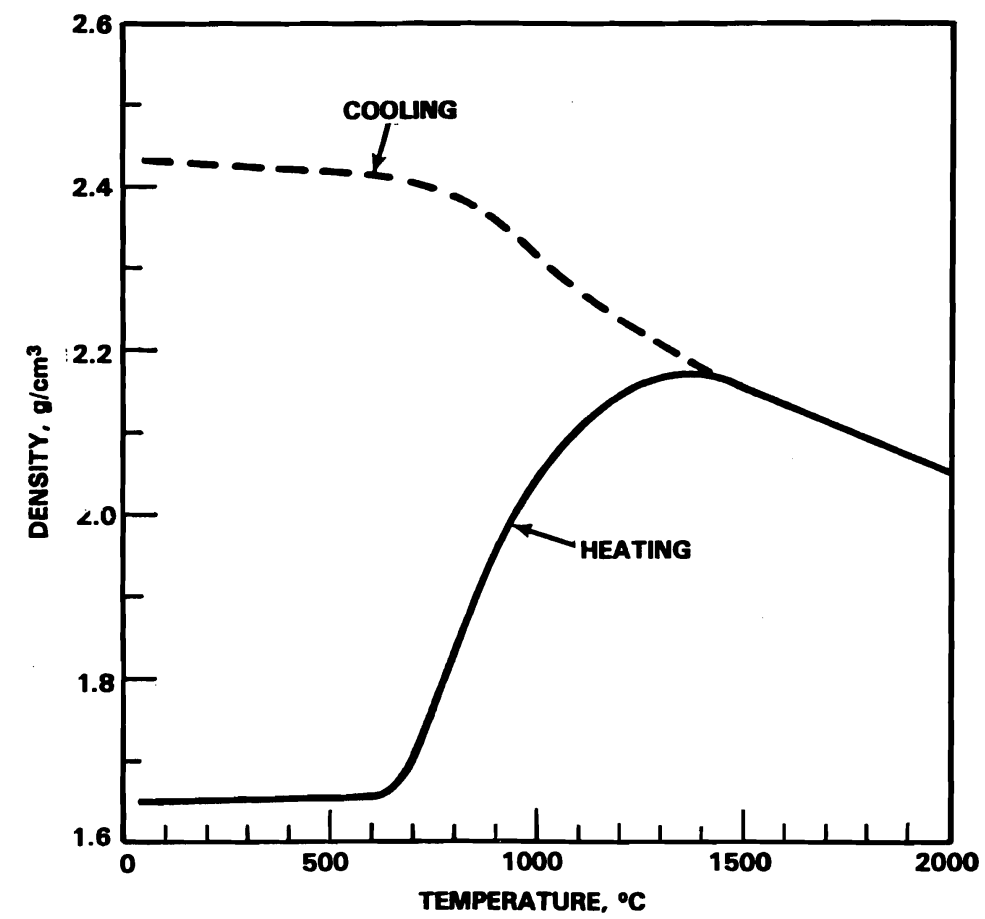

FIGURE 41. Change in Hanford Soil Density During Processing

expansion of the material. During cooling, the density will increase as the molten soil contracts and then solidifies.

It is expected that all vitrified soils in this study will exhibit densities in the range of 2.2 to $2.5 \mathrm{~g} / \mathrm{cm}^{3}$, regardless of initial density. Those sites with lower initial densities would require more backfill material for recontouring the land subsequent to the ISV process.

\section{PERFORMANCE PREDICTIONS FOR DIFFERENT SITE GEOMETRIES}

Physical geometries of potential ISV waste sites range from wide, shallow zones (e.g., ponds) to narrow, deep zones (e.g., bore shafts). The zone which an ISV process can vitrify in one operation has certain width and depth limits imposed by maximum voltage, maximum power, and soil properties. A mathematical model has been developed for predicting ISV process performance for different burial site geometries and for assisting with process scale-up to a large commercial system. It is intended to reduce and in many cases eliminate the need 
for expensive and time consuming field tests. The modeling simulation can reveal the effects that changes in soil properties, power system design, and waste site geometry will have on process performance. Information such as energy consumption, mass vitrified, operating time, melt depth, and melt width are readily available from the model.

\section{Mathematical Model}

The ISV mathematical model has been developed using a desktop computer equipped with a BASIC language operating system. During operation of the program, the ISV melt zone depth grows downward in equally spaced increments. At each step, an energy balance is performed using power input, heat losses, and soil properties to determine the mass vitrified and time required for the vitrification. Power input is dependent on power transformer size, voltage tap selection, and melt zone resistance. The equations used to calculate power are

$$
P=\frac{v^{2}}{R}
$$

(constant voltage operation)

and

$$
P=I^{2} R
$$

(constant current operation)

The resistance is calculated between edge electrodes $R_{e}$ and diagonal electrodes $R_{d}$ as described by the following two equations:

$$
\begin{aligned}
& R_{e}=\rho \frac{\ln \left(\frac{2 S_{e}}{D}\right)}{\pi D_{g}} \\
& R_{d}=\rho \frac{\ln \left(\frac{2 S_{d}}{D}\right)}{\pi D_{g}}
\end{aligned}
$$

where

$$
\begin{aligned}
\rho & =\text { average electrical resistivity of the glass } \\
S_{e} & =\text { electrode separation along the edge } \\
S_{d} & =\text { diagonal electrode separation. }
\end{aligned}
$$


The electrode diameter $D$ and molten glass depth $D_{g}$ also affect resistance. The overall melt zone resistance is then calculated by:

$$
R=\frac{R_{d} R_{e}}{R_{d}+R_{e}}
$$

The mathematical model calculates heat losses through the exposed upper surface and into the surrounding soil. Heat losses into the soil are calculated using a constant heat flux value applied to the molten zone side and bottom surface area in contact with soil. The surface heat losses are determined in a similar fashion using the area defined by the four corner electrodes for heat transfer. Heat flux values have been determined from pilot-scale test data. Using an average soil thermal conductivity of $0.20 \mathrm{~W} / \mathrm{m}^{\circ} \mathrm{K}$, the heat flux from molten glass to surrounding soil ranged from 2.3 to $3.2 \mathrm{~kW} / \mathrm{m}^{2}$. The maximum value, $3.2 \mathrm{~kW} / \mathrm{m}^{2}$, was conservatively selected as the heat flux term for heat losses into the surrounding soil. Based on a measured nominal surface temperature of $570^{\circ} \mathrm{C}$, the heat flux through the upper surface was $32 \mathrm{~kW} / \mathrm{m}^{2}$. This value agrees with actual pilot-scale test data and was selected as the surface heat flux term for the model.

The model assumes that glass temperature was constant and thermal conduction of the electrodes had no effect. While glass temperature does change during an actual operation due to changing power density, the average temperature used by the model agrees well with actual pilot-scale data. Thermal conduction by the electrodes causes the molten zone growth downward to be slightly greater at the electrodes.

The results of the model were compared with those of PSFT 1 and PSRT. Table 26 lists the parameters used for the model. The model predictions agree very well with actual test data as shown in Table 27. All predicted parameters deviated $<7 \%$ from the actual test parameters during PSFT 1 . Figures 42 and 43 show the power input predicted by the model and that measured during PSFT 1 and PSRT, respectively. The model predictions are very close to the actual case. 
TABLE 26. Model Parameters Used for PSFT 1 and the PSRT

Parameter

Maximum power, kW

Transformer voltage taps, V

Electrode spacing, $m$

Electrode diameter, $\mathrm{cm}$

Surface heat flux, $\mathrm{kW} / \mathrm{m}^{2}$

Soil heat flux, $\mathrm{kW} / \mathrm{m}^{2}$

Average temperature, ${ }^{\circ} \mathrm{C}$

Soil heat capacity, $\mathrm{cal} / \mathrm{g}^{\circ} \mathrm{C}$

Soil moisture content, $\%$

Soil density, $\mathrm{g} / \mathrm{cm}^{3}$

Glass density (at temperature), $\mathrm{g} / \mathrm{cm}^{3}$
PSFT 1

295

$960 \& 480$

1.15

5.08

32

3.2

1900

0.24

5

1.6

2.2
PSRT

400

$1000,560, \& 422$

1.2

15.2

32

3.2

2000

0.24

5

1.6

2.2

TABLE 27. Actual and Predicted Test Data for PSFT 1 and the PSRT

\begin{tabular}{|c|c|c|c|c|c|c|}
\hline & & PSFT 1 & & & PSRT & \\
\hline Parameter & Actual & Predicted & $\%$ Dev. & Actual & Predicted & \% Dev \\
\hline Run time, $h$ & 21.0 & 20.7 & -1.4 & 23 & 21.8 & -5.2 \\
\hline Melt depth, m & 1.1 & 1.17 & +6.0 & 1.5 & 1.5 & 0 \\
\hline Melt width, m & 1.8 & 1.92 & +6.3 & 1.8 & 2.17 & +20 \\
\hline Volume vitrified, $\mathrm{m}^{3}$ & 3.6 & 3.4 & -5.9 & $4.9^{(a)}$ & 5.3 & +8.2 \\
\hline Mass vitrified, $\mathrm{kg}$ & 5670 & 5380 & -5.4 & $8600(a)$ & 8500 & -1.2 \\
\hline Average power, kW & 205 & 201 & -1.5 & 300 & 300 & 0 \\
\hline Total energy, kWh & 4300 & 4200 & -2.4 & 6900 & 6500 & -5.8 \\
\hline Energy $/ \mathrm{mass}, \mathrm{kWh} / \mathrm{kg}$ & 0.76 & 0.78 & +2.6 & 0.80 & 0.76 & -5.0 \\
\hline
\end{tabular}

(a) Estimated values. 


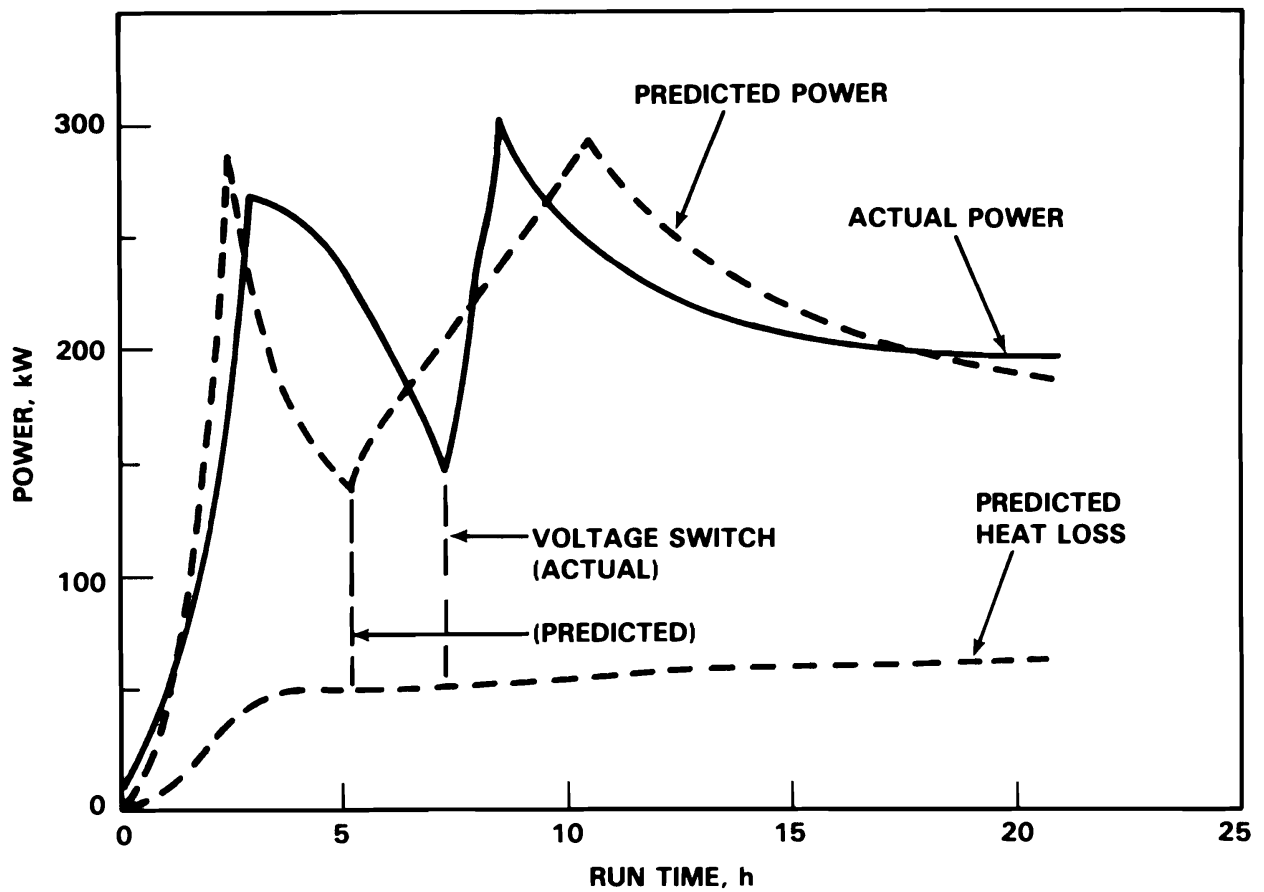

FIGURE 42. Predicted and Measured Operating Parameters for PSFT 1

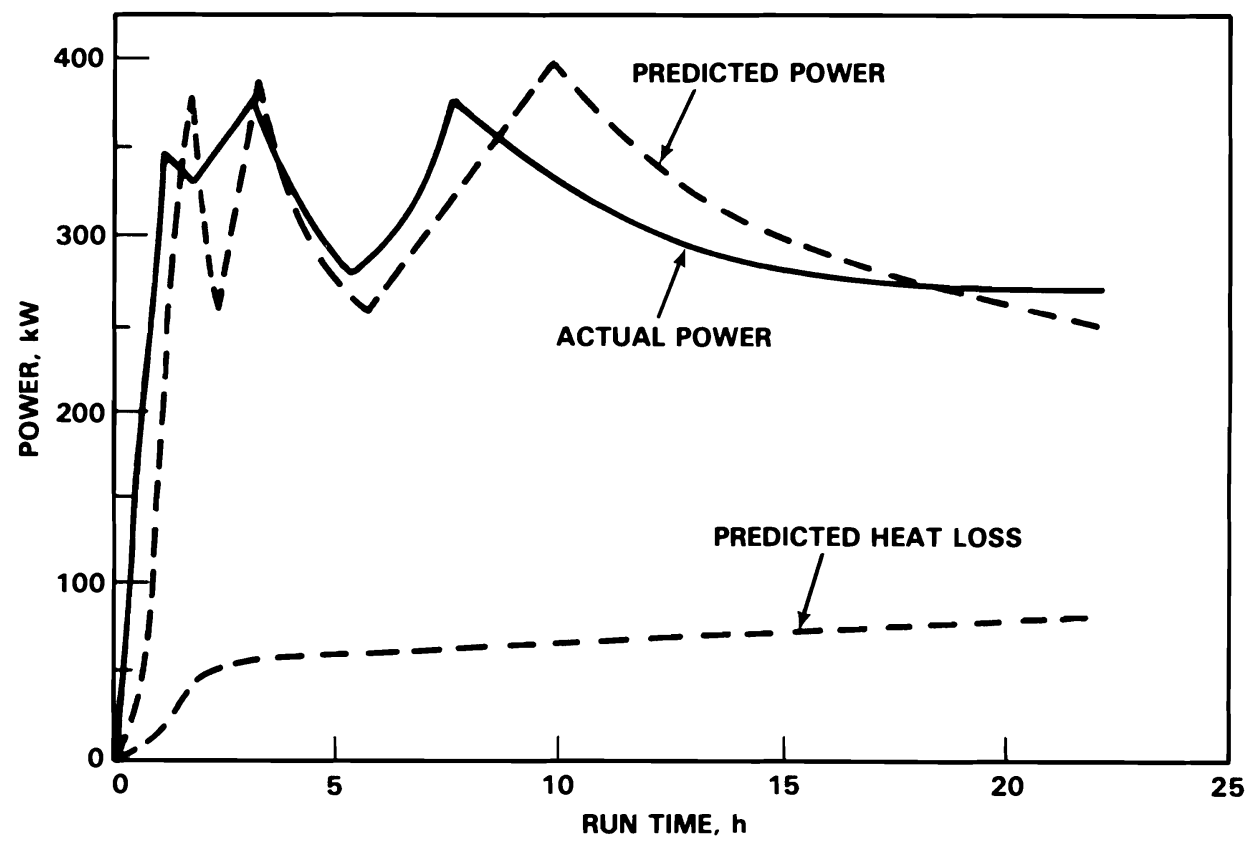

FIGURE 43. Predicted and Measured Operating Parameters for the PSRT 


\section{Large-Scale Mathematical Predictions}

Since the model results agreed well with field test data, the model was then used to predict the performance of a $3750 \mathrm{~kW}$ large-scale ISV system. The major control variables were electrode separation, soil moisture, and surface heat loss.

Because resistance between electrode pairs drops as the vitrified zone grows, the large-scale ISV system is based on a power transformer having 14 voltage taps ranging from $4160 \mathrm{~V}$ and $450 \mathrm{~A}$ per electrode pair for startup, down to $400 \mathrm{~V}$ and $4000 \mathrm{~A}$ per electrode pair late in the run. (At this lowest voltage tap, the amperage is limited by the physical size of the transformer coils.) By selecting more voltage taps, a higher average power can be maintained during the ISV operation.

Figure 44 shows the required startup voltage as a function of electrode separation. The plot was derived using the mathematical model after being calibrated with data from the two-electrode, engineering-scale test unit and four-electrode, pilot-scale test unit. The data point for the pilot scale is the average for the first three field tests. Extra graphite can be added to reduce the magnitude of the startup voltage, if necessary, to achieve startups for separations larger than $6 \mathrm{~m}$.

\section{Hanford Predictions}

The effect of electrode separation on melt depth and run time in Hanford soil containing $5 \%$ moisture can be seen in Figure 45 . The surface heat flux area was assumed to be nominal, as it was for the pilot-scale model. Melt depths greater than $15 \mathrm{~m}$ would be possible using electrode separations $\leq 4 \mathrm{~m}$; however, run times of $\geq 600$ hours would be necessary.

As a conservative measure, the surface heat flux was also applied to the total upper area of the molten glass zone, which expands during operation beyond the area defined by the four electrodes. This more closely models the case where no insulative cold cap is present. Figures 46 and 47 show the highheat-loss model predictions for soil containing 5 and $25 \%$ moisture, respectively. The melt depth at which heat losses become $90 \%$ of total power varies from $3 \mathrm{~m}$ using a $7 \mathrm{~m}$ electrode separation, to $11.6 \mathrm{~m}$ with a $3 \mathrm{~m}$ electrode 


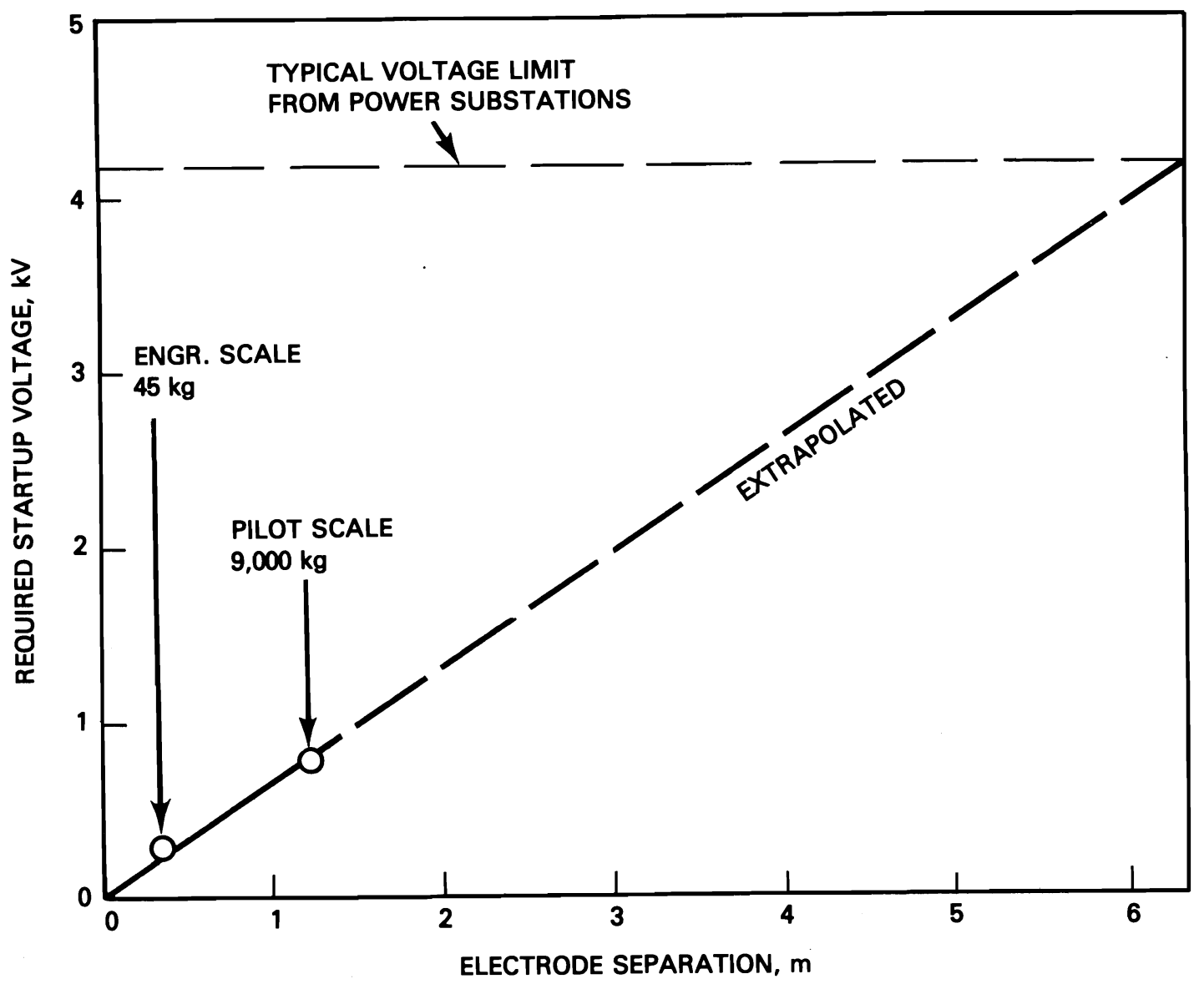

FIGURE 44. Scale-Up Correlations for Startup

separation. The increased soil moisture does not reduce the attainable melt depth but it does increase the time required to reach that depth. Soil moisture has the same effect on ISV as an increased soil heat capacity would since additional heat is required to convert the water at ambient temperature to a superheated vapor.

\section{Eastern Site Predictions}

Although it has been shown that differences in certain soil properties at various waste sites throughout the U.S. are small, differences in moisture content among sites are large. The soil moisture content above the water table at eastern sites such as ORNL or SRP averages between 20 and $25 \%$ while at Hanford, 4 to $5 \%$ is more typical. In situ vitrification of moist soil sites will require additional energy to evaporate the water. 


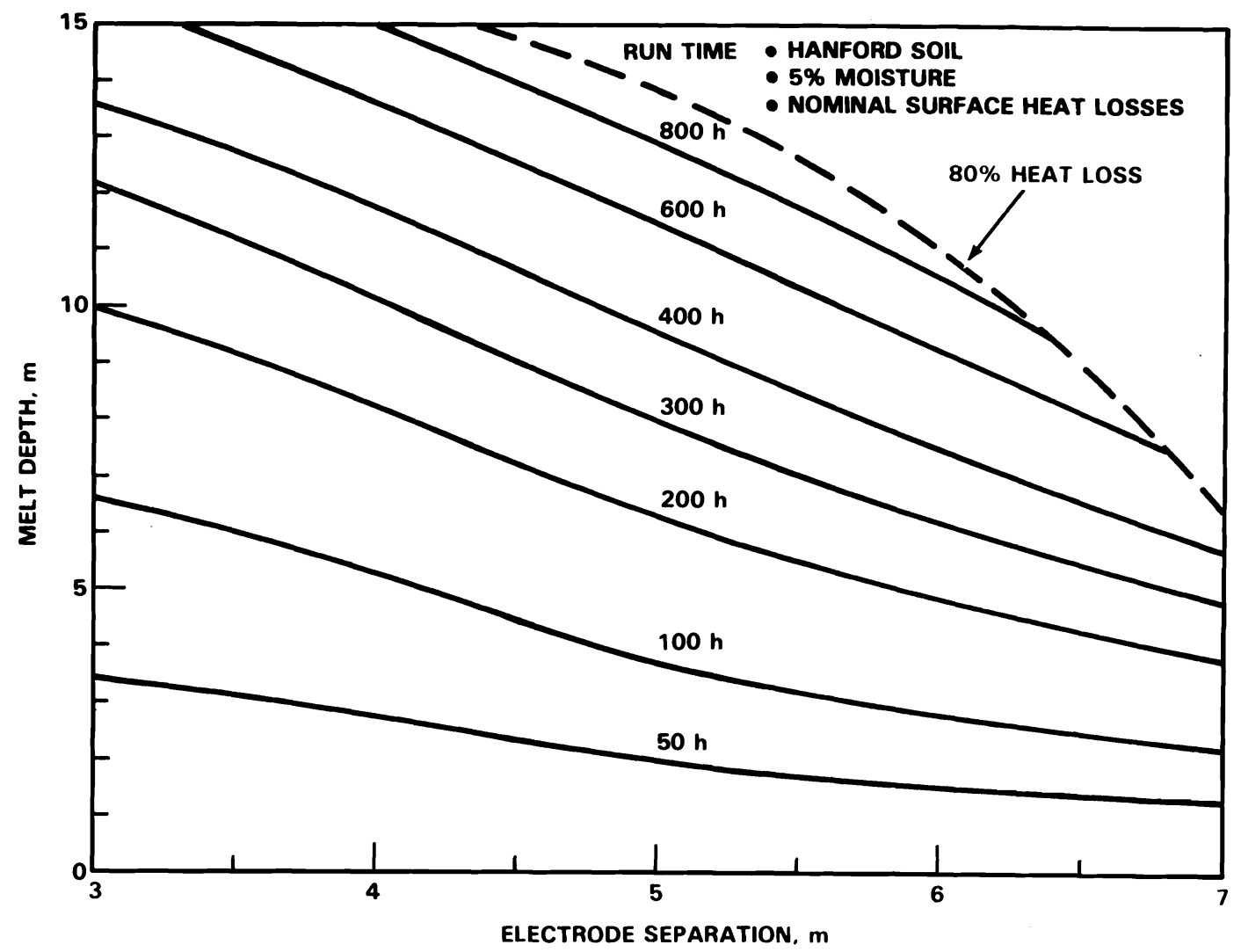

FIGURE 45. Effect of Electrode Separation on Melt Depth and Run Time for Hanford Soil with Nominal Heat Losses and 5\% Moisture

Factors which influence the level of moisture in a particular soil are water table depth, climatic events, and a soil's hydraulic properties. The factor which has the largest effect on ISV is the water table depth. The water table is the upper surface of the water-saturated zone when the aquifer is unconfined. The degree of saturation can range from 10 to $60 \%$, depending on soil porosity. Additional power is required to vitrify waste below the water table since water may be recharged into the area being vitrified. Engineered barriers or water wells could be used to artificially lower the water table and reduce or eliminate water recharge during an ISV operation.

Climatic events, water potential, and hydraulic conductivity at saturation are responsible for the soil moisture content above the water table. The amount of precipitation controls, in part, the rate at which water is added to 


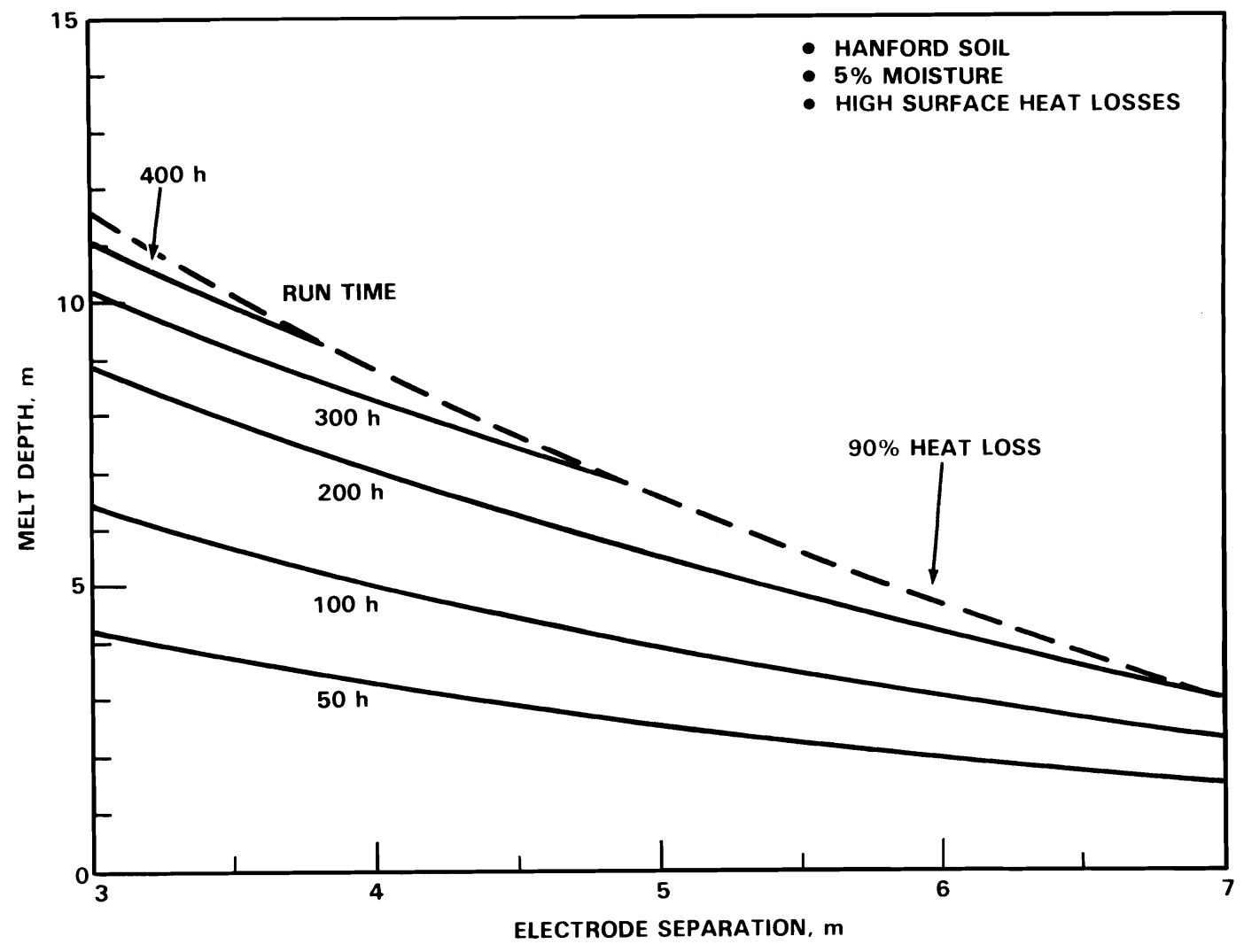

FIGURE 46. Effect of Electrode Separation on Melt Depth and Run Time for Hanford Soil with High Heat Losses and 5\% Moisture

the soil, while soil characteristics determine the conductance of water through the waste site. The volume of bonded water in soil is also somewhat dependent on the rate of drainage.

Water can accumulate in a burial trench, even though the trench is located well above the water table. The permeability of the disturbed soil placed over the waste site is typically much higher than that of the surrounding undisturbed soil. Buried waste, with its irregularities and void space, further increases waste site permeability. Precipitation can accumulate at the bottom of the trench, becoming ponded above the actual water table, since water drains through the excavated waste area faster than through undisturbed soil. Ponded water may exist in TRU waste trench bottoms at sites like ORNL and SRP, which 


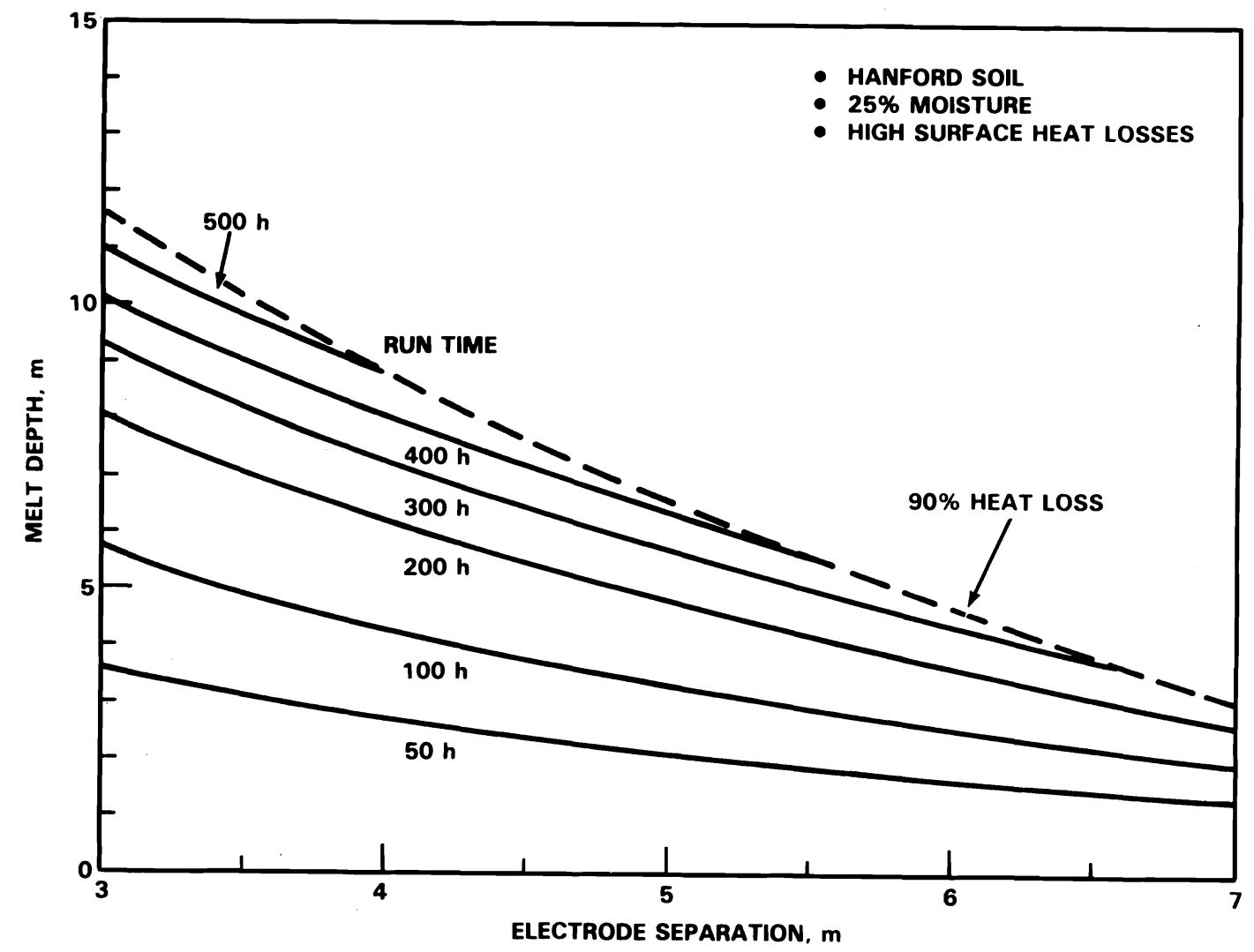

FIGURE 47. Effect of Electrode Separation on Melt Depth and Run Time for Hanford Soil with High Heat Losses and 25\% Moisture

receive high annual rainfall. In large waste trenches with relatively impermeable soil surrounding the trench, ponded water will increase the required power input for ISV.

Limitations to ISV imposed by soil moisture are most probable at ORNL, which has trenches excavated to depths below the water table. Trenches at ORNL are typically 2.1 to $4.3 \mathrm{~m}$ deep, and the depth to the water table ranges from ground level to $4.6 \mathrm{~m}$, depending on location and season (Webster 1979). A burial-ground scenario was used to evaluate potential moisture limitations to the ISV process under extreme conditions at ORNL. The burial trench used in the scenario was excavated to a depth of $4.3 \mathrm{~m}$ in an area with the water table at ground level and a highly permeable, sandy layer below the $6.4 \mathrm{~m}$ level (see Figure 48). Water permeability for ORNL soil averages $3.0 \mathrm{~cm} / \mathrm{d}$ (Luxmoore, 


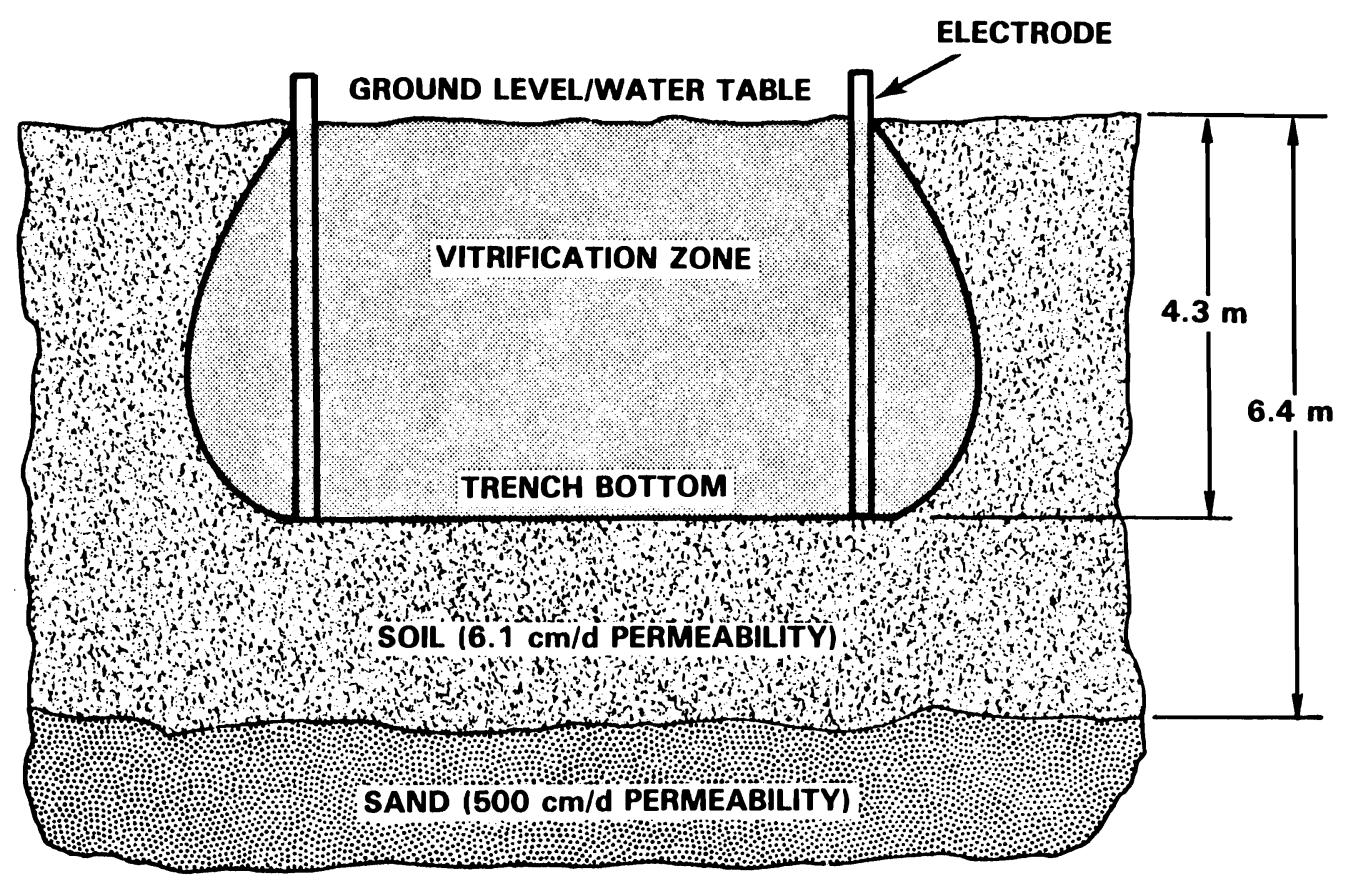

FIGURE 48. Burial-Ground Scenario for Moisture Limitations Analysis

Spalding, and Monroe 1981). Soil in the upper $6.4 \mathrm{~m}$ is conservatively assumed to have a porosity of $57 \%$ and a permeability of $6.1 \mathrm{~cm} / \mathrm{d}$. The permeability of the sandy area below $6.4 \mathrm{~m}$ is assumed to be high, at $500 \mathrm{~cm} / \mathrm{d}$.

The mathematical model was used to determine the maximum vitrification depth attainable for ISV in the scenario. Changes were made to the model to account for the increased power needed to evaporate water, which continues to recharge the vitrification area because of the hydraulic head. The model simulations are based on saturated ORNL soil $\left(0.93 \mathrm{~g} / \mathrm{cm}^{3}\right.$ dry bulk density) and an ISV glass density of $2.5 \mathrm{~g} / \mathrm{cm}^{3}\left(2.2 \mathrm{~g} / \mathrm{cm}^{3}\right.$ at $\left.2000^{\circ} \mathrm{C}\right)$.

The maximum depth attainable for various electrode spacings and soil moisture conditions is shown in Figure 49. In situ vitrification can effectively solidify soil to the trench bottom with an electrode spacing of $\leq 6 \mathrm{~m}$ on a side for the worst-case moisture scenario. The primary depth limitation is imposed by the aquifer depth. Based on model predictions shown in Figure 50, moisture levels will not limit the ISV process at ORNL, provided that the desired vitrification zone does not join with any areas of high permeability. 


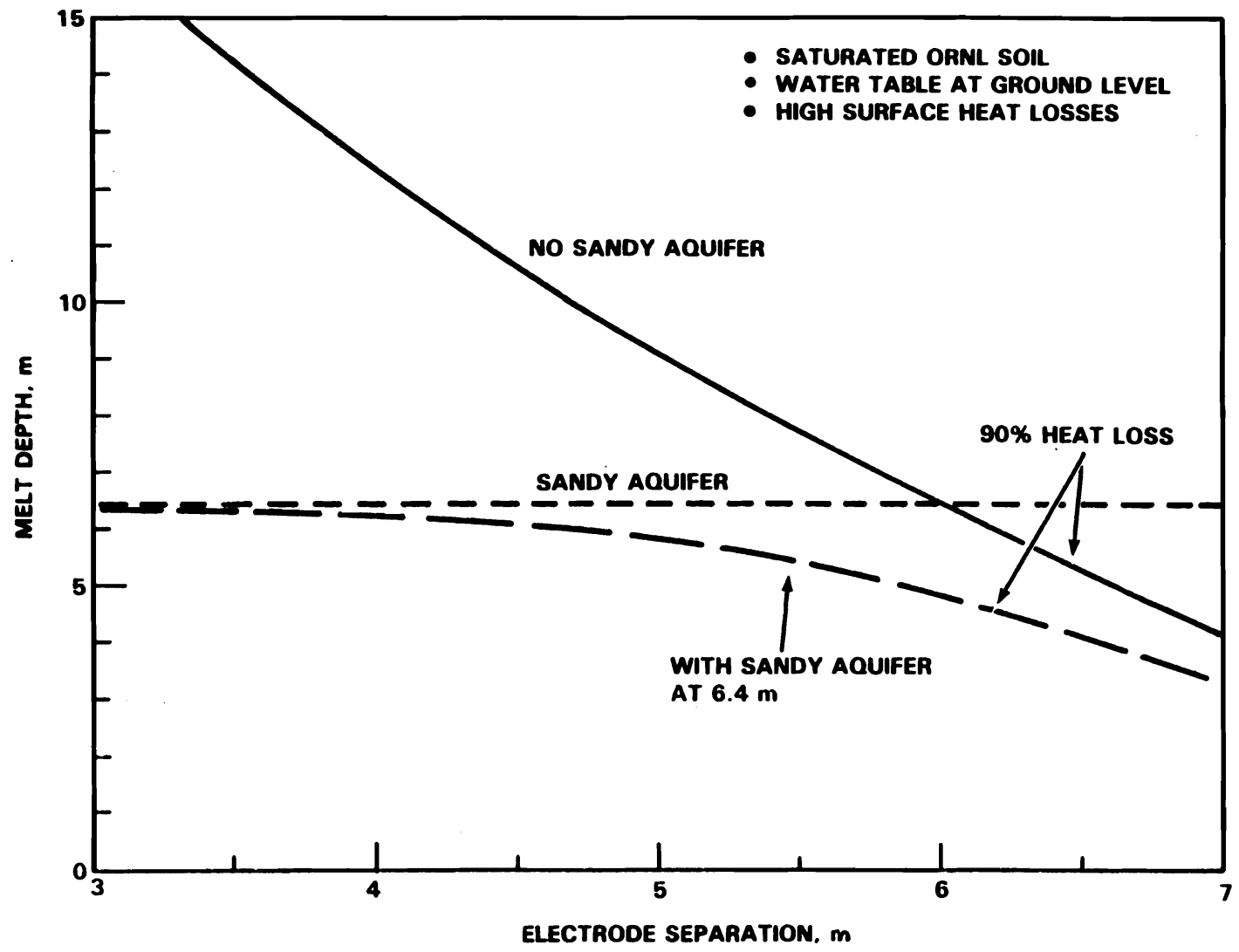

FIGURE 49. Effect of Sandy Aquifer on Melt Depth for Saturated ORNL Soil with High Heat Losses

ANALYSIS OF WASTE INCLUSION LIMITS

Many waste sites contain buried inclusions within the soil which may affect the ISV process. Transuranic contaminated soil sites often include wood or concrete cribs, ceramic French drains, and tile fields. Solid-waste burial grounds incorporate a large quantity and wider variety of wastes, such as metal drums and process components, combustibles, and concrete monoliths. The soil inclusions studied here are metals, cements, ceramics, combustibles, sealed containers, explosives, and elements which could cause a criticality. Predicted effects of each waste type on the ISV process are discussed in the following sections. 


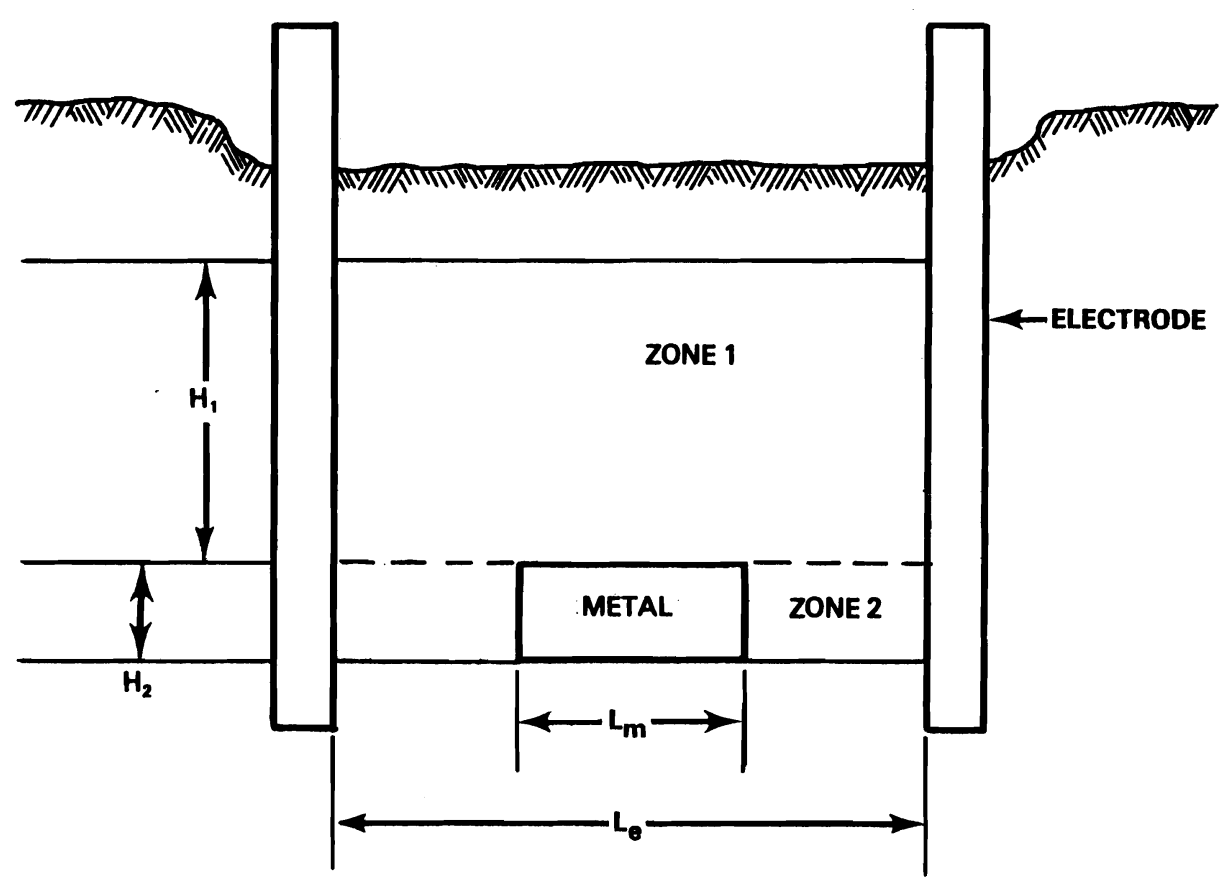

FIGURE 50. Metal Inclusion Model

\section{Metals}

Metal, which has a much higher electrical conductivity than molten soil, can decrease electrode voltage when present during ISV, and in extreme cases can result in a short circuit. A mathematical model and a series of four engineering-scale tests were used to evaluate the effect of metals on the ISV process.

The metal inclusion model is based on a two-electrode system. Figure 50 shows the physical model, with the metal resting at the bottom of the melt in Zone 2. Zone 1 is the high-temperature glass area in which the mean temperature is $\sim 1700^{\circ} \mathrm{C}$, while Zone 2 is the cooler leading edge of the melt zone. As the melt grows and proceeds downward through a metal object, the metal will melt and settle in the cooler Zone 2 area, resolidifying if temperatures are below the metal's melting point $\left(1565^{\circ} \mathrm{C}\right.$ for carbon steel and 1420 to $1500^{\circ} \mathrm{C}$ for stainless steel).

The metal inclusion model was used to evaluate the effect of varying Zone 1 depth, Zone 2 depth, metal width, and metal volume on the electrode 
voltage, power, and power density. The model correlates quite well with test data when no metal was present.

Figure 51 shows the effect of the metal width as a fraction of the electrode spacing on power and voltage for a pilot-scale electrode pair. As the fraction increases, the power and voltage decline gradually until the metal approaches the electrodes and a short circuit occurs. The power distributions as a function of $L_{m} / L_{e}$ (length of metal divided by distance between electrodes) are shown in Figure 52. As the metal path increases between electrodes, hightemperature areas form in the melt between the metal and electrodes in Zone 2. A cool area is likely to form above the metal in Zone 1 if convective currents are insufficient in the molten glass. The result may be an increased cold cap.

The model also predicts that varying the mass of metal in the soil has essentially no effect on power input and electrode voltage for a given metal width. The power and voltage decrease by $<0.1 \%$ when the metallic mass is increased by a factor of 10 for a given $L_{m} / L_{e}$ ratio, according to the model.

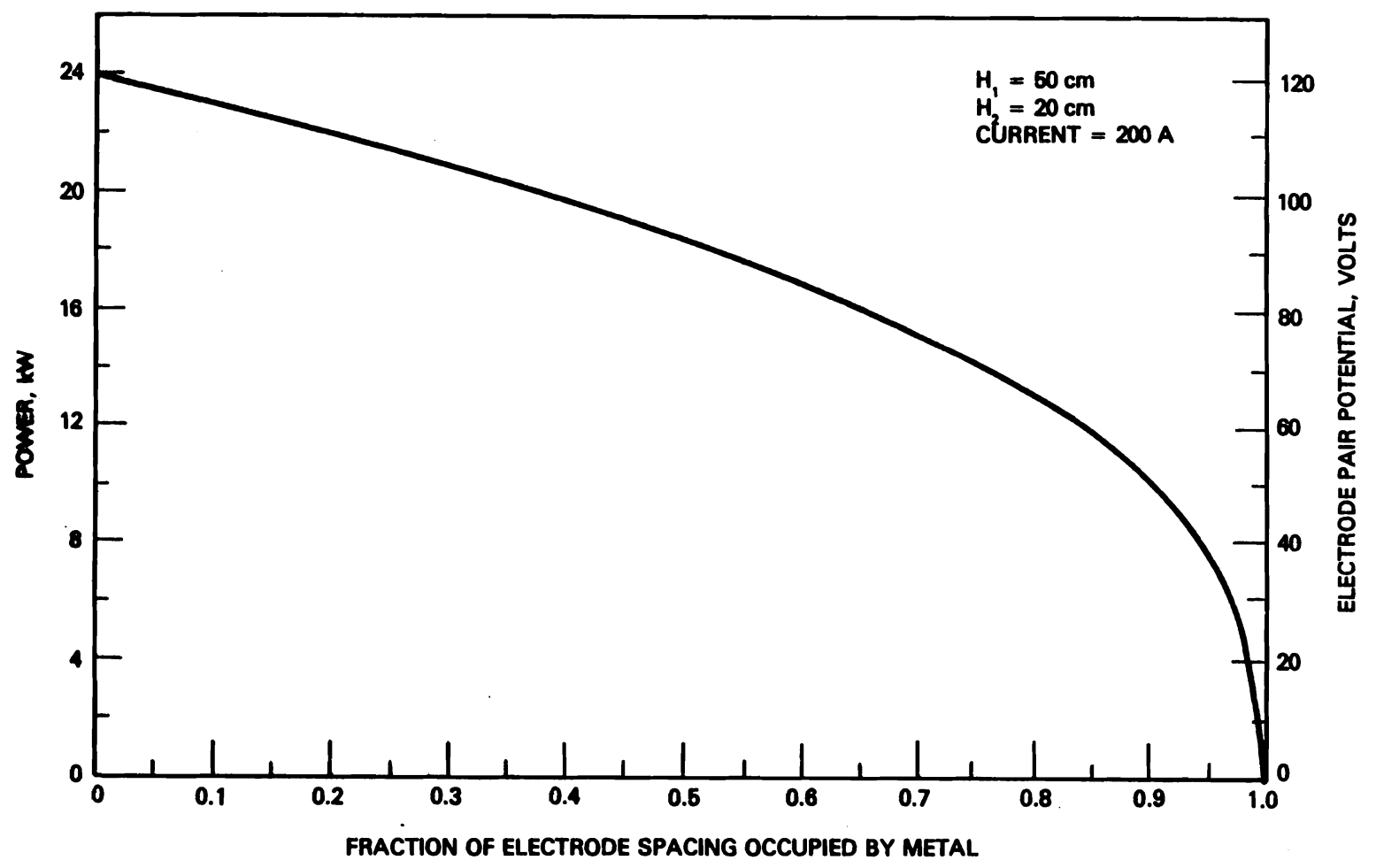

FIGURE 51. Effect of Metal Width on Power and Electrode Potential 


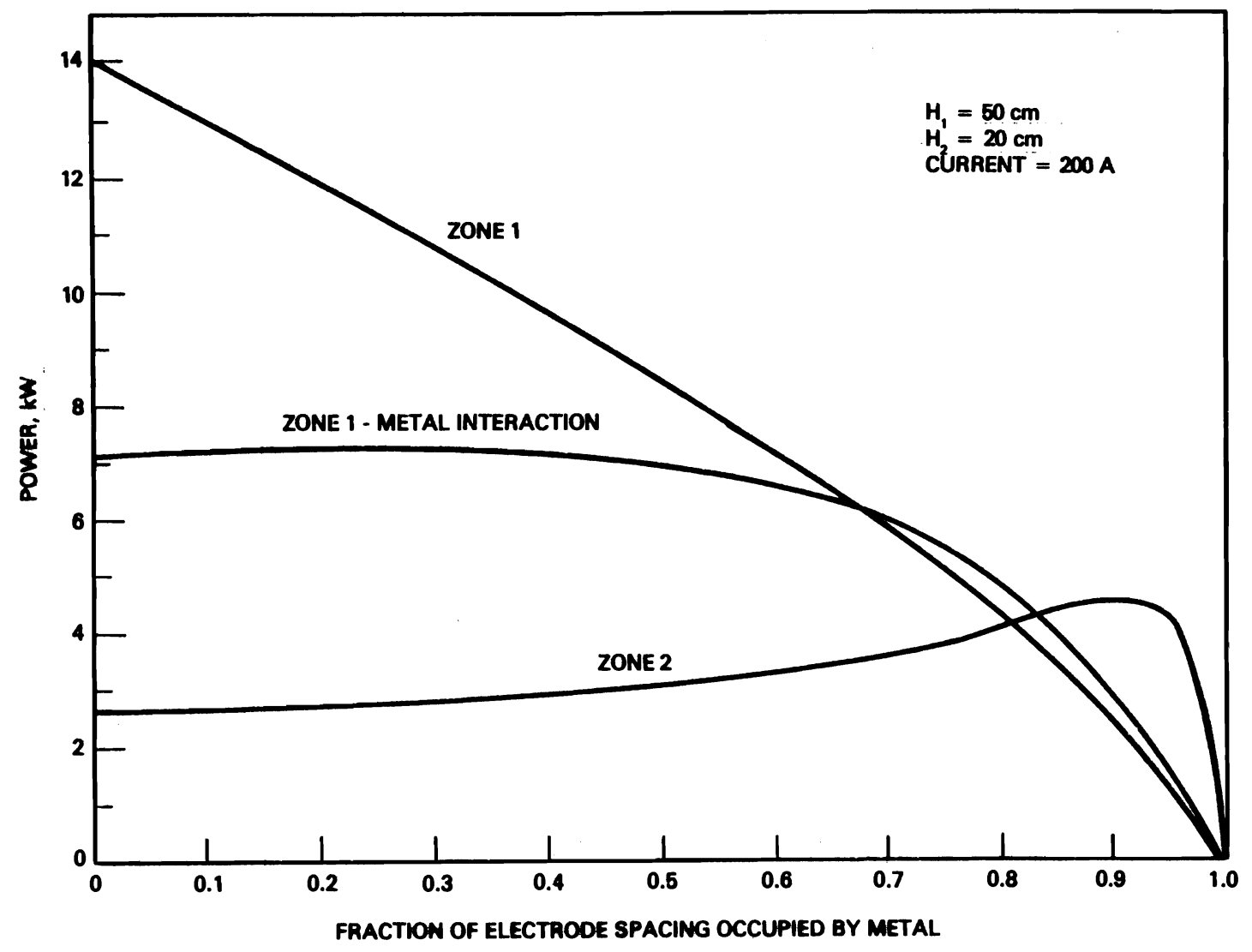

FIGURE 52. Effect of Metal Width on Power Distribution

Four engineering-scale laboratory tests, ESLT 10 through ESLT 13, were performed to verify the effects of metal inclusions on the ISV process. Summaries of each test are given in Table 28. The quantity of metal placed in the soil ranged from 2 to $5 \%$ of the final vitrified block weight. Each test proceeded to completion with no major difficulties. In ESLT 12, a stainless steel and a carbon steel canister, each containing metal scrap of the same composition, were placed edge to edge, occupying $71 \%$ of the distance between electrodes. To complete the test, it was necessary to increase the power to the engineering-scale unit from 7 to $10 \mathrm{~kW}$. This may have been due to the heat-fin effect of the metal, which increased heat losses to the soil.

Figure 53 shows the effect of metal inclusions as predicted by the model compared to actual data from the engineering-scale ISV system. The model predicted a larger drop in voltage due to metal inclusions than was actually observed. At an $L_{m} / L_{e}$ ratio of 0.7 , engineering-scale tests showed a voltage 
TABLE 28. Summary of Results from Engineering-Scale Laboratory Tests Containing Metal Inclusions

Test Parameter

Power limit, kW

Metal mass, $\mathrm{kg}$

Metal loading, wt\%

Electrode spacing fraction occupied by metal, $\mathrm{L}_{m} / \mathrm{L}_{e}$

Combustible mass, $\mathrm{kg}$

Run time, $h$

Total energy, kWh

Average power, kW

Mass solidified, $\mathrm{kg}$

Energy/mass, kWh/kg
ESLT 10

7

1.5

3

0.35

0

13

78

6

47

1.6
ESLT 11

7

0.9

2

0.35

0.2

12

69

6

46

1.5
ESLT 12

10

2.4

5

0.71

0.35

ESLT 13

10

1.2

2

0

9

83

9

69

$49 \quad 63$

1.4

1.3

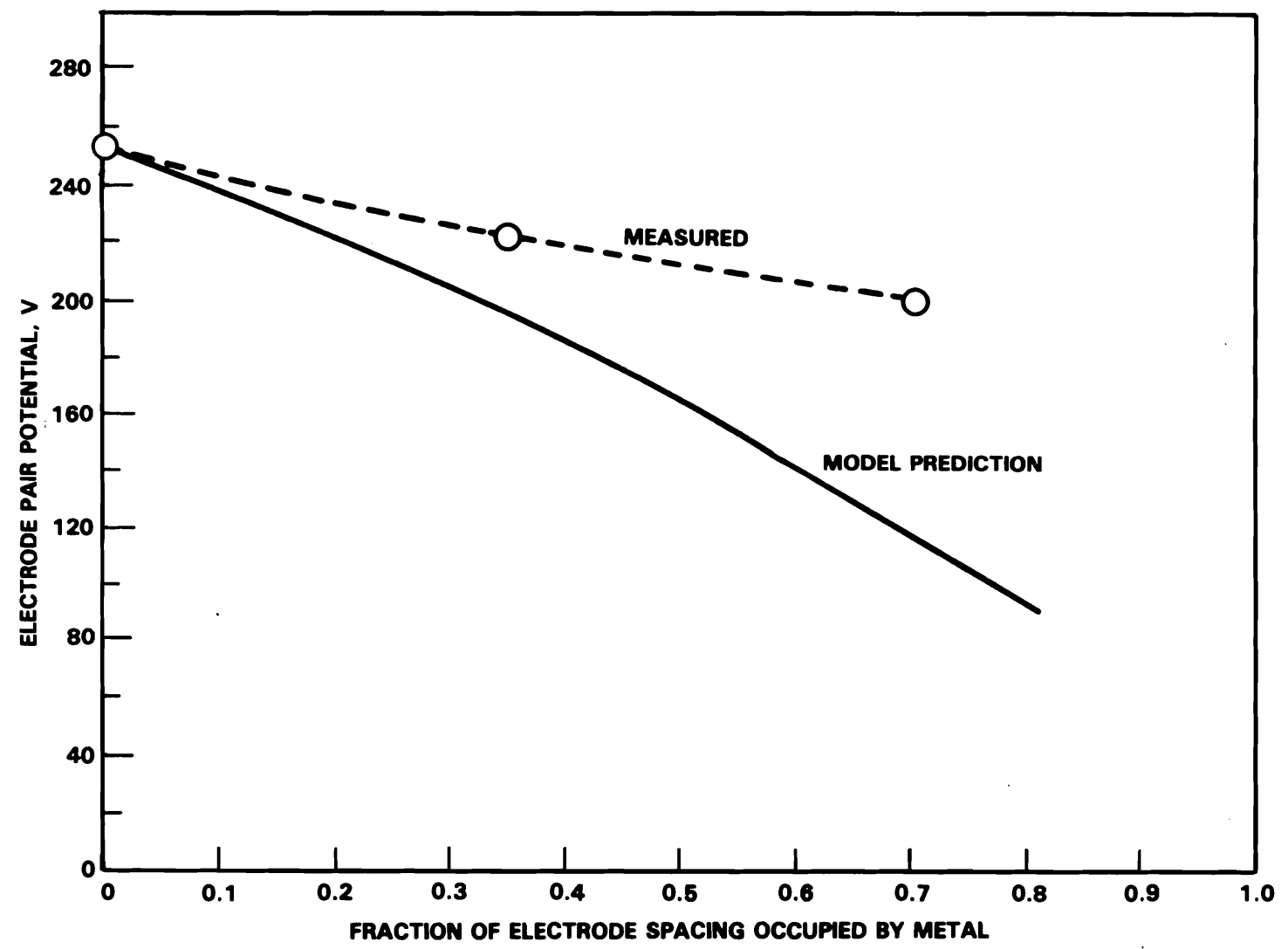

FIGURE 53. Measured and Predicted Voltage Drop Due to a Metallic Inclusion 
drop of $21 \%$. This means that the lowest voltage tap of the power transformer should be designed $21 \%$ lower than required with normal soil to maintain the same high power input level during ISV of soil with metal inclusions.

Cements and Ceramics

Unlike metals, the electrical conductivities of cement and ceramic waste inclusions are not high enough relative to the soil to create a short circuit. Instead, they are usually in the oxide form and are very similar to many of the compounds found naturally in soil. The volume of cement and ceramic waste inclusions in a waste trench is typically very small compared to combustible and metallic waste volumes. The cements and ceramics include large concrete casks used to contain industrial wastes at most TRU sites, cement paste in corrugated metal pipes at LANL, and concrete cribs and vitrified clay French drains at Hanford. Because almost all buried nonmetallic materials are some form of cement product, concrete waste inclusions are analyzed most extensively in this section, although other ceramic materials will also be discussed.

Cement can be defined as an adhesive complex of nonmetallic oxides, with lime $(\mathrm{CaO})$ as the primary constituent. Hardened cement contains up to $33.3 \mathrm{wt} \%$ (20 wt\% average) water, which acts as the adhesive for the complexed oxides (Lea 1971). Concrete contains less water $(\sim 5 \%)$ because of the high volume of sand and gravel present.

The compounds in cements are formed by the interaction during burning of $\mathrm{CaO}, \mathrm{SiO}_{2}, \mathrm{Al}_{2} \mathrm{O}_{3}$, and $\mathrm{Fe}_{2} \mathrm{O}_{3}$ compounds. Although the percentages of these compounds vary greatly among cement types (see Table 29), when combined they make up over $85 \%$ of each cement type. Portland cement is composed of over $90 \% \mathrm{Ca}$, $\mathrm{Al}_{2} \mathrm{O}_{3}$, and $\mathrm{SiO}_{2}$. Of the three major oxide constituents in concrete, both $\mathrm{CaO}$ and $\mathrm{Al}_{2} \mathrm{O}_{3}$ lower electrical conductivity upon addition to soil, while $\mathrm{SiO}_{2}$ does not (Stanek 1977). Concrete also has a higher specific heat than soil. As a result, concrete may not heat quickly enough to become completely vitrified during an ISV operation. 
TABLE 29. Composition of Various Cements

\begin{tabular}{|c|c|c|}
\hline \multirow[b]{2}{*}{ Component } & \multicolumn{2}{|c|}{ Composition, wt\% } \\
\hline & Portland Cement & Other Cements $(\mathrm{a})$ \\
\hline $\mathrm{CaO}$ & 64.1 & 38 to 65 \\
\hline $\mathrm{SiO}_{2}$ & 22.0 & 5 to 27 \\
\hline $\mathrm{Al}_{2} \mathrm{O}_{3}$ & 5.5 & 3 to 39 \\
\hline $\mathrm{Fe}_{2} \mathrm{O}_{3}$ & 3.0 & 0 to 13 \\
\hline $\mathrm{SO}_{3}$ & 2.1 & 0 to 4 \\
\hline $\mathrm{Fe} 0$ & 0 & 0 to 4 \\
\hline$S$ & 0 & 0 to 1 \\
\hline
\end{tabular}

(a) Includes Erz, Ferrari, Kuhl, Portland Blast Furnace, Eisen-Portland, Hochofen, Slag Supersulphated, and High Alumina cements (Lea 1971).

To verify the ability of the ISV process to handle cement, ESLTs 14 and 15 were conducted using relatively large concrete masses in the soil. In the first test, a carbon steel can encapsulated in concrete was vitrified, while in the second test, two monoliths, one of concrete and the other of cement paste, were vitrified (see Table 30 for test summaries). After the tests, all of the concrete had been vitrified within the blocks. Glass samples of the first concrete ISV test were analyzed and showed very uniform Ca distribution throughout the glass melt.

At ambient temperature, hardened Portland cement, with $>20$ wt\% water, is much more electrically conductive than normal soil. As heat is generated in and around the concrete inclusion, it begins to expand as a result of the thermal expansion coefficient. At temperatures above $100^{\circ} \mathrm{C}$, the expansion of the concrete paste and aggregate begins to be opposed by a contraction mechanism as water is driven off. At $300^{\circ} \mathrm{C}$, contraction due to water loss becomes greater than the thermal expansion, and the material starts shrinking, with ultimately $\geq 0.5 \%$ contraction from the original ambient dimensions (Harada et al. 1972; Zoldners 1971). This continues past 400 to $450^{\circ} \mathrm{C}$, where free $\mathrm{Ca}_{2} \mathrm{OH}_{2}$ is dehydrated. The partially dehydrated cement starts expanding again at temperatures 
TABLE 30. Summary of Results from Engineering-Scale Laboratory Tests Containing Concrete Inclusions

\begin{tabular}{|c|c|c|}
\hline Test Parameter & ESLT 14 & ESLT 15 \\
\hline Power limit, kW & 12 & 17 \\
\hline Cement mass, $\mathrm{kg}$ & 4.9 & 6.1 \\
\hline Cement loading, wt\% & 8.8 & 6.5 \\
\hline Metal mass, kg & 0.16 & 0.69 \\
\hline Metal loading, wt\% & 0.3 & 0.7 \\
\hline $\begin{array}{l}\text { Electrode spacing fraction } \\
\text { occupied by concrete, } L_{m} / L_{e}\end{array}$ & 0.44 & 0.46 \\
\hline Total energy, kWh & 63 & 120 \\
\hline Average power, $\mathrm{kW}$ & 8 & 13 \\
\hline Mass solidified, $\mathrm{kg}$ & 56 & 94 \\
\hline Energy/mass, $\mathrm{kWh} / \mathrm{kg}$ & 1.1 & 1.3 \\
\hline
\end{tabular}

exceeding $700^{\circ} \mathrm{C}$. Because the aggregate is continually expanding while the cement paste is contracting, severe cracking occurs. As a result, the concrete structure is broken up into smaller fragments which are believed to be uniformly dispersed throughout the glass by convection currents. Although the rate of complete dehydration is slow at $534^{\circ} \mathrm{C}$, complete dehydration occurs quickly at temperatures above $1090^{\circ} \mathrm{C}$ (Petersen 1966). The ISV large-scale system, as described previously, will accommodate these water releases.

The electrical resistivity of the melted soil increases as the cement is melted and becomes uniformly dispersed. This was observed during ESLT 14, in which an $8.8 \%$ loading of concrete in the soil raised the molten zone's electrical resistivity significantly (see Figure 54). Because the ISV operating voltage depends in part on the electrical resistivity of the molten path and the distance between electrodes, an increase in electrical resistivity caused by concrete can be offset by a corresponding decrease in electrode spacing. A decreased electrode spacing should be required only if the cement inclusion is at or near the surface of the waste site. If the concrete is encountered after the melt zone has grown, higher voltage taps should be available on the power transformer to accommodate any increased resistivity caused by the concrete. 


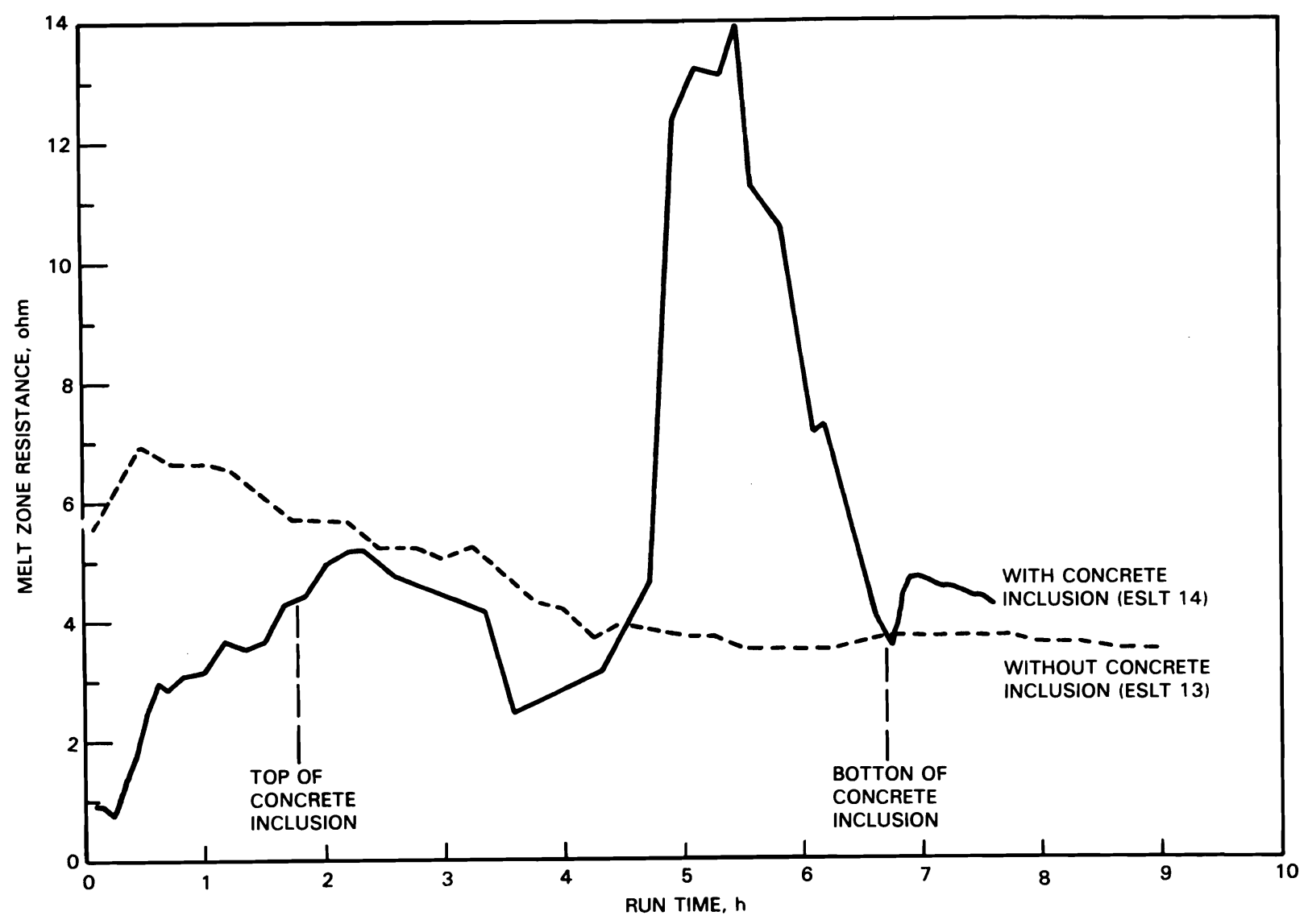

FIGURE 54. Effect of Concrete Inclusions on Melt Zone Resistance

This increased resistivity of the molten zone may be compensated for by a voltage increase to one of the previous voltage taps. The power input to the melt zone will not be reduced.

The volume of water vapor given off during concrete dehydration adds to the volume normally treated by the ISV off-gas system. Figure 55 shows the required off-gas capacity for various concrete and cement loadings. The graphs assume that the specific heats and melting rates of soil, cement, and concrete are the same. At most, even a 100\% loading of cement paste in a TRU site increases required off-gas capacities by less than a factor of 2 . Concrete, which is more common than cement paste, can only increase off-gas requirements by $10 \%$.

Large concrete structures (e.g., trench caps, cribs, large industrial waste boxes) are common in TRU waste sites. Concrete is more conductive than 


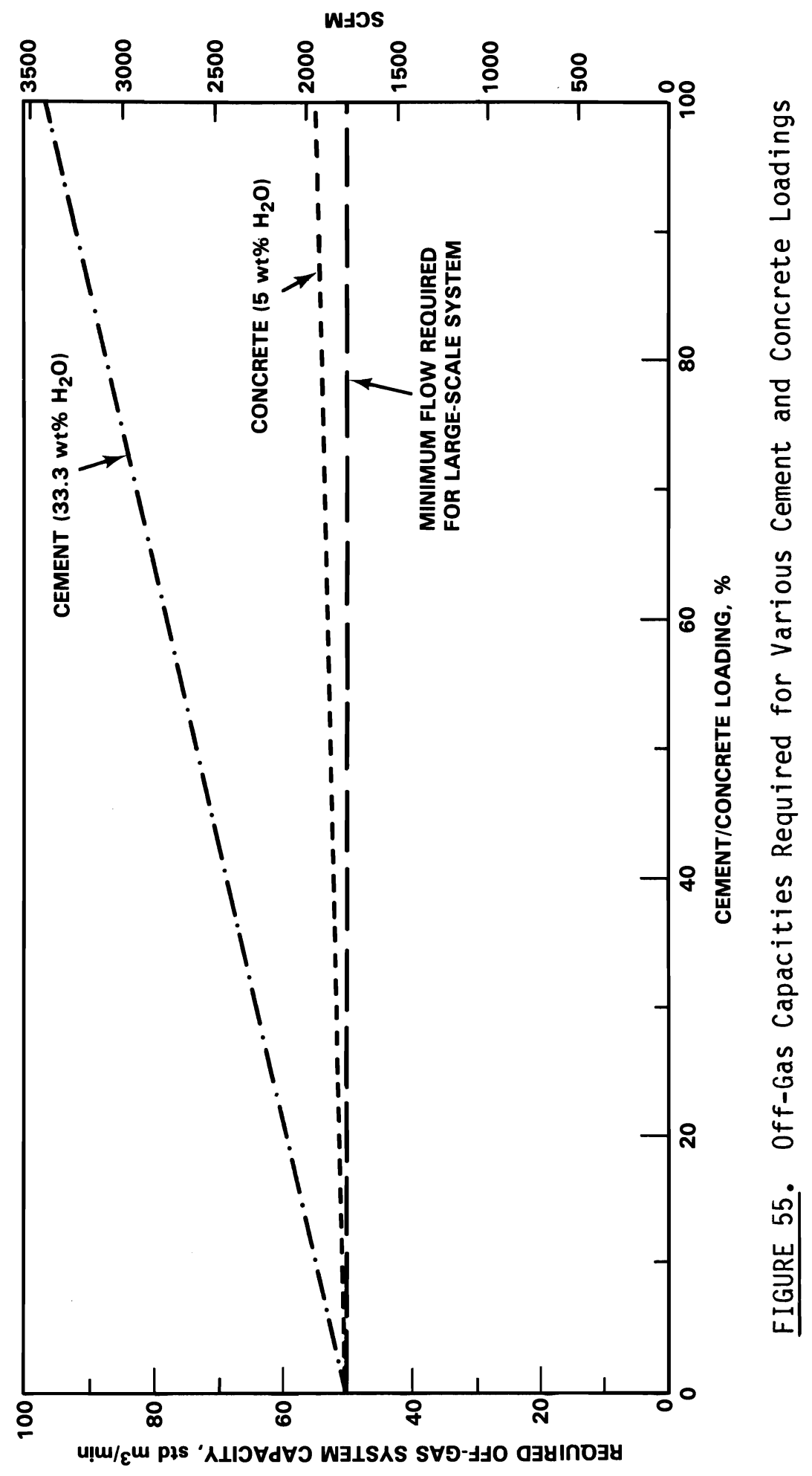


unmelted soil; however, an electrical short is not possible during ISV if the concrete occupies a large portion of the space between electrodes because the molten soil is much more conductive than concrete.

The vitrification of ceramic materials is not expected to limit the process significantly. The high melting points and refractory nature of most ceramics will prevent them from completely melting or dissolving. To determine the degree of encapsulation in the melt, alumina and zirconia bricks were included in PSFT 3. Visual inspection of the glass after vitrification revealed a high degree of ceramic encapsulation with minimal surrounding void space.

Combustibles

During ISV of a waste site, any solid combustible waste within the soil is pyrolyzed into combustible gases at the high temperatures of the melt. The gases move upward through the molten zone, expanding as they are heated. Combustion does not occur until the pyrolyzed gases contact air at the molten soil's surface, since only limited supplies of oxygen exist in the soil and the molten glass is reducing in nature. Several effects of these gas releases must be considered in establishing the design of the hood and off-gas system:

- Gases carry with them to the off-gas system a portion of radionuclide elements associated with the combustible waste. (Note that only the contaminants associated with the combustibles are available for release--those already incorporated in the melt remain with the vitreous mass.)

- The protective cold cap may break up as the gases are released, increasing heat losses and hood temperatures.

- Unburned combustible gases which are superheated in the molten zone burn in the hood plenum, creating high temperatures in the hood and increasing the heat removal requirements of the off-gas system.

- The gas generation rate of buried combustibles determines the maximum processing flow rate. 
The magnitude of these effects is directly proportional to the rate at which pyrolyzed gases are generated and released. Engineering- and pilot-scale tests have shown that combustible gas release is sporadic and may occur in a very short time period. During ESLT $11,0.2 \mathrm{~kg}$ of simulated combustible waste was placed inside a metal canister. Active surface combustion of the pyrolyzed gases occurred over an 18 minute period during the 12 hour test. Thus the release period was only $2.5 \%$ of the total ISV time. Similar observations have been made during the PSFTs.

For example, PSFT 3 was conducted to evaluate ISV performance with a $208 \mathrm{~L}$ (55 gal) metal drum containing simulated combustible waste and soil buried between electrodes. Figure 56 illustrates the simulated waste drum placement, and Table 31 gives the waste composition. When the molten soil first contacted the waste drum, rapid venting of pyrolyzed gases and carbonaceous particulate occurred for 230 minutes. The off-gas particle loading was high during this period, reaching $3600 \mathrm{mg} / \mathrm{m}^{3}$. Slower ventings occurred at two other times later in the test, lasting for 15 to 30 minutes each. The ISV process was operated for 38 hours; however, most pyrolysis gas venting took place over a period of about 1 hour (2.6\% of the total ISV time).

The large-scale system capacity of $104 \mathrm{std} \mathrm{m}^{3} / \mathrm{min}$ is capable of containing combustion gas effluents from a variety of waste configurations. Assuming an inverse exponential release rate of combustible gases over 30 minutes (based on engineering- and pilot-scale tests), the large-scale system is able to contain gas released from combustible volumes, as shown in Figure 57, when molten soil contacts them. Pyrolyzed gases from combustible volumes as large as $0.9 \mathrm{~m}^{3}$ can be contained without losing hood vacuum while continually supplying $20 \%$ excess combustion air. Likewise, a combustible volume of $>3 \mathrm{~m}^{3}$ would be contained before hood vacuum is lost if combustion air is not supplied. The same off-gas system is capable of containing the gases generated from a void volume of $4.3 \mathrm{~m}^{3}$ with a design factor of 2 . This assumes the gases are released uniformly over a 5 second period as molten glass rapidly fills the void volume (Figure 58). For homogeneous mixtures of combustibles and as little as 30 vol\% soil, the large-scale off-gas system is capable of providing $20 \%$ excess combustion air and containing combustion gas from $3200 \mathrm{~kg}$ combustibles for every 
0
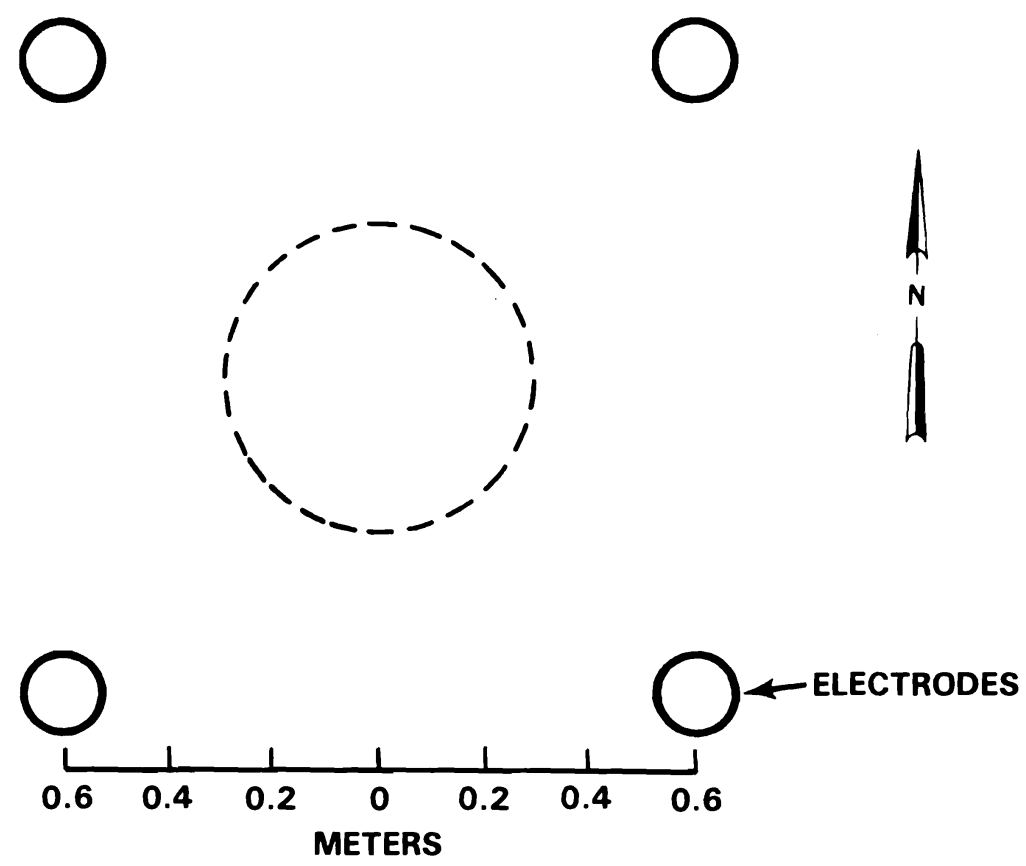

TOP VIEW

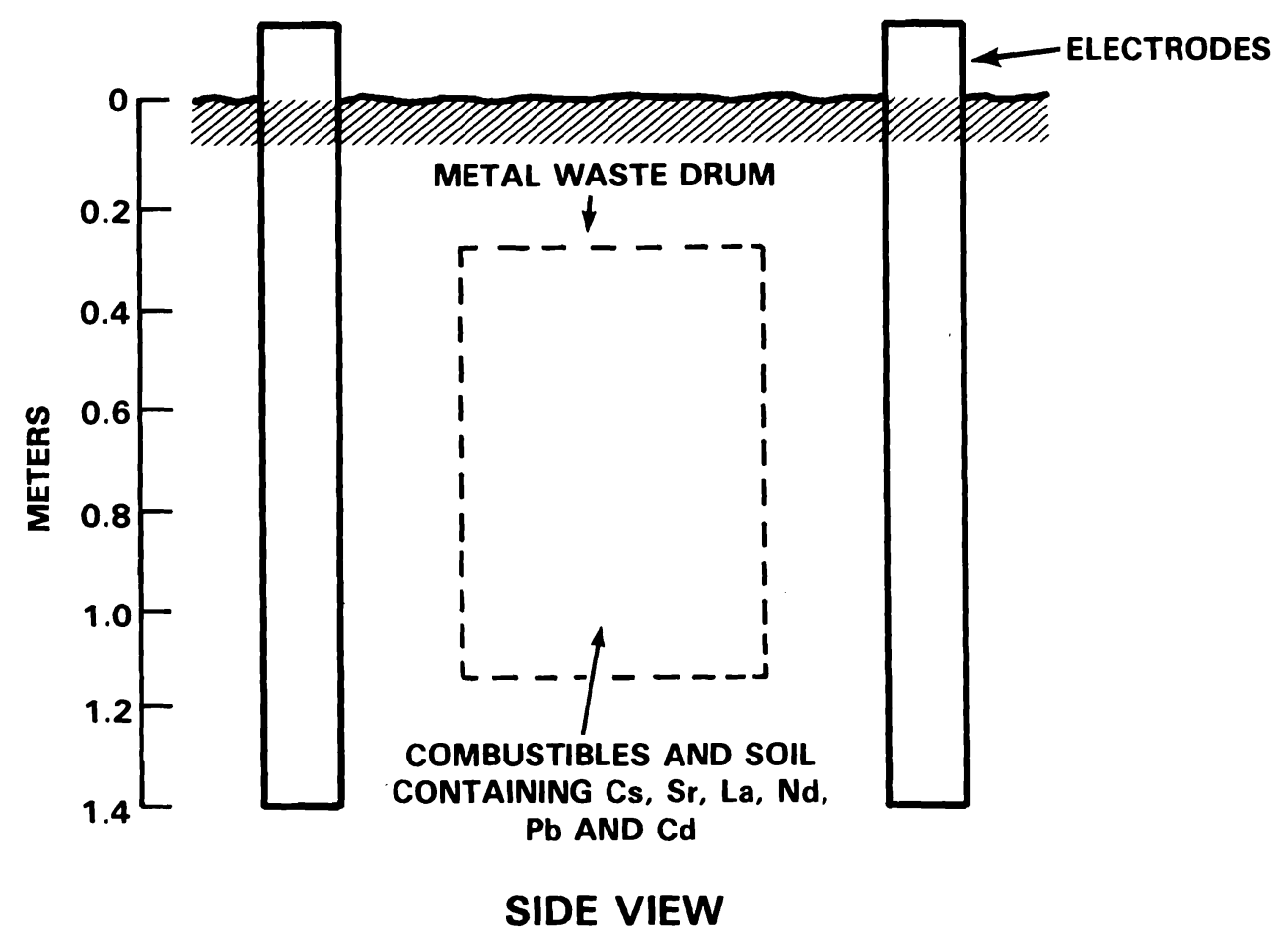

FIGURE 56. Simulated Waste Configuration for PSFT 3 
TABLE 31. Waste Drum Combustibles Content During PSFT 3

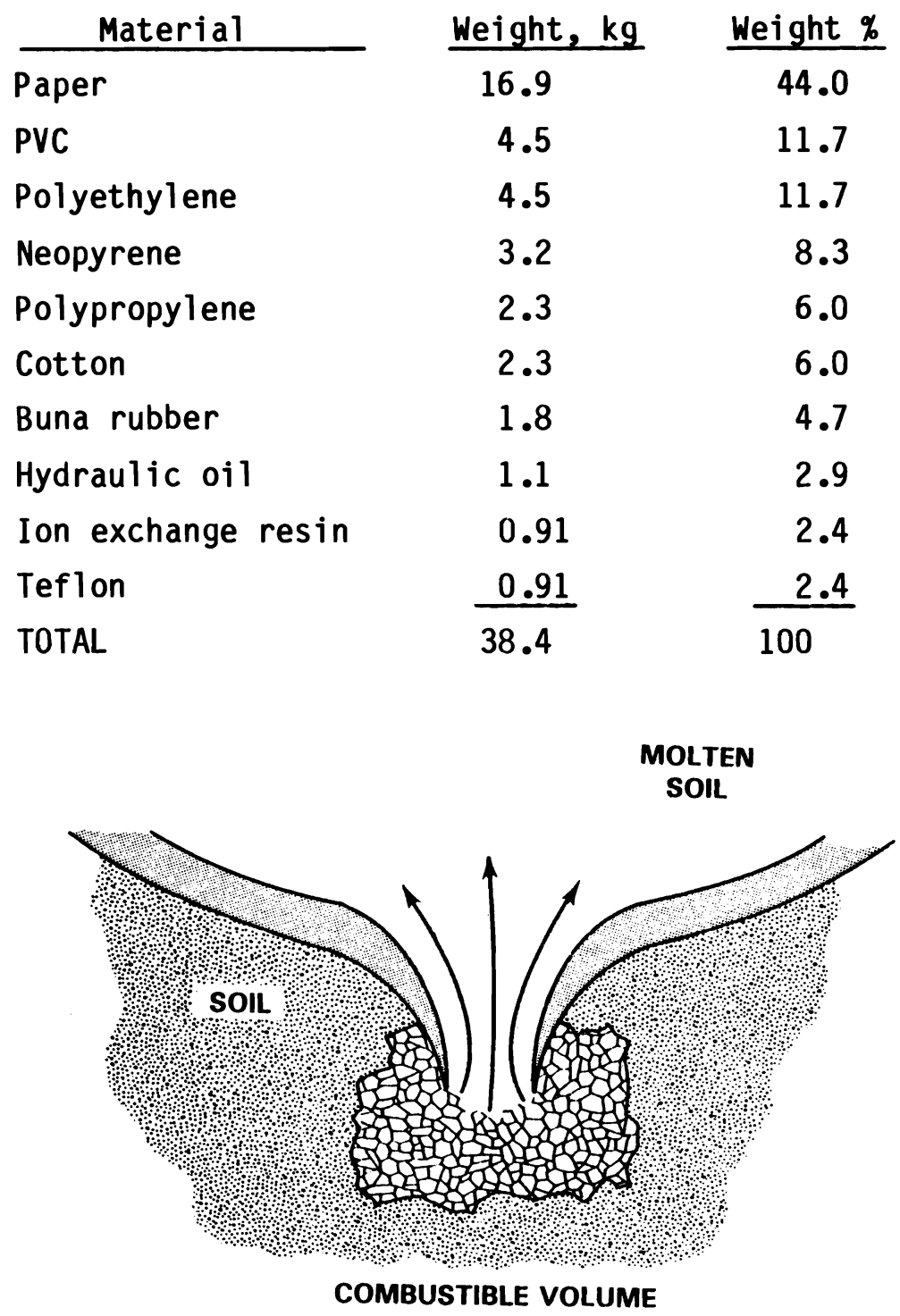

FIGURE 57. Gas Release from a Combustible Volume

meter of depth being vitrified per setting. The predicted performance of the process under these types of conditions is also based on a design factor of 2 . Sealed Containers

Gas may also be released rapidly from a sealed container in soil that is being vitrified. Containers holding combustibles can build up pressure, and 


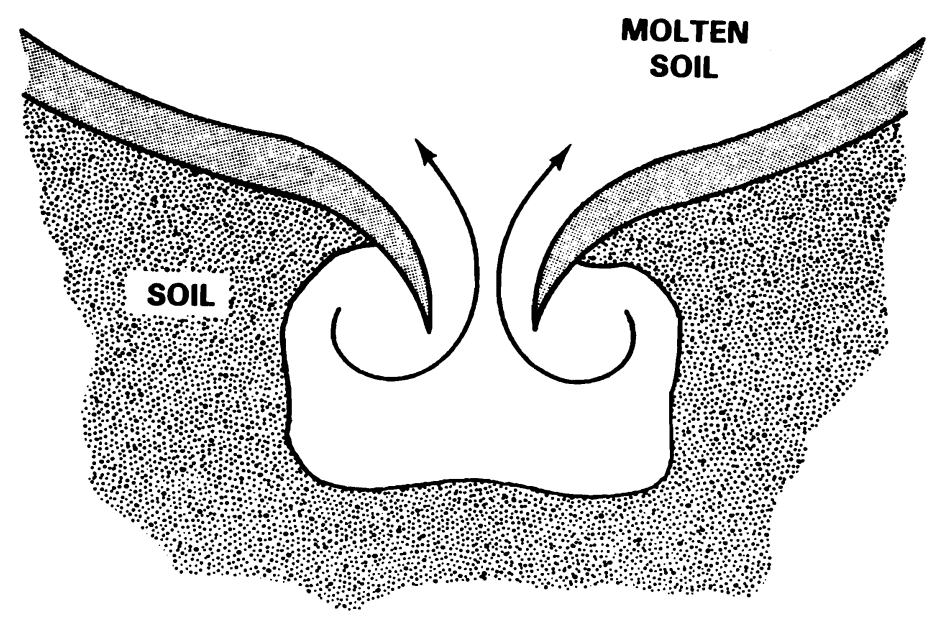

VOID VOLUME

FIGURE 58. Gas Release from a Void Volume

when they are breached, release that pressure, with gases escaping to the hood over a very short time period ( 2 seconds).

In some cases after the container is breached, it may reseal itself. As shown in Figure 59, the impervious, fused soil layer which borders the vitreous soil becomes sealed to the metal container. Since the melting temperature of most steels is near $1400^{\circ} \mathrm{C}$ and the temperature of the partially fused zone is $1100^{\circ} \mathrm{C}$, the metal container can protrude into the fused zone, trapping the gases inside the container. When enough pressure is built up, it is postulated that the fused zone cracks, releasing gases into the hood.

Theoretical gas releases have been calculated for various geometries of sealed metal containers to determine the maximum gas release rate after the fused zone has been breached. Table 32 shows a greater release rate with a $19 \mathrm{~L}$ (5 gal) bucket than with a $208 \mathrm{~L}(55 \mathrm{gal})$ drum. This is due to the fact that a greater pressure is required to breach the fused zone over the narrower gap between the metal sides of a $19 \mathrm{~L}$ bucket, resulting in a higher burst pressure and a greater gas release rate.

Sealed containers that do not contain gas-generating combustibles can also release gases rapidly when breached. During PSCT 1, a rapid (2 to 5 second) release of gases exceeding hood vacuum was observed on three occasions from a $19 \mathrm{~L}$ (5 gal) metal bucket containing $60 \mathrm{~kg}$ of chemicals in nitrate form. 


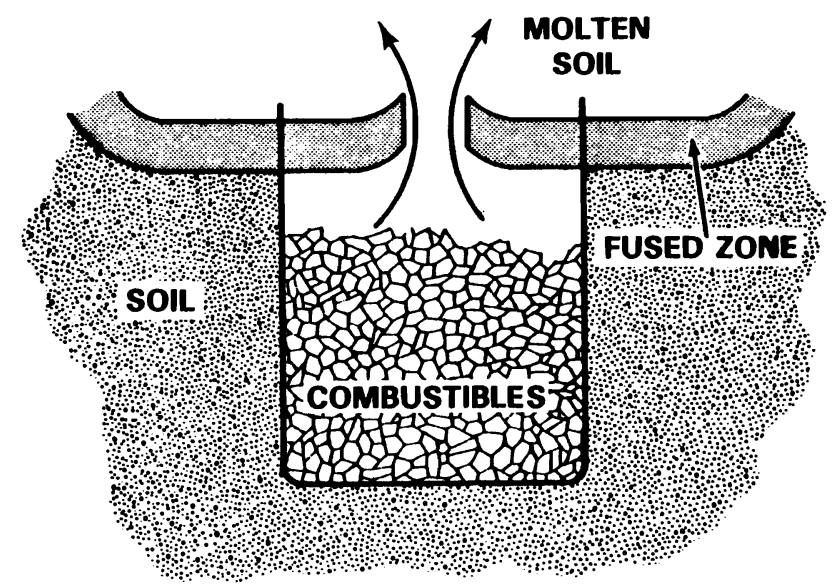

METAL CONTAINER

FIGURE 59. Gas Release from a Sealed Metal Container

IABLE 32. Gas Release Rates from a Sealed Metal Container

\begin{tabular}{lcccc} 
Container & Dia, m & $\begin{array}{c}\text { Burst } \\
\text { Pressure, } \\
\text { atm }\end{array}$ & $\begin{array}{c}\text { Max. Gas } \\
\text { Release Rate, } \\
\text { std m/min }\end{array}$ \\
\cline { 1 - 2 } 19 L (5 gal) bucket & 0.27 & 25 & 64 \\
34 L (10 gal) bucket & 0.27 & 25 & 64 \\
208 L (55 gal) bucket & 0.56 & 6 & 35
\end{tabular}

Containers of material with a high moisture content can also release water vapor rapidly. The $220^{\circ} \mathrm{C}$ isotherm, which precedes the vitreous zone by $\sim 25 \mathrm{~cm}$, can vaporize water at 25 atm pressure. The water vapor, even in a nonmetallic container, can create a gas release when breached comparable to those listed in Table 32.

It should be noted, however, that the maximum postulated gas release is well within the capacity of the large-scale off-gas system of $104 \mathrm{std} \mathrm{m}^{3} / \mathrm{min}$. Therefore, as long as the combustible or void volumes inside the sealed containers meet the criteria outlined in the previous section, the ISV process is designed to accommodate such releases. Even though sealed containers limit the applicability of the pilot-scale off-gas system, their presence does not hamper the operation of the large-scale system. 


\section{Explosives}

The partial or full detonation of chemicals during ISV can result in the same undesirable effects listed in the previous section on combustibles. These effects may be more pronounced because the chemical structures of explosives, which include oxidizers, cause them to react very rapidly. Explosives may exist as inclusions or homogeneous mixtures within soil, as chemicals within a waste container, or as military ordnance items. The probability of buried military-grade explosives in TRU waste sites is extremely small; chemical mixtures such as organics and nitrates are more likely.

Conditions that would nitrate organic wastes such as cotton rags by nitric acid are very unlikely at a waste site. To achieve a significant degree of nitration, a hydrophilic agent such as sulfuric acid must be present since the final degree of nitration is strongly dependent on the final water concentration equilibrium (Chedin, Tribot, and Feneant 1948; Doree 1933; 0tt et al. 1947). Without such an agent, less than one-third of the hydroxide sites on cotton can become nitrated, even when concentrated $72 \%$ nitric acid is present.

The burial of military explosives would be in violation of the U.S. Army AMC Regulation Safety Manual (US Army 1970), which states that collected explosives and chemical wastes must not be disposed of by being buried. U.S. military organizations dispose of surplus explosives by burning. Nevertheless, even though it would be very poor practice to bury surplus bulk explosives with radioactive waste, the possibility exists. An analysis was performed to determine the effects of ISV on explosive inclusions and mixtures within the waste, using military-grade explosives as worst case. Descriptions of these explosives are given in Military Explosives, U.S. Army Manual TM 9-1300-214 (US Army 1967).

The hazards associated with the excavation, transportation, and incineration of dry humus soil contaminated with TNT and/or RDX have been assessed by Kirshenbaum (1982). Explosive/soil mixtures were subjected to impact, friction, electrostatic shock, and flame sensitivity tests. Contaminated soil mixtures from the Alabama Army Ammunition Plant, Umatilla Army Depot, Louisiana Army Ammunition Plant, and Savannah Army Depot were also assessed. Kirshenbaum determined that soil containing up to $25 \mathrm{wt} \%$ TNT and/or RDX can be excavated, 
transported, and incinerated safely. Soil containing $>10$ wt\% of the explosives is thermally reactive, which indicates that such mixtures unconfined could burn when heated to 175 to $200^{\circ} \mathrm{C}$. This would indicate that soil containing a homogeneous distribution of $>10$ wt\% up to 25 wt\% explosives will behave similarly to other combustible waste sites and can be vitrified safely.

Explosives can partially or fully detonate by three mechanisms:

1. self-heating when held at or above a minimum critical temperature for a period of time

2. rapid heating of an encased or confined explosive

3. pressurization caused by an impact or shock wave.

The minimum critical temperature for detonation depends upon the composition, size, and concentration of an explosive. As shown in Figure 60, when the diameter of a specific explosive increases, the critical temperature decreases (Dobratz 1981). Dilution of an explosive with soil will increase the critical temperature or the size of explosive required for an explosion at a given temperature.

High explosives, which include ammonium nitrate, ammonium perchlorate, Composition A, Composition B, H-6, HMX, lead azide, lead styphnate, NC, Pentolite, PETN, picric acid, RDX, Tetryl, and TNT, will decompose completely at temperatures $<400^{\circ} \mathrm{C}$ (Dobratz 1981). All these explosives typically melt 80 to $200^{\circ} \mathrm{C}$ below their decomposition temperatures. During ISV, soil below the advancing molten zone is heated to $100^{\circ} \mathrm{C}$, where it remains until all moisture has evaporated ( 2 hours). Once dry, the soil heats at a rapid rate of $\sim 10^{\circ} \mathrm{C} /$ min until it fuses into the molten zone. At this heating rate, explosive inclusions which are not contained would melt, soak into the surrounding soil, and decompose rather than self-heat to a detonation. Unmelted explosives with a critical temperature of $\leq 100^{\circ} \mathrm{C}$ could detonate during the time that the soil moisture is evaporating. Thus the probability of a detonation within a disposal site is reduced significantly if the explosive has a critical temperature $>100^{\circ} \mathrm{C}$. Even a moderately stable explosive such as PETN will not have a critical temperature as $10 \mathrm{w}$ as $100^{\circ} \mathrm{C}$ unless the charge diameter is $\geq 0.6 \mathrm{~m}$. The probability of such an inclusion is small. Contained explosives located to the 


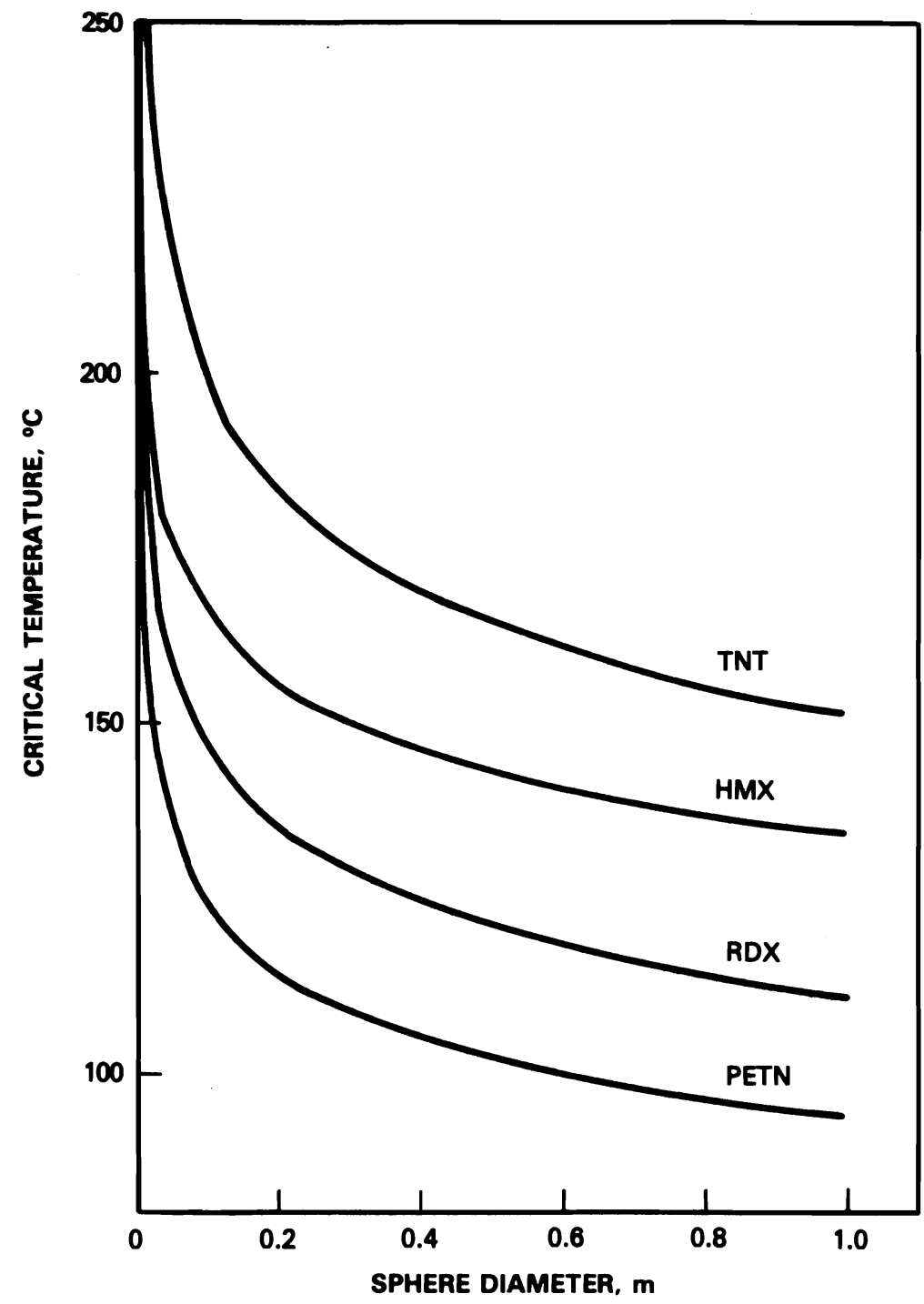

FIGURE 60. The Effect of Charge Diameters on Critical Temperatures for Some Pure Explosives (Dobratz 1981)

side of the ISV melt zone, however, could soak for a sufficient time above the critical temperature to cause a detonation.

Off gases produced from the decomposition or detonation of explosives such as TNT or HMX are not toxic because they are mostly $\mathrm{N}_{2}, \mathrm{NO}_{x}, \mathrm{H}_{2} \mathrm{O}, \mathrm{CO}_{2}$, and $\mathrm{CO}$, which can be easily treated by conventional off-gas equipment. An alkaline soil will act to absorb some of the nitric oxides. The gas volume generated by TNT and HMX ranges from 0.65 to $0.80 \mathrm{~m}^{3} / \mathrm{kg}$ of explosive. 
Intact ordnance items present a more serious detonation potential. Bombs and shells explode in a few minutes in a fuel fire, usually showing partial, if not full, detonation. Full or partial detonation of a $225 \mathrm{~kg}$ bomb in a shallow land burial trench would almost certainly breach the surface. For an ISV soil heating rate of $10^{\circ} \mathrm{C} / \mathrm{min}$, a high-integrity ordnance item would explode before the soil around it was fused; therefore, both soil particles and molten glass would be ejected from the trench. Ordnance items that are touching or that are within a critical distance apart will also undergo sympathetic detonation due to shock pressurization.

All possible explosives have not been evaluated, so the general safety of processing pure explosives and explosive/soil mixtures by ISV has not been fully resolved. Additional work is recommended to adequately address limitations to vitrifying soil which contains explosive chemical mixtures. It can be stated, however, that without proper precautions, ISV should not be applied to sites which contain or have the potential of containing intact ordnance items. To determine whether ordnance items are present, a historical survey should be made of each site, including a search for written procedures covering disposal practices during the time that the sites were in use.

Criticality

Since ISV changes the physical and chemical nature of the waste, the potential for criticality was evaluated. Transuranic radionuclides which emit neutrons may reach criticality if they are sufficiently concentrated or if the moderation properties of the waste site become altered.

Transuranic elements capable of sustaining a nuclear chain reaction that are common to waste sites are listed in Table 33 with their estimated subcritical mass limits (ANS 1975; ANS 1982; Clayton 1979). Table 34 shows the radionuclide content of buried and stored TRU waste at INEL. These values are approximate for other TRU waste sites. Since ${ }^{239} \mathrm{Pu}$ accounts for the greatest fraction of fissionable radionuclides at TRU waste sites, and also has one of the smaller subcritical mass limits, the criticality analysis presented in this section is based on the effects of ISV on this isotope. 
TABLE 33. Estimated Subcritical Mass Limits for Various Transuranic Nuclides

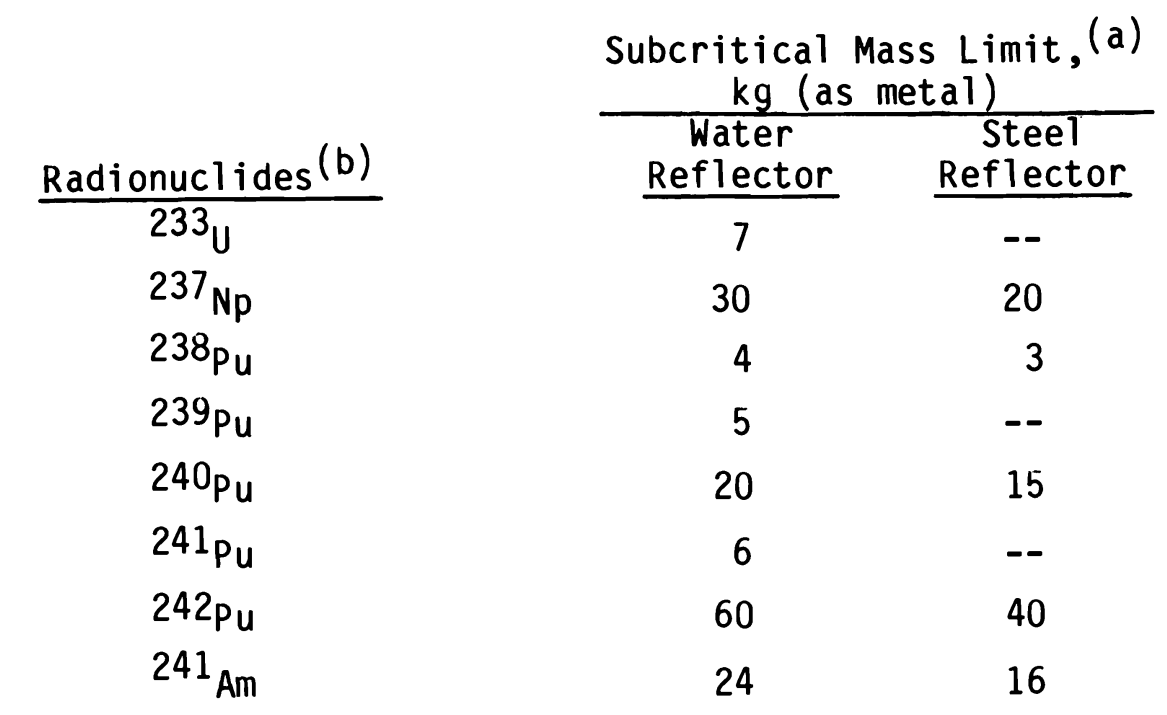

(a) Assumes spherical geometries and optimal moderation (ANS 1975; ANS 1982; Clayton 1979).

(b) Those found in significant quantities in TRU waste.

TABLE 34. Radionuclide Content of Buried and Retrievable TRU Waste at INEL (a)

\begin{tabular}{|c|c|c|c|c|}
\hline \multirow{2}{*}{$\begin{array}{c}\text { TRU } \\
\text { Radionuclides }\end{array}$} & \multicolumn{2}{|c|}{ Buried Waste } & \multicolumn{2}{|c|}{ Retrievable Waste } \\
\hline & $\mathrm{g}$ & $\%$ & $\mathrm{~g}$ & $\%$ \\
\hline $233_{U}$ & 50 & 0.01 & 55,500 & 20.0 \\
\hline${ }^{238} \mathrm{Pu}$ & 31 & 0.01 & 896 & 0.32 \\
\hline${ }^{239} \mathrm{pu}$ & 345,000 & 89.4 & 192,000 & 69.1 \\
\hline${ }^{240} \mathrm{Pu}$ & 24,300 & 6.29 & 14,300 & 5.14 \\
\hline $241 \mathrm{Pu}$ & 1,620 & 0.42 & 836 & 0.30 \\
\hline${ }^{242} \mathrm{Pu}$ & 50 & 0.01 & 50 & 0.02 \\
\hline $241_{A m}$ & 15,000 & 3.88 & 14,300 & 5.14 \\
\hline${ }^{244} \mathrm{Cm}$ & 0 & 0 & 13 & $<0.1$ \\
\hline Total weight, $g$ & \multicolumn{2}{|c|}{386,000} & \multicolumn{2}{|c|}{278,000} \\
\hline Total volume, $\mathrm{m}^{3}$ & \multicolumn{2}{|c|}{62,300} & \multicolumn{2}{|c|}{34,000} \\
\hline TRU density, $\mathrm{g} / \mathrm{m}^{3}$ & \multicolumn{2}{|c|}{6.20} & \multicolumn{2}{|c|}{8.18} \\
\hline
\end{tabular}

(a) Emplaced as of 12-31-77 (US DOE 1979). 


\section{Moderation Effects}

An important factor affecting the criticality potential of TRU waste trenches during ISV is the amount and degree of neutron-absorbing and neutronreflecting material near the fissionable material. It is known that during ISV at least four changes occur that might cause changes in the neutron reflection/ absorption properties of the waste site:

- Soil densifies and becomes glasslike.

- Organics and combustibles pyrolyze and are released from the melt.

- Water evaporates out of the melt area.

- Metal melts and settles to the bottom of the melt zone, leaving most of the vitrified area free of metal.

Critical limits have been calculated for Hanford soil containing Pu (Ridgway and Carter 1972). These calculations were for soil with 30 and 40 vol\% void space containing $\mathrm{Pu}$ and water within the void. The minimum critical mass is that mass of $\mathrm{Pu}$ required to reach a critical configuration under optimal conditions, and is greater than the subcritical mass limit discussed earlier. The minimum critical areal concentration is the minimum Pu mass per unit area in an infinite slab required to achieve criticality, assuming a homogeneous $\mathrm{Pu}$ distribution within a slab of optimal thickness.

The minimum critical mass for $\mathrm{Pu}\left(97 \mathrm{wt} \%{ }^{239} \mathrm{Pu}\right.$ and $3 \mathrm{wt} \%{ }^{240} \mathrm{Pu}$ ) in soil which is fully saturated with water is given in Table 35 for various degrees of reflection. Water-saturated soil is assumed as a worst case since the minimum critical mass is smallest when fully reflected. All of the minimum critical masses occur in the $\mathrm{Pu}$ concentration range of 10 to $20 \mathrm{~kg} / \mathrm{m}^{3}$. As a conservative measure, the minimum critical mass in Hanford soil is assumed to be $1.7 \mathrm{~kg}$, the value for $40 \%$ void space and full water reflection.

The melting process during ISV actually causes the ${ }^{239} \mathrm{Pu}$ minimum critical mass to increase because water is removed. Once the moisture has evaporated, the minimum critical mass increases to that of a dry sphere of plutonium oxide. The subcritical limit for an oxide sphere is $10.2 \mathrm{~kg} \mathrm{Pu}(11.5 \mathrm{~kg}$ as oxide). This value is for water-reflected oxide spheres at optimum conditions. 
TABLE 35. Minimum Critical Mass of Plutonium in Water-

Saturated Soil

\begin{tabular}{|c|c|c|}
\hline \multirow[b]{2}{*}{ Reflection } & \multicolumn{2}{|c|}{$\begin{array}{c}\text { Minimum Critjcal } \\
\text { Mass, kg Pu(a) } \\
\end{array}$} \\
\hline & $\begin{array}{l}30 \text { Vol\% } \\
\text { Soil Void } \\
\end{array}$ & $\begin{array}{l}40 \text { Vol\% } \\
\text { Soil Void } \\
\end{array}$ \\
\hline Unreflected & 4.1 & 3.0 \\
\hline $2.54 \mathrm{~cm}$ water & 3.2 & 2.3 \\
\hline Full water reflected & 2.4 & 1.7 \\
\hline
\end{tabular}

(a) $97 \mathrm{wt} \%{ }^{239} \mathrm{Pu}$ and $3 \mathrm{wt} \% 240 \mathrm{Pu}$ (Ridgway and Carter 1972).

The minimum critical areal concentration for Pu in Hanford soil is about $2.9 \mathrm{~kg} / \mathrm{m}^{2}$ for full water reflection. The concentration at which this occurs is about $8 \mathrm{~kg} / \mathrm{m}^{3}$ for an infinite slab about $36 \mathrm{~cm}$ thick. A waste site should be capable of vitrification if it has an areal Pu concentration of $<1.0 \mathrm{~kg} / \mathrm{m}^{2}(33 \%$ of the $2.9 \mathrm{~kg} / \mathrm{m}^{2}$ critical areal concentration) with no mechanisms of lateral concentration, or if it contains a total Pu mass $<0.6 \mathrm{~kg}(33 \%$ of the $1.7 \mathrm{~kg}$ minimum critical mass).

When fissile and organic materials densify prior to combustible decomposition, their potential for criticality increases. Plutonium has a smaller minimum critical mass when moderated by materials with higher hydrogen densities than water. In particular, polyethylene as a moderator results in a minimum critical mass of $0.36 \mathrm{~kg}$ (Thompson 1977). Both polyethylene and polypropylene are commonly discarded in TRU waste as bags, gloves, bottles, etc. Normal storage of these items results in a low moderator density in waste containers and packages. However, heating during ISV may cause these materials to melt and collect in a more dense form at the bottom of the waste container. The potential result is a near-optimum distribution of $\mathrm{Pu}$ in the organic moderator before the ISV process can decompose these materials and drive off the hydrogen. This phenomenon, although highly unlikely, could occur at temperatures under $300^{\circ} \mathrm{C}$. The minimum critical areal concentration for $\mathrm{Pu}$ decreases to $2.4 \mathrm{~kg} / \mathrm{m}^{2}$ for a polyethylene reflected system. The safe ISV operating limit 
becomes $0.8 \mathrm{~kg} / \mathrm{m}^{2}$ ( $33 \%$ of $2.4 \mathrm{~kg} / \mathrm{m}^{2}$ ) when large quantities of hydrogenated organics like polyethylene are present in drums or other waste containers.

\section{Mechanisms for Plutonium Concentration}

Plutonium concentration mechanisms become important if the areal Pu concentration limits listed in the previous section are exceeded. Several mechanisms have been identified for evaluation:

- Various TRU radionuclides in ISV glass may become insoluble, allowing some fissionable material to settle out of the molten glass.

- Dense TRU oxide particles may settle to the melt bottom.

- Reducing conditions in the molten zone may reduce some fissionable compounds to their metallic state and subsequently cause them to settle at the melt bottom in a more concentrated form.

Although Pu may enter the waste site as a sulfate, nitrate, hydroxide, halide, or carbonate, most $\mathrm{Pu}$ in TRU waste is converted to an oxide during ISV heating because plutonium oxides are highly stable. Plutonium (IV) silicate is also very stable; e.g., if any plutonium oxide reaction occurs during ISV, it will be to incorporate the $\mathrm{Pu}$ into the silicate matrix.

Reduction of $\mathrm{Pu}$ from the oxide to the metallic form during ISV is not thermodynamically favorable. An examination of the standard free energy of formation of various oxides as a function of temperature (Figure 61) shows that both $\mathrm{U}$ and $\mathrm{Pu}$ are highly electropositive metals, with stable oxide forms. This is usually the case with other actinide elements as well. Other major oxides in the soil (including $\mathrm{Fe}_{2} \mathrm{O}_{3}, \mathrm{SiO}_{2}$, and $\mathrm{Al}_{2} \mathrm{O}_{3}$ ) are thermodynamically more likely to be reduced to their elemental forms than plutonium oxide or uranium oxide.

Based on known plutonium oxide solubilities in high-level waste glasses, solubility limits are not expected to be exceeded during ISV of any TRU waste site. High-level waste glasses, which are very similar to ISV glass, have recorded plutonium oxide solubilities higher than $2 \%$ (Scheffler et al. 1977). 


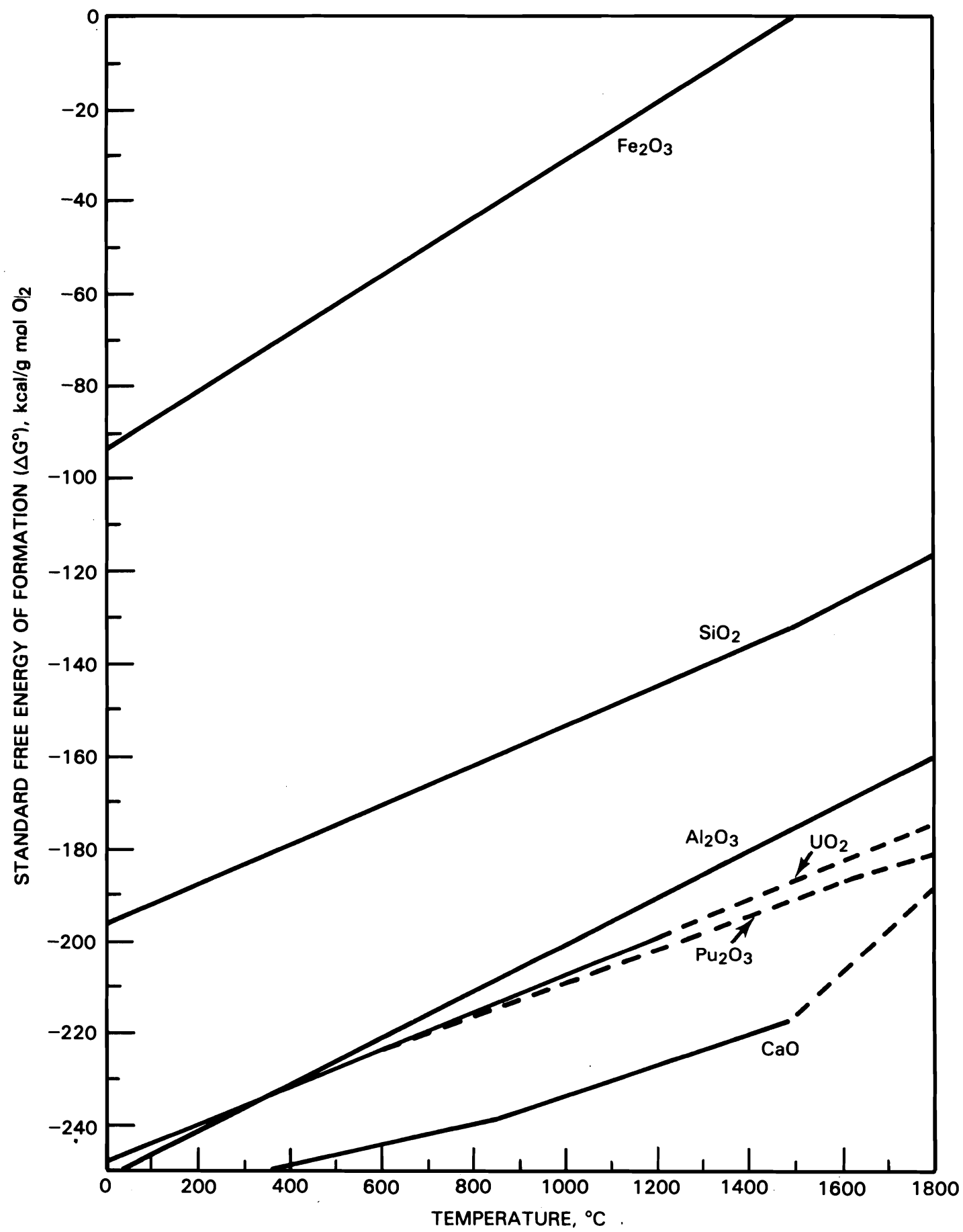

FIGURE 61. Standard Free Energy of Formation for Various Metal Oxides 
This solubility limit is over 10 times greater than the highest Pu concentration at any TRU contaminated soil site, with the exception of two or three reverse wells at Hanford.

The thorough convective mixing which is characteristic of ISV is expected to dilute any zones of high $\mathrm{Pu}$ concentration, further reducing the potential for a criticality. This was verified in actual ISV tests where simulated waste material was spiked with rare earth elements (Ce, La, and $\mathrm{Nd}$ ), which are expected to behave similarly to $\mathrm{Pu}$. An example of a typical distribution pattern has been provided in Figure 34. This sampling information illustrates that Ce became uniformly distributed laterally throughout the block. This uniform distribution of the rare earths suggests that actinides such as $\mathrm{Pu}$ would not migrate. The distribution of $\mathrm{Ce}$ and other elements aids in dispelling the concerns over selective migration effects.

Concentration by settling of undissolved plutonium oxide during ISV is considered unlikely for two basic reasons: 1) the ISV melt advances at a very slow rate, $<10 \mathrm{~cm} / \mathrm{h}$, so that any plutonium oxide in the upper part of the melt will have a long time period to dissolve before it could concentrate in significant amounts with plutonium oxide deeper in the waste site; and 2) plutonium oxide is typically a fine powder, which, even if it were to remain undissolved, will become thoroughly mixed within the glass by strong convective currents.

\section{CONCLUSIONS}

Parameters which affect the ISV process have been evaluated, including soil properties, moisture content, and waste inclusions. Mathematical predictions were made for the large-scale system at Hanford as well as other U.S. sites based on soil property data.

Soil properties from nine waste sites show little variation. Sites from which soils were tested include Barnwell, South Carolina; Hanford, Washington; INEL, Idaho; LANL, New Mexico; Maxey Flats, Kentucky; NTS, Nevada; ORNL, Tennessee; Sheffield, Illinois; and West Valley, New York. The soil properties most important to operation of the ISV process (fusion temperature, specific heat, thermal conductivity, and electrical conductivity) are similar to those 
of Hanford soils, which have been successfully vitrified during engineeringand pilot-scale tests. No ISV limitations have been identified due to soil property variations for the soils tested.

A mathematical model was developed to predict ISV process performance for different burial site geometries and to assist with scale-up from pilot to large scale. The model predicts that a melt depth of from $10 \mathrm{~m}$ to over $15 \mathrm{~m}$ is possible with a $3750 \mathrm{~kW}$ large-scale process, depending on heat losses. These depths are only possible at an electrode separation of $\leq 3.5 \mathrm{~m}$. As electrode separation is increased, the melt depth becomes limited by surface heat loss area. At a separation of $6 \mathrm{~m}$, the attainable depth ranges from $4 \mathrm{~m}$ to $10 \mathrm{~m}$, again being dependent on the heat losses.

The model predicts that an increase in soil moisture content above the water table will not reduce the melt depth attainable; however, the power required to vitrify the soil will increase. If the vitrification zone is below the water table, the soil must have a relatively high permeability, allowing water recharge before the ISV depth limit is reduced significantly. Model predictions were made for ORNL soil, assuming the water table is at ground level. The predictions show that soil moisture levels will not limit the ISV depth at ORNL, provided that areas of high permeability are not below or adjacent to the vitrification zone. Techniques are available for lowering the water table by pumping so that the attainable depth could be increased.

The effects on the ISV process of buried metals, cements, ceramics, combustibles, sealed containers, and explosives have been analyzed. Criticality limitations were also addressed. Both mathematical modeling and engineeringscale testing predict that the effects of metal inclusions will be insignificant unless a full short circuit is approached. During testing, the metal limit was not reached. A metal inclusion, accounting for $5 \%$ of the final block weight and occupying $70 \%$ of the distance between electrodes, was successfully vitrified. The electrode voltage was reduced $21 \%$ compared to the case when no metal was present; however, this was within the capabilities of the power supply. The large-scale ISV power system will have 14 voltage taps, which gives the system the ability to adapt to voltage changes caused by metal inclusions. 
In situ vitrification of soils containing concrete or pure cement inclusions decreases electrical conductivity of the melt zone and adds water vapor to the off-gas system. The flexibility designed into the large-scale power system compensates for any conductivity change resulting from vitrification of concrete or cement. With a design capacity of $104 \mathrm{std} \mathrm{m}^{3} / \mathrm{min}$, the large-scale off-gas system will handle water vapor and air inleakage generated during vitrification of pure cement.

Many other nonmetallic ceramic materials do not completely melt or dissolve during ISV. Nevertheless, they are effectively encapsulated by the glass and do not present a problem.

Buried combustible wastes pyrolyze, move to the melt surface, and burn during the ISV process. This increases both gas volume and heat load to the off-gas system. The large-scale off-gas system capacity will allow vitrification of a variety of waste configurations. Calculations show that combustible packages up to $0.9 \mathrm{~m}^{3}$ and void volumes up to $4.3 \mathrm{~m}^{3}$ can be processed without loss of hood vacuum. If combustibles are distributed relatively evenly throughout the soil, the off-gas system is capable of handling gases from soil containing $3200 \mathrm{~kg}$ of combustibles per meter of depth. This capacity includes additional air added to the hood to maintain $20 \%$ excess combustion air and assumes that the peak combustion rate is twice the average.

Sealed containers can rapidly release gas during ISV. However, the maximum postulated gas release is well within the capacity of the large-scale offgas system. As long as the combustible and void volumes inside the sealed container are within $4.3 \mathrm{~m}^{3}$ and $0.9 \mathrm{~m}^{3}$, respectively, the ISV process is designed to accommodate such releases.

Soil containing up to 25 wt\% TNT and/or RDX can be incinerated safely as long as the mixture is not contained (Kirshenbaum 1982). A contained explosive adjacent to an ISV melt zone may partially detonate if it is heated and allowed to soak at its critical temperature. Additional work is needed to determine the extent of this potential limitation. Intact ordnance items can explode upon rapid heating and should not be processed by ISV. Further study is required to better define the types of explosives likely to be present at TRU waste sites and the conditions under which those materials can detonate. 
In situ vitrification changes the geometry and moderation characteristics of a burial site. When fissionable materials are present in the site, the changes may affect criticality potential (keffective) without changing fissionable material content.

The study of the effects of ISV on the criticality potential of various TRU waste sites indicates the following:

- No credible concentration mechanism for ${ }^{239} \mathrm{Pu}$ or any other fissionable nuclei has been identified.

- As long as a waste site to be vitrified has a total Pu mass $<0.6 \mathrm{~kg}$ or an areal concentration $<1.0 \mathrm{~kg} / \mathrm{m}^{2}$, it should be able to be safely stabilized by ISV. For safety reasons, these limits are set at $33 \%$ of the minimum critical values.

- When large quantities of hydrogenated organic materials such as polyethylene are present with $\mathrm{Pu}$ in waste drums or other high integrity containers, the areal concentration limit is reduced slightly, to $0.8 \mathrm{~kg} / \mathrm{m}^{2}$. 


\section{ECONOMIC ANALYSIS}




\section{ECONOMIC ANALYSIS}

This section presents an economic analysis of ISV based on 12 possible configurations for pilot- and large-scale systems. The first six configurations were evaluated based on a radioactive site application, federal government ownership, and a site with a contaminated zone having the dimensions of $90 \mathrm{~m}$ long $\times 30 \mathrm{~m}$ wide $\times 5 \mathrm{~m}$ deep. These configurations represent a range of feasible applications for this waste solidification process. With the exception of configuration 1, which is a pilot-scale system, the configurations are characterized based on large-scale application. Other configuration descriptors include location (Hanford or generic site), power base (local or portable), expected heat loss (average or high), and manpower level (average or above average). The first six configurations are summarized in Table 36 . A second set of six configurations ( 7 through 12 ) was also evaluated based on vitrifying a generic waste trench located at Hanford and a site in the eastern U.S. This second set of configurations, evaluated for comparison with the first, will be discussed later in this section.

After identifying the six configurations of ISV included in this study, it is necessary to more specifically define the cost contributors. The cost analysis was broken down into site activities, equipment requirements, operations, and consumable supplies. Individual components of these categories

TABLE 36. Descriptions of Six Configurations for ISV of TRU Contaminated Soil

\begin{tabular}{|c|c|c|c|c|c|c|c|}
\hline Configuration & Scale & Site & Power & Heat Loss & $\begin{array}{l}\text { Manpower } \\
\text { Level } \\
\end{array}$ & $\begin{array}{l}\text { Number } \\
\text { of Sets } \\
\end{array}$ & $\begin{array}{l}\text { Run Time } \\
\text { Per Set, h }\end{array}$ \\
\hline 1 & Pilot & Hanford & Local & Average & Average & 300 & 220 \\
\hline 2 & Large & Hanford & Local & High & Average & 48 & 120 \\
\hline 3 & Large & Hanford & Local & Average & Average & 48 & 90 \\
\hline 4 & Large & Hanford & Local & Average & Above Avg. & 48 & 90 \\
\hline 5 & Large & Generic & Local & Average & Average & 48 & 90 \\
\hline 6 & Large & Generic & Portable & Average & Average & 48 & 90 \\
\hline
\end{tabular}


are listed in Table 37 and are described in the following sections. Some of the components are not included in the cost of every configuration. (a)

The section following the cost component description discusses the financing consequences associated with federal ownership of ISV equipment. The next

\section{TABLE 37. Major Contributors to ISV Costs}

\section{Site Activities}

- Transporting equipment to and from site

- Clearing veyetation

- Rough grading

- Removing overburden

- Acquiring and applying backfill material

\section{Operations}

- Process preparations

Drill holes and place electrodes

Spread graphite starter material

Position frame and hood, secure electrodes

Connect power cables and off-gas line

Vitrify

Disconnect power cables and off-gas line

Remove frame and hood

Backfill vitrified area

Move power cables along lines

- Processing

Off-gas treatment system

Power system

Radiation or toxic chemical monitoring

Melt verification

off-gas waste disposal
Equipment

- Power

Portable generator

Power lines

Substation

Power cables

- Mechanical

Electrode frame and hood Drilling machinery

Crane

Front-end loader

- Off-Gas and monitoring

Off-gas treatment system

Radiation and off-gas monitors/alarms

Consumable Supplies

- Electrodes

- Fuel

- Electricity

(a) For example, each configuration would require either power lines from the nearest source or a portable generator, but not both. 
section presents cost estimates associated with implementing each of the six configurations. The costs are summarized in the text and compared in table form.

\section{SITE ACTIVITIES}

Site activities include transporting equipment to and from the site, clearing vegetation, grading the ground, removing overburden, and acquiring and applying backfill material as needed (Table 37 ). Soil sampling, well logging, and other activities associated with site characterization have been excluded from this analysis because of expected similarities in cost regardless of the stabilization alternative employed. Otherwise, the costs developed here represent the full cost of vitrification.

Each of the six configurations was analyzed on the basis that no overburden was removed. If overburden could be removed safely, it would always be advantageous to do so from a cost standpoint. For example, removal of the top meter from a $2700 \mathrm{~m}^{2}$ site would cost less than $\$ 10,000$, compared to the hundreds of thousands of dollars needed for labor and power charges to vitrify the same area to a $1 \mathrm{~m}$ depth. In short, site activity costs will be insignificant when compared to labor, consumable supplies, and equipment for the majority of potential ISV applications.

\section{EQUIPMENT REQUIREMENTS}

Data on equipment requirements were acquired from vendors and cost estimating manuals (Means 1980; Guthrie 1974) where possible. Other equipment requirements were estimated based on scaling up from smaller sizes. All costs were adjusted to 1982 dollars.

Electrical equipment requirements are largely determined by voltage and current needs. Increased current requires larger conductors, whereas increased voltage requires more insulation. At the high ( $>1000 \mathrm{~A})$ level of current required for ISV, power cables become rather large $(\sim \mathrm{cm}$ dia), precluding their cost effectiveness as a power line. For this reason both the primary power line (200 $\mathrm{m}$ from nearest $13.8 \mathrm{kV}$ power source) and secondary power line (90 m, paralleling the vitrification site) were assumed to carry $13.8 \mathrm{kV}$ power. Power lines are more conducive to the transport of high-voltage power, because separation in 
space fulfills part of the insulation requirements. High-voltage transmission lines are also more efficient. Substation (transformer) costs are similarly affected by voltage and current. Here, the product of volts multiplied by amps, or power, is the principal cost-controlling factor, rather than either voltage or current.

Power equipment requirements and the resulting costs were estimated based on the above information and data acquired from the following sources. The cost of a $3 \mathrm{MW}$ portable generator was obtained from 0'Brien Machinery Co., (a) and power cabling cost data were acquired from the Phelps-Dodge Co. (b) Power line and substation costs were developed based on unit cost and scaling data from Means (1980) and Guthrie (1974).

Three pieces of heavy equipment are necessary for ISV operations: a drilling or augering machine for placing the electrodes in the ground, a crane for transporting the electrode frame and hood from one set to the next, and a frontend loader for backfilling. Consideration was given to the question of renting rather than buying the equipment. Given the length of the projects ( 9 months to 10 years) and the cost of renting these types of equipment (typically several hundred dollars per day), the choice was made to purchase these three pieces of equipment. Heavy equipment costs are based on cost estimates provided by Highway Equipment Co., (c) Coast Crane Co., (d) and Caterpillar Equipment, Inc. (e)

Both power equipment and heavy equipment costs are itemized in Table 38 for pilot- and large-scale systems. The powerline cost is the same for the two systems because both require powerlines of the same length and voltage.

(a) Telephone conversation between D. R. Brown, Pacific Northwest Laboratory, and personnel at O'Brien Machinery Co., November 1982.

(b) Telephone conversation between S. A. Weakley, Pacific Northwest Laboratory, and D. Nelson, Phelps Dodge representative, December 1982.

(c) Telephone conversation between S. A. Weakley, Pacific Northwest Laboratory, and personnel at Highway Equipment Co., October 1979.

(d) Telephone conversation between L. W. Long, Pacific Northwest Laboratory, and personnel at Coast Crane Co., April 1979.

(e) Telephone conversation between D. R. Brown, Pacific Northwest Laboratory, and personnel at Caterpillar Equipment Inc., December 1982. 
TABLE 38. Power Equipment and Heavy Equipment Costs for the Pilot- and Large-Scale Systems

\begin{tabular}{|c|c|c|}
\hline Equipment & $\begin{array}{c}\text { Cost, } \\
\text { Pilot Scale } \\
\end{array}$ & $\frac{1982 \$}{\text { Large Scale }}$ \\
\hline Portable generator (a) & N/A & 785,000 \\
\hline Power lines & 15,000 & 15,000 \\
\hline Substation & 75,000 & 150,000 \\
\hline Power cables & 5,500 & 11,000 \\
\hline Drilling machinery & 68,000 & 68,000 \\
\hline Crane & 56,000 & 74,000 \\
\hline Front-end loader & 30,000 & 50,000 \\
\hline
\end{tabular}

(a) The portable generator is only used in configuration 6 .

Similarly, the drilling machinery is the same for both systems since the electrode size does not change. Substation and power cables scale according to power level; the crane and front-end loader scale according to the electrode frame and hood size and backfilling rate, respectively.

Costs for the pilot-scale off-gas system plus electrode frame and hood were quoted by equipment vendors and fabricators and include delivery to PNL. Largescale system cost estimates for the same equipment were developed by scaling up pilot-scale costs according to changes in the principal design variable, off-gas flow rate. Off-gas equipment was broken down into flow related and instrumentation categories. Flow related equipment costs, e.g., scrubbers, blowers, filters, tanks, piping, etc., were scaled up based on individual scaling factors for each equipment type and the change in capacity (flow rate). Instrumentation equipment costs were increased by a substantially smaller fraction, since these equipment types are not directly affected by volumetric changes.

Costs for the large-scale electrode frame and hood were scaled up from the pilot-scale equipment in a manner similar to that for the off-gas system. The total fabricated cost for frame and hood was divided into material and labor charges. Material charges were adjusted by a factor of $5 / 1.2$ (the ratio of large-scale width to pilot-scale width) based on the increase in frame size and requirements for heavier gauge material. Labor costs, principally for welding 
and handling, were also adjusted to reflect the increased size and gauge. offgas system and off-gas containment hood costs are given in Table 39 for both the pilot- and large-scale systems.

\section{OPERATIONS}

This section describes the manpower requirements resulting from the operations associated with ISV. The labor-intensive nature of ISV makes the assessment of manpower requirements and wage rates a critical part of the cost analysis. Process preparation and processing operations are analyzed.

\section{Process Preparation}

The time required for each setting of the electrode frame and hood is the sum of the vitrification time to depth, plus the cooldown period, plus the time required to move the off-gas equipment to the next set. Total project time is equal to the time per set multiplied by the number of sets. The time per set for the pilot- and large-scale systems is shown in Table 40. The number of sets depends on the dimensions of the site to be vitrified and the area vitrified per set. This latter characteristic is a function of electrode spacing, vitrification time per set, and acceptable allowances for overlap between vitrified blocks. Appropriate data for determining the total number of sets for each configuration are summarized in Table 41.

TABLE 39. Off-Gas System and Electrode Frame and Hood Costs for the Pilotand Large-Scale Systems

\begin{tabular}{lccc}
\multicolumn{1}{c}{ Component } & & \multicolumn{2}{c}{ Cost, 1982 $\$$} \\
\cline { 1 - 1 } $\begin{array}{l}\text { Flow-related Scale } \\
\text { off-gas equipment }\end{array}$ & & $\frac{\text { Large Scale }}{184,000}$ & 468,000 \\
$\begin{array}{l}\text { Instrumentation for } \\
\text { off-gas equipment }\end{array}$ & 188,000 & 328,000 \\
$\begin{array}{l}\text { Installation of } \\
\text { off-gas equipment }\end{array}$ & 179,000 & 382,000 \\
$\begin{array}{l}\text { off-gas containment } \\
\text { hood; cost per single } \\
\text { unit, three required }\end{array}$ & & 12,000 & 65,000
\end{tabular}


TABLE 40. Time Requirements for Each Setting

\begin{tabular}{lccc} 
Vitrification & $\begin{array}{c}\text { Pilot Scale, } \\
\text { 5-m Depth, } \\
\text { h/set }\end{array}$ & $\begin{array}{c}\text { Large Scale, } \\
\text { 5-m Depth, } \\
\text { h/set }\end{array}$ \\
\cline { 2 - 2 } $\begin{array}{l}\text { Cooldown period } \\
\begin{array}{c}\text { Moving equipment } \\
\text { Total }\end{array}\end{array}$ & $\begin{array}{c}2.5 \\
226.5\end{array}$ & & $\frac{4}{110}$
\end{tabular}

TABLE 41. Electrode Spacing and Vitrification Settings

\begin{tabular}{|c|c|c|}
\hline Parameter & $\begin{array}{l}\text { Pilot Scale, } \\
5 \mathrm{~m} \text { Depth } \\
\end{array}$ & $\begin{array}{l}\text { Large Scale, } \\
5 \mathrm{~m} \text { Depth }\end{array}$ \\
\hline Electrode spacing, $m$ & 1.0 & 4.7 \\
\hline $\begin{array}{l}\text { Separation between elec- } \\
\text { trodes of adjacent set, } m\end{array}$ & 2.0 & 2.8 \\
\hline Width vitrified per set, $\mathrm{m}$ & 3.0 & 7.5 \\
\hline Area to be vitrified, $m$ & $90 \times 30$ & $90 \times 30$ \\
\hline Set matrix & $10 \times 30$ & $4 \times 12$ \\
\hline Number of settings & 300 & 48 \\
\hline
\end{tabular}

Personnel for process preparation (see Table 42) are required at scheduled intervals (once per setting of the off-gas containment hood). Manpower requirements were estimated for each of the process preparation activities for both pilot- and large-scale systems. Despite the difference in equipment size, the manpower requirement was estimated to be the same for both systems. There are two major reasons for this. First, the principal activity within this category, drilling and placement of electrodes, is identical for each system; and second, work crews must often be called out for a minimum of 4 hours, regardless of the length of the task.

As a practical matter, local union rules may require several different types of crews covering the various craft jurisdictions. Each of these crews has a predetermined number of people associated with it. In light of these facts, the economic analysis includes consideration of both average and above-average labor requirements. These estimates are summarized in Table 42. 
TABLE 42. Manpower Requirements for Process Preparation

\begin{tabular}{|c|c|c|}
\hline & Manpower & te, man-hours/set \\
\hline Classification & Average & Above Average \\
\hline Electrician & 4 & 8 \\
\hline Laborer & 34 & 76 \\
\hline Operator & 19 & 42 \\
\hline
\end{tabular}

A manpower rate was obtained for each person involved in ISV operations, with appropriate differentials allowed according to job class and site location. Processing personnel were classified as technicians, radiation monitors, or engineers. Process preparation personnel were classified as operators, electricians, laborers, or maintenance. Manpower rates for Hanford operations reflect current costs for J. A. Jones (a) (process preparation operations plus site work) and PNL (processing operations) personnel. The manpower rates cover both direct and indirect (including overhead) costs. Separate manpower rates were developed for process preparations and site work personnel at the generic site (Means 1981). The lower generic-site manpower rates reflect U.S. average direct-manpower costs. Processing operations manpower rates do not vary significantly between Hanford and national averages. The rates for all of the labor catagories, summarized in Table 43, were adjusted to reflect 1982 costs.

Processing

During vitrification of radioactive wastes, it was estimated that one person would be required for each of the four processing operations listed in Table 37. These four people would be required for various portions of each day for the duration of the vitrification program. The subjective nature of the hourly need of a radiation monitor again led to the inclusion of both a high and low processing operations labor estimate. The average and above average manpower requirements for each position are outlined in Table 44 for day, swing, and graveyard shifts.

(a) Telephone conversation between D. R. Brown, Pacific Northwest Laboratory, and P. J. Mills, J. A. Jones Construction Co., November 1982. 
TABLE 43. Manpower Rates for In Situ Vitrification

(includes indirect and overhead costs)

\begin{tabular}{lcc} 
& \multicolumn{2}{c}{ Manpower Rate, $1982 \$ / \mathrm{h}$} \\
\cline { 2 - 3 } Job Classification & $\begin{array}{c}\text { Hanford Site, } \\
\text { Federal Ownership }\end{array}$ & $\begin{array}{c}\text { Generic Site, } \\
\text { Federal Ownership }\end{array}$ \\
\cline { 3 - 3 } Electrician & 46.37 & 37.51 \\
Engineer & 45.00 & 45.00 \\
Laborer & 38.35 & 31.03 \\
Operator & 40.56 & 32.81 \\
Radiation monitor & 40.00 & 40.00 \\
Technician & 40.00 & 40.00
\end{tabular}

TABLE 44. Labor Estimate for Processing Operations at a Radioactive Site

\begin{tabular}{|c|c|c|c|c|c|}
\hline \multirow[b]{2}{*}{ Job Classification } & \multicolumn{3}{|c|}{ Workers Per Shift } & \multirow{2}{*}{$\begin{array}{l}\text { Total Man- } \\
\text { Days/Day }\end{array}$} & \multirow{2}{*}{$\begin{array}{l}\text { Total Man-hours/ } \\
100 \mathrm{~h} \mathrm{Set} \\
\end{array}$} \\
\hline & Day & Swing & Graveyard & & \\
\hline Enyineer & 1 & 0 & 0 & 1 & 36.7 \\
\hline Maintenance & 0.5 & 0 & 0 & 0.5 & 18.3 \\
\hline Operator & 2 & 2 & 2 & 6 & 220 \\
\hline Radiation monitor(a) & $0.5(1)$ & $0.1(1)$ & $0.1(1)$ & $0.7(3)$ & $25.7(110)$ \\
\hline Total & & & & $8.2(10.5)$ & $300.7(385)$ \\
\hline
\end{tabular}

(a) Values in parentheses represent high manpower estimate with fulltime radiation monitor.

In addition to the manpower requirements and their associated labor charges, the cost of disposing of liquid wastes collected in the of $f$-gas system must be included. Approximately $3028 \mathrm{~L}$ (800 gal) per large-scale setting and $757 \mathrm{~L}$ (200 gal) per pilot-scale setting must be disposed of at a cost of $\$ 2.01 / \mathrm{L}$ $(\$ 0.53 / \mathrm{gal})$. This results in additional charges of $\$ 20,350\left(\$ 1.51 / \mathrm{m}^{3}\right)$ and $\$ 31,800\left(\$ 2.36 / \mathrm{m}^{3}\right)$ for the large- and pilot-scale systems, respectively. 
Consumable Supplies

Consumable supplies include electrodes and electrical power or fuel. The graphite electrodes employed in the vitrification process remain in the ground and are not reused. The number of electrodes required for a given area is directly proportional to the number of sets of the electrode frame required to complete vitrification. Cost data for graphite electrodes were obtained from both Great Lakes Carbon $(\mathrm{a})$ and Airco-Spear ${ }^{(b)}$ companies. Cylindrical electrode costs are proportional to weight (or volume). In addition to the raw material costs, there are additional costs for machining the electrode tops and joining the $1.8 \mathrm{~m}$ segments of longer electrodes with connectors.

Electrical power requirements are a significant portion of the operating cost, whether local or portable power is used. Hanford power costs roughly $\$ 0.029 / \mathrm{kWh}$, while the average national industrial rate is $\$ 0.049 / \mathrm{kWh}$. The marginal cost of power from the portable generator available from 0'Brien Machinery is $\$ 0.0825 / \mathrm{kWh}$, based on an efficiency of $0.28 \mathrm{~L} / \mathrm{kWh}(0.075 \mathrm{gal} / \mathrm{kWh})$ and a fuel cost of $\$ 4.16 / \mathrm{L}(\$ 1.10 / \mathrm{gal})$. The power requirements for the six configurations are given in Table 45 .

TABLE 45. Power Requirements for ISV Configurations 1 Through 6

\begin{tabular}{cc} 
Configuration & $\begin{array}{c}\text { Energy } \\
\text { Requirement, kWh }\end{array}$ \\
\cline { 2 - 2 } 1 & $2.904 \times 10^{7}$ \\
2 & $1.958 \times 10^{7}$ \\
3 & $1.469 \times 10^{7}$ \\
4 & $1.469 \times 10^{7}$ \\
5 & $1.469 \times 10^{7}$ \\
6 & $1.469 \times 10^{7}$
\end{tabular}

(a) Telephone conversation between K. H. Oma, Pacific Northwest Laboratory, and personnel at Great Lakes Carbon Co., March 1983.

(b) Telephone conversation between K. H. Oma, Pacific Northwest Laboratory, and personnel at Airco-Spear Co., March 1983. 


\section{FINANCING}

Federal ownership was assumed for operations at both Hanford and the generic site. Financing affects the capitalized or equipment portion of ISV costs. The cost of capital equipment must be spread out over its useful life rather than attributing purchased equipment costs to any single project or year. This spreading of the capital costs is effectively handled by multiplying capital costs by the fixed-charge rate. The fixed-charge rate is a fraction which, when multiplied by the capital investment, represents the contribution of capital costs, income taxes, and other miscellaneous costs and taxes to a uniform annualized capital cost. The fixed-charge rate is a function of the cost of capital, equipment life, tax rates, depreciation, and tax credit allowances. The fixed-charge rate resulting from the federal financing assumptions listed in Table 46 is 0.145 .

The capital cost per cubic meter is calculated by dividing the annualized capital cost by the annual vitrification rate. The annual vitrification rate is $80 \%$ of the volume that would be vitrified if the equipment were to operate 24 hours a day, 365 days a year. The $20 \%$ difference allows for regular maintenance, unplanned shutdowns, and those periods when the equipment is between assigned operations.

\section{CONCLUSIONS}

The unit cost, productivity, and consumption data defined and developed in the previous sections were integrated to produce cost estimates for each of the six ISV configurations. These cost estimates are shown in Table 47.

\section{TABLE 46. Federal Financing Assumptions}

\begin{tabular}{lll}
\multicolumn{1}{c}{ Parameter } & \multicolumn{1}{l}{ Value } \\
Equipment life, yr & 10 \\
Cost of capital, $\%$ & 7 \\
Depreciation & N/A \\
Tax credit & N/A \\
Miscellaneous costs, $\%$ & 0.25 \\
Miscellaneous taxes, $\%$ & 0
\end{tabular}


TABLE 47. Cost Summary for ISV Configurations 1 Through 6 (based on vitrifying a $90 \mathrm{~m} \times 30 \mathrm{~m} \times 5 \mathrm{~m}$ deep site)

\begin{tabular}{|c|c|c|c|c|c|c|c|}
\hline \multirow[b]{2}{*}{ Configuration } & \multicolumn{7}{|c|}{ Cost, $1982 \$ / \mathrm{m}^{3}$ of Soil Vitrified } \\
\hline & Site & Equipment & Labor & $\begin{array}{c}\text { Waste } \\
\text { Disposal }\end{array}$ & Electrode & Power & Total \\
\hline 1 & 2 & 87 & 609 & 2 & 96 & 62 & 858 \\
\hline 2 & 2 & 18 & 63 & 2 & 15 & 42 & 142 \\
\hline 3 & 2 & 14 & 51 & 2 & 15 & 32 & 116 \\
\hline 4 & 2 & 14 & 73 & 2 & 15 & 32 & 138 \\
\hline 5 & 1 & 14 & 50 & 2 & 15 & 53 & 135 \\
\hline 6 & 1 & 21 & 50 & 2 & 15 & 90 & 179 \\
\hline
\end{tabular}

The most striking observation is the economy-of-scale shown in the comparison of the pilot-scale system (configuration 1 ) to the large-scale system (configurations 2 through 6 ). Vitrification cost decreases by a factor of 6 as electrode spacing is increased from 1.0 to $4.7 \mathrm{~m}$. Increasing electrode spacing sharply decreases the number of sets required to vitrify the entire site and since labor and electrode costs are proportional to the number of sets, these costs also drop sharply. The enhanced utilization of the capital equipment also serves to provide economies-of-scale as the annual vitrification capacity increases from 1390 to $17,900 \mathrm{~m}^{3} / \mathrm{yr}$. For comparison, the charge for low-level defense waste disposal at Hanford is $\$ 145 / \mathrm{m}^{3}$, and the cost of placing TRU waste in retrievable storage is $\$ 370 / \mathrm{m}^{3}$. Portable power is an expensive option, as shown by the comparison of cases 5 and 6 . Consumables (fuel for the generator) become the dominating cost and equipment costs also rise substantially for the portable power configuration. Final reconciliation of manpower requirements between the average (case 3 ) and above average (case 4) estimates will have a significant, but not dominating, cost effect.

The cost figures presented in Table 47 were used to estimate the total cost for vitrifying the contaminated zone shown in Figure 62 for the 216-Z-1A site at Hanford. Vitrifying a waste volume of $2900 \mathrm{~m}^{3}$ with the pilot-scale equipment would cost $\$ 2.5$ million. If large-scale equipment were employed, the estimated cost would be $\$ 340,000$ based on the conditions associated with configuration 3 . If the most conservative aspects of configurations 2 and 4 (high heat loss and 

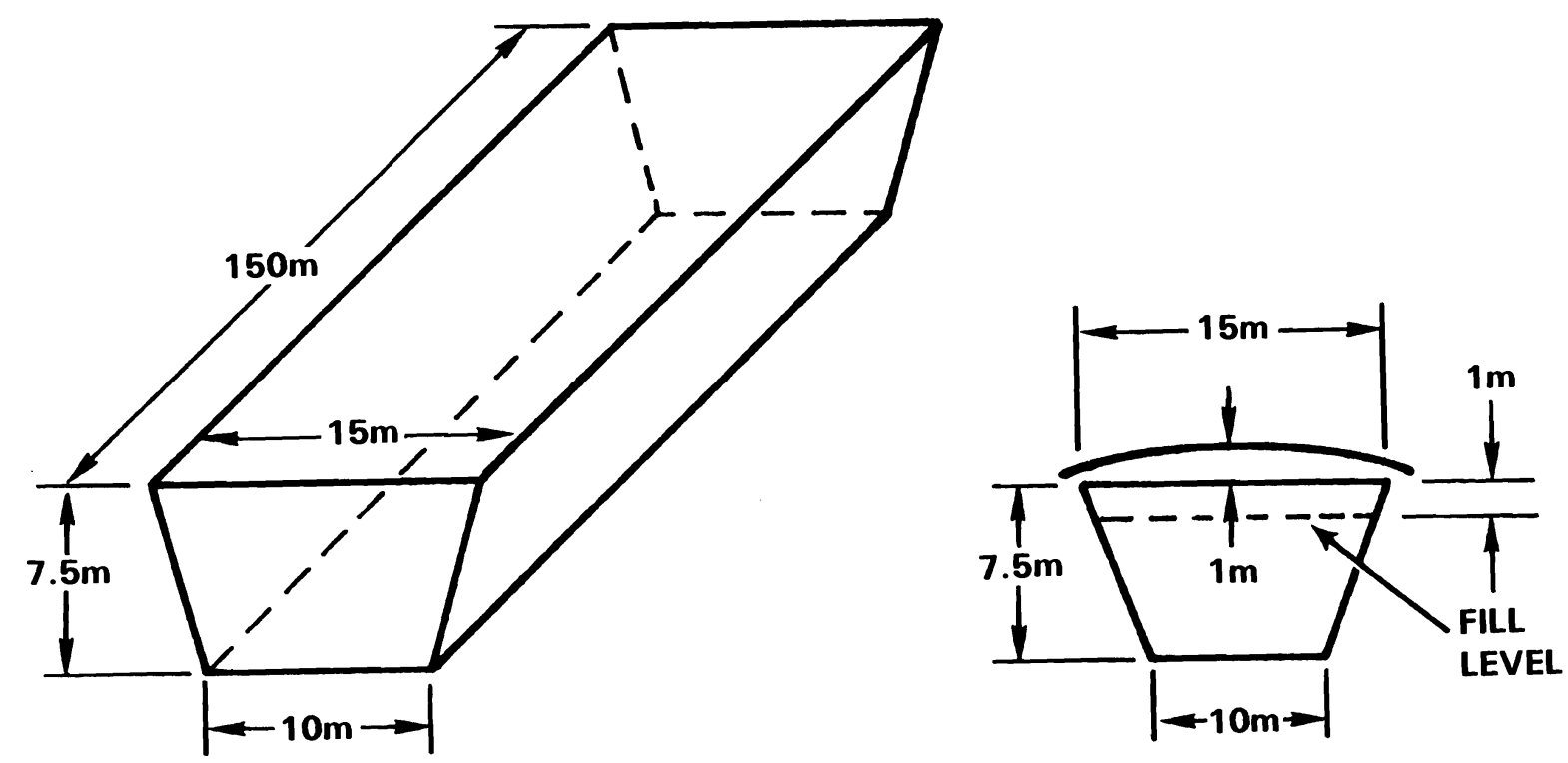

Trench dimensions $(L \times W \times D)(a)$

\begin{tabular}{|c|c|}
\hline Hanford Site & Eastern Site \\
\hline $\begin{array}{l}5 \times 15 \times 7.5 \mathrm{~m} \\
51 \times 16 \times 8 \mathrm{~m} \\
5 \%\end{array}$ & $\begin{array}{l}150 \times 15 \times 7.5 \mathrm{~m} \\
152 \times 17 \times 8.5 \mathrm{~m} \\
25 \%\end{array}$ \\
\hline
\end{tabular}

Contaminated zone dimensions ( $L$
Soil moisture (dry weight bases)

FIGURE 62. Characteristics of a Generic Waste Trench

(a) These dimensions are the same as described in Murphy and Holter (1980).

above average labor) were combined, the cost could be $\$ 490,000$, still less than $20 \%$ of the cost for pilot-scale vitrification.

The cost of vitrifying a waste trench at Hanford was compared to the cost of vitrifying a trench at a federal site in the eastern United States. The dimensions of the trench are the same for both locations and are shown in Figure 62.

The dimensions of the contaminated zone to be vitrified were assumed to be an additional $0.5 \mathrm{~m}$ on each side of the original trench boundary for the site at Hanford and an additional $1.0 \mathrm{~m}$ on each side for a site in the eastern U.S. It was also assumed that the soil of the eastern site has a higher moisture content. Table 48 presents the operating parameters for a large-scale ISV process at both the eastern and western sites.

Differences in costs among the configurations result from varying the assumptions regarding site location, surface heat loss, and electrode spacing 
TABLE 48. Operating Parameters for a Large-Scale ISV Process (configurations 7 through 12)

\begin{tabular}{|c|c|c|c|c|c|c|c|c|}
\hline Configuration & Site & $\begin{array}{l}\text { Heat } \\
\text { Loss }\end{array}$ & $\begin{array}{l}\text { Electrode } \\
\text { Spacing, m }\end{array}$ & $\begin{array}{c}\text { Separation } \\
\text { Between } \\
\text { Adjacent Sets, m } \\
\end{array}$ & $\begin{array}{l}\text { Width Vitrified } \\
\text { per Set, } m \\
\end{array}$ & $\begin{array}{l}\text { Set } \\
\text { Matrix }\end{array}$ & $\begin{array}{l}\text { Number } \\
\text { of Sets }\end{array}$ & $\begin{array}{l}\text { Run Time } \\
\text { per Set, } h\end{array}$ \\
\hline 7 & West & High & 3.8 . & 1.5 & 5.3 & $3 \times 29$ & 87 & 210 \\
\hline 9 & West & Average & 6.3 & 1.7 & 8.0 & $2 \times 20$ & 40 & 430 \\
\hline 10 & East & High & 4.1 & 1.6 & 5.7 & $3 \times 27$ & 81 & 410 \\
\hline 11 & East & Average & 4.1 & 1.6 & 5.7 & $3 \times 27$ & 81 & 230 \\
\hline
\end{tabular}


(Table 49). Site location is important for two reasons. Electrical power is less costly at Hanford than at the eastern location. The dryness of western soils results in an additional cost advantage over the eastern site, because less energy is needed to remove the water during vitrification. Surface heat loss has an obvious effect on the time (and thus cost) required to vitrify a given volume of soil. Higher heat losses reduce vitrification efficiency and require additional electric power to complete the melting process. Electrode spacing also has an effect on cost. Increasing electrode spacing (compare configurations 8 and 9 , and 11 and 12 ) reduces the number of sets by approximately a factor of 2 , but increases the run time per set by a factor between 3 and 4 .

The cost of ISV for each of the trench configurations is higher than for all of the large-scale configurations (2 through 6) previously evaluated. Specifically, one might expect the cost of configuration $8\left(\$ 199 / \mathrm{m}^{3}\right)$ to be closer to the cost for configuration $2\left(\$ 116 / \mathrm{m}^{3}\right)$, as described in Tables 36 and 37 . Both configurations are based on Hanford site conditions with an average heat loss. Three factors contribute to the cost difference:

- The process efficiency for vitrifying the deeper $(7.5 \mathrm{~m}$ vs. $5.0 \mathrm{~m})$ trench site is lower (see Figure 46 for illustration of the relationship between electrode spacing, depth, and run time).

- The closer electrode spacing required for the trench configuration results in extra settings of the off-gas containment hood.

TABLE 49. Cost Summary for ISV Trench Configurations 7 through 12

\begin{tabular}{|c|c|c|c|c|c|c|c|}
\hline \multirow[b]{2}{*}{ Configuration } & \multicolumn{7}{|c|}{ Cost, $1982 \$ / \mathrm{m}^{3}$ of soil vitrified } \\
\hline & Site & Equipment & Labor & $\begin{array}{c}\text { Waste } \\
\text { Disposal }\end{array}$ & Electrode & Power & Total \\
\hline 7 & 1 & 37 & 125 & 2 & 19 & 92 & 276 \\
\hline 8 & 1 & 26 & 90 & 2 & 19 & 61 & 199 \\
\hline 9 & 1 & 34 & 108 & 1 & 9 & 88 & 241 \\
\hline 10 & 1 & 57 & 183 & 2 & 16 & 247 & 506 \\
\hline 11 & 1 & 33 & 109 & 2 & 16 & 139 & 300 \\
\hline 12 & 1 & 51 & 157 & 1 & 7 & 229 & 446 \\
\hline
\end{tabular}


- In a TRU contaminated soil site (configurations 2 through 6 ), the ratio of the waste vitrified to volume vitrified approaches 1 . In a specific configuration such as a trench, this ratio decreases, increasing the cost when viewed from the standpoint of $\$ / \mathrm{m}^{3}$ of waste vitrified. 


\section{ANALYSIS OF OCCUPATIONAL AND PUBLIC SAFETY}


is given by Oma, Farnsworth, and Rusin (1982).] Gibson (1982) has developed an empirical relationship based on conditions at 216-Z-1A to estimate Pu migration through Hanford soil.

The 216-Z-1A tile field was built in 1949. Details of the tile field construction are shown in Figure 63. The surface dimensions of the tile field are about $60 \times 110 \mathrm{~m}$. The side walls of the $5.8 \mathrm{~m}$ deep excavation were sloped inward, resulting in floor dimensions of about $30 \mathrm{~m}$ wide by $80 \mathrm{~m}$ long. An evaluation of a contaminated zone that is 5 to $7.5 \mathrm{~m}$ wide by $90 \mathrm{~m}$ long was made and represents an accurate estimation of the area requiring vitrification at this particular site. These dimensions are used to calculate the number of settings required for both pilot- and large-scale systems.

The tile-field distribution system for the liquid waste is composed of $20 \mathrm{~cm}$ dia fired clay pipe laid out in a herringbone pattern with a $79 \mathrm{~m} 1 \mathrm{ong}$

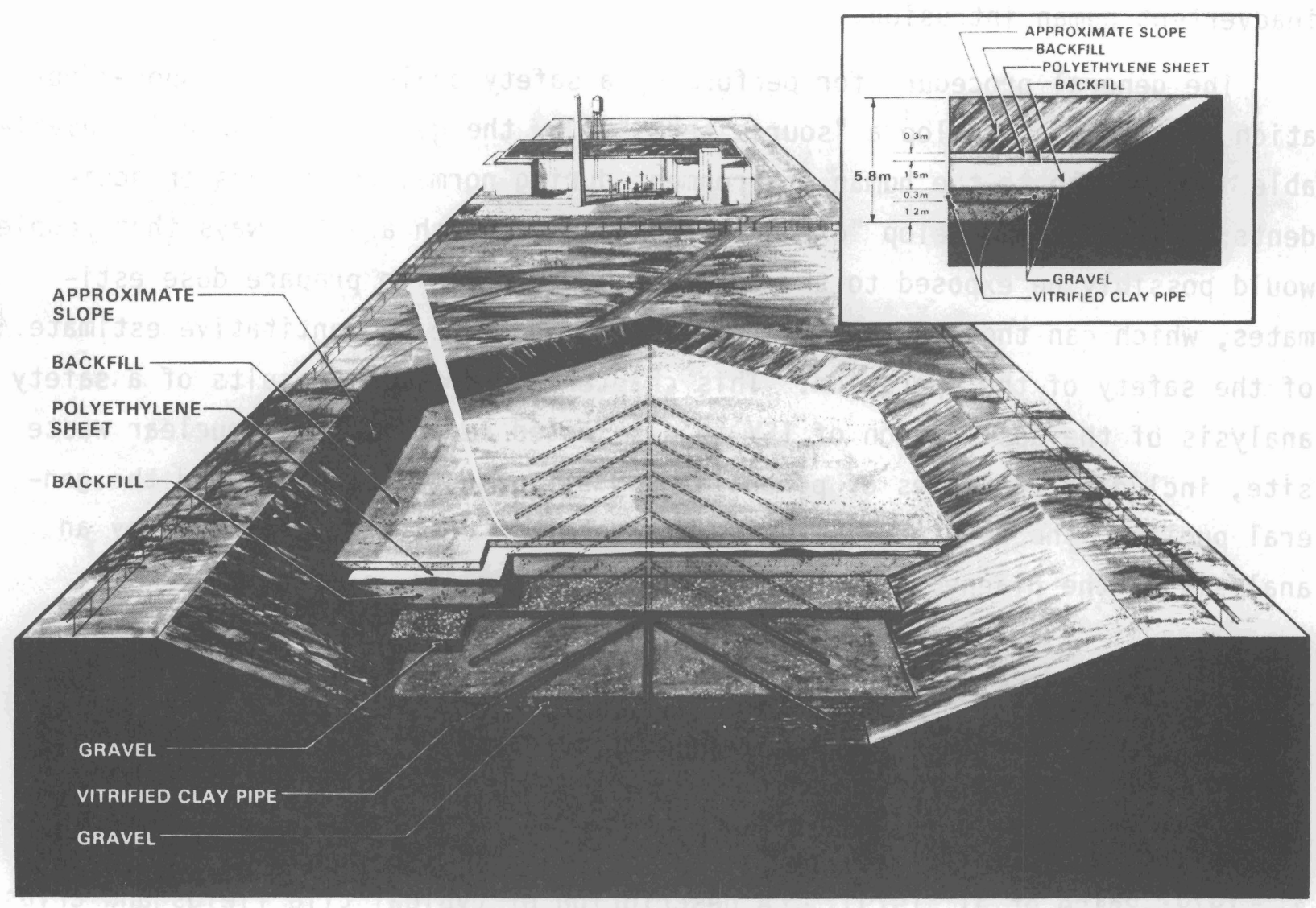

FIGURE 63. Construction of the 216-Z-1A Tile Field (Price et al. 1979) 


\section{ANALYSIS OF OCCUPATIONAL AND PUBLIC SAFETY}

Prior to 1970, TRU contaminated material was disposed of by burial as lowlevel waste. The National Academy of Sciences (NAS 1978) and others have found that retrieval of this waste for disposal in a geologic repository can be more hazardous than disposing this waste in place. The current approach embodies applying ISV in conjunction with surface barriers for in situ disposal of these wastes at Hanford.

Current in situ disposal concepts being evaluated include 1) soil and rock barriers, 2) concrete or asphalt barriers, 3) grout injection, and 4) in situ vitrification. These types of engineered barriers are designed to protect against natural erosion, excessive water infiltration through the site, plant and/or animal intrusion, and inadvertent human intrusion. The most potentially significant of these mechanisms at Hanford and those for which barriers are being designed are erosional processes, animal and/or plant intrusion, and inadvertent human intrusion.

The general procedure for performing a safety analysis of a proposed operation is to first develop a "source term," i.e. the quantity of material available for release to the human environment during normal conditions or accidents; to secondly develop "exposure scenarios," which are the ways that people would possibly be exposed to the sources; and finally to prepare dose estimates, which can then be related to standards to give a quantitative estimate of the safety of the operation. This chapter presents the results of a safety analysis of the application of ISV to a selected representative nuclear waste site, including estimates of potential radiation dose to workers and the general public. The reference site (source term) is described, followed by an analysis of the planned operations and the site in its final state.

\section{SELECTION AND DESCRIPTION OF THE 216-Z-1A TILE FIELD}

The 216-Z-1A tile field at Hanford was chosen as the reference site for ISV because it is the most highly characterized of the four sites considered, as a result of well drilling, monitoring, and analytical programs (Kasper et a1. 1979; Price et al. 1979). [A description of typical tile fields and cribs 
trunk line and 7 pairs of $21 \mathrm{~m}$ lateral sections. The clay distribution system lies on top of about $1 \mathrm{~m}$ of gravel and is in turn covered by almost $2 \mathrm{~m}$ of gravel. This layer of gravel is covered with $3250 \mathrm{~m}^{2}$ of $0.05 \mathrm{~cm}$ thick polyethylene sheeting to act as an impermeable barrier.

From 1949 to 1959 the 216-Z-1A complex received overflow wastes from three adjacent cribs--216-Z-1, 216-Z-2, and 216-Z-3 (Figure 64). By 1959 the cribs were deactivated and the $216-Z-1 A$ tile field was removed from service until 1964, when it was reopened to receive aqueous and organic waste from the $\mathrm{Pu}$ reclamation facility located in Hanford's $Z$ Plant. The waste was released to the tile field in batches. Calculations suggest that the volume of liquid disposed at any one time was normally not sufficient to distribute through the entire pipe system (Crawley 1969). As a result, the waste entered the sediments within a few meters of where it entered the distribution system.

To make effective use of the tile field, it was divided into three sections (Figure 64). Waste was discharged to the head of the A section from 1964 to 1966. In 1966 the A section was bypassed. A $5 \mathrm{~cm}$ stainless-steel pipe was placed within the clay pipe (see Figure 63) to change the point of discharge to the head of the B section. In 1967 the B section was bypassed using additional stainless-steel pipe (for a total of $53 \mathrm{~m}$ ), and then waste was discharged to the head of the $C$ section. In 1969 the tile field was retired from service. Radionuclide Waste Form and Inventory

From 1949 to 1959 the 216-Z-1A complex received wastes originating from the analytical and developmental laboratories and process operations at Z Plant. The waste consisted primarily of a dilute, basic, aqueous solution containing $\mathrm{Pu}$. About $50 \mathrm{~g}$ of $\mathrm{Pu}$ in $1 \times 10^{6} \mathrm{~L}$ of aqueous waste reached the 216Z-1A complex during this 10 year period (Price et al. 1979). During the second period of activity (1964 to 1969), the tile field received waste originating from the Pu reclamation facility. The bulk of the waste was a concentrated aqueous solution of nitrates with an average $\mathrm{pH}$ of 1.0 . The volume of waste received has been estimated at about $5.2 \times 10^{6} \mathrm{~L}$ (see Table 50 ) of aqueous waste containing about $57 \mathrm{~kg}$ of $\mathrm{Pu}$. The inventory of waste discharged to the individual sections of the tile field is shown in Table 50 . 


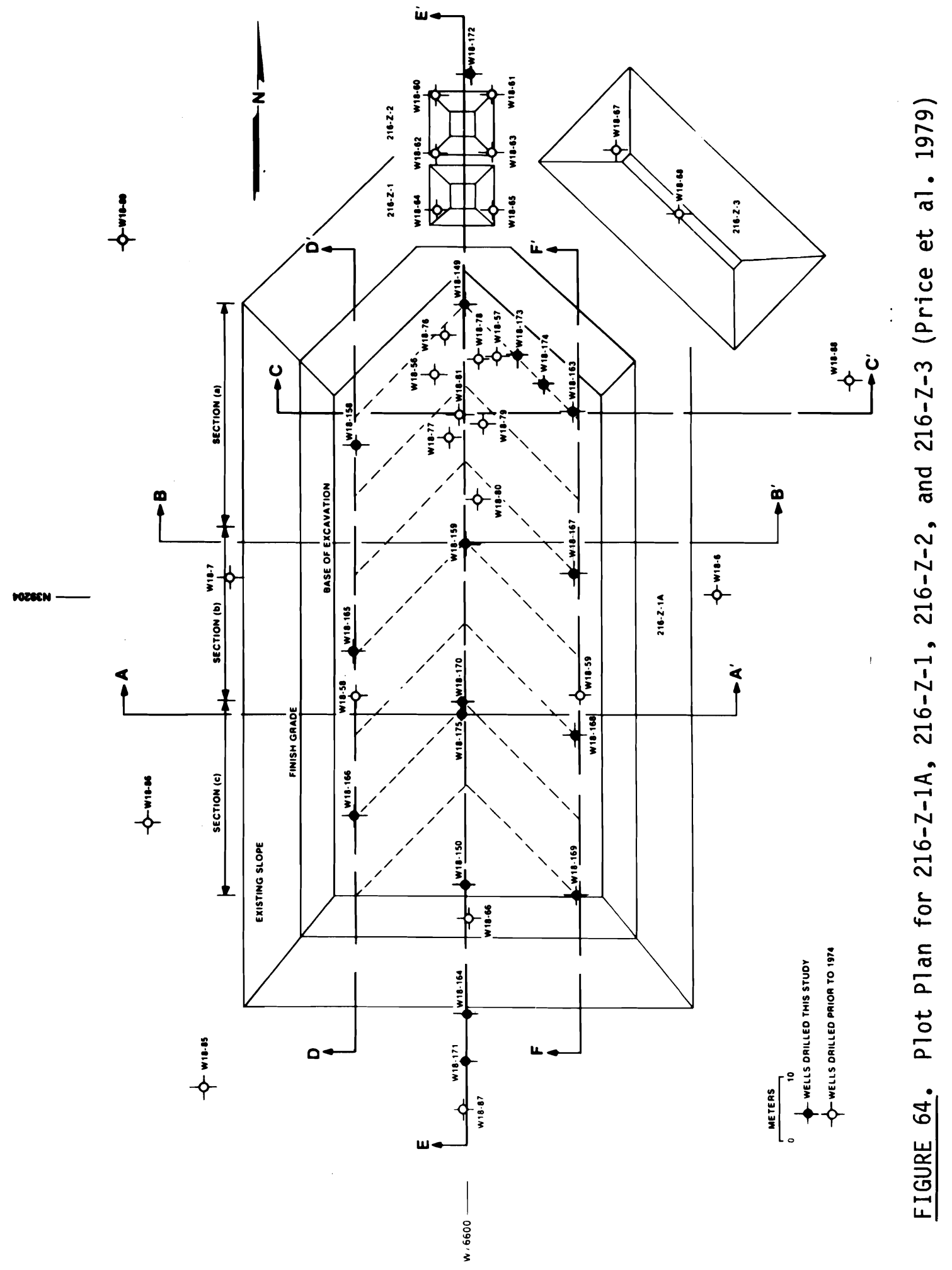


TABLE 50. Estimate of Waste Volume, Plutonium, and Americium Discharged to the 216-Z-1A Tile Field (Kasper et al. 1979)

\begin{tabular}{|c|c|c|c|}
\hline Section & Volume, L & $\mathrm{Pu}, \mathrm{kg}$ & $\mathrm{Am}, \mathrm{kg}$ \\
\hline A & $1.9 \times 10^{6}$ & 30.0 & -- \\
\hline B & $1.9 \times 10^{6}$ & 16.6 & -- \\
\hline C & $1.4 \times 10^{6}$ & 10.8 & -- \\
\hline Total & $5.2 \times 10^{6}$ & 57.4 & $1^{(a)}$ \\
\hline
\end{tabular}

(a) Based on the estimated efficiency of the Am recovery process.

Well drilling, monitoring, and analytical programming were conducted to determine the distribution of Pu beneath the complex (Kasper et al. 1979; Price et al. 1979). The data generated from this effort were used to construct activity profiles for individual wells. Based on gravimetric data and the activity profile (Price et al. 1979), cross sections beneath the tile field revealed the geology and the distribution of the TRU elements. Figure 65 shows a north-south cross section and Figures 66,67 , and 68 show east-west cross sections of the combined Pu and Am activity beneath the crib complex.

Price et al. (1979) concluded that the highest concentrations of Pu and Am $\left(3.8 \times 10^{4} \mathrm{nCi} / \mathrm{g}\right.$ and $2.6 \times 10^{3} \mathrm{nCi} / \mathrm{g}$ of sediment, respectively) occur within the first $3 \mathrm{~m}$ of sediment beneath the central distribution pipe. The maximum vertical extent of TRU activity was found about $30 \mathrm{~m}$ below the bottom of the tile field (which is still $25 \mathrm{~m}$ above the regional water table). The data are reported in Price et al. (1979) for the test well (299-W18-149) containing the highest concentration of $\mathrm{Pu}$ and $\mathrm{Am}$ as a function of depth.

The fission products present in the $216-\mathrm{Z}-1 \mathrm{~A}$ tile field are ${ }^{60} \mathrm{Co},{ }^{90} \mathrm{Sr}$, ${ }^{106} \mathrm{Ru}$, and ${ }^{137} \mathrm{Cs}$. The activities of each of these materials are $<0.3 \mathrm{Ci}$.

Chemical Waste Form

Organic wastes consisting mainly of carbon tetrachloride $\left(\mathrm{CCl}_{4}\right)$ and tributyl phosphate (TBP) were discharged to 216-Z-1A in an aqueous solution with an average $\mathrm{pH}$ of 1.0 during the 5 year period from 1964 to 1969 


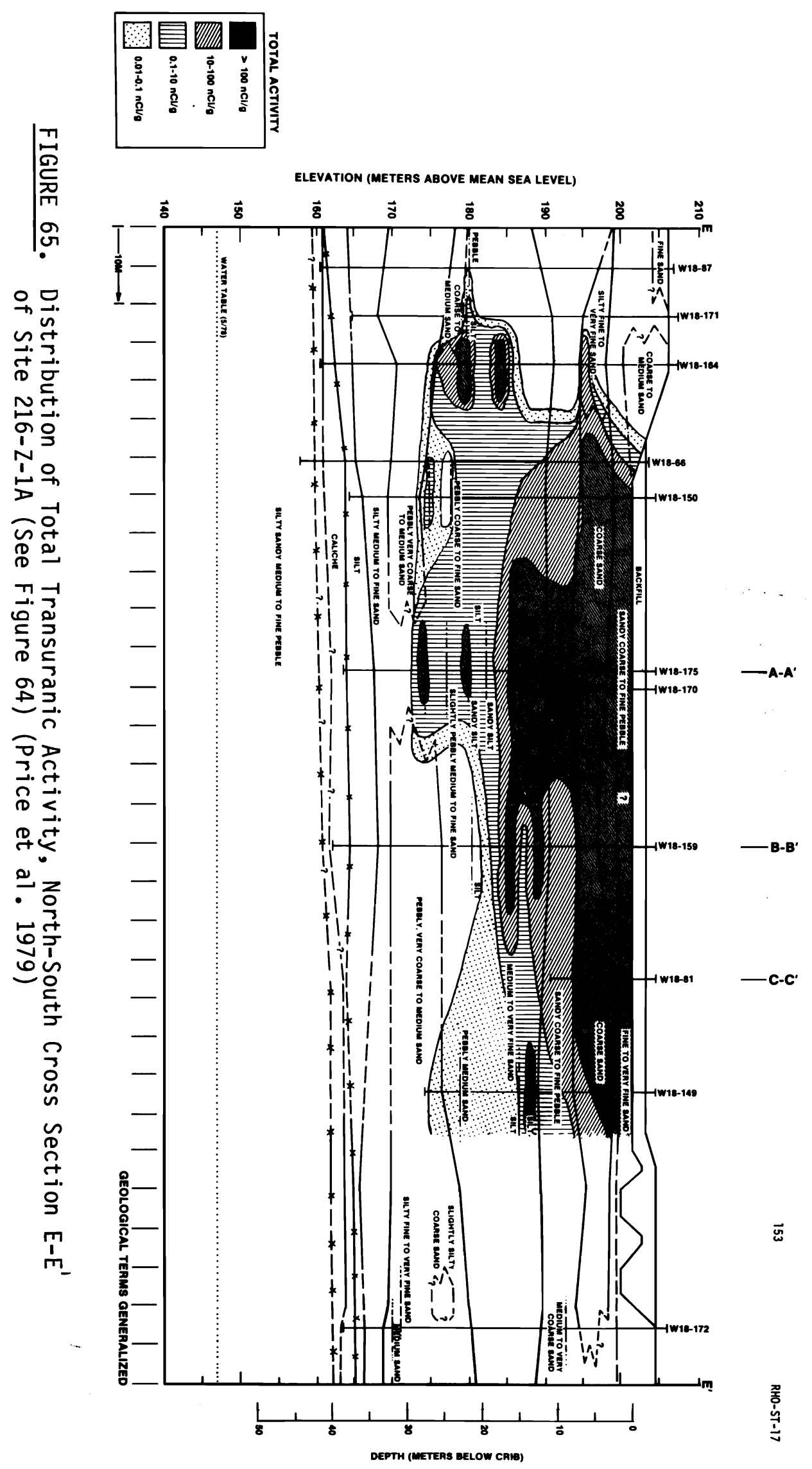




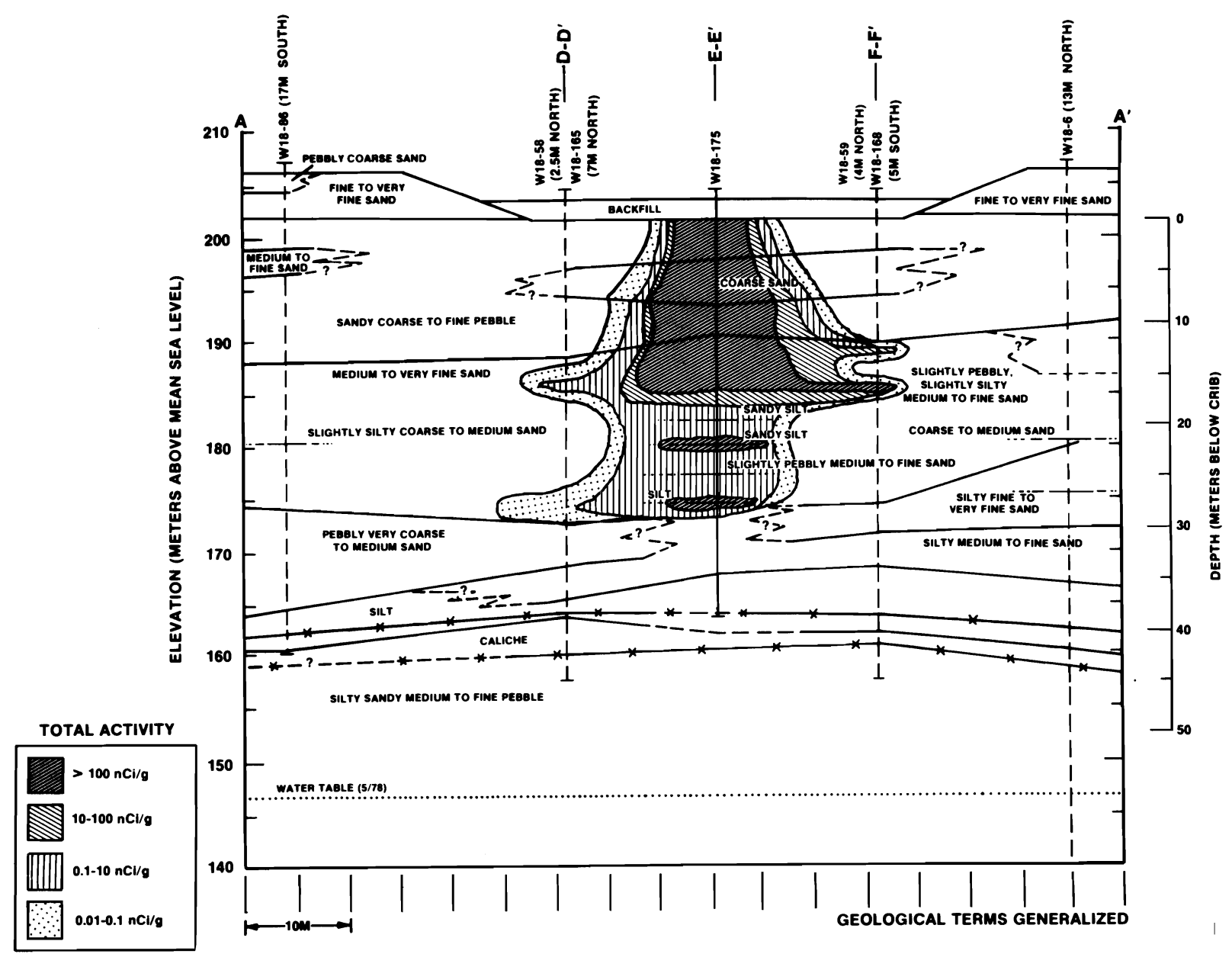

FIGURE 66. Distribution of Total Transuranic Activity, East-West Cross Section Through Points A-A' (see Figure 64) (Price et al. 1979)

(Owens 1981). Additional nonradioactive effluent species and their molarities

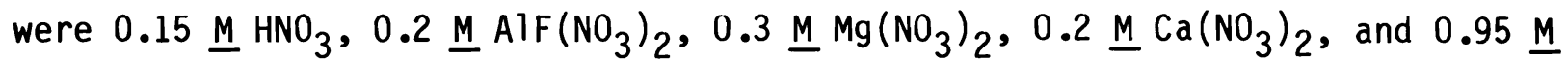
$\mathrm{NaNO}_{3}$

POTENTIAL NEAR-TERM (OPERATIONAL) RADIATION EXPOSURES

During vitrification of the reference site, the proposed ISV activities would place workers in proximity to radiation fields. Minor atmospheric releases of radionuclides would expose members of the general public to very 


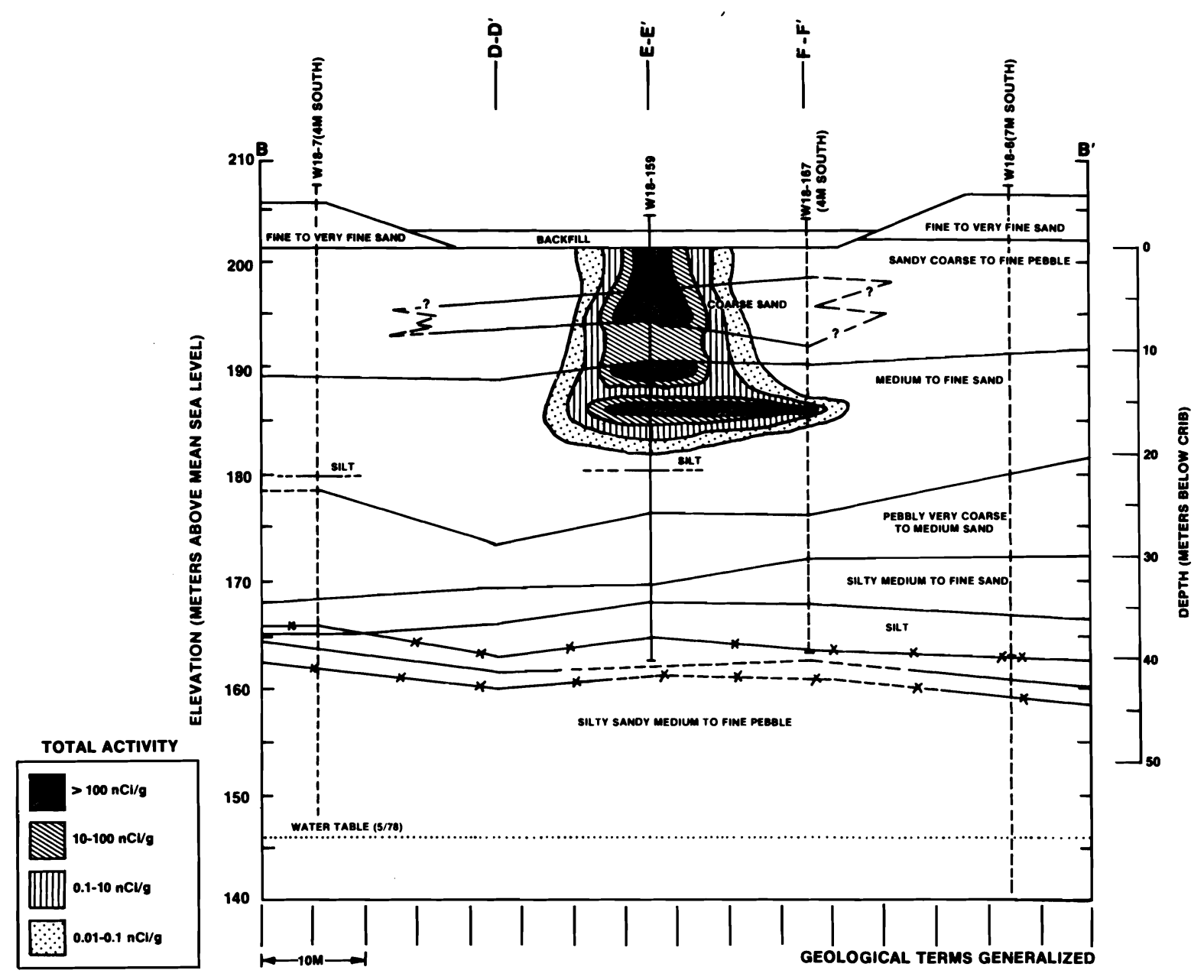

FIGURE 67. Distribution of Total Transuranic Activity, East-West Cross Section Through Points B-B' (see Figure 64) (Price et al. 1979)

low levels of radiation. Accidents or unplanned events could further expose both workers and the public. These cases are developed and examined in the following sections.

Normal Operations

The source terms used for calculation of the occupational and public exposures are based on 1) measurement of gaseous evolution of elements during vitrification, 2) capabilities of the off-gas system as presently designed, and 3 ) estimates of radionuclide inventory in the waste site. 


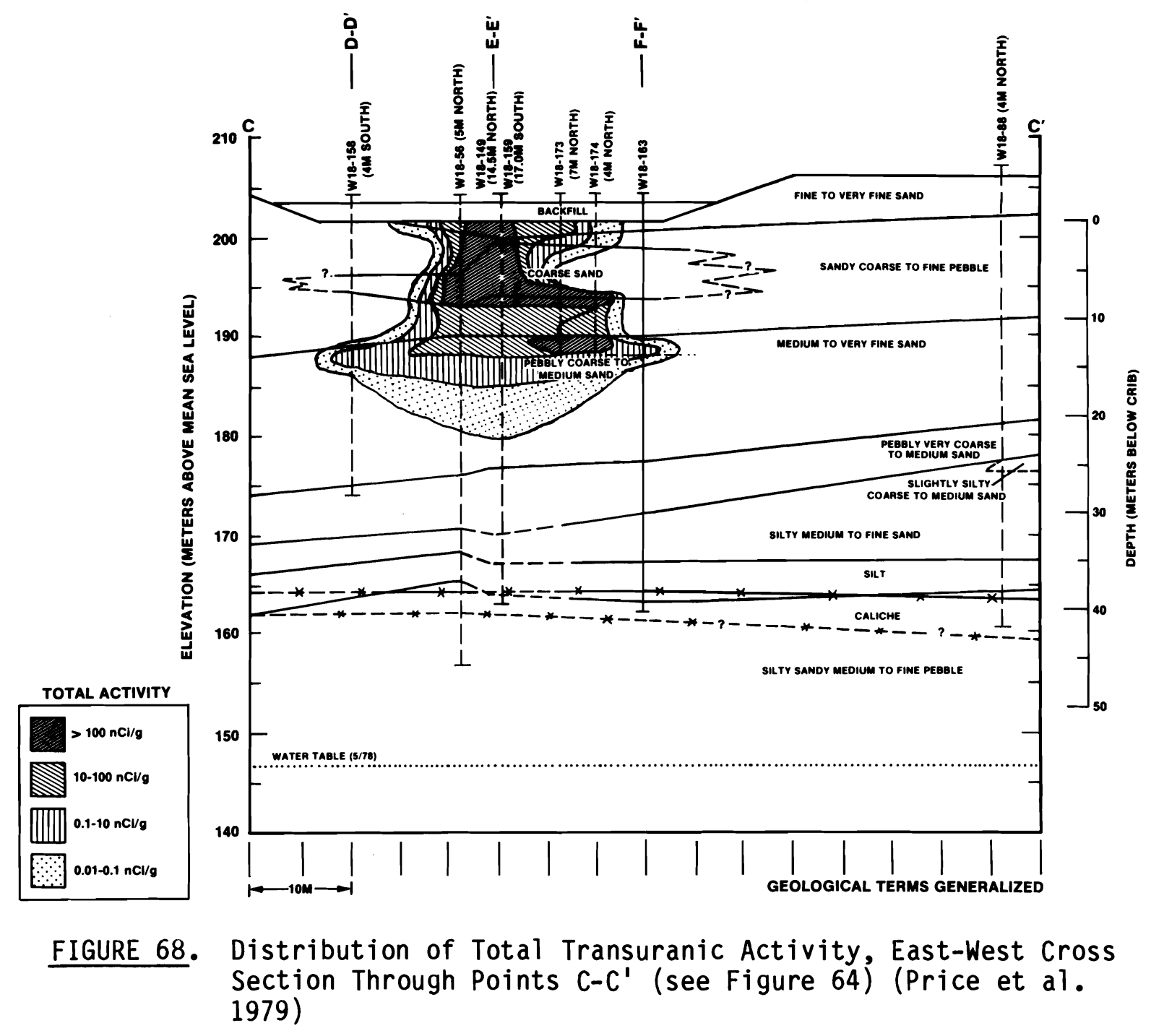

Release rates from the soil during vitrification were estimated from previous ISV field tests (Oma, Farnsworth, and Rusin 1982). Rate constants were developed for three possible operating conditions: operation with a cold cap, operation without a cold cap, and rapid venting. Release rate fractions for elements in the site are listed in Table 51. Operation with a cold cap of solidified soil was assumed to occur during $75 \%$ of the runs. Routine operation without a cold cap was assumed for the remaining 25\%. Rate constants for venting pertain only to sites containing combustibles and were used only as a basis for release in some of the accident scenarios. Total fractions of material released in a single run were based on a 120 hour run time. 
TABLE 51. Elemental Fractions Released During Vitrification of the 216-Z-1A Site

Element With Cold Cap, \%/h Without Cold Cap, \%/h

$\begin{array}{lcccl}\text { Co } & <5 \times 10^{-3(b)} & 5 \times 10^{-3} & & 0.58 \mathrm{avg} ; 1.2 \max (\mathrm{c}) \\ \text { Cs } & <5 \times 10^{-3(b)} & 5 \times 10^{-3} & & 1.6 \mathrm{avg} ; 3.5 \max (\mathrm{c}) \\ \text { Sr } & 0 & 5 \times 10^{-4} & & 0.1 \mathrm{avg} ; 0.12 \max (\mathrm{b}) \\ \text { TRU } & 0 & 5 \times 10^{-3} & & 0.38 \mathrm{avg} ; 1.0 \max (\mathrm{c}) \\ \text { Ru } & 0 & 0 & & \end{array}$

(a) Percent of element associated with combustibles only.

(b) Release fractions of $5 \times 10^{-3}$ were used for the exposure analysis.

(c) Maximum gas venting rate was used for certain accidental release scenarios.

The collection efficiency of each component of the off-gas system was estimated from previous tests and from manufacturers' data. Conservatively estimated decontamination factors (DFs) for each component are listed in Table 52 for the elements present in the waste site.

The 216-Z-1A waste inventory as reported by Owens (1981) (with slight modifications) provided the basis for the radionuclide source term. Table 53 lists the isotope inventory for the entire 216-Z-1A waste site and for the region vitrified during each run. For purposes of analysis, the waste inventory was assumed to be concentrated along the waste distribution pipe, in a volume approximately $90 \mathrm{~m} \times 5 \mathrm{~m} \times 4 \mathrm{~m}$ (see Figure 69). A highly radioactive zone (10 times the activity of the remaining contaminated areas) was located at each of the main distribution points. The concentrations of radionuclides in each of these "hotter" zones are given in Table 53, as are the integrated 120hour release fractions for operation with and without a cold cap. Also given in this table are the total quantities released per run (over a hot spot). The set was assumed to have a cold cap during $75 \%$ of the run and no cold cap for the remaining $25 \%$. The fraction released during venting was not used for normal operation calculations. 
TABLE 52. Hood-to-Stack Decontamination Factors for the Off-Gas

Treatment System

\begin{tabular}{|c|c|c|}
\hline Component & Cs or $\mathrm{Sr}$ & TRU or Co \\
\hline Quench tower & 10 & 10 \\
\hline Hydro-Sonic scrubber & 10 & 10 \\
\hline Separator & 1 & 1 \\
\hline $\begin{array}{l}\text { Tube and shell } \\
\text { condenser }\end{array}$ & 10 & $10^{2}$ \\
\hline Separator & 1 & 1 \\
\hline Heater & 1 & 1 \\
\hline HEPA filter & 10 & 10 \\
\hline
\end{tabular}

TABLE 53. Inventories and Release Fractions for $120 \mathrm{~h}$ Runs at the 216-Z-1A Site

\begin{tabular}{|c|c|c|c|c|c|}
\hline Radionuclide & $\begin{array}{r}216-Z-1 \mathrm{~A} \\
\text { Inventory }\end{array}$ & $\begin{array}{l}\text { Inventory } \\
\text { Per Set, } \\
\mathrm{Ci}_{\mathrm{i}}(\mathrm{a}) \\
\end{array}$ & $\begin{array}{l}\text { Fraction } \\
\text { Released: } \\
\text { With } \\
\text { Cold Cap } \\
\end{array}$ & $\begin{array}{l}\text { Fraction } \\
\text { Released: } \\
\text { Without } \\
\text { Cold Cap } \\
\end{array}$ & $\begin{array}{l}\text { Quantity } \\
\text { Released from } \\
\text { Soil During } \\
\text { Set, } C i(a, b) \\
\end{array}$ \\
\hline${ }^{238} \mathrm{Pu}$ & $1.8 \times 10^{1}$ & $4.3 \times 10^{0}$ & 0 & $6.0 \times 10^{-3}$ & $6.5 \times 10^{-3}$ \\
\hline${ }^{239} \mathrm{pu}$ & $8.5 \times 10^{2}$ & $2.0 \times 10^{2}$ & 0 & $6.0 \times 10^{-3}$ & $3.0 \times 10^{-1}$ \\
\hline $240 \mathrm{pu}$ & $2.1 \times 10^{2}$ & $5.0 \times 10^{1}$ & 0 & $6.0 \times 10^{-3}$ & $7.5 \times 10^{-2}$ \\
\hline${ }^{241} \mathrm{Pu}$ & $2.5 \times 10^{3}$ & $6.0 \times 10^{2}$ & 0 & $6.0 \times 10^{-3}$ & $9.0 \times 10^{-1}$ \\
\hline $242 \mathrm{pu}$ & $7.0 \times 10^{-2}$ & $1.7 \times 10^{-2}$ & 0 & $6.0 \times 10^{-3}$ & $2.6 \times 10^{-5}$ \\
\hline $241_{A m}$ & $3.4 \times 10^{3}$ & $8.1 \times 10^{2}$ & 0 & $6.0 \times 10^{-3}$ & $1.2 \times 10^{0}$ \\
\hline $90 s r$ & $7.7 \times 10^{-1}$ & $1.8 \times 10^{-1}$ & 0 & $6.0 \times 10^{-4}$ & $2.7 \times 10^{-4}$ \\
\hline $106_{\mathrm{Ru}}$ & $8.9 \times 10^{-3}$ & $2.1 \times 10^{-3}$ & 0 & 0 & 0 \\
\hline${ }^{137} \mathrm{Cs}$ & $1.4 \times 10^{-1}$ & $3.3 \times 10^{-2}$ & $6.0 \times 10^{-3}$ & $6.0 \times 10^{-3}$ & $2.0 \times 10^{-4}$ \\
\hline${ }^{60} \mathrm{Co}$ & $3.0 \times 10^{-2}$ & $7.1 \times 10^{-3}$ & $6.0 \times 10^{-3}$ & $6.0 \times 10^{-3}$ & $4.3 \times 10^{-5}$ \\
\hline $233 u$ & $3.6 \times 10^{-2}$ & $8.6 \times 10^{-3}$ & 0 & $6.0 \times 10^{-3}$ & $1.3 \times 10^{-5}$ \\
\hline $234 U$ & $3.7 \times 10^{-2}$ & $8.8 \times 10^{-3}$ & 0 & $6.0 \times 10^{-3}$ & $1.3 \times 10^{-5}$ \\
\hline $235 u$ & $1.1 \times 10^{-3}$ & $2.6 \times 10^{-4}$ & 0 & $6.0 \times 10^{-3}$ & $3.9 \times 10^{-7}$ \\
\hline $238 u$ & $2.7 \times 10^{-2}$ & $6.4 \times 10^{-3}$ & 0 & $6.0 \times 10^{-3}$ & $9.6 \times 10^{-6}$ \\
\hline
\end{tabular}

(a) Inventory is for one of three "hot spots"; other runs contain 1/10 this activity.

(b) Assumes runs had cold cap $75 \%$ of time, no cold cap $25 \%$ of time. 


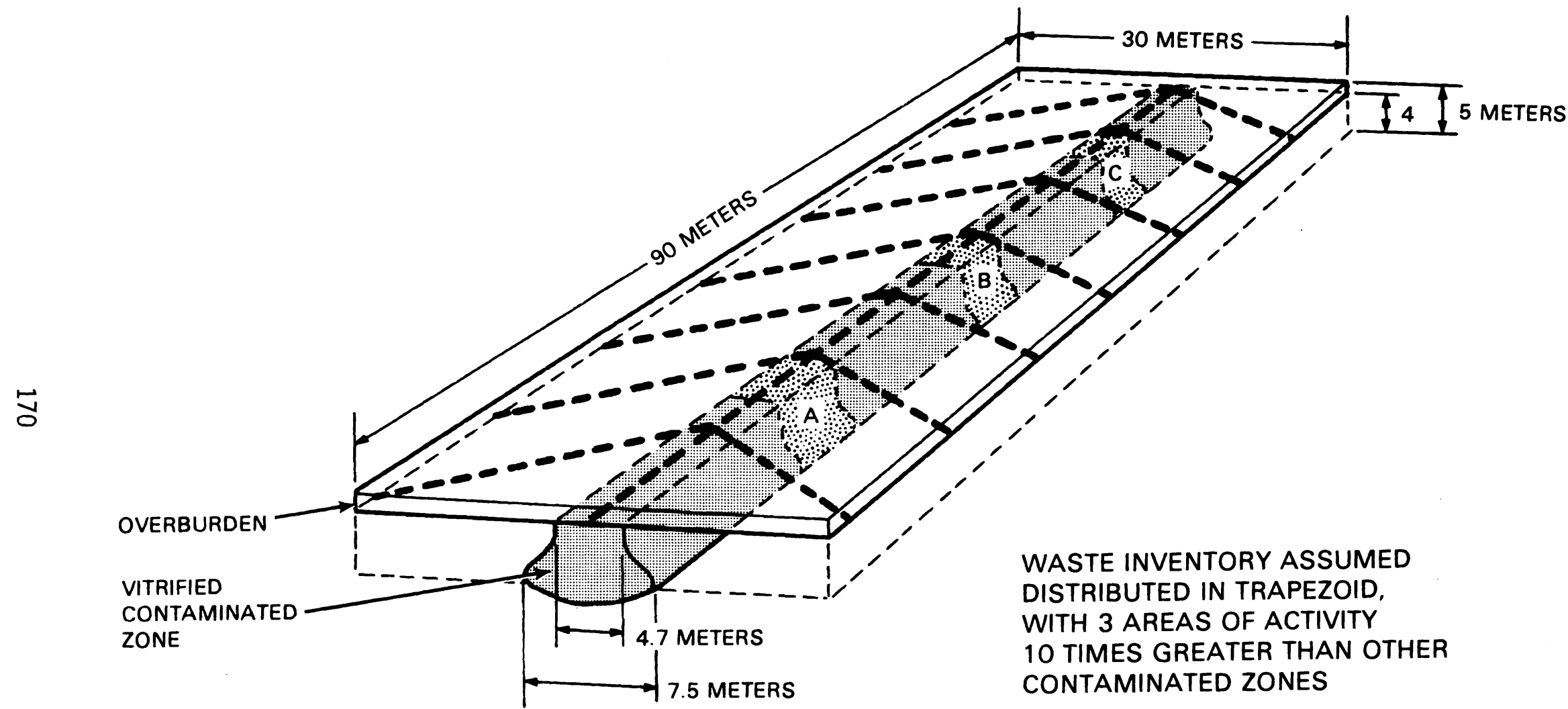

FIGURE 69. Waste Distribution in $90 \times 4 \times 4 \mathrm{~m}$ Site 


\section{Occupational Exposure During Routine Operations}

Occupational doses for routine operations were estimated for activities occurring during vitrification runs and during the changeover period between runs.

Activities during the run for which doses were calculated include 1) observing the melt, 2) working in the van containing the off-gas system, and 3) other activities that cause a worker to be in the vicinity of the site. Activities during the changeover period include 1) placing the electrodes, 2) placing the hood, and 3) draining and flushing the off-gas system scrub solution tanks. Worker locations and task durations developed for each activity are listed in Table 54. For this analysis, placing the electrodes includes drilling the holes for the electrodes, inserting the electrodes, and spreading the graphite/frit between the electrodes. Placing the hood includes moving the hood from one location to the next, and hooking up and checking the electrical and off-gas systems. Draining the scrub tanks takes 48 man-hours and includes

TABLE 54. Occupational Doses for 216-Z-1A Vitrification, 120 Hour Run, 15 Sets

\begin{tabular}{lcccc}
\multicolumn{1}{c}{ Activity } & $\begin{array}{c}\text { Number of } \\
\text { Personnel }\end{array}$ & $\begin{array}{c}\text { Man-Hours } \\
\text { per Run }\end{array}$ & $\begin{array}{c}\text { Total } \\
\text { Man- } \\
\text { Hours }\end{array}$ & $\begin{array}{c}\text { Total Occupa- } \\
\text { tional Whole } \\
\text { Body Dose, } \\
\text { man-rem }\end{array}$ \\
\cline { 1 - 3 } $\begin{array}{l}\text { Overburden removal } \\
\text { Electrode emplacement }\end{array}$ & 1 & - & 100 & $2 \times 10^{-10}$ \\
Hood placement & 4 & 60 & 900 & $9 \times 10^{-2}$ \\
Observation of melt & 4 & 16 & 240 & $1 \times 10^{-8}$ \\
Work in off-gas van & 1 & 24 & 360 & $2 \times 10^{-3}$ \\
Draining of collection tanks & 1 & 30 & 450 & $5 \times 10^{-4}$ \\
Work in site vicinity & 1 & 48 & 720 & $7 \times 10^{-4}$ \\
Background radiation (a) & 1 & 120 & 1800 & $1 \times 10^{-8}$ \\
& 1 & 120 & 1800 & $1 \times 10^{-2}$
\end{tabular}

(a) Background exposure rate in uncontaminated area assumed to be $7 \mu \mathrm{R} / \mathrm{h}$. 
preparing and flushing each tank three times. An additional activity, removing overburden, was not required for the reference site but has been included in this analysis of the vitrification process.

The ISOSHLD model (Engel, Greenborg, and Hendrickson 1966) was used to calculate the doses from routine occupational activities. The calculations further assumed that 1) the site would be covered by a $1 \mathrm{~m}$ layer of uncontaminated overburden and 2) the entire site inventory would be contained within the zone to be vitrified, i.e., the top $4 \mathrm{~m}$ of waste. All of the routine doses estimated are contributed primarily from ${ }^{60} \mathrm{Co}$ and ${ }^{137} \mathrm{Cs}$.

The greatest occupational doses for the entire site result from electrode emplacement because of the workers' assumed proximity to contaminated materials brought to the surface during hole-drilling for the electrodes. The maximum collective dose is $9 \times 10^{-2}$ man-rem, while the maximum individual dose is $1 \times$ $10^{-2}$ rem (see Table 54). This dose is significantly less than the DOE guidelines of $5 \mathrm{rem} / \mathrm{yr}$ or $3 \mathrm{rem} /$ quarter whole body exposure to an individual worker (DOE Order 5480.1A, US DOE 1981a), even with conservative assumptions. For comparison, the natural background exposure rate in the Hanford area is about $7 \mu \mathrm{R} / \mathrm{h}$, so the highest routine occupational dose received by a worker from ISVrelated activities is less than or equal to the exposure from natural backyround.

The low dose associated with 100 hours of overburden removal, $2 \times 10^{-10}$ man-rem, indicates that this activity will not measurably contribute to the overall dose of ISV.

\section{Public Exposure During Routine Operations}

The quantities of radionuclides released to the off-gas system from the vitrification of the 216-Z-1A site are shown in Table 53. The off-gas DFs given in Table 34 indicate that the release fraction will be $\sim 1 \times 10^{-5}$ of the amount vented from the soil to the off-gas system. This airborne release of radioactivity is the dominant exposure pathway to the public from vitrification of the site.

Standard Hanford models and methods were used to calculate doses to members of the public from these releases (Napier 1982). These models include 
contributions to dose from submersion in contaminated air, inhalation of gases and particulates, and ingestion of food crops upon which the airborne matter may be deposited.

One-year doses and 50-year dose commitments for the critical organ $(a)$ of a maximum exposed individual living on the Hanford site boundary and to the general public living within $80 \mathrm{~km}$ of the site are given in Table 55. The largest site-specific doses to the body from airborne releases are to bone: a 50-year dose commitment of $1 \times 10^{-5}$ rem to the maximum exposed individual, and $5 \times 10^{-1}$ man-rem to the entire population. The major contributors to dose are the nuclides ${ }^{239} \mathrm{Pu},{ }^{240} \mathrm{Pu}$, and ${ }^{241} \mathrm{Am}$.

The DOE regulations on exposure to the general public, DOE Order 5480.1A, Chapter 11 (U.S. DOE 1981a), limit the dose to the maximum-exposed individual to $<0.5 \mathrm{rem} / \mathrm{yr}$, and $0.175 \mathrm{rem} / \mathrm{yr}$ to the average individual in the public. The doses calculated for ISV operation at the 216-Z-1A site are insignificant in comparison with these standards, an indication of the overall safety of the ISV operation.

\section{Postulated Abnormal Operations}

This section presents the estimated radiological effects of potential credible accidents (or abnormal operating conditions) during ISV. The accidents considered are believed to represent the worst impacts possible during ISV. The accident scenarios are based on present designs and planned operating conditions. They are not predictions that any of these accidents will happen.

TABLE 55. Critical Organ Dose Commitments to the Public from Routine ISV Operations

\begin{tabular}{|c|c|c|}
\hline Dose & $\begin{array}{l}\text { Maximum Exposed } \\
\text { Individual, rem }\end{array}$ & $\begin{array}{c}\text { Population, } \\
\text { man-rem }\end{array}$ \\
\hline 1st yr & $3 \times 10^{-8}$ & $9 \times 10^{-3}$ \\
\hline $50 \mathrm{yr}$ & $1 \times 10^{-5}$ & $5 \times 10^{-1}$ \\
\hline
\end{tabular}

(a) Critical organ is that organ receiving the highest dose. 
The approach used to develop the accident analysis and subsequent dose evaluation was to 1) identify the various steps of the ISV operation, 2) determine release mechanisms that could breach the radionuclide containment systems and release radionuclides to the biosphere for each step, 3) estimate the maximum fraction of radionuclides that might be released, and 4) calculate doses resulting from the estimated releases.

The accident scenarios are briefly described, followed by a discussion of the occupational and public doses resulting from the accidental releases.

\section{Description of Accidental Release Scenarios}

The consequences of accidents possible during the vitrification of an area are dependent on the quantities of radionuclides involved. To put an upper bound on the possible releases, all accidents described are assumed to occur during or after 120 hours of operation at the most highly contaminated zones in the reference site. This condition represents the largest contaminated soil volume that would be available for any single event and the maximum source for the various accidents.

Four accident scenarios have been identified as having the potential to occur at the representative site 216-Z-1A. These are 1) an uncontrolled venting from a subsurface structure, 2) a break in the off-gas containment pipe, 3) a liquid leak in the off-gas control van, and 4) a gaseous leak in the offgas van. Three additional scenarios are also identified as being possible at other sites, but not at 216-Z-1A. These include 5) the possibility of accidental excavation of the waste while removing overburden, 6) criticality of fissionable materials, and 7) a waste-induced explosion. These accidents are only addressed qualitatively to give perspective to potential hazards of the ISV process.

1. Uncontrolled venting from a subsurface structure. The run is proceeding normally when localized venting of gas from the waste-site surface outside the hood is noticed. The phenomenon, which is investigated by a radiation monitor, is short-lived, and the run continues unabated. It is later determined that the venting was due to limited volatilization and pressurization of waste liquid 
remaining in a $6 \mathrm{~m}$ long section of the stainless steel distribution pipe. Doses for this scenario were estimated using the waste concentration listed in Table 53. The source term is listed in Table 56.

2. Break in line between hood and off-gas system. The run is proceeding normally, with no cold cap. The effluent line between hood and off-gas system breaks, releasing the gaseous effluents directly to the atmosphere. Power to the electrodes is cut off immediately. As a cold cap forms over the melt area, the effluents released to the atmosphere decrease exponentially with a 1/2-hour half-time. Gaseous effluents are released to the atmosphere for a 4 hour period before a sufficient cold cap is formed to prevent further discharge. The doses for this scenario were estimated assuming the release rates determined for the absence of a cold cap, listed in Table 51. The quantities of radionuclides released are reported in Table 56 .

3. Collection tank leak. The run is progressing in a normal manner with only 20 hours remaining until the run is to be completed. A leak develops in the bottom of one quencher-scrubber collection tank, which allows the entire contents of the tank to spill into the pan that lines the floor of the hood. The decision is made to complete the run without one of the scrubbers. Ten 1/2-hour sampling periods are spent in the off-gas van, resulting in an additional dose to the worker. No radionuclides are released to the atmosphere, so this accident does not affect the public. The total quantities of radionuclides spilled to the hood are listed in Table 56.

4. Gaseous effluent release to the off-gas vans. The run is progressing in a normal manner when a leak develops in the off-gas system after the off gas clears the blower and is inside the van. Because the off gas is very humid and could damage the equipment, the run is terminated at this point. Therefore, the workers spends only one 1/2-hour sampling period in the contaminated atmosphere. This accident would not increase the exposure of the offsite population above that received from normal operations. The source term is listed in Table 56. 


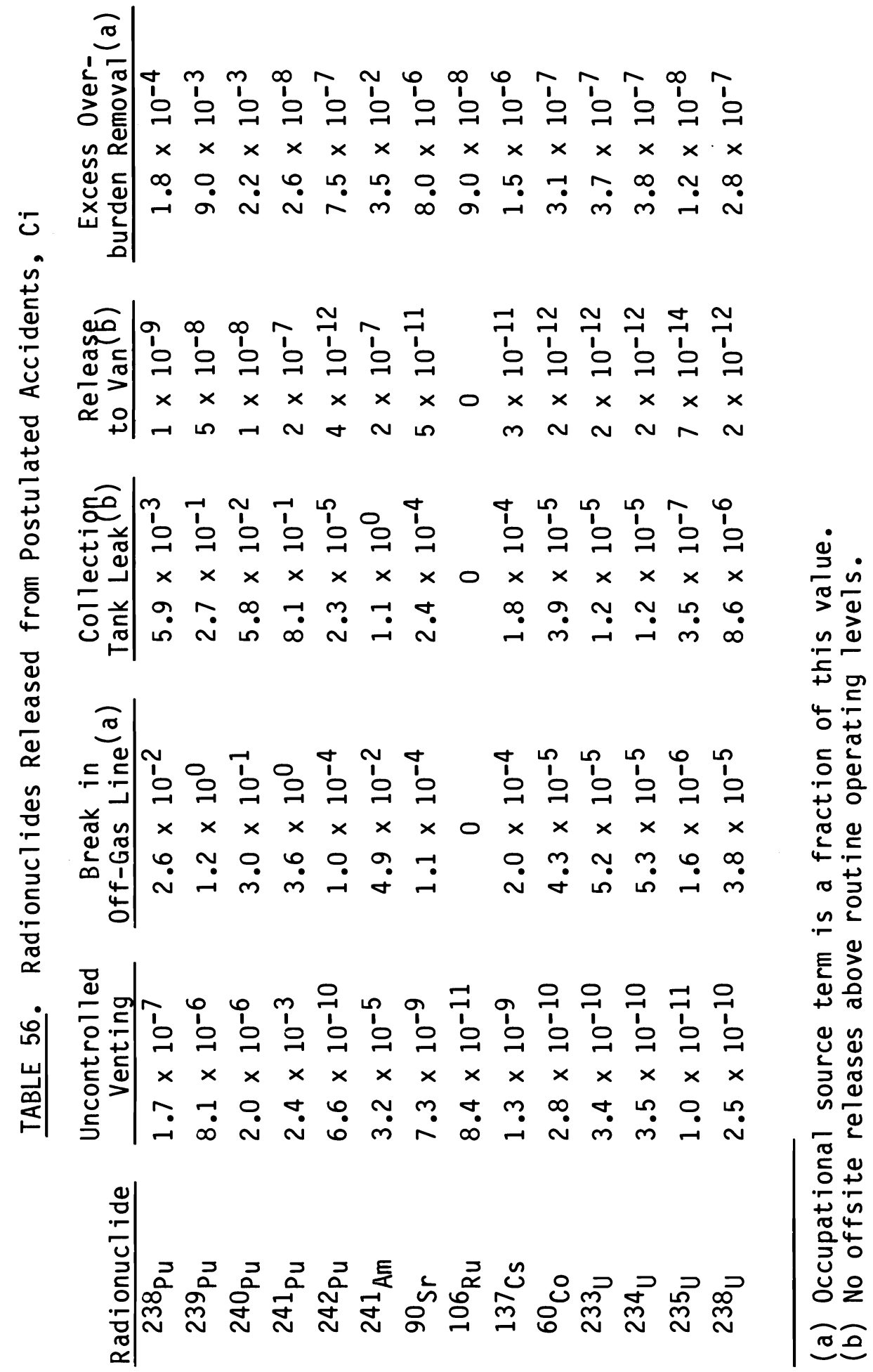


5. Excess overburden removal. The reference site $216-Z-1 A$ has only $\sim 1.5 \mathrm{~m}$ of overburden, making its removal unnecessary. However, other sites at Hanford are more deeply buried. Vitrification of deep layers of overburden may not be practical or economically justifiable. Therefore, the overburden might be removed using conventional earthmoving techniques.

As the overburden is removed using large earthmoving equipment, it is checked by radiation monitors. It is assumed that, due to inaccurate survey or operator error, a section of contaminated soil is uncovered. The error is discovered immediately by the monitor, and the area is covered with clean soil. The area that was uncovered is assumed to be the width of the contaminated zone, about $6 \mathrm{~m} \times 2 \mathrm{~m}$. The amount of contaminated dust suspended from clearing and covering this area is $2 \mathrm{~kg}$, released over a period of $10 \mathrm{~min}-$ utes. The soil is assumed to have the radionuclide concentration of the "hot zones." The radionuclide release is listed in Table 56.

6. Criticality. Detailed calculations have shown that a minimum critical areal concentration of Pu metal in wet Hanford soils is $2.9 \mathrm{~kg} / \mathrm{m}^{2}$, with full water reflection (Oma, Farnsworth, and Rusin 1982). According to the same study, this value increases to $14.5 \mathrm{~kg} / \mathrm{m}^{2}$ for dry soil with $\mathrm{Pu}$ in the oxide form. A safety factor of 0.33 is applied, suggesting that any site with $<1.0 \mathrm{~kg} / \mathrm{m}^{2}$ for wet soil (or about $5 \mathrm{~kg} / \mathrm{m}^{2}$ for dry soil with plutonium oxide) would be acceptable for ISV without danger of inducing a criticality.

The peak soil concentration of ${ }^{239} \mathrm{Pu}$ in reference site $216-\mathrm{Z}-1 \mathrm{~A}$ is $4 \times 10^{4} \mathrm{nCi} / \mathrm{g}{ }^{239} \mathrm{Pu}$ and ${ }^{240} \mathrm{Pu}$ in a limited area around the distributor pipe (Kennedy et al. 1982). This level of contamination reaches a depth of $1 \mathrm{~m}$ below the pipe. Using an activity fraction of $80 \%{ }^{239} \mathrm{Pu}$, this would be about $5 \times 10^{-4} \mathrm{~g} 239 \mathrm{Pu} / \mathrm{g}$ soil. Thus, the areal concentration would be $0.9 \mathrm{~kg} / \mathrm{m}^{2} 239 \mathrm{Pu}$. This is well below the acceptable areal concentration, and even further below the critical concentration. No mechanisms during the ISV process can be postulated which result in lateral concentration of the 
$\mathrm{Pu}$ (Oma, Farnsworth, and Rusin 1982); therefore, a criticality incident is not considered possible for this site. Because the 216-Z-1A site contains a greater contamination level then any of the other contaminated soil sites, criticality is not of great concern for these types of sites. However, if ISV application is to be used for other site types, such as caissons or retrievably stored TRU wastes, a more detailed criticality investigation would be in order.

7. Explosions. The ISV process results in very high temperatures in the soil/glass volume. If contained organic matter is encountered, it will generally pyrolyze and combust when the gases reach the soil surface. The only time that this might not occur is during vitrification of sites containing highly reactive or potentially explosive materials. The off-gas system is designed to contain large transient pressure surges, but a large enough explosion could cause venting around the hood, or even disrupt the hood and off-gas lines. This would result in a release mechanism similar to that described above for an off-gas line leak. For such a scenario, the gas-venting release rates of Table 51 would be more applicable than the nocold-cap rates used for the line-break scenario. Releases and doses could be as much as an order of magnitude greater than from a simple line break.

No explosive materials are believed to be present in the $216-Z-$ $1 \mathrm{~A}$ site, or in most of the other TRU contaminated soil sites. However, the concentration and configuration of combustible materials and their potential for explosion would be evaluated for each before vitrification would be attempted.

Doses Resulting from Postulated Releases

The accident with the most damaging consequences is a break in the off-gas line before the off gases are treated. First year lung doses to a worker standing downwind of the vented gases could be as high as 10 rem. First year doses to members of the general public out of the immediate vicinity would be much lower, on the order of 0.03 rem to the lung of a maximum exposed 
individual 5 miles away on State Highway 240. The cumulative first year dose to the entire population $80 \mathrm{~km}$ around the site would be only 100 man-rem. Doses to workers from releases during vitrification are given in Table 57 . Doses to the public from these same activities are listed in Table 58.

The radiological consequences of uncontrolled venting of a fraction of the waste inventory are lower than those for a break in the off-gas line. The

TABLE 57. Occupational Doses from Postulated Accidental Releases (120 hour run, 15 sets, concentrated inventory)

\begin{tabular}{|c|c|c|c|c|c|}
\hline \multirow[b]{2}{*}{ Accident } & \multirow{2}{*}{$\begin{array}{c}\begin{array}{c}\text { Number } \\
\text { of }\end{array} \\
\text { Personnel } \\
\end{array}$} & \multirow{2}{*}{ 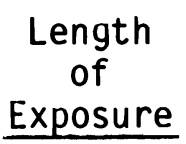 } & \multicolumn{3}{|c|}{$\begin{array}{c}\text { 1st Year Dose Commitment } \\
\text { to Each Worker, rem }\end{array}$} \\
\hline & & & Total Body & Bone & Lung \\
\hline $\begin{array}{l}\text { Uncontrolled } \\
\text { venting }\end{array}$ & 1 & $1 \mathrm{~min}$ & $1 \times 10^{-3}$ & $2 \times 10^{-2}$ & $2 \times 10^{0}$ \\
\hline $\begin{array}{l}\text { Off-gas line } \\
\text { break }\end{array}$ & 1 & $5 \mathrm{~min}$ & $6 \times 10^{-3}$ & $1 \times 10^{-1}$ & $1 \times 10^{1}$ \\
\hline $\begin{array}{l}\text { Collectjign tank } \\
\text { leak }\end{array}$ & 1 & $5 \mathrm{~h}$ & $5 \times 10^{-1}$ & --- & -- \\
\hline $\begin{array}{l}\text { Gaseous release } \\
\text { to van }\end{array}$ & 1 & 30 min & $2 \times 10^{-5}$ & $3 \times 10^{-4}$ & $4 \times 10^{-2}$ \\
\hline $\begin{array}{l}\text { Excess overburden } \\
\text { removal }\end{array}$ & 2 & $10 \mathrm{~min}$ & $3 \times 10^{-3}$ & $4 \times 10^{-2}$ & $5 \times 10^{0}$ \\
\hline
\end{tabular}

(a) External radiation exposure only.

TABLE 58. Public Dose Commitments from Postulated Accidental Releases

Maximum

Exposed Individual, rem Population, man-rem

\begin{tabular}{|c|c|c|c|c|}
\hline \multirow[b]{2}{*}{ Accident } & & \multicolumn{2}{|r|}{ 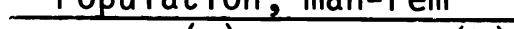 } \\
\hline & 1 st year $(\mathrm{a})$ & $50 \operatorname{year}^{(b)}$ & 1st year (a) & 50 year $(b)$ \\
\hline Uncontrolled venting & $5 \times 10^{-5}$ & $5 \times 10^{-4}$ & $2 \times 10^{-1}$ & $2 \times 10^{0}$ \\
\hline Off-yas line break & $3 \times 10^{-2}$ & $3 \times 10^{-1}$ & $1 \times 10^{2}$ & $1 \times 10^{3}$ \\
\hline $\begin{array}{l}\text { Excessive overburden } \\
\text { removal }\end{array}$ & $1 \times 10^{-2}$ & $9 \times 10^{-2}$ & $3 \times 10^{1}$ & $3 \times 10^{2}$ \\
\hline
\end{tabular}

(a) Lung dose.

(b) Bone dose. 
first year lung dose to the maximum exposed worker would be 2 rem, as shown in Table 57. First year lung doses to members of the general public remain low, $5 \times 10^{-5}$ rem for the maximum exposed individual and 0.2 man-rem to the surrounding population (Table 58 ).

The only other accident with potential for offsite release of radionuclides is the accidental penetration of the waste while removing overburden (although overburden removal is not planned for site 216-Z-1A). The monitors and equipment operators could receive as much as 5 rem, if neither were wearing respirators at the time, while the offsite individual would probably receive $<0.01$ rem.

The other accidents studied have no atmospheric release of radionuclides. The nuclides are contained in the gloveboxes in the off-gas system trailer. Doses to workers in the van are 0.5 rem for the liquid leak and 0.04 rem for the gaseous leak, as reported in Table 57.

There are no standards for doses resulting from accidental releases. However, accidents that result in any individual receiving a total body dose $>25$ rem must be reported immediately, and any that result in a dose $>5$ rem for the total body must be reported within 72 hours (DOE Order 5484.1, Chapter 1; U.S. DOE 1981b). None of the public doses from potential accidents at site 216-Z-1A fall within this category. While the maximum calculated dose of 10 rem to the lungs of an occupationally exposed worker exceeds the calendar quarter limit of $5 \mathrm{rem}$, the dose commitment does not exceed the annual limit of 15 rem. Since radiation doses received in accidental conditions are chargeable to the radiation exposure records of the exposed individual, the decision as to whether the individual could continue to work in a radiation area would have to be made on a case-by-case basis (Order 5480.1A, US DOE 1981a).

POTENTIAL FAR-TERM RADIATION EXPOSURES

Following ISV of a waste site, the radionuclides initially present remain locked inside a large, obsidian-like monolith. A key question in determining the suitability of a site for ISV is the relative benefit gained by vitrifying the site. The measure of benefit is the reduction of potential radiation dose from the waste site to individuals in the future. 
The potential routes through which people may be exposed to radionuclides or radiation are called exposure pathways. The general pathways can be thought of as external exposure, inhalation, and ingestion. External exposure results from direct radiation from air, water, soil, and contaminated structures. Inhalation doses can result from breathing aerosols released from facilities or resuspended materials. Pathways of ingestion are water, fish, waterfowl, other game, food crops, animal products, or direct consumption of small amounts of material transferred from contaminated surfaces to the hands. The potential dose to an individual that might result from residual contamination at a site (the Allowable Residual Contamination Level, or ARCL) (Napier 1982) is calculated in a radiation exposure scenario analysis by summing the exposures through all of the selected pathways.

The key to ARCL is an analysis of the maximum annual radiation dose to an individual. This dose is calculated by summing the doses from appropriate exposure pathways. The pathways are chosen depending on the ways an individual could be exposed for the release mode considered. The collection of appropriate pathways is called an exposure scenario. The ability to choose the exposure scenario is what gives the method the flexibility to handle many types of sites, inventories, and locations.

Preliminary investigations have been performed to determine the location of the individual most likely to be affected by contaminated sites. In a previous study of conditions at Hanford, individuals were postulated to live downwind and downstream at distances of $10 \mathrm{~km}, 1 \mathrm{~km}$, and onsite (Napier 1982). For all times and for all exposure scenarios, radiation dose rates to the individuals living out of the immediate vicinity of the contaminated areas were found to be orders of magnitude smaller than those received by the onsite individual. Thus, the onsite exposure scenarios have been determined to be the most critical. For unrestricted use, the general types of potential exposure scenarios for maximum-exposed individuals are as follows:

- Transient

- Permanent resident

- well drilling, excavation

- contact with soil, inhalation of resuspended material 
- drinking of well water

- backyard garden

- Inadvertent intruder

- Intentional intruder

- resource recovery

- use of recovered resource.

The potential for radiation doses to individuals has been examined for each of these general scenarios. The most restrictive are examined in detail in this report. For contaminated soil areas, the permanent resident is the individual most likely to receive radiation doses, although the intruder has the possibility of receiving the highest doses.

For the purposes of this analysis, dose estimates have been calculated for individuals exposed at times 1000 and 10,000 years in the future. For comparison, dose estimates are provided for the 216-Z-1A reference site with three possible end-state configurations: 1) its present condition (no mitigative action taken), 2) with a rock and earthen barrier, and 3) with the most highly contaminated zone vitrified and the remainder covered with a barrier.

For each of the exposure scenarios listed above, a number of pathways exist which provide a route for radionuclide transport from the waste to the biosphere. For Hanford, these may be generalized as groundwater transport, biotic transport (as in crops or animal products), atmospheric transport, and direct contact.

For waste sites in the 200 East and 200 West Areas at Hanford, the groundwater pathways contribute only marginally to dose. The distance from the waste to the groundwater $(>60 \mathrm{~m})$, coupled with the high sorption of Hanford soils and the low annual rainfall, result in little radionuclide migration to the groundwater (NAS 1978; Issacson and Brown 1978). Studies have further shown that even if the radionuclides are leached to groundwater, offsite population doses 
are very small (Wallace et al. 1980), and thus are not of concern. Thus, transport through the vadose zone ${ }^{(a)}$ to groundwater is not important for most Hanford sites.

The pathways of concern to the resident individual, then, are direct irradiation, inhalation of resuspended material, and ingestion of contaminated crops and animal products (illustrated in Figure 70 ). The relative importance of each of these pathways is a function of the length of exposure, as defined by the exposure scenario.

The site does not pose any hazard for transients, either as it now exists or with any barriers or vitrification applied. The dose rate at the ground surface at any time in the future will be essentially at background levels. This is shown in Table 59. The presence of the overburden on the site acts as shielding to any penetrating radiation, as well as eliminates any possibility of inhalation of contaminated surface materials.

It is possible that a future inhabitant of the site might grow a homevegetable garden directly on top of the waste site. If no remedial actions are taken at the $216-\mathrm{Z}-1 \mathrm{~A}$ site, this individual could receive up to $10 \mathrm{rem} / \mathrm{yr}$ from such exposure. The dose rate does not change from 1000 to 10,000 years in the future, in spite of the radioactive decay of the waste, because the surface overburden would be simultaneously eroding, allowing greater uptake by the crops. An effective barrier to crop penetration of the wastes, such as a rock/soil cap or vitrification, could lower the dose potential by at least 3 orders of maynitude, to around $10 \mathrm{mrem} / \mathrm{yr}$, if it did not preclude the pathway entirely. These results are also shown in Table 59.

The scenarios that vividly illustrate the differences between no-action, barrier application, and selective ISV are those that involve physical intrusion into the actual waste zone such as well-drilling through the waste zone or digging basements, irrigation ditches, sewer lines, or highways. (The drilling scenario does not contribute to drinking water contamination because the

(a) A subsurface zone containing water below atmospheric pressure and air or gases at atmospheric pressure (also unsaturated zone or zone of aeration). 


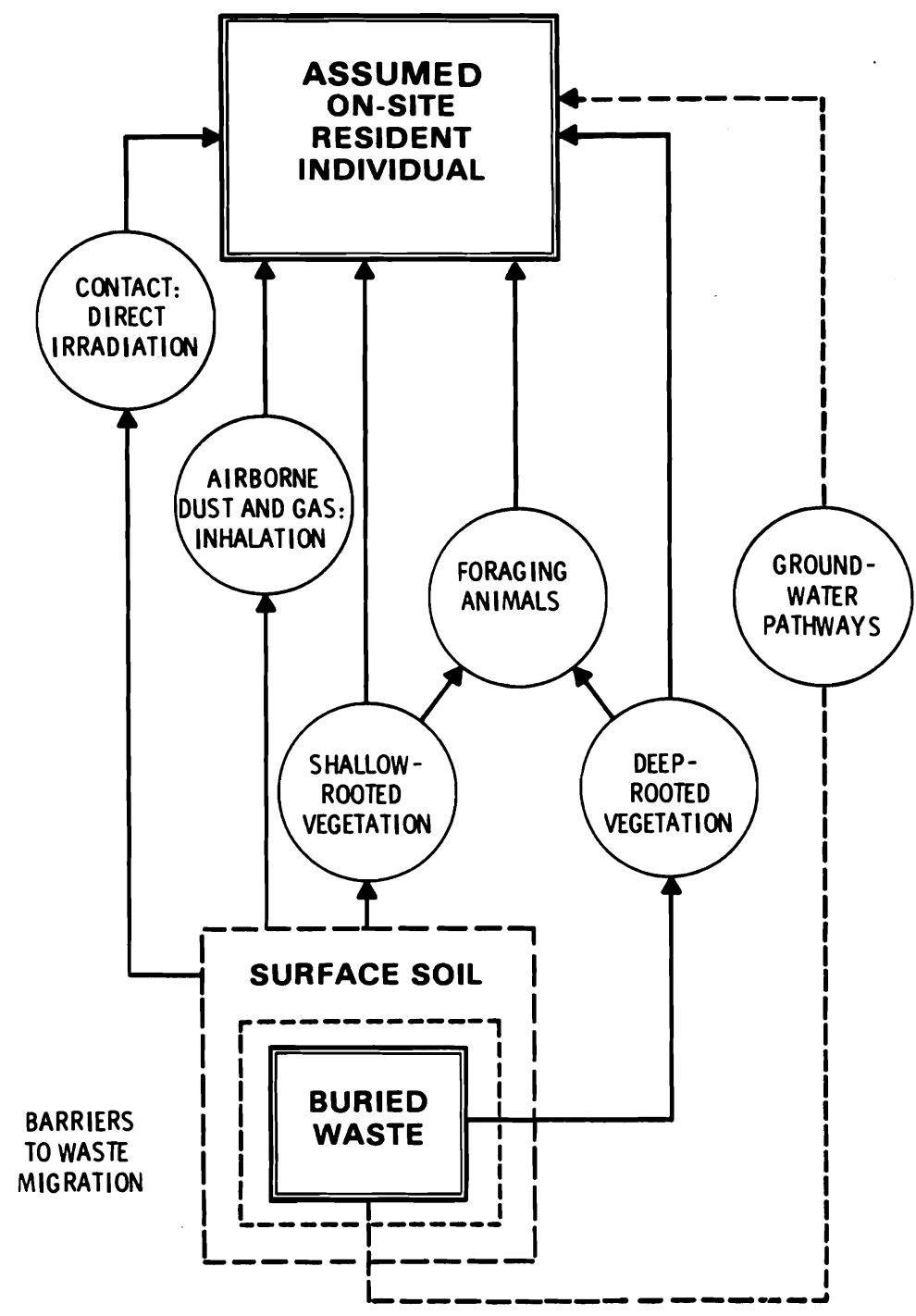

FIGURE 70. Important Exposure Pathways at Hanford (Napier 1982)

TABLE 59. Public Dose Estimates for Far-Term Routine Scenarios

Year 1,000 Year 10,000

Direct Irradiation Maximum Annual Total Body Dose

Nonvitrified site Background Background

Vitrified site Background Background

Barrier over site Background Background

Ingestion Maximum Annual Bone Dose, rem

Nonvitrified site

10

10

Vitrified site

0.01

0.01

Barrier over site

0.01

0.01 
chances of nuclide migration to the groundwater are very small, and because Hanford wells are cased to prevent collapse.

A drilling scenario is the worst case for a glass (vitrified) waste form. The action of a drill bit on the hard waste causes it to fragment into very small particles that can be inhaled. However, the particles are more dense and less soluble than unvitrified soil, so the resuspension is slightly less than for soil, and the translocation of inhaled particles from lung to bone (the critical organ) is greatly reduced. The quantity of radioactive material that may be brought to the surface from drilling through a hot spot is also reduced through vitrifying, since the hot spot soil is diluted by a large volume of cleaner material when the site is vitrified. Thus, even though drilling tends to maximize the exposure potential for the glassified waste, the potential doses are less than for drilling through the unvitrified soil beneath the surface of a site.

The presence of the intruder in the waste zone, as might occur from digging through the site for a basement or ditch, is a worst case for nonvitrified material. The forces involved in digging result in high resuspension of the non-agglomerated soils, and therefore result in high inhalation doses. The glass monolith of the vitrified site, however, will break into large chunks upon impact, and the fraction available for resuspension and inhalation will be very small. This can be seen in Table 60. The lung doses to intruders/residents at the 216-Z-1A site from nonvitrified material are quite high far into the future. However, the dose to an intruder from the vitrified soil is actually of the same order of magnitude as that dose he might receive if he never intruded at all and only grew crops on the vitrified site (see Table 59). The process of vitrification reduces potential dose to future intruders to reasonable levels, which surface barriers alone cannot do.

The vitrified soil block resembles black, shiny obsidian. If a future intruder were to reclaim a large piece and use it in his home (for example, to build a fireplace or coffee table), he could be exposed to direct penetrating radiation. For the radionuclide mixture in the $216-Z-1 A$ reference site, this 
TABLE 60. Public Dose Commitments for Far-Term Intrusion, rem

\begin{tabular}{|c|c|c|c|c|}
\hline & \multicolumn{2}{|c|}{ Year 1000} & \multicolumn{2}{|c|}{ Year 10,000} \\
\hline & 1st $\operatorname{Year}(a)$ & 50 Year (b) & 1st Year (a) & 50 Year (b) \\
\hline \multicolumn{5}{|l|}{ Drilling } \\
\hline Unmodified site & 24 & 880 & 16 & 550 \\
\hline Vitrified site & 6 & 15 & 3 & 8 \\
\hline Barrier over site & 24 & 880 & 16 & 550 \\
\hline \multicolumn{5}{|l|}{ Excavation } \\
\hline Unmodified site & 48 & 1600 & 33 & 1100 \\
\hline Vitrified site & 0.006 & 0.02 & 0.003 & 0.008 \\
\hline Barrier over site & 48 & 1600 & 33 & 1100 \\
\hline Vitrified Curio(c) & 0.2 & 10 & 0.1 & 5 \\
\hline
\end{tabular}

(a) Lung dose.
(b) Bone dose.
(c) Total body dose.

could result in a dose rate of about twice the natural background in 1000 years, falling to a dose rate equal to background in 10,000 years. These values are given in Table 60 .

POTENTIAL CHEMICAL HAZARDS

The 216-Z-1A site has received unknown quantities of potentially hazardous organic chemicals (Owens 1981) such as carbon tetrachloride $\left(\mathrm{CCl}_{4}\right)$, tributyl phosphonate (TBP), and dibutylbutyl phosphonate (DBBP). Carbon tetrachloride is a highly toxic substance and suspected carcinogen (IARC 1971). Much of its toxicity may be the result of metabolic transformations which include conversion to chloroform, hexachloroethane, and phosgene (Cook, Daughton, and Alexander 1978; Kubic and Anders 1980). It appears that $\mathrm{CCl}_{4}$ is relatively stable in soils and groundwater with no evidence of microbial decomposition.

The alkyl-phosphates such as TBP are apparently prone to chemical hydrolysis and therefore should be degraded in soils. However, a recent survey of Canadian drinking water supplies (Williams and Lebel 1981) shows that TBP is 
present in rivers, lakes, wells, and brooks. While assessments have assured rapid hydrolysis and biodeyradation of alkyl-phosphates such as TBP in aquatic environments, these substances have been found in aquatic oryanisms.

The alkyl-phosphonates have been studied more intensively, yet firm data are still lacking. Alkyl-phosphonates such as DBBP are believed to be persistent in the environment because of the resistance of the $C-P$ bond to chemical hydrolysis, thermal deconposition, photolysis, and biological drainage. This, coupled with the fact that alkyl-phosphonates are now being found in surface waters, suggests that they may be persistent in the environment.

Hanford soils probably do not support a large enough microbial population for a long enough period during the year to significantly reduce TBP, DBBP, and $\mathrm{CCl}_{4}$, so any losses would most likely be minor, resulting from volatilization and dissolution in soil water.

Carbon tetrachloride, TBP, and DBBP present health hazards in their own right, and form other toxic substances when heated to decomposition. Several papers document the formation of perchloroethane and perchlorobenzene from thermal pyrolysis (Tsuge, Leary, and Isenhour 1974; Keiter et al. 1978), and there are several papers describing the formation of substantial quantities of perchloroethylene from pyrolysis of $\mathrm{CCl}_{4}$ in the presence of catalytic materials (including metal oxides) (Kuznetsov and Pekhov 1967; Dynsenov et al. 1974). Gaseous chlorine can also be expected (Jarvis 1970), as well as oxides of chlorine and phosgene. Carbon tetrachloride, tetrachloroethylene, and perchlorobenzene are on the U.S. Environmental Protection Agency's (EPA's) list of 129 priority pollutants (Keith and Teilliard 1979) from industrial and wastewater discharges. However, in ISV pilot-scale tests, pyrolyzed organics ignited upon release from the melt zone and actively burned within the off-gas containment hood. Therefore, the organics present at a particular site are not expected to pose a serious health hazard during the ISV process.

\section{CONCLUSIONS}

The maximum occupational dose received for any routine activity at the $216-Z-1 A$ site was $9 \times 10^{-2}$ man-rem. This resulted from electrode emplacement for the entire site. The maximum dose received by a single worker during 
vitrification of the entire site is estimated to be $1 \times 10^{-2} \mathrm{rem}$, received while installing electrodes. Even though this dose was based on conservative assumptions, it is significantly below the DOE guidelines of $5 \mathrm{rem} / \mathrm{yr}$ or 3 rem/quarter to an individual worker. Therefore, it can be assumed that for TRU sites at Hanford where the ISV process may be considered, the process would not be restricted by considerations of occupational dose.

The general public could possibly be exposed to radiation and radionuclides from ISV of the 216-Z-1A waste site, both in the short term during the actual operation, and in the long term following cessation of waste management activities at the site. The doses are estimated to be far below federal standards.

The fraction of isotopes released will be $\sim 1 \times 10^{-5}$ of the amount vented to the off-gas system from the soil. The largest doses resulting from vitrifying the entire inventory are to bone, with a 50 year dose commitment of $1 \times$ $10^{-5}$ rem to the maximum exposed individual and $5 \times 10^{-1}$ man-rem to the entire population.

The DOE regulations on exposure to the general public limit the dose to any individual to $<0.5 \mathrm{rem} / \mathrm{yr}$, and $0.175 \mathrm{rem}$ to the average individual in the public. Thus, the doses calculated for routine ISV operation at the 216-Z-1A site are 4 orders of magnitude below the standards, an indication of the overall acceptability of the operation.

If the site is vitrified and covered by a $1 \mathrm{~m}$ layer of soil, the doses an individual would receive after planting a garden over the site and consuming the produce would be at least 3 orders of magnitude less than they would be if the site did not receive remedial action. Surface barriers could also have this effect by reducing doses through crop ingestion. The first year dose commitment at any time in the future would be less than the DOE annual limit of 0.5 rem to the critical organ.

The major benefit of ISV comes in the consideration of future inadvertent (or intentional) intruders into the waste zone. Reduction in radiation dose from 1 to as much as 5 orders of magnitude may be achieved over no-action or surface barrier application. 
Current barrier designs are capable of preventing surface erosion and plant or animal intrusion into the site. However, there is no way to predict future human activity with enough certainty to preclude the possibility of an inadvertent human intrusion. Although in situ vitrification cannot prevent an intrusion, it may mitigate its consequences. 
WASTE SITE APPLICATIONS ASSESSMENT 


\section{WASTE SITE APPLICATIONS ASSESSMENT}

The purpose of this section is to present the philosophical and technical considerations for the application of ISV to the stabilization of radioactive waste. Examples of Hanford sites where ISV is being considered as an immobilization step will be presented as well. An overview of potential ISV applications to other DOE sites was developed by Oma, Farnsworth, and Rusin (1982).

DOE is evaluating options (US DOE 1982) for the long-term disposal of TRU waste. These options must be feasible, technically effective, environmentally acceptable, operationally safe, and affordable.

Because of the radiotoxicities and long half-lives of the TRU radionuclides, deep geologic emplacement is the disposal method favored by DOE. This method will isolate TRU wastes from the environment and minimize potential threats to public health and safety. However, the National Academy of Sciences (NAS 1978) has stated that retrieval of buried TRU for disposal in a geologic repository could be more hazardous than disposing the waste in place. Further, DOE's long-range master plan for defense transuranic waste management (DOE 1983) states that "deep geologic disposal may not be the most economical means of safe disposal for all TRU wastes." DOE Order 5820.1 (US DOE 1982) allows DOE field organizations to establish new or alternative TRU waste management practices. ISV is one of the engineered permanent disposal alternatives being considered for "greater confinement" disposal (confinement which is greater than shallow land burial).

In seeking technically effective, feasible, and affordable waste management of TRU wastes (including Hanford soils), ISV is considered a new in-place stabilization method to complement geologic disposal. ISV could be a technically and environmentally acceptable technique that might preclude the necessity of exhumation and geologic disposal. For Hanford soils, a combination of selective vitrification and barriers may be the most cost effective in-place stabilization technique (Kennedy et al. 1982). 
The following discussion applies only to buried TRU wastes that require remedial action, ranging from TRU contaminated soil sites (cribs, tile fields, ditches, etc.) to solid burial sites (trenches, caissons, etc.). It is also assumed that grouting is not a stabilization option for buried TRU because its long term (>10,000-year) stability has not yet been shown (Young et al. 1982). With these constraints, three basic stabilization options remain: engineered barriers, exhumation, and ISV.

\section{ENGINEERED BARRIERS}

The use of soil, riprap, and boulder covers as an engineered barrier is currently being considered as a method for reducing intrusion into shallow-land burial, uranium tailings sites, and selected TRU sites. The costs of covering buried waste with soil and riprap of random sizes has been recorded by Means $(1980)$. These values were used to estimate the cost of excavating, hauling, and spreading additional cover material: about $\$ 12 / \mathrm{m}^{3}$ for soil, $\$ 26 / \mathrm{m}^{3}$ for riprap, and $\$ 42 / \mathrm{m}^{3}$ for boulders (Kennedy et al. 1982). These numbers need to be adjusted to the level of 1982 dollars. In addition, the incremental costs associated with working in a radiation zone should be added. An additional allowance should be made for selective placement of boulders and revegetation and for any instrument necessary to measure near-term performance. Rough planning estimates indicate that this would increase the costs to $\$ 21 / \mathrm{m}^{3}$ for soil, $\$ 45 / \mathrm{m}^{3}$ for riprap, and $\$ 90 / \mathrm{m}^{3}$ for boulders. (Rockwell is currently performing cost estimates for engineered barriers for TRU sites at Hanford. When the Rockwell estimates are available they will replace the estimates given above.)

Engineered barriers are a viable greater-confinement candidate for western (arid) sites where the groundwater pathway is not expected to be significant. However, if an unconfined aquifer is close to the western disposal site, barriers alone may be insufficient.

For eastern (wet) sites, the hydrological pathway is generally significant and thus may preclude the use of engineered barriers alone for long-term protection. Current barrier designs are capable of preventing surface erosion, plant and animal intrusion, and water infiltration into the site. However, there is no way to predict activity with enough certainty to preclude human 
intrusion for long periods (1000 to 10,000 years). Reviewing the results of the far-term performance assessments of barriers when faced with human intrusion, the need for supplementary treatment prior to the erection of an engineered barrier is suggested. Paralleling a "defense in depth" philosophy, the supplementary treatment would lessen the consequences of inadvertent human intrusion.

EXHUMATION AND REPOSITORY DISPOSAL

Exhumation is the first in a series of steps usually leading to geologic disposal. Exhumation is followed by inspection, processing, packaging of TRU, certification, shipping, and finally disposal in a geologic repository. During the inspection, processing, and certification steps, if it is determined that some of the exhumed material is low level waste, it may be disposed of as such. Experience at INEL (US DOE 1982) has shown that significant quantities of secondary wastes can be generated that may be considered TRU. In some cases the volume of secondary waste approaches $50 \%$ of the volume of waste exhumed.

Developing cost estimates for exhumation, processing, certification, shipping, and disposal in a geologic repository is difficult because of the limited data base and wide variety of conditions that buried wastes face. Based on experience at INEL, it is reasonable to assume that exhumation costs will be $\$ 7,000$ to $\$ 17,000 / \mathrm{m}^{3}$ ( $\$ 200$ to $\left.\$ 500 / \mathrm{ft}^{3}\right)$. Processing and certification of retrievably stored TRU scheduled for emplacement in a geologic repository are estimated to cost at least $\$ 2000 / \mathrm{m}^{3}$. The processing and certification steps are required to insure compliance with the repository waste acceptance criteria. It is reasonable to assume that the processing and certification costs for exhumed material would be at least as much as for currently generated TRU. Some allowance should be made for the secondary wastes generated during these steps. The authors are reluctant to assign a cost at this time because of the high degree of uncertainty in attempting to make a general estimate. Rather, this cost element is identified for the benefit of those attempting to make specific estimates.

Interim storage is another cost element that needs to be considered. If there is a delay between processing, certification, and shipping because 
repository space is not available, then an allowance for interim storage is necessary. Interim storage would cost at least $\$ 2000 / \mathrm{m}^{3}$ for 1 ow 1 evel wastes requiring greater confinement while awaiting final geologic disposal.

Until design for a TRU-waste shipping container (TRU PAC) is approved, it is difficult to estimate shipping costs. At this time it will be identified as a cost element to be considered. Geologic repository charges are anticipated to be about $\$ 4500 / \mathrm{m}^{3}$ (US DOE 1980). This can vary with the cost recovery scenario, so for planning purposes a range of $\$ 3000$ to $\$ 5000$ is suggested. The cost considerations presented above are listed in Table 61.

TABLE 61. Cost Considerations Associated with Exhumation of TRU and Its Disposal in a Geologic Repository

\begin{tabular}{ll}
\multicolumn{1}{c}{ Activity } & \multicolumn{1}{c}{ Cost, $\$ / \mathrm{m}^{3}$} \\
\cline { 1 - 1 } Exhumation & 7,000 to 17,000 \\
Processing and certification & 2,000 \\
Secondary waste & Allowance required \\
Interim storage & Allowance if required \\
Shipping & Allowance required \\
Repository charges & $\frac{3,000 \text { to } 5,000}{12,000 \text { to } 24,000 \text { plus }}$ \\
$\quad$ TUTAL & allowances
\end{tabular}

In addition to the rather significant costs of exhumation, the availability of repository space and the potential increase in public and occupational exposure should be considered in studies of the trade-offs between exhumation plus geologic disposal and in-place stabilization with greater confinement techniques.

In reviewing the information presented above, it appears that a greater confinement disposal technique is preferable to exhumation and geologic disposal. Further, it would appear that a combination of greater confinement techniques will be the most cost effective approach. For buried TRU sites at Hanford that require remedial action, a combination of selective vitrification and engineered barriers will be a cost effective approach. 
SELECTIVE ISV AT HANFORD

A list of sites to be considered for disposal by greater confinement techniques (combining selected vitrification and barriers) was developed for Hanford. The criteria for establishing the list were twofold: first, that sites contain a significant quantity $(\geq 500 \mathrm{~g})$ of $\mathrm{Pu}$ and second, that sites require remedial action based on preliminary screening calculations using the ARCL technique. The candidate sites that were identified are shown in Tables 62 (TRU contaminated soil sites) and 63 (solid waste sites).

The approach for selective vitrification in combination with engineered barriers in a TRU contaminated soil site (tile field) is shown graphically in Figures 69 and 71. Using this approach, all of the TRU (>100 nCi/g) is immobilized in the vitrified mass. The vitrified mass for this site is about $3200 \mathrm{~m}^{3}$; the cost would be about $\$ 500,000$ for 2 months of operation (from data presented in the Economic Analysis chapter). A barrier would be placed over the vitrified mass and the balance of the site to prevent erosion of the surrounding soil and to prevent plants and burrowing animals from intruding into the low level ( $<100 \mathrm{nCi} / \mathrm{g}$ ) wastes.

Vitrification of a solid burial site is more complex. The capabilities of the large-scale system are shown in Figure 72 . It should be noted that the void and combustible package volumes represent the system capabilities to handle a single event; that is, the hot air/gases released over a 2 to 10 second period. As long as the gas releases are spaced further apart, multiple events could be handled with the presently designed large-scale system. Implicit in this statement is the need to control flow of the molten glass during processing. Some control of processing rate can be achieved by adjusting power level; however, when void volumes are large, pretreatment prior to vitrification is recommended.

Pretreatment consists of filling the void with a suitable solid that would be incorporated into the vitreous mass. Research into the proper type of material and method of application is required. However, the development effort 
TABLE 62. Candidate TRU Contaminated Soil Waste Sites for Selective Vitrification and Engineered Barriers (Harmon and King 1980)

\begin{tabular}{|c|c|c|c|c|}
\hline Site & Type & Location & Area, $m^{2}$ & $\mathrm{Pu}, \mathrm{kg}$ \\
\hline $216-B-7 A \& B$ & Crib & $200 \mathrm{E}$ & 310 & 4.3 \\
\hline $216-S-1 \& 2$ & Crib & $200 \mathrm{~W}$ & 700 & 1.2 \\
\hline $216-T-18$ & Crib & $200 \mathrm{~W}$ & 340 & 1.8 \\
\hline $216-T-32$ & Crib & $200 \mathrm{~W}$ & 320 & 3.2 \\
\hline $216-Z-1 A$ Complex & Tile field & $200 \mathrm{~W}$ & 1600 & 64 \\
\hline $216-z-3$ & crib & $200 \mathrm{~W}$ & 550 & 57 \\
\hline $216-z-7$ & Crib & $200 \mathrm{~W}$ & 780 & 2.0 \\
\hline $216-z-8$ & French drain & $200 W$ & 1.2 & 0.48 \\
\hline $216-Z-9$ & Trench & $200 \mathrm{~W}$ & 530 & 38 \\
\hline $216-z-12$ & Crib & $200 \mathrm{~W}$ & 1900 & 25 \\
\hline $216-z-18$ & Crib & $200 \mathrm{~W}$ & 340 & 23 \\
\hline
\end{tabular}

TABLE 63. Candidate Solid Waste Sites for Selective Vitrification and Engineered Barriers (Harmon and King 1980)

\begin{tabular}{|c|c|c|c|c|c|}
\hline Site $(a)$ & Type & Volume, $\mathrm{m}^{3}$ & Area, $\mathrm{m}^{2}$ & $\mathrm{Pu}, \mathrm{kg}$ & $U, \mathrm{~kg}$ \\
\hline $218-W-4 B$ & Caisson 1 & 6.4 & & 0.47 & 150 \\
\hline $218-W-4 B$ & Caisson 3 & 5.4 & & 0.48 & 100 \\
\hline $218-W-4 B$ & Caisson 4 & 4.7 & & 0.73 & 49 \\
\hline $218-W-4 B$ & Caisson Alpha 1 & 5.8 & & 1.5 & 41 \\
\hline $218-W-4 B$ & Caisson Alpha 2 & 3.7 & & 0.51 & 1.4 \\
\hline $218-W-4 B$ & Caisson Alpha 3 & 4.3 & & 1.1 & 3.3 \\
\hline $218-W-4 B$ & $\begin{array}{l}\text { Caisson UNI-1 } \\
\text { (plugged) }\end{array}$ & 0.3 & & +0.3 & --- \\
\hline $218-W-1$ & Burial ground & --- & 4,300 & 94 & --- \\
\hline $218-W-2$ & Burial ground & --- & 15,000 & 130 & -- \\
\hline $218-W-3$ & Burial ground & --- & 16,000 & 68 & --- \\
\hline $218-W-4 A$ & Burial ground & --- & 20,000 & 35 & -- \\
\hline $218-W-4 B$ & Burial ground & --- & 12,000 & 57 & --- \\
\hline
\end{tabular}

(a) All sites are located in the 200W area. 


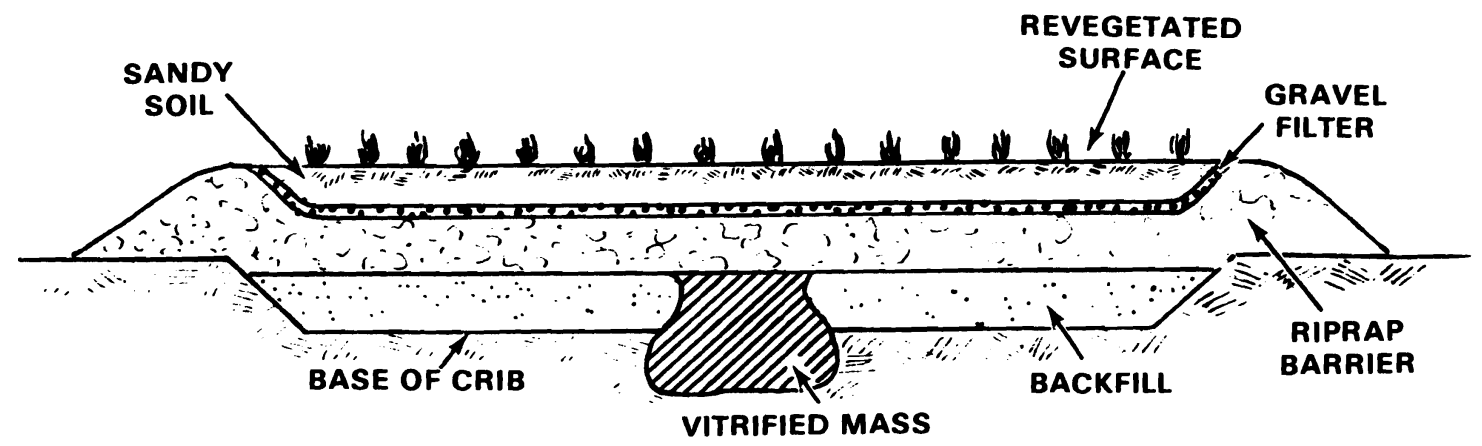

FIGURE 71. Cross-Section View of Trench Incorporating Greater Confinement Stabilization Technique

is expected to be minor. Current plans are leaning toward the injection of glass beads or sand into void volumes in caissons.

The setup for vitrification of a caisson is shown schematically in Figure 73. Note that voids have been filled with sand or glass to control the flow of the vitreous mass during processing. The figure also illustrates how gas release events can be controlled by filling the space between sealed containers within the caisson. A more detailed discussion of controlling gas releases is provided in the Process Description chapter, which discusses the capabilities of the large-scale system. Preliminary estimates indicate that a caisson can be vitrified in one ISV operation lasting about 2 weeks.

Along with other studies, cost and time estimates of disposal by vitrification versus other options still need to be performed. However, preliminary evaluations indicate that the time factor for site stabilization using ISV is competitive with other methods.

Vitrification of solid waste burial trenches is similar to the approach discussed for TRU contaminated soil sites. The approach includes selective vitrification in combination with engineered barriers. Characterization of the site to be vitrified would be a necessary precursor; however, most of the characterization could be accomplished without physical contact with the waste 


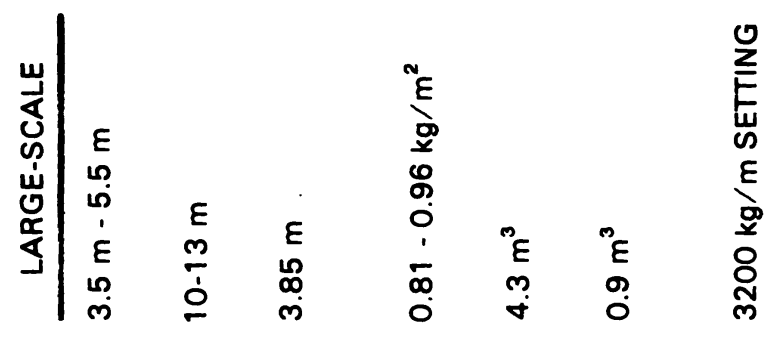

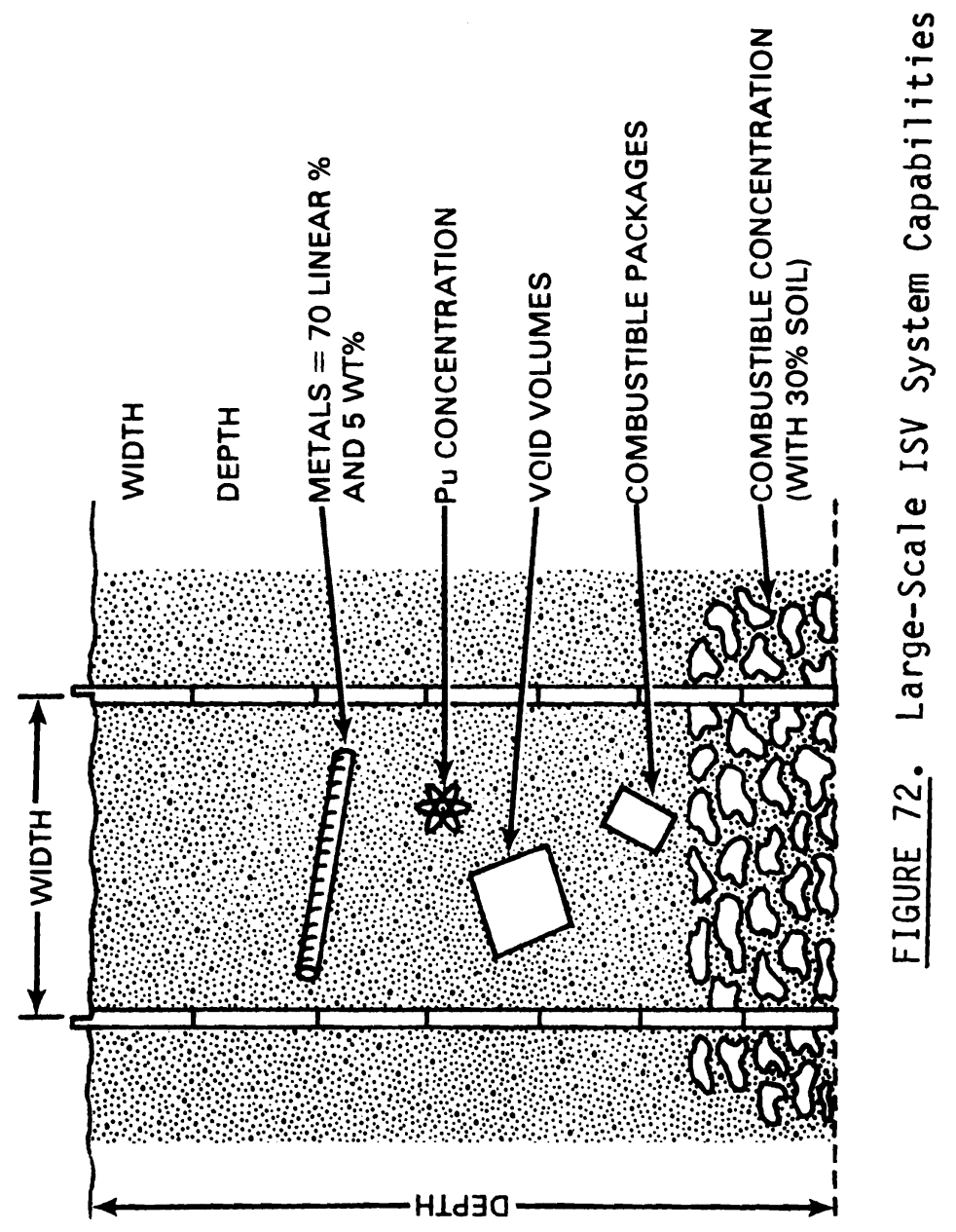




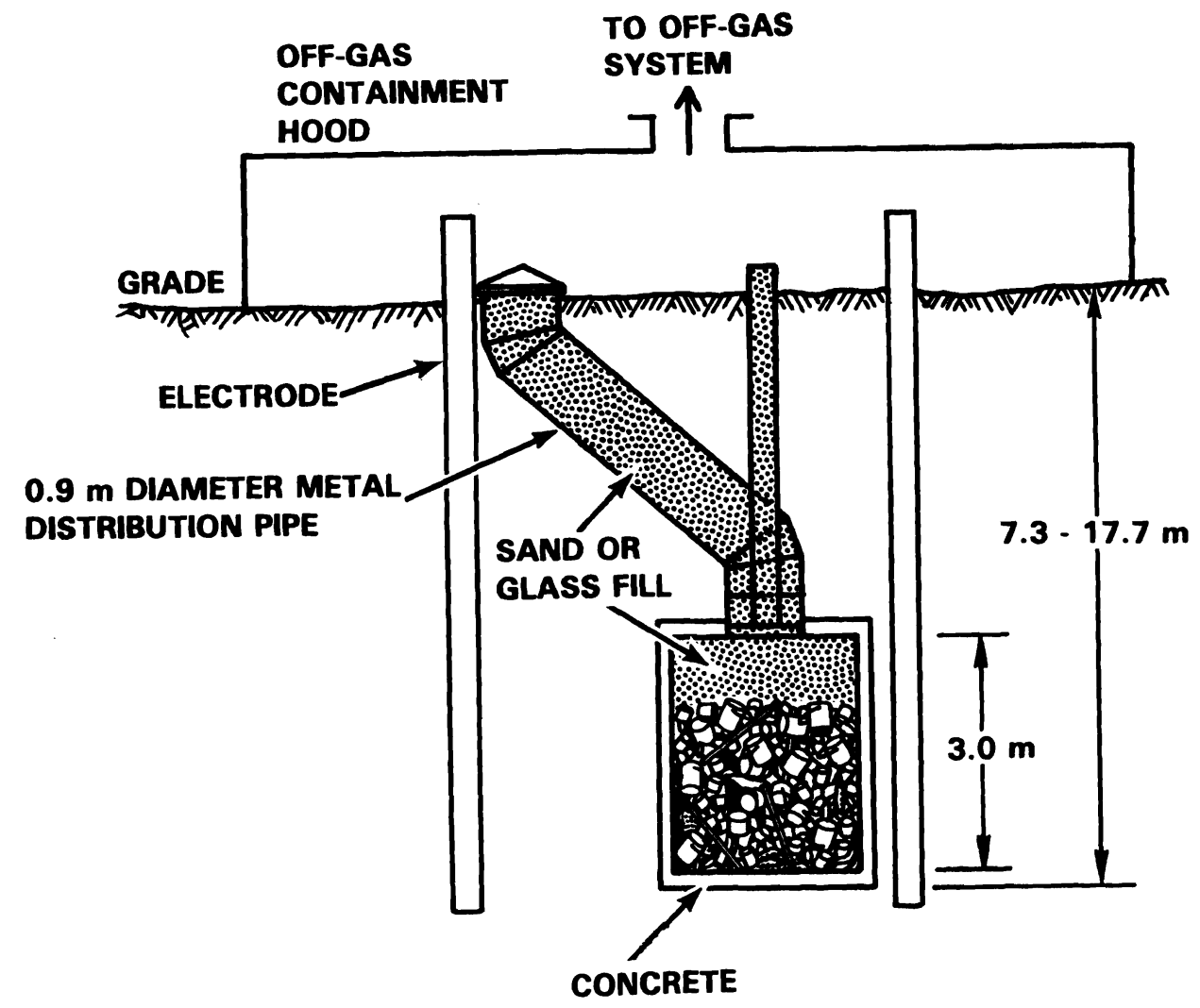

\section{FIGURE 73. Vitrification of a Typical Hanford Caisson}

using equipment such as ground penetrating radar. Again the location, and treatment as necessary, of void volumes that exceed the large-scale system capability would be required.

There is significant potential at the Hanford site for use of in situ vitrification as a disposal technique for TRU wastes. Also, the most cost effective approach appears to be a combination of selective vitrification and engineered barriers.

Before ISV can be chosen as the disposal technique for the candidate TRU sites, several key items need to be accomplished:

- testing of the large-scale ISV system at actual waste sites 
- determination that in-place stabilization with engineered barriers is an acceptable practice through completion of an environmental impact statement being prepared for waste disposal at Hanford

- performance of detailed cost/benefit studies comparing ISV to other disposal options

- review of candidate site records in sufficient detail to screen out sites that would exceed process capabilities. Selective characterization efforts should also be conducted. 


\section{REFERENCES}




\section{REFERENCES}

American National Standard (ANS). 1975. "Nuclear Criticality Safety in Operations with Fissionable Materials Outside Reactors." ANS-8.1, ANSI N16. 11975, American Nuclear Society.

American National Standard (ANS). 1982. "Nuclear Criticality Control of Special Actinide Elements." ANS-8.15, American Nuclear Society.

Bates, J. L. 1975. Properties of Molten Coal Slags Relating to Open-Cycle MHD. Final report to the National Science Foundation. BNWL-B-466, Pacific Northwest Laboratory, Richland, Washington.

Bishoff, James R. and Robert J. Hudson. 1979. Early Waste Retrieval Final Report. TREE-1321, EG\&G Idaho, Inc., Idaho Falls, Idaho.

Brouns, R. A. and C. L. Timmerman. 1982. "In Situ Thermoelectric Stabilization of Radioactive Wastes." In Proceedings of the Symposium on Waste Management ' 82 , ed. Ray P. Post, pp. 449-463. University of Arizona, College of Engineering, Tucson, Arizona.

Brouns, R. A., J. L. Buelt, and W. F. Bonner. 1983. "In Situ Vitrification of Soil." U.S. Patent 4,376,598, March 1983.

Buelt, J. L. et al. 1979. "A Review of Continuous Ceramic-Lined Melters and Associated Experience at PNL." Presented at The International Symposium on Ceramics on Nuclear Waste Management in Cincinnati, Ohio, April 1979. PNL-SA-7590, Pacific Northwest Laboratory, Richland, Washington.

Chedin, J., A. Tribot, and S. Feneant. 1948. "The Particulate State of Concentrated Nitric Acid and the Nitrating Ability of Cellulose." Comptes Rendus 226:2068-70.

Clayton, E. D. 1979. Anomalies of Nuclear Criticality. PNL-SA-4868, Rev. 5, Pacific Northwest Laboratory, Richland, Washington.

Cook, A. M., C. B. Daughton, and M. Alexander. 1978. "Phosphate Utilization by Bacteria." Journal of Bacteriology 133(1):85-90.

Crawley, D. T. 1969. Plutonium-Americium Soil Penetration at 234-5 Building Crib Sites. ARH-1278, AtTantic Richfield Hanford Company, Richland, Washington.

Dobratz, B. M. 1981. LLNL Explosives Handbook. UCRL-52997, Lawrence Livermore National Laboratory, Berkeley, California.

Doree, C. 1933. The Methods of Cellulose Chemistry. Van Nostrand, New York. 
Dynsenov, M. I., G. I. Nikishin, Zh. B. Dandybaev, M. Zh. Zhanshin, and T. G. Sarbaev. 1974. "Preparation of Perchloroethylene by Carbon Tetrachloride Pyrolysis." Dokl. Resp. Nauchno-Tekh. Konf, Neptekhim, 3rd Vol. 1:119-126. Chem. Abst. 83(21)178187.

Engel, R. L., J. Greenborg, and M. M. Hendrickson. 1966. ISOSHLD--A Computer Code for General Purpose Isotope Shielding Analysis. BNWL-236, Pacific Northwest Laboratory, Richland, Washington.

Ewing, R. C. and R. F. Hoaker. 1979. Naturally Occurring Glasses: Analogues for Radioactive Waste Forms. PNL-2776, Pacific Northwest Laboratory, Richland, Washington.

Gibson, M. W. 1982. Estimated Radioactive Waste Inventories and Contaminated Soil Volumes at Hanford. RHO-SD-RE-TI-017, Rockwell Hanford Operations, Richland, Washington.

Guthrie, K. M. 1974. Process Plan Estimating, Evaluation, and Control. Craftsmen Book Co. of Hinenca, Los Angeles.

Harada, T., et al. 1972. "Strength, Elasticity and Thermal Properties of Concrete Subjected to Elevated Temperatures." In Concrete for Nuclear Reactors, Vol. 1, pp. 377-406. SP-34. American Concrete Institute, Detroit, Michigan.

Harmon, K. M. and J. C. King. 1980. Resource Book - Decommissioning of Contaminated Facilities at Hanford, Revision 3. PNL-MA-558, Pacific Northwest Laboratory, Richland, Washington.

International Agency for Research on Cancer (IARC). 1971. "The Evaluation of Carcinogenic Risk to Man." Monograph 1:53-60.

Isaacson, R. E. and D. J. Brown. 1978. Environmental Assessment Related to Hanford Radioactive Waste Burial. RHO-SA-36, Rockwell Hanford Operations, Richland, Washington.

Jarvis, A. 1970. "Combustion Reactions of a Pyrotechnic White Smoke Composition." Combust. Flame 14(3):313-320.

Kasper, R. B., S. M. Price, M. K. Addition, R. M. Smith, G. V. Last, and G. L. Wagernar. 1979. Transuranic Distribution Beneath a Retired Underground Disposal Facility, Hanford Site. RHO-SA-131, Rockwell Hanford Operations, Richland, Washington.

Kasper, R. B. 1981. Field Study of Plutonium Transport in the Vadose Zone. RHO-SA-224, Rockwell Hanford Operations, Richland, Washington.

Keiter, R., T. Ahnger, A. Marucie and T. Baldwin. 1978. "The Preparation of Anhydrous Chromium (III) Chloride and the Pyrolys is of Carbon Tetrachloride." Journal of Chemical Education 55:52. 
Keith, L. H. and W. A. Teilliard. 1979. "Priority Pollutants I--A Perspective View." Environmental Science and Technology 13(4):416-423.

Kennedy, W. E., Jr., R. L. Aaberg, B. A. Napier, and J. K. Soldat. 1982. Transuranic Advanced Disposal Systems: Preliminary $239 \mathrm{Pu}$ Waste Disposal Criteria for Hanford. PNL-4254, Pacific Northwest Laboratory, Richland, Washington.

Kingery, W. D. 1960. Introduction to Ceramics. John Wiley and Sons, New York.

Kirshenbaum, M. S. 1982. Reactivity of Explosives/Sediment Mixtures. ARLCD-TR-82007, U.S. Army Armament and Development Command, Large Caliber Weapon Systems Laboratory, Dover, New Jersey.

Kubic, R. L. and M. W. Anders. 1980. "Metabolism of Carbon Tetrachloride to Phosgene." Life Sciences 26:2151-2155.

Kuznetosov, A. F. and G. F. Pekhov. 1967. "Tetrachloroethylene." Izobret., Prom. Obraztsy, Tovarnye znaki 44(18):32. USSR Patent SU201386.

Laursen, T. and W. A. Lanford. 1978. "Hydration of Obsidian." Nature $276(9): 153-156$.

Lazar, I. 1977. "Making the Choice Among Dry, Liquid, and Gas Transformers." Specifying Enyineer 37:130-131.

Lea, F. M. 1971. The Chemistry of Cement and Concrete. 3rd ed. Chemical Publishing Co., Inc., New York.

Luxmoore, R. J., B. P. Spalding, and I. M. Monroe. 1981. "Areal Variation and Chemical Modification of Weathered Shale Infiltration Characteristics." Soil Sci. Soc. Am. J. 45:687-691.

Materials Characterization Center (MCC). 1981. Nuclear Waste Materials Handbook--Waste Form Test Methods. DOE/TIC-11400, Department of Energy, Washington, D.C.

MCElroy, J. L. 1975. Quarterly Progress Report -- Research and Development Activities, Waste Fixation Program, April through June 1975. BNWL-1932, Pacific Northwest Laboratory, Richland, Washington.

Means, R. S. 1980. Mechanical and Electrical Cost Data 1980. Robert Snow Means Co., Inc., Kingston, Massachusetts.

Means, R. S. 1981. 1981 Labor Rates for the Construction Industry. Robert Snow Means Co., Inc., Kingston, Massachusetts. 
Murphy, E. S. and G. M. Holter. 1980. Technology, Safety, and Costs of Decommissioning a Reference Low-Level Waste Burial Ground. NUREG/CR-0570 Vo1. 1, Prepared for the U.S. Nuclear Regulatory Commission by Pacific Northwest Laboratory, Richland, Washington.

Napier, B. A. 1982. A Method for Determining "Allowable Residual Contamination Levels" of Radionuclide Mixtures in Soil. PNL-3852, Pacific Northwest Laboratory, Richland, Washington.

National Academy of Sciences. 1978. Radioactive Wastes at the Hanford Reservation, A Technical Review. National Research Council, Washington, D.C.

Norton, F. H. 1968. Refractories. McGraw-Hill Book Co., New York.

Oma, K. H., R. K. Farnsworth, and J. M. Rusin. 1982. In Situ Vitrification: Application Analys is for Stabilization of Transuranic Waste. PNL-4442, Pacific Northwest Laboratory, Richland, Washington.

0tt, E., et al. 1947. Volume V of High Polymers Cellulose and Cellulose Derivatives. Interscience, New York.

Owens, K. W. 1981. Existing Data on the 216-Z Liquid Waste Sites. RHO-LD-114, RockwelT Hanford Operations, Richland, Washington.

Parrott, J. E. and A. D. Stuckes. 1975. Thermal Conductivity of Solids. Pion Ltd., London, United Kingdom.

Petersen, P. H. 1966. "Hardened Concrete--Resistance to High Temperature." In Concrete and Concrete-Making Materials. STP169-A, American Society for Testing and Materials, Baltimore, Maryland.

Platt, A. M. 1973. Quarterly Progress Report -- Research and Development Activities, Waste Fixation Program, December 1972 Through March 1973. BNWL-1741, Pacific Northwest Laboratory, Richland, Washington.

Price, S. M., R. B. Kasper, M. K. Addition, R. M. Smith, and G. V. Last. 1979. Distribution of Plutonium and Americium Beneath the 216-Z Crib: A Status Report. RHO-ST-17, Rockwell Hanford Operations, Richland, Washington.

Ridgway, K. R. and R. D. Carter. 1972. Criticality Prevention Parameters of Plutonium in Soils. ARH-2622, Atlantic Richfield Hanford Company, Richland, Washington.

Ross, W. A. et al. 1982. Comparative Leach Testing of Alternative TRU Waste Forms. PNL-SA-9903, Pacific Northwest Laboratory, Richland, Washington.

Scheffler, K. et al. 1977. Long Term Leaching of Silicate Systems: Testing Procedure, Actinide Behavior and Mechanism (German). KFK 2456, Gesellschaft fur Rernforschung. Mbh, Karlsruhe, West Germany. 
Stanek, J. 1977. Electric Melting of Glass. Elsevier Scientific Publishing Company, Amsterdam, The Netherlands.

Strachan, D. M., R. P. Turcotte, and B. 0. Barnes. 1980. "MCC-1: A Standard Leach Test for Nuclear Waste Forms." PNL-SA-8783, Pacific Northwest Laboratory, Richland, Washington.

Thompson, J. K. 1977. "Technical Note--Minimum Critical Mass of PlutoniumPolyethylene System Found to be Significantly Lower than Plutonium-Water System." Nuclear Technology 33:235-236.

Timmerman, C. L. and R. 0. Lokken. 1983. "Characterization of Vitrified Soil Produced by In Situ Vitrification." Presented at the Second International Symposium of Ceramics in Nuclear Waste Management, April 24-27, 1983, Chicago, Illinois. PNL-SA-10759, Pacific Northwest Laboratory, Richland, washington.

Tsuge, S., J. J. Leary and T. L. Isenhour. 1974. "CCl4--Reactions at High Temperatures." Journal of Chemical Education 51:256-267.

U.S. Department of the Army. 1967. Military Explosives. Department of the Army Technical Manual TM 9-1300-214 C2, Washington, D.C.

U.S. Department of the Army. 1970. AMC Regulation Safety Manual. AMCR-385100, Army Material Command, Alexandria, Virginia.

U.S. Department of Energy (DOE). 1979. Environmental and Other Evaluations of Alternatives for Lony-Term Management of Stored INEL Transuranic Waste. DOE/ET-0081 (revised), DOE Office of Nuclear Waste Management, Washington, D.C.

U.S. Department of Energy. 1980. Final Environmental Impact Statement for the Waste Isolation Pilot Plant. DOE EIS-0026, Washington, D.C.

U.S. Department of Energy. 1981a. Environmental Protection, Safety, and Health Protection Programs for DOE Operations. Order 5480.1A, Washington, D.C.

U.S. Department of Energy. 1981b. Environmental Protection, Safety, and Health Protection Information Reporting Requirements. Order 5484.1 , Washington, D.C.

U.S. Department of Energy. 1982. Long-Range Master Plan for Defense Transuranic Waste Management. DOE-TRU-8201, Washington, D.C.

U.S. Department of Energy. 1983. Long-Range Master Plan for Defense Transuranic Waste Management. DOE-TRU-8201, Washington, D.C. 
U.S. Nuclear Regulatory Commission (NRC). 1981. Draft EIS on 10 CFR Part 61, "Licensing Requirements for Land Disposal of Radioactive Waste." NUREG-0782, Vols. 1 \& 2. Washington, D.C.

Wallace, R. W. et al. 1980. Topical Report on Release Scenario Analysis of Long-Term Management of High-Level Defense Waste at the Hanford Site. PNL-3363, Pacific Northwest Laboratory, Richland, Washington.

Webster, D. A. 1979. "Land Burial of Solid Radioactive Waste at Oak Ridge National Laboratory, Tennessee: A Case History." In Management of Low-Level Radioactive Wastes, ed. M. W. Carter et al., pp. 731-746. Pergamon Press, New York.

Williams, D. T. and G. L. Lebel. 1981. A National Survey of Tri(haloalkyl)Trialkyl-, and Triarylphosphates in Canadian Drinking Water. Bull. Environm. Contam. and Toxicol. 27:450-457.

Young, J. K. et al. 1982. Environmental Factors Affecting Long-Term Stabilization of Radon Suppression Covers for Uranium MilT Tailings. PNL-4193, Pacific Northwest Laboratory, Richland, Washington.

Zoldners, N. G. 1971. "Thermal Properties of Concrete Under Sustained Elevated Temperatures." In Temperature and Concrete, Publication SP-25, pp. 1-32. American Concrete Institute, Detroit, Michigan. 


\section{DISTRIBUTION}




\section{DISTRIBUTION}

No. of

Copies

\section{OFFSITE}

27 DOE Technical Information Center

2 Nuclear Regulatory Commission 7915 Eastern Avenue

Silver Springs, MD 20910

ATTN: R. E. Cunningham

J. Roberts

R. D. Smith

Division of Waste Management Nuclear Regulatory Commission Washington, DC 20555

D. M. Rohrer

Office of Inspection and Enforcement

Nuclear Regulatory Commission MS359 EW/W

Washington, DC 20555

Materials Section Leader High-Level Waste Licensing Branch

Nuclear Regulatory Commission Washington, DC 20555

W. F. Holcomb

U.S. Public Health Service 19377 Keymar Way

Gaithersburg, MD 20879

W. E. Mott

DOE Division of Environmental Control Technology

Washington, DC 20545

4 DOE Terminal Waste Disposal and Remedial Action

GTN

Washington, DC 20545

ATTN: J. E. Baublitz, NE-24

F. E. Coffman, NE-20

J. R. Coleman, NE-25

D. J. McGoff, NE-23
No. of

Copies

3 DOE Office of Defense Waste and Byproducts Management GTN

Washington, DC 20545

ATTN: J. E. Dieckhoner

J. J. Jicha

G. K. Oertel

J. W. Bennett

Geologic Repository Division

DOE Nuclear Waste Policy Act

Project Office

S-10, Forrestal

Washington, DC 20585

3 Geologic Repository Division DOE Nuclear Waste Policy Act Project Office

GTN

Washington, DC 20545

ATTN: C. R. Cooley, S-10/NE-22

C. H. George, S-10/NE-22

R. Stein

W. W. Ballard, Jr.

DOE Office of Spent Fuel

Management and Reprocessing

Systems

NE-40, GTN

Washington, DC 20545

M. J. Lawrence

Storage Projects

DOE Nuclear Waste Policy Act

Project Office

S-10, Forrestal

Washington, DC 20585

S. A. Mann

DOE Chicago Operations Office

9800 South Cass Avenue

Argonne, IL 60439 
No. of

Copies

J. 0. Neff

DOE National Waste Program Office

505 King Avenue

Columbus, $\mathrm{OH} 43201$

J. D. Hamric

DOE Idaho Operations Office

550 2nd Street

Idaho Falls, ID 83401

Office of the Assistant Manager for Energy Research and Development

DOE Oak Ridge Operations Office P.0. Box E

Oak Ridge, TN 37830

2 Oak Ridge National Laboratory

P.0. Box $Y$

Oak Ridge, TN 37830

ATTN: L. J. Mezga

T. H. Row

2 Los Alamos National Laboratory P.0. Box 1663

Los Alamos, NM 87544

ATTN: D. T. Oakley

R. N. Rogers

2 DOE Savannah River Operations Office

P.0. Box A

Aiken, SC 29801

ATTN: E. S. Goldberg

T. B. Hindman

2 Exxon Nuclear Idaho

P.0. Box 2800

Idaho Falls, ID 83401

ATTN: D. L. Condotta

File Copy

G. B. Levin

EG\&G Idaho

P.0. Box 1625

Idaho Falls, ID 83415
No. of

Copies

S. G. Harbinson

DOE San Francisco Operations

1333 Broadway

Oakl and, CA 94612

R. Y. Lowrey

DOE Albuquerque Operations

Office

P.0. Box 5400

Albuquerque, NM 87185

2 Allied-General Nuclear Services

P.0. Box 847

Barnswel1, SC 29812

ATTN: J. A. Buckham

A. Williams

2 Argonne National Laboratory

9700 South Cass Avenue

Argonne, IL 60439

ATTN: J. H. Kittel

M. J. Steindler/

L. E. Trevorrow

3 Battelle Memorial Institute

Office of Nuclear Waste

I solation

505 King Avenue

Columbus, $\mathrm{OH} 43201$

ATTN: N. E. Carter

S. Goldsmith

B. Rawles

K. V. Gilbert

Rockwell International

Rocky Flats Plant

P.0. Box 464

Golden, CO 80401

3 E. I. du Pont de Nemours Company

Savannah River Laboratory

Aiken, SC 29808

ATTN: J. L. Crandall

E. J. Hennelly

S. Mirshak 
No. of Copies

Paul F. Hadala, Assistant Chief Geotechnical Laboratory Waterways Experiment Station Corps of Engineers

P.0. Box 631

Vicksburg, MS 39180

Thaddeus D. Johnson, Chief Civil Engr. Research Branch Cold Regions Research \&

Engineering Lab

Corps of Engineers

72 Lyme Road

Hanover, NH 03755

Timothy M. Small, Technical Assistant

Engineering Support Laboratory MERADCOM

Fort Belvoir, VA 22060

2 Technical Division

USATHAMA

Edgewood Arsenal, MD 21010

ATTN: Robert P. Bartel 1

Dennis Wynne

R. Williams

Electric Power Research Institute

3412 Hillview Avenue

P.0. Box 10412

Palo Alto, CA 94304

R. K. Brown

Westinghouse Electric Corporation

Advanced Energy Systems Division

WIPP Library

P.0. Box 40039

Albuquerque, NM 87196

J. L. Knabenschuh

Nuclear Fuels Services, Inc.

P.0. Box 191

West Valley, NY 14171
No. of

Copies

2 Bechtel National, Inc.

Box 3965

San Francisco, CA 94119

ATTN: J. L. Jardine

W. A. Freeby

J. L. Larocca, Chairman

Energy Research and Development Authority

Empire State Plaza

Albany, NY 12223

2 Sandia Laboratories

Albuquerque, NM 87185

ATTN: D. R. Anderson

W. Weart

R. G. Post

College of Engineering

University of Arizona

Tucson, AZ 85721

L. L. Hench

Dept. of Materials Science and Engineering

University of Florida

Gainesville, FL 32611

ONSITE

5 DOE Richland Operations Office

H. E. Ransom

E. A. Bracken

0. J. Elgert

R. D. Izatt

J. J. Schreiber (2)

10 Rockwell Hanford Operations

R. A. Deju

K. A. Gasper

H. E. McGuire

J. W. Patterson

I. E. Reep

J. H. Roecker

P. F. Shaw

S. A. Wiegman 
D. D. Wodrich
File Copy

UNC United Nuclear Industries

T. E. Dabrowski

Westinghouse Hanford Company

A. G. Blasewitz

99 Pacific Northwest Laboratory

W. F. Bonner

R. L. Brodzinski

R. A. Brouns

D. R. Brown

J. L. Buelt (10)

L. L. Burger/R. D. Scheele/ L. A. Bray

J. G. Carter

T. D. Chikalla

L. L. Clark

R. A. Craig/C. R. Cole

R. L. Dillon

D. W. Dragnich

V. F. FitzPatrick (10)

R. M. Fleischman

W. A. Glass

C. R. Hann

K. A. Hawley

J. H. Jarrett

S. E. King (2)

M. R. Kreiter
L. T. Lakey

J. M. Latkovich

R. C. Liikala

R. P. Marshall/W. R. Wiley/ D. B. Cearlock

J. L. McEl roy

G. B. Mellinger

P. J. Mellinger

J. E. Mendel/M. D. Merz

J. E. Minor/D. H. Siemens

K. S. Murthy/R. F. McCallum

B. A. Napier

I. C. Nelson/J. G. Stephan

R. E. Nightingale

D. E. Olesen

K. H. Oma (10)

A. M. Platt

J. M. Rusin

J. V. Robinson

D. J. Silviera (5)

S. L. Stein

B. Steelman

J. L. Swanson/E. J. Wheelwright

C. L. Timmerman (10)

G. L. Tingey/G. A. Jensen

R. P. Turcotte/ G. L. McVay

C. M. Unruh

H. H. Van Tuyl

B. E. Vaughan

R. E. Westerman

R. D. Widrig

L. D. Williams

Technical Information (5)

Publishing Coordination vg (2) 